\section{OAK RIDGE NATIONAL LABORATORY}

MARTIN MARIETTA

\title{
Validation of Multigroup Neutron Cross Sections and Calculational Methods for the ANS Against the FOEHN Critical Experiments
}

\author{
L. A. Smith \\ J. C. Gehin \\ F. X. Gallmeier \\ J. P. Renier \\ B. A. Worley
}

May 1995

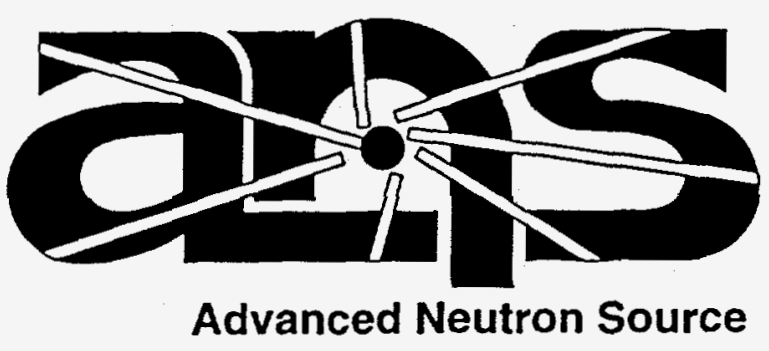


This report has been reproduced directly from the best available copy.

Available to DOE and DOE contractors from the Office of Scientific and Technical Information, P.O. Box 62, Oak Ridge, TN 37831; prices available from (615) 576-8401, FTS 626-8401.

Available to the public from the National Technical Information Service, U.S. Department of Commerce, 5285 Port Royal Rd., Springfield, VA 22161.

This report was prepared as an account of work sponsored by an agency of the United States Government. Neither the United States Government nor any agency thereof, nor any of their employees, makes any warranty, express or implied, or assumes any legal liability or responsibility for the accuracy, completeness, or usefulness of any information, apparatus, product, or process disclosed, or represents that its use would not infringe privately owned rights. Reference herein to any specific commercial product, process, or service by trade name, trademark, manufacturer, or otherwise, does not necessarily constitute or imply its endorsement, recommendation, or favoring by the United States Government or any agency thereof. The views and opinions of authors expressed herein do not necessarily state or reflect those of the United States Government or any agency thereof. 


\section{DISCLAIMER}

Portions of this document may be illegible in electronic image products. Images are produced from the best available original document. 

L. A. Smith*
J. C. Gehin
F. X. Gallmeier
J. P. Renier
B. A. Worley

*Oak Ridge Institute for Science and Energy Oak Ridge, Tennessee

DATE PUBLISHED - May 1995

\author{
Prepared by \\ OAK RIDGE NATIONAL LABORATORY \\ Oak Ridge, Tennessee 37831-6285 \\ managed by \\ LOCKHEED MARTIN ENERGY SYSTEMS, INC. \\ for the \\ U.S. DEPARTMENT OF ENERGY \\ under contract DE-AC05-84OR21400
}


$\rightarrow-$

- 
LIST OF FIGURES $\ldots \ldots \ldots \ldots \ldots \ldots \ldots \ldots \ldots \ldots \ldots \ldots \ldots \ldots \ldots \ldots \ldots$ vii

LIST OF TABLES $\ldots \ldots \ldots \ldots \ldots \ldots \ldots \ldots \ldots \ldots \ldots \ldots \ldots \ldots \ldots \ldots \ldots$

ACKNOWLEDGMENTS $\ldots \ldots \ldots \ldots \ldots \ldots \ldots \ldots \ldots \ldots \ldots \ldots \ldots \ldots \ldots$

EXECUTIVE SUMMARY $\ldots \ldots \ldots \ldots \ldots \ldots \ldots \ldots \ldots \ldots \ldots \ldots \ldots \ldots \ldots$ xvii

ABSTRACT $\ldots \ldots \ldots \ldots \ldots \ldots \ldots \ldots \ldots \ldots \ldots \ldots \ldots \ldots \ldots \ldots \ldots \ldots \ldots$

1. INTRODUCTION $\ldots \ldots \ldots \ldots \ldots \ldots \ldots \ldots \ldots \ldots \ldots \ldots \ldots \ldots \ldots \ldots \ldots \ldots \ldots$

1.1 BACKGROUND AND OBJECTIVE $\ldots \ldots \ldots \ldots \ldots \ldots \ldots \ldots \ldots \ldots$

1.2 ORGANIZATION OF REPORT $\ldots \ldots \ldots \ldots \ldots \ldots \ldots \ldots \ldots \ldots$

2. DESCRIPTION OF THE FOEHN EXPERIMENT $\ldots \ldots \ldots \ldots \ldots \ldots \ldots \ldots$

2.1 INTRODUCTION $\ldots \ldots \ldots \ldots \ldots \ldots \ldots \ldots \ldots \ldots \ldots \ldots \ldots \ldots \ldots \ldots$

2.2 COMPONENTS OF THE FOEHN REACTOR $\ldots \ldots \ldots \ldots \ldots \ldots \ldots \ldots$

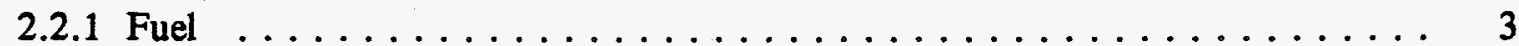

2.2.2 Control Element $\ldots \ldots \ldots \ldots \ldots \ldots \ldots \ldots \ldots \ldots \ldots \ldots \ldots$

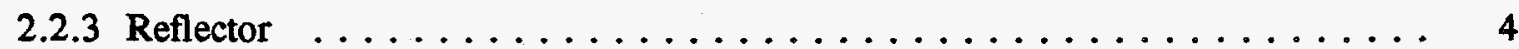

2.2.4 Boron Endplates $\ldots \ldots \ldots \ldots \ldots \ldots \ldots \ldots \ldots \ldots \ldots \ldots$

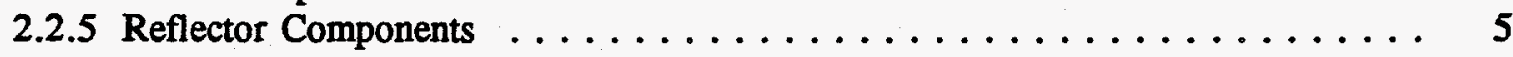

2.3 MEASURED DATA $\ldots \ldots \ldots \ldots \ldots \ldots \ldots \ldots \ldots \ldots \ldots \ldots \ldots \ldots \ldots$

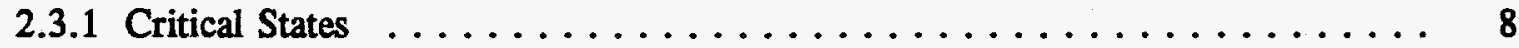

2.3.2 Power Distribution $\ldots \ldots \ldots \ldots \ldots \ldots \ldots \ldots \ldots \ldots \ldots, 8$

2.3.3 Thermal Flux $\ldots \ldots \ldots \ldots \ldots \ldots \ldots \ldots \ldots \ldots \ldots \ldots, 8$

2.3.4 Rendement $\ldots \ldots \ldots \ldots \ldots \ldots \ldots \ldots \ldots \ldots \ldots \ldots \ldots$

2.4 EXPERIMENTAL UNCERTAINTIES $\ldots \ldots \ldots \ldots \ldots \ldots \ldots \ldots \ldots$

2.4.1 Geometrical Uncertainties $\ldots \ldots \ldots \ldots \ldots \ldots \ldots \ldots \ldots \ldots$

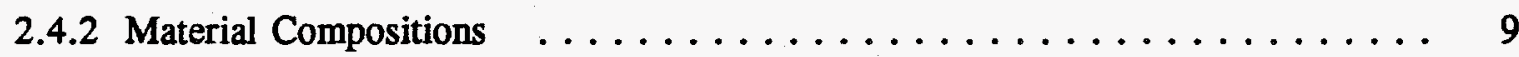

2.5 ERROR ESTIMATES $\ldots \ldots \ldots \ldots \ldots \ldots \ldots \ldots \ldots \ldots \ldots$

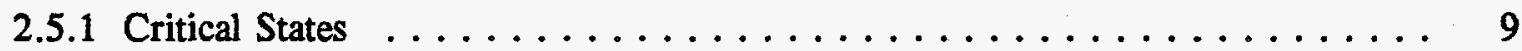

2.5.2 Power Distribution Measurements $\ldots \ldots \ldots \ldots \ldots \ldots \ldots \ldots$

2.5.3 Thermal-Flux Measurements $\ldots \ldots \ldots \ldots \ldots \ldots \ldots \ldots \ldots \ldots, 10$

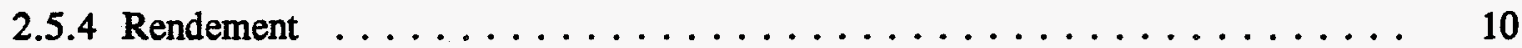

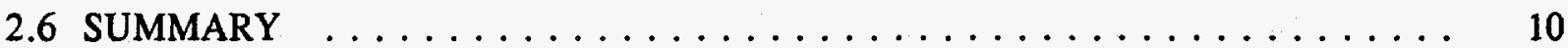




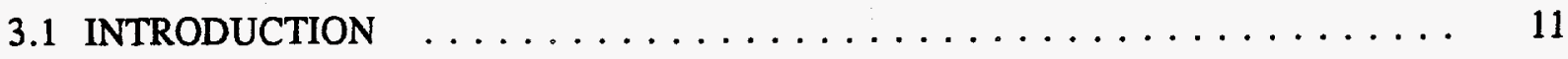

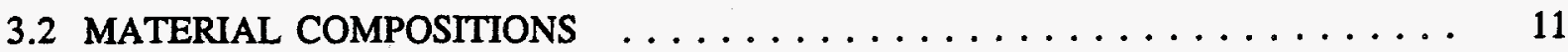

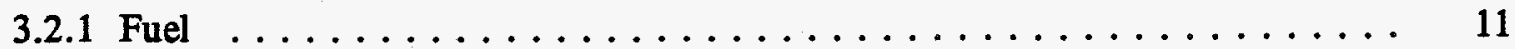

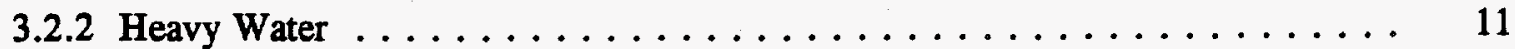

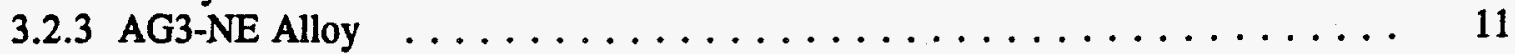

3.3 CROSS SECTION PROCESSING METHODOLOGY $\ldots \ldots \ldots \ldots \ldots \ldots \ldots$

3.3.1 Resonance Processing . . . . . . . . . . . . . . . . . 13

3.3.1.1 Unresolved Resonance Energy Range $\ldots \ldots \ldots \ldots . \ldots \ldots \ldots$

3.3.1.2 Resolved Resonance Energy Range . . . . . . . . . . . . . . 13

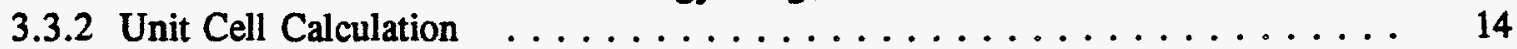

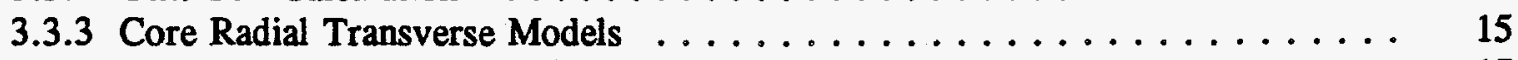

3.3.4 Boron Endplate Model . . . . . . . . . . . . . . . . . . 17

3.4 TWO-DIMENSIONAL (R-Z) MODEL DESCRIPTIONS . . . . . . . . . . . 17

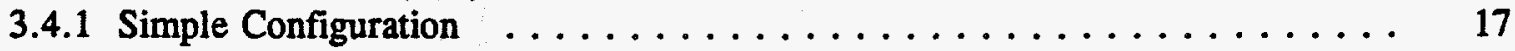

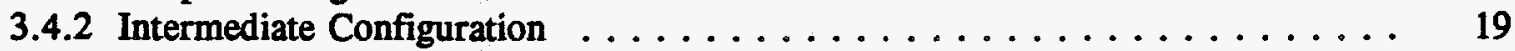

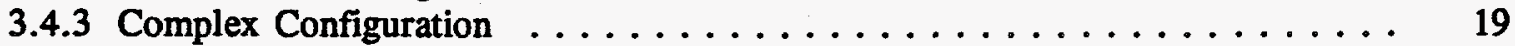

3.4.3.1 Void in the Reflector Components ............... 19

3.4.3.2 Aluminum in the Void Regions of the Reflector

Components .......................... 19

3.4.3.3 Constant Aluminum Density in the Reflector . . . . . . . . . . . 19

3.5 COMPUTER CODES USED FOR THE TWO-DIMENSIONAL

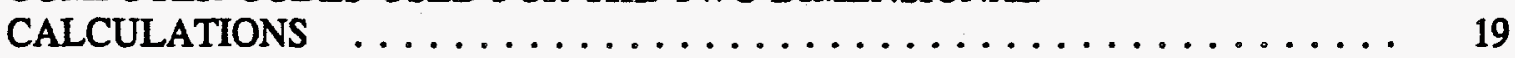

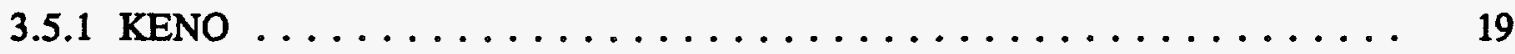

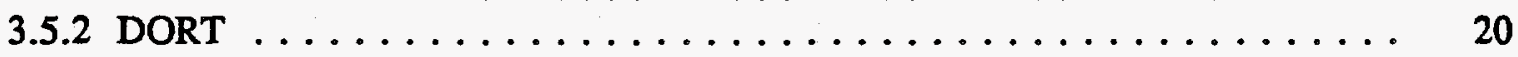

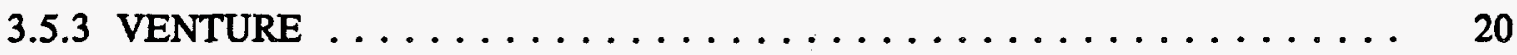

3.6 DETERMINATION OF CALCULATED QUANTITIES . . . . . . . . . . . . 20

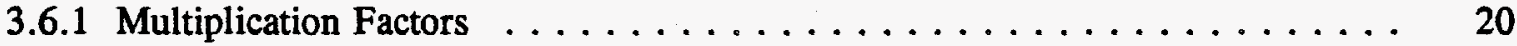

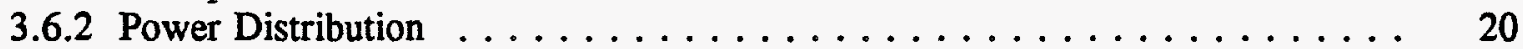

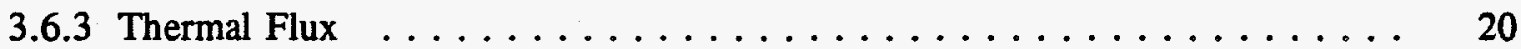

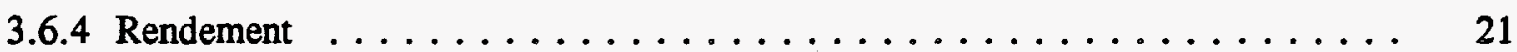

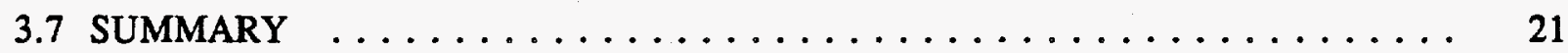

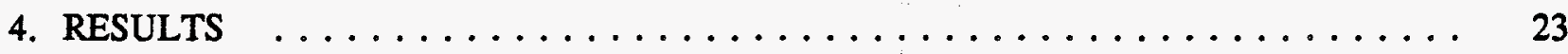

4.1 INTRODUCTION $\ldots \ldots \ldots \ldots \ldots \ldots \ldots \ldots \ldots \ldots \ldots \ldots \ldots \ldots \ldots \ldots$

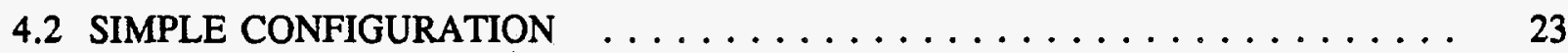

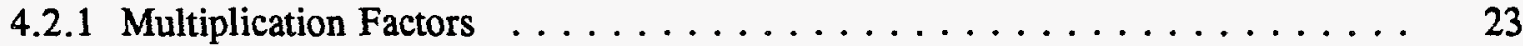

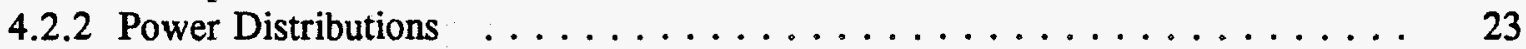

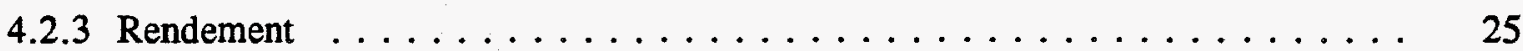




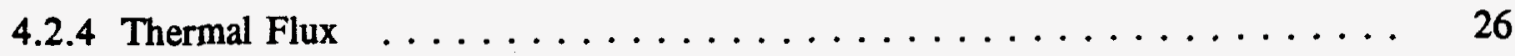

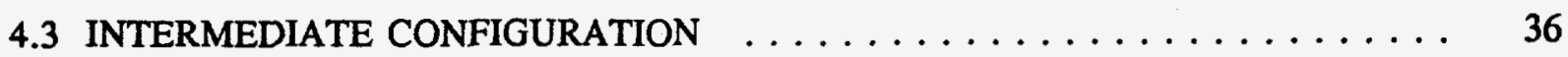

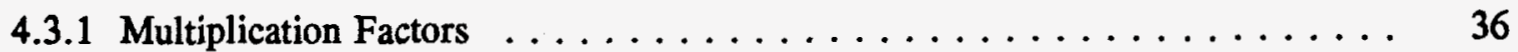

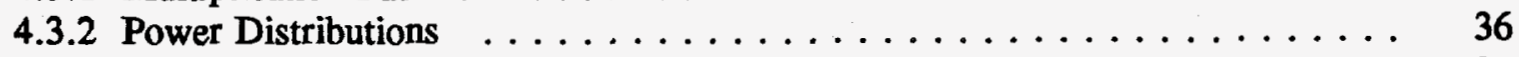

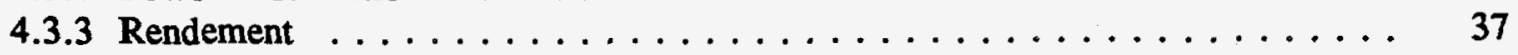

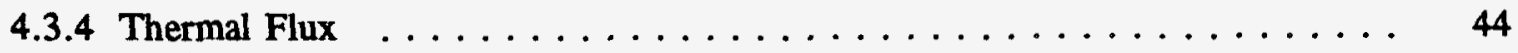

4.4 COMPLEX CONFIGURATION $\ldots \ldots \ldots \ldots \ldots \ldots \ldots \ldots \ldots \ldots \ldots$

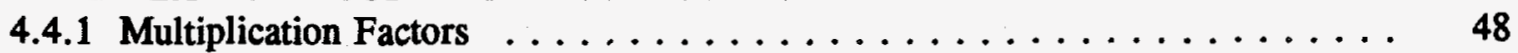

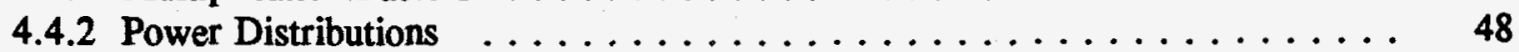

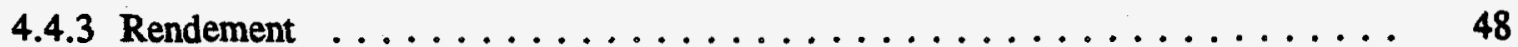

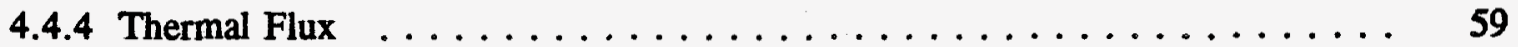

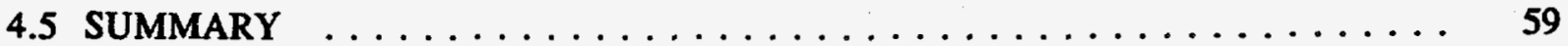

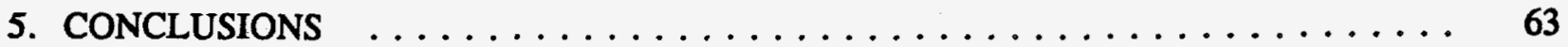

6. REFERENCES $\ldots \ldots \ldots \ldots \ldots \ldots \ldots \ldots \ldots \ldots \ldots \ldots \ldots \ldots \ldots \ldots \ldots \ldots \ldots \ldots$

Appendix A. ATOM DENSITIES FOR FOEHN EXPERIMENT MATERIALS $\ldots \ldots$. . A A-1

Appendix B. TABLES OF MEASURED AND CALCULATED RELATIVE POWER DENSITY AND THERMAL FLUX VALUES $\ldots \ldots \ldots \ldots \ldots \ldots$ B-

Appendix C. DIFFERENCES IN FOEHN CALCULATIONAL MODELS $\ldots \ldots \ldots$

\section{DISCLAIMER}

This report was prepared as an account of work sponsored by an agency of the United States Government. Neither the United States Government nor any agency thereof, nor any of their employees, makes any warranty, express or implied, or assumes any legal liability or responsibility for the accuracy, completeness, or usefulness of any information, apparatus, product, or process disclosed, or represents that its use would not infringe privately owned rights. Reference herein to any specific commercial product, process, or service by trade name, trademark, manufacturer, or otherwise does not necessarily constitute or imply its endorsement, recommendation, or favoring by the United States Government or any agency thereof. The views and opinions of authors expressed herein do not necessarily state or reflect those of the United States Government or any agency thereof. 


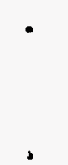




\section{LIST OF FIGURES}

Figure

Page

2.1 Borated aluminum and aluminum plates in the boron endplate package . . . . . . . 4

2.2 Reflector components in the complex configuration of the FOEHN experiment . . . . 6

2.3 Diagram of the cold source in the FOEHN experiment $\ldots \ldots \ldots \ldots \ldots \ldots$

2.4 Diagram of the hot source in the FOEHN experiment $\ldots \ldots \ldots \ldots \ldots \ldots$

3.1 Outline of the procedure used to create multigroup cross sections for the FOEHN

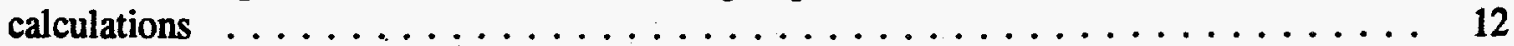

3.2 Unit cell model of a fuel plate in the FOEHN element $\ldots \ldots \ldots \ldots \ldots \ldots$

3.3 XSDRNPM model of the radial transverse at the midplane of the FOEHN fuel

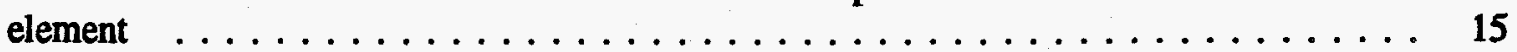

3.4 XSDRNPM model used to calculate weighted cross sections for the boron endplate

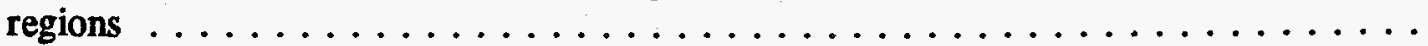

3.5 R-Z geometry FOEHN model used in the KENO, DORT, and VENTURE calculations $\ldots \ldots \ldots \ldots \ldots \ldots \ldots \ldots \ldots \ldots \ldots \ldots \ldots \ldots$

4.1 $K_{\text {eff }}$ values for the simple FOEHN configuration calculated with KENO using 99-

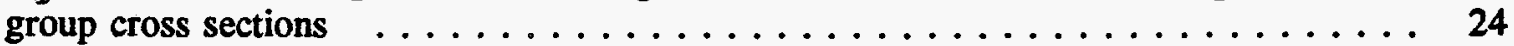

4.2 Comparison of $k_{\text {eff }}$ values for the simple FOEHN configuration calculated with different computer codes using 20-group cross sections $\ldots \ldots \ldots \ldots \ldots \ldots \ldots$

4.3 Comparison of experimental radial power density traces and KENO values calculated using 99-group cross sections for the simple FOEHN configuration . . . . . . . . .

4.4 Comparison of experimental axial power density traces and KENO values calculated using 99-group cross sections for the simple FOEHN configuration . . . . . . . . . .

4.5 Comparison of experimental radial power density traces and DORT values calculated using 20-group cross sections for the simple FOEHN configuration . . . . . . . . 30

4.6 Comparison of experimental axial power density traces and DORT values calculated using 20-group cross sections for the simple FOEHN configuration . . . . . . . . 30

4.7 Comparison of experimental radial power density traces and VENTURE values calculated using 20-group cross sections for the simple FOEHN configuration

4.8 Comparison of experimental axial power density traces and VENTURE values calculated using 20-group cross sections for the simple FOEHN configuration . . . . .

4.9 Comparison of experimental radial thermal flux traces with DORT values calculated using 20-group cross sections for the simple FOEHN configuration . . . . . . . . .

4.10 Comparison of experimental axial thermal flux traces with DORT values calculated using 20-group cross sections for the simple FOEHN configuration . . . . . . . . .

4.11 Comparison of experimental radial thermal flux traces with VENTURE values calculated using 20-group cross sections for the simple FOEHN configuration .....

4.12 Comparison of experimental axial thermal flux traces with VENTURE values calculated using 20-group cross sections for the simple FOEHN configuration . . . . .

4.13 $K_{\text {eff }}$ values for the intermediate FOEHN configuration calculated with KENO using 99-group cross sections $\ldots \ldots \ldots \ldots \ldots \ldots \ldots \ldots \ldots \ldots$

4.14 Comparison of $k_{\text {eff }}$ values for the intermediate FOEHN configuration calculated with different computer codes using 20 -group cross sections $\ldots \ldots \ldots \ldots \ldots \ldots$ Comparison of experimental radial power density traces and KENO values calculated using 99 -group cross sections for the intermediate FOEHN configuration . . . . . . . 
4.16 Comparison of experimental axial power density traces and KENO values calculated using 99-group cross sections for the intermediate FOEHN configuration . . . . . . . 41

4.17 Comparison of experimental radial power density traces and DORT values calculated using 20-group cross sections for the intermediate FOEHN configuration . . . . . . 42

4.18 Comparison of experimental axial power density traces and DORT values calculated using 20-group cross sections for the intermediate FOEHN configuration . . . . . . .

4.19 Comparison of experimental radial power density traces and VENTURE values calculated using 20-group cross sections for the intermediate FOEHN configuration . .

4.20 Comparison of experimental axial power density traces and VENTURE values calculated using 20-group cross sections for the intermediate FOEHN configuration .

4.21 Comparison of experimental radial thermal flux traces with DORT values calculated using 20-group cross sections for the intermediate FOEHN configuration . . . . . . .

4.22 Comparison of experimental axial thermal flux traces with DORT values calculated using 20-group cross sections for the intermediate FOEHN configuration . . . . . .

4.23 Comparison of experimental radial thermal flux traces with VENTURE values calculated using 20-group cross sections for the intermediate FOEHN configuration . .

4.24 Comparison of experimental axial thermal flux traces with VENTURE values calculated using 20-group cross sections for the intermediate FOEHN configuration . .

4.25 $K_{\text {eff }}$ values for the complex FOEHN configuration calculated with KENO using 99group cross sections and void in the reflector components 4

Comparison of $k_{\text {eff }}$ values for the complex FOEHN contiguration calculated with different computer codes using 20-group cross sections and void in the reflector

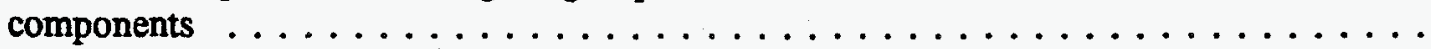

4.27 $K_{\text {eff }}$ values for the complex FOEHN configuration calculated with KENO using 99group cross sections and aluminum in the void regions of the reflector components ...

4.28 Comparison of $k_{\text {eff }}$ values for the complex FOEHN configuration calculated with different computer codes using 20-group cross sections and aluminum in the void regions of the reflector components $\ldots \ldots \ldots \ldots \ldots \ldots \ldots \ldots$

4.29 $K_{e f f}$ values for the complex FOEHN configuration calculated with KENO using 99group cross sections and a constant aluminum density in the reflector $\ldots \ldots \ldots \ldots$

4.30 Comparison of $k_{\text {eff }}$ values for the complex FOEHN configuration calculated with different computer codes using 20 -group cross sections and a constant aluminum density in the reflector $\ldots \ldots \ldots \ldots \ldots \ldots \ldots \ldots \ldots \ldots$

4.31 Comparison of experimental radial power density traces and DORT values calculated using 20-group cross sections for the different models of the complex FOEHN

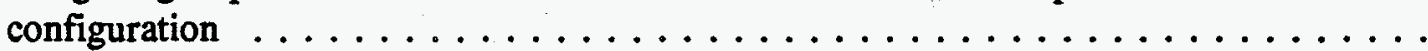

4.32 Comparison of experimental axial power density traces and DORT values calculated using 20-group cross sections for the different models of the complex FOEHN

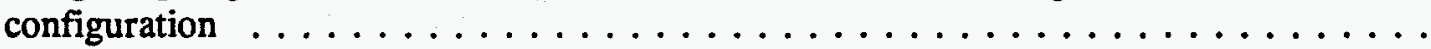

4.33 Comparison of experimental radial power density traces and VENTURE values calculated using 20-group cross sections for the differert models of the complex

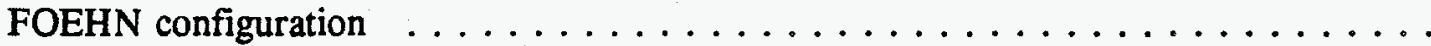

4.34 Comparison of experimental axial power density traces and VENTURE values calculated using 20-group cross sections for the different models of the complex FOEHN configuration

4.35 Comparison of experimental radial thermal flux traces with DORT values calculated using 20-group cross sections for the different models of the complex FOEHN configuration 
4.36 Comparison of experimental radial thermal flux traces with VENTURE values calculated using 20-group cross sections for the different models of the complex

FOEHN configuration 



\section{LIST OF TABLES}

Table

Page

ES.1 Average eigenvalues of the critical states of the three FOEHN configurations

calculated using different computer codes $\ldots \ldots \ldots \ldots \ldots \ldots \ldots \ldots \ldots$ xviii

ES.2 Average and maximum percent differences between the measured and calculated

power distributions for the three FOEHN configurations $\ldots \ldots \ldots \ldots \ldots \ldots$

$2.1 \quad$ Characteristics of the FOEHN fuel element $\ldots \ldots \ldots \ldots \ldots \ldots \ldots$

2.2 Description of reflector components in the FOEHN experiment $\ldots \ldots \ldots \ldots$

$3.1 \quad$ Composition of AG3-NE alloy $\ldots \ldots \ldots \ldots \ldots \ldots$

3.2 Dancoff correction factors and equivalent slab thicknesses for the FOEHN fuel element and control element $\ldots \ldots \ldots \ldots \ldots \ldots \ldots \ldots \ldots \ldots$

3.3 Energy structure of 20-group cross sections collapsed from the 99 energy group

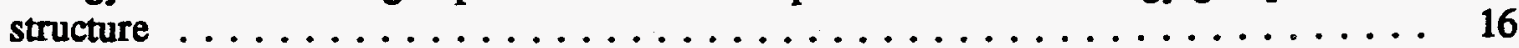

4.1 Comparison of eigenvalues for the simple FOEHN configuration cases using

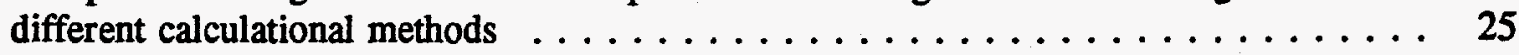

4.2 Average and maximum power density percent differences for the simple FOEHN

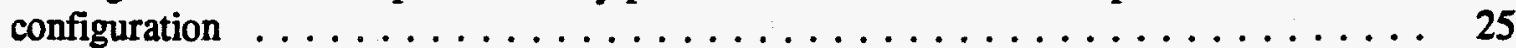

4.3 Nonmatching points for power densities calculated with KENO using 99-group cross

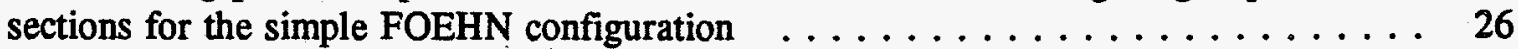

4.4 Percent differences between measured power densities and values calculated with KENO using 99-group cross sections for the simple FOEHN configuration . . . . . . 27

4.5 Percent differences between measured power densities and values calculated with DORT using 20-group cross sections for the simple FCEHN configuration . . . . . . .

4.6 Percent differences between measured power densities and values calculated with VENTURE using 20-group cross sections for the simple FOEHN configuration $\ldots \ldots 28$

4.7 Rendement values calculated for the simple FOEHN configuration . . . . . . . . 32

4.8 Percent differences between measured thermal fluxes and values calculated with DORT using 20-group cross sections for the simple FOEHN configuration $\ldots \ldots \ldots 32$

4.9 Percent differences between measured thermal fluxes and values calculated with VENTURE using 20-group cross sections for the simple FOEHN configuration $\ldots \ldots 33$

4.10 Comparison of eigenvalues for the intermediate FOEHN configuration cases using

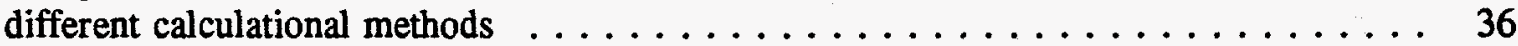

4.11 Average and maximum power density percent differences for the intermediate FOEHN configuration $\ldots \ldots \ldots \ldots \ldots \ldots \ldots \ldots \ldots \ldots \ldots$

4.12 Nonmatching points for power densities calculated with KENO using 99-group cross sections for the intermediate FOEHN configuration $\ldots \ldots \ldots \ldots \ldots$

4.13 Percent differences between measured power densities and values calculated with KENO using 99-group cross sections for the intermediate FOEHN configuration $\ldots . .39$

4.14 Percent differences between measured power densities and values calculated with DORT using 20-group cross sections for the intermediate FOEHN configuration

4.15 Percent differences between measured power densities and values calculated with VENTURE using 20-group cross sections for the intermediate FOEHN configuration ............................ 40

4.16 Rendement values calculated for the intermediate FOEHN configuration . . . . . . . 44 
4.17 Percent differences between measured thermal fluxes and values calculated with DORT using 20-group cross sections for the intermediate FOEHN configuration

4.18 Percent differences between measured thermal fluxes and values calculated with VENTURE using 20-group cross sections for the intermediate FOEHN configuration

4.19 Comparison of eigenvalues for the complex FOEHN configuration cases using

different calculational methods with void in the reflector components . . . . . . . . .

4.20 Comparison of eigenvalues for the complex FOEHN configuration cases using different calculational methods with aluminum in the void regions of the reflector

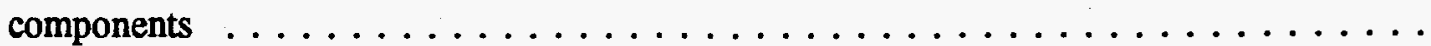

4.21 Comparison of eigenvalues for the complex FOEHN configuration cases using different calculational methods with a constant aluminum density in the reflector . . . .

4.22 Average and maximum power density percent differences for the different models of the complex FOEHN configuration $\ldots \ldots \ldots \ldots \ldots \ldots \ldots \ldots \ldots$

Percent differences between measured power densities and values calculated with DORT using 20-group cross sections for the complex FOEHN configuration with void in the reflector components $\ldots \ldots \ldots \ldots \ldots \ldots \ldots \ldots$

4.24 Percent differences between measured power densities and values calculated with DORT using 20-group cross sections for the complex FOEHN configuration with aluminum in the void regions of the reflector components $\ldots \ldots \ldots \ldots \ldots$

4.25 Percent differences between measured power densities and values calculated with DORT using 20-group cross sections for the complex FOEHN configuration with a constant aluminum density in the reflector $\ldots \ldots \ldots \ldots \ldots \ldots$

4.26 Percent differences between measured power densities and values calculated with VENTURE using 20-group cross sections for the complex FOEHN configuration with void in the reflector components $\ldots \ldots \ldots \ldots \ldots \ldots \ldots \ldots \ldots$

4.27 Percent differences between measured power densities and values calculated with VENTURE using 20-group cross sections for the complex FOEHN configuration with aluminum in the void regions of the reflector components $\ldots \ldots \ldots \ldots$

4.28 Percent differences between measured power densities and values calculated with VENTURE using 20-group cross sections for the complex FOEHN configuration with a constant aluminum density in the reflector $\ldots \ldots \ldots \ldots \ldots \ldots$

4.29 Rendement values calculated for the different models of the complex FOEHN

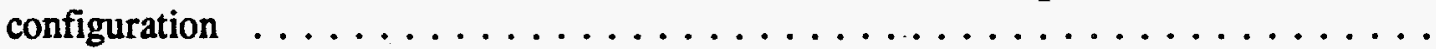

Average and maximum thermal flux percent differences for the different models of the complex FOEHN configuration $\ldots \ldots \ldots \ldots \ldots \ldots \ldots \ldots$

4.31 Percent differences between measured thermal fluxes and values calculated with DORT using 20-group cross sections for the different models of the complex FOEHN

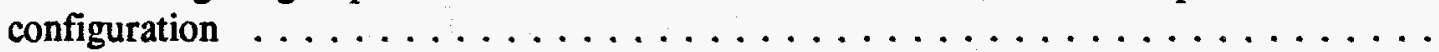
Percent differences between measured thermal fluxes and values calculated with VENTURE using 20-group cross sections for the different models of the complex FOEHN

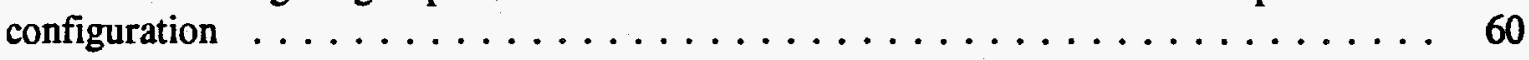

A.1 Atom densities for materials in the simple FOEHN configuration $\ldots \ldots \ldots \ldots \ldots$

A.2 Atom densities for materials in the intermediate FOEHN configuration model . . . . A A-3

A.3 Atom densities for materials in the complex FOEHN configuration model . . . . . . . A 4

A.4 Boron-10 concentrations and control element positions for the simple FOEHN configuration cases 
A.5 Boron-10 concentrations and control element positions for the intermediate FOEHN

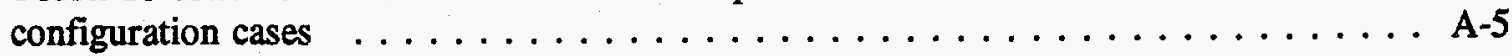

A.6 Boron-10 concentrations and control element positions for the complex FOEHN

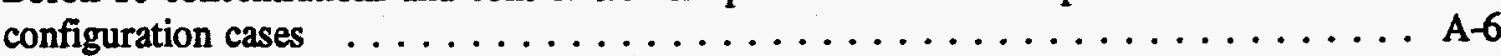

B.1 Measured relative power density values for the simple FOEHN configuration ...... B-1

B.2 Measured thermal flux values for the simple FOEHN configuration $\ldots \ldots \ldots \ldots$ B-2

B.3 Measured relative power density values for the intermediate FOEHN

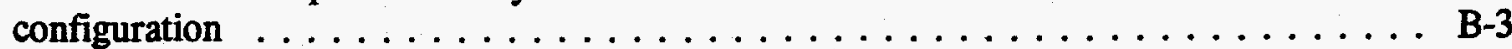

B.4 Measured thermal flux values for the intermediate FOEHN configuration $\ldots \ldots \ldots$ B-4

B.5 Measured relative power density values for the complex FOEHN configuration ..... B-5

B.6 Measured thermal flux values for the complex FOEHN configuration ... . . . . B B

B.7 Relative power density values calculated with KENO using 99-group cross sections for the simple FOEHN configuration . . . . . . . . . . . . . . . B-6

B.8 Two sigma standard deviations for the relative power density values calculated with KENO using 99-group cross sections for the simple FOEHN configuration $\ldots \ldots$ B-6

B.9 Relative power density values calculated with DORT using 20-group cross sections for the simple FOEHN configuration $\ldots \ldots \ldots \ldots \ldots \ldots \ldots$ B-7

B.10 Relative power density values calculated with VENTURE using 20-group cross sections for the simple FOEHN configuration $\ldots \ldots \ldots \ldots \ldots \ldots$ B-7

B.11 Thermal fluxes calculated with DORT using 20-group cross sections for the simple FOEHN configuration . . . . . . . . . . . . . . . . . B 8

B.12 Thermal fluxes calculated with VENTURE using 20-group cross sections for the simple FOEHN configuration $\ldots \ldots \ldots \ldots \ldots \ldots \ldots \ldots$ B-8

B.13 Relative power density values calculated with KENO using 99-group cross sections for the intermediate FOEHN configuration $\ldots \ldots \ldots \ldots \ldots \ldots \ldots$ B-9

B.14 Two sigma standard deviations for the relative power density values calculated with KENO using 99-group cross sections for the intermediaie FOEHN configuration . . . B B-9

B.15 Relative power density values calculated with DORT using 20-group cross sections for the intermediate FOEHN configuration $\ldots \ldots \ldots \ldots \ldots \ldots \ldots \ldots$ B-10

B.16 Relative power density values calculated with VENTURE using 20-group cross sections for the intermediate FOEHN configuration $\ldots \ldots \ldots \ldots \ldots \ldots \ldots$ B-10

B.17 Thermal fluxes calculated with DORT using 20-group cioss sections for the intermediate FOEHN configuration . . . . . . . . . . . . . . B-11

B.18 Thermal fluxes calculated with VENTURE using 20-group cross sections for the intermediate FOEHN configuration . . . . . . . . . . . . . . . B-11

B.19 Relative power density values calculated with DORT using 20-group cross sections for the complex FOEHN configuration with void in the reflector components $\ldots .$. B-12

B.20 Relative power density values calculated with DORT using 20-group cross sections for the complex FOEHN configuration with aluminum in the void regions of the reflector components

B.21 Relative power density values calculated with DORT using 20-group cross sections for the complex FOEHN configuration with a constant aluminum density in the reflector

B.22 Relative power density values calculated with VENTURE using 20-group cross sections for the complex FOEHN configuration with void in the reflector

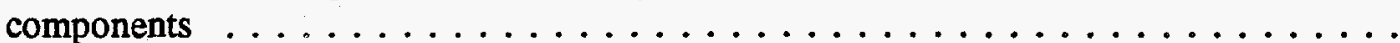


B.23 Relative power density values calculated with VENTURE using 20-group cross sections for the complex FOEHN configuration with aluminum in the void regions of

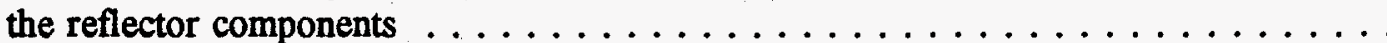

B.24 Relative power density values calculated with VENTUIE using 20-group cross sections for the complex FOEHN configuration with a constant aluminum density in the reflector

B.25 Thermal fluxes calculated with DORT using 20-group cross sections for the different models of the complex FOEHN configuration $\ldots \ldots \ldots \ldots \ldots \ldots \ldots$

B.26 Thermal fluxes calculated with VENTURE using 20-group cross sections for the different models of the complex FOEHN configuration

B-15 


\section{ACKNOWLEDGMENTS}

The authors would like to thank the Advanced Neutron Source Project office at Oak Ridge National Laboratory. This project funded appointments for the first and third authors through the U.S.

Department of Energy Postgraduate Research Training Program administered by Oak Ridge Institute for Science and Education, which made the completion of this work possible. We would also like to thank F. C. Difilippo, R. T. Primm, J. M. Ryskamp, D. L. Selby, and B. Terry for reviewing the draft report. 



\section{EXECUTIVE SUMMARY}

Neutronics analysis of the Advanced Neutron Source (ANS) reactor ${ }^{1}$ is being performed at Oak Ridge National Laboratory using the KENO ${ }^{2}$ Monte Carlo transport code, the DORT ${ }^{3}$ discrete ordinates transport code, and the VENTURE ${ }^{4}$ diffusion theory code. Cross sections derived from the ANSL-V 99-group neutron master library ${ }^{5}$ are used in the calculations. The ANSL-V library was developed specifically for the ANS reactor physics and shielding analysis.

This study was designed to validate multigroup cross sections generated from the ANSL-V library and ANS calculational methods against measured data from the FOEHN critical experiment. ${ }^{6}$ The FOEHN experiment was performed to validate the calculational methods used in the design of the Franco-German High Flux Reactor. The FOEHN criticals have several features that are very similar to the current design of the ANS. The two most notable similarities are the use of highly enriched uranium in an involute fuel-plate geometry and the use of heavy water as the moderator and reflector material.

In the FOEHN experiment, three configurations are examined. The simple configuration consists of only the fuel and control elements in the reflector tank. The intermediate configuration includes boron endplates at the upper and lower edges of the fuel element. The complex configuration includes the boron endplates and reflector components (beam tubes, irradiation facilities, etc.). Critical states, power distributions, and thermal fluxes were measured for each configuration. The rendement, the neutron efficiency of the system, was also measured. The errors associated with these measurements were reported. Estimates of the errors were reevaluated in ref. 9.

Models of the FOEHN experiment were developed for the KENO, DORT, and VENTURE neutronics codes. Because the simple and intermediate configurations of the FOEHN experiment are azimuthally symmetric, these configurations can be explicitly modeled in $\mathrm{R}-\mathrm{Z}$ geometry, and the correctness of these models is limited only by minor material and geometric assumptions that were made because of incomplete documentation of the experiment. Because the reflector components in the complex FOEHN configuration cannot be explicitly modeled with the current versions of these codes, three reflector component homogenization schemes were developed and evaluated by comparison against measured data.

Cross sections from the ANSL-V 99-group master library were processed using modules from the AMPX $^{11}$ code system. Eigenvalues were calculated with KENO using both 99-group and 20-group cross sections. The DORT and VENTURE calculations were performed using 20-group cross sections. Power distributions were calculated using KENO with 99-group cross sections. Power distributions, thermal fluxes, and the rendement were computed with DORT and VENTURE.

Table ES. 1 shows the average eigenvalues calculated for the critical cases of each configuration. The use of 99 energy groups estimates criticality to within $0.2 \%$ for the simple and intermediate configurations. The KENO and DORT transport calculations using 20 groups predict criticality to within $0.5 \%$, while the VENTURE diffusion theory calculations are accurate to within $1.1 \%$ for the simple and intermediate configurations. In the analysis in ref. 13, the average values for the simple and intermediate configurations were $0.9982 \pm 0.0017$ and $0.9951 \pm 0.0021$, respectively.

The complex configuration modeled with void in the reflector components overpredicts a multiplication factor of unity because streaming effects in the reflector components are not accurately predicted. The models with aluminum in the void regions of the reflector components and a constant aluminum density in the reflector were forced to yield multiplication factors near unity so that the calculated power distributions could be compared against the measured data. 
The average differences between the calculated and measured power density values for each configuration are shown in Table ES.2. The errors in the measured power density values were reported as $1 \%$ in the FOEHN report. ${ }^{6}$ Reference 9 reports the errors to be from 4 to $8 \%$. The average differences for the transport calculations are slightly larger than the VENTURE diffusion theory results even though the transport calculations yield eigenvalues closer to unity. The exact uncertainty in the measured data at the upper and lower edges of the fuel element is unknown. The plates holding the measuring probes became deformed after repeated use. If these edge locations are not considered, the average differences are within $4 \%$ for all the configurations. Another uncertainty must be considered when comparing power density values at the inner edge of the fuel element. Previously calculated power distributions $s^{6,9,14}$ have overestimated the measured values near the tip of the control element. If these points and the upper and lower edge values are not considered, the maximum differences range from -7.66 to $-15.11 \%$. The power distributions reported in ref. 9 for each configuration are similar to the results obtained in this report.

Thermal fluxes were calculated with DORT and VENTURE. The average differences between the calculated and measured values for the simple and intermediate configurations are $<8 \%$. In ref. 9 , experimental errors of $12 \%$ must be assumed to yield results that are compatible with the $2 \sigma$ statistical uncertainty of the calculated values. Only radially averaged values can be compared for the complex configuration. The largest average difference (13.98\%) of the three complex approximations occurs in the model with void in the reflector components. The original FOEHN report states that the thermal flux measurement errors are $2 \%$, although ref. 9 estimates a range from 3.3 to $22.8 \%$.

The work in this report shows that multiplication factors, power distributions, and thermal fluxes for the FOEHN experiment can be calculated within the measurement errors using multigroup cross sections derived from the ANSL-V master cross-section library. The calculated parameters are comparable to those determined in the independent studies documented in refs. 9,13 , and 14 . The general trends of overpredicting or underpredicting the measured data are similar. The results show that the calculational methods used in this work accurately predict the measured values of the FOEHN experiment, a highly enriched, heavy-water-moderated system that has many similarities with the current ANS design.

Table ES.1. Average eigenvalues of the critical states of the three FOEHN configurations calculated using different computer codes

\begin{tabular}{|c|c|c|c|c|}
\hline \multirow[t]{2}{*}{ Configuration } & \multicolumn{2}{|c|}{ KENO } & \multirow{2}{*}{$\begin{array}{l}\text { DORT } \\
\text { 20-group }\end{array}$} & \multirow{2}{*}{$\begin{array}{l}\text { VENTURE } \\
\text { 20-group }\end{array}$} \\
\hline & 99-group & 20-group & & \\
\hline Simple & $1.0018 \pm 0.0013^{a}$ & $1.0046 \pm 0.0013$ & 1.0046 & 1.0108 \\
\hline Intermediate & $0.9983 \pm 0.0020$ & $1.0025 \pm 0.0019$ & 1.0008 & 1.0014 \\
\hline $\begin{array}{l}\text { Complex with void in the reflector } \\
\text { components }\end{array}$ & $1.0162 \pm 0.0018$ & $1.0205 \pm 0.0018$ & 1.0190 & 1.0206 \\
\hline $\begin{array}{l}\text { Complex with aluminum in the void } \\
\text { regions of the reflector components }\end{array}$ & $0.9993 \pm 0.0018$ & $1.0042 \pm 0.0018$ & 1.0030 & 1.0039 \\
\hline $\begin{array}{l}\text { Complex with a constant aluminum } \\
\text { density in the reflector }\end{array}$ & $0.9996 \pm 0.0018$ & $1.0030 \pm 0.0019$ & 1.0035 & 1.0047 \\
\hline
\end{tabular}

\footnotetext{
${ }^{a}$ The reported statistical uncertainty is two standard deviations.
} 
Table ES.2. Average and maximum percent differences between the measured and calculated power distributions for the three FOEHN configurations

\begin{tabular}{|c|c|c|c|c|c|c|}
\hline \multirow{2}{*}{ Configuration } & \multicolumn{3}{|c|}{ Average percent difference $^{a}$} & \multicolumn{3}{|c|}{ Maximum percent difference ${ }^{b}$} \\
\hline & $\begin{array}{l}\text { KENO } \\
\text { 99-group }\end{array}$ & $\begin{array}{c}\text { DORT } \\
\text { 20-group }\end{array}$ & $\begin{array}{l}\text { VENTURE } \\
20 \text {-group }\end{array}$ & $\begin{array}{l}\text { KENO } \\
\text { 99-group }\end{array}$ & $\begin{array}{c}\text { DORT } \\
20 \text {-group }\end{array}$ & $\begin{array}{l}\text { VENTURE } \\
20 \text {-group }\end{array}$ \\
\hline Simple & 3.43 & 3.22 & 2.94 & $21.61(9.33)$ & $18.00(-8.67)$ & $13.17(13.17)$ \\
\hline Intermediate & $4.50(2.86)$ & $3.45(1.68)$ & $2.45(1.87)$ & $-20.50(-9.67)$ & $-19.88(-8.33)$ & $-12.46(-7.66)$ \\
\hline $\begin{array}{l}\text { Complex with void in the reflector } \\
\text { components }\end{array}$ & - & $4.82(2.92)$ & $3.37(2.91)$ & - & $-23.17(-12.28)$ & $-15.42(-8.39)$ \\
\hline $\begin{array}{l}\text { Complex with aluminum in the void } \\
\text { regions of the reflector } \\
\text { components }\end{array}$ & -- & $5.11(3.15)$ & $3.51(2.96)$ & - & $-22.90(-12.98)$ & $-14.88(-8.06)$ \\
\hline $\begin{array}{l}\text { Complex with a constant aluminum } \\
\text { density in the reflector }\end{array}$ & - & $5.74(3.73)$ & $4.12(3.45)$ & - & $-22.57(-15.11)$ & $-14.72(-10.27)$ \\
\hline
\end{tabular}

${ }^{a}$ The average values in parentheses were calculated without including the points at the upper and lower edges of the fuel element.

The maximum values in parentheses for the simple configuration were determined without including the points at the inner edge of the fuel element near the tip of the control element. The maximum values in parentheses for the intermediate and complex configurations were determined without including the points at the upper and lower edges of the fuel element or the points at the inner edge of the element near the tip of the control element. 



\begin{abstract}
The FOEHN critical experiment was analyzed to validate the use of multigroup cross sections and Oak Ridge National Laboratory neutronics computer codes in the design of the Advanced Neutron Source. The ANSL-V 99-group master cross section library was used for all the calculations. Three different critical configurations were evaluated using the multigroup KENO Monte Carlo transport code, the multigroup DORT discrete ordinates transport code, and the multigroup diffusion theory code VENTURE. The simple configuration consists of only the fuel and control elements with the heavy water reflector. The intermediate configuration includes boron endplates at the upper and lower edges of the fuel element. The complex configuration includes both the boron endplates and components in the reflector.

Cross sections were processed using modules from the AMPX system. Both 99-group and 20group cross sections were created and used in two-dimensional models of the FOEHN experiment. KENO calculations were performed using both 99 -group and 20-group cross sections. The DORT and VENTURE calculations were performed using 20-group cross sections. Because the simple and intermediate configurations are azimuthally symmetric, these configurations can be explicitly modeled in $\mathrm{R}-\mathrm{Z}$ geometry. Since the reflector components cannot be modeled explicitly using the current versions of these codes, three reflector component homogenization schemes were developed and evaluated for the complex configuration.

Calculated eigenvalues for the simple and intermediate configurations using KENO with 99-group cross sections are within $0.2 \%$ of unity. The 20 -group transport results are within $0.5 \%$ of unity while the diffusion theory results overestimate unity by as much as $1.1 \%$. Eigenvalues calculated using a smeared reflector component model are overpredicted by all three codes by approximately $2 \%$. The reflector compositions in two other models were adjusted to yield eigenvalues near unity so that calculated power distributions could be compared against measured data.

Power density distributions were calculated with KENO using 99-group cross sections and with DORT and VENTURE using 20-group cross sections. The average differences between the measured values and the values calculated with the different computer codes range from 2.45 to $5.74 \%$.

Measured thermal fluxes in the reflector are compared to DORT and VENTURE calculated values. The maximum differences between the measured and calculated thermal flux values for the simple and intermediate configurations are $\sim 13 \%$, while the average differences are $<8 \%$.
\end{abstract}




\section{INTRODUCTION}

\subsection{BACKGROUND AND OBJECTIVE}

Neutronics calculations for the Advanced Neutron Source (ANS) reactor ${ }^{1}$ are being performed using the multigroup $\mathrm{KENO}^{2}$ Monte Carlo transport code, the multigroup DORT ${ }^{3}$ discrete ordinates transport code, and the multigroup diffusion theory code VENTURE. ${ }^{4}$ Ongoing efforts are being carried out at Oak Ridge National Laboratory (ORNL) to validate the multigroup cross sections derived from the ANSL-V5 99-group library for ANS reactor core analysis. The ANSL-V library was developed specifically for the ANS reactor physics and shielding analysis.

Previous studies have been performed to validate the ANSL-V library against solution criticals and simple critical configurations. The objective of this work is to validate the use of ORNL neutronics computer codes and multigroup cross sections derived from the ANSL-V library against measured data from the FOEHN critical experiment.

\subsection{ORGANIZATION OF REPORT}

The FOEHN critical experiment is described in Chap. 2. The measured quantities of interest are discussed, and some of the experimental uncertainties are presented. In Chap. 3, the calculational models used in this work are described. The models used for cross section processing and the twodimensional (2-D) core calculations are presented in detail for the simple, intermediate, and complex configurations. In Chap. 4, calculated multiplication factors, power distributions, and thermal fluxes are compared with measured values. Results are included from the calculations with the KENO, DORT, and VENTURE codes using 99-group and 20-group cross sections. Conclusions are made in Chap. 5, and references are included in Chap. 6. 



\section{DESCRIPTION OF THE FOEHN EXPERIMENT}

\subsection{INTRODUCTION}

The FOEHN critical experiment was performed to validate the calculational methods used in the design of the Franco-German High Flux Reactor. ${ }^{6}$ The geometries used in this experiment have features similar to those of the ANS reactor, most notably the use of highly enriched uranium in a fuel-plate geometry, the use of heavy water as moderator and reflector material, and the use of experimental facilities (beam tubes, cold source, and hot source) in the heavy water reflector. Therefore, analyses of this experiment will be used to provide an initial validation of the methods used to perform reactor physics analyses of the ANS reactor.

The FOEHN experiment was divided into three parts (simple, intermediate, and complex) based on their general geometry. The simple configuration consists of only the fuel element with no boron endplates or reflector components. The intermediate configuration includes the boron endplates at the upper and lower edges of the fuel element. The complex configuration contains both the boron endplates and the reflector components. The various parts of the FOEHN experiment are described in this chapter. Also, the data measured during the experiment and the experimental uncertainties are discussed.

\subsection{COMPONENTS OF THE FOEHN REACTOR}

\subsubsection{Fuel}

The FOEHN fuel consists of a single cylindrical element. Characteristics of the element are outlined in Table 2.1. Involute-shaped fuel plates are held between two cylindrical tubes. The fuel element is $800-\mathrm{mm}$ high. The inner radius of the element is $140 \mathrm{~mm}$, and the outer radius is $195 \mathrm{~mm}$. The cylindrical tubes that hold the fuel plates are 5-mm thick and are fabricated from an AG3-NE aluminum alloy. Some of the excess reactivity during the experiment was compensated by the addition of dissolved boron to the coolant in the gaps between the fuel plates of the fuel element. The fuel element was placed in a watertight vessel so that dissolved boron would be present only in the coolant between the fuel plates. The upper and lower lids of the vessel are 6-mm thick. Using the fuel-plate dimensions, the free volume in the fuel zone region is $27.0 \mathrm{~L}$. When the vessel was filled, the volume was measured to be $28.85 \mathrm{~L}$. The effects of this discrepancy are discussed in Sect. 2.4.1.

\subsubsection{Control Element}

The control element is a 1-m-long nickel cylindrical tube. The tube is 5-mm thick and has an inner radius of $12.1 \mathrm{~mm}$. The element is driven by a motor from below the fuel element. The control element position is the distance from the fully inserted position to the upper edge of the control element. The fully inserted position (the reference position, $0.0 \mathrm{~mm}$ ) is $100 \mathrm{~mm}$ above the upper edge of the fuel element. 
Table 2.1. Characteristics of the FOEHN fuel element

\begin{tabular}{ll}
\hline \multicolumn{1}{c}{ Parameter } & \multicolumn{1}{c}{ Description } \\
\hline Fuel & U-Al alloy with $90 \mathrm{wt} .{ }^{235} \mathrm{U}$ \\
Fuel load $\left(\mathrm{kg}{ }^{235} \mathrm{U} / \mathrm{m}^{2}\right)$ & 0.568 \\
Total ${ }^{235} \mathrm{U}$ mass $(\mathrm{kg})$ & 8.556 \\
Number of fuel plates & 276 \\
Plate length (mm) & $800 \pm 0.5$ \\
Plate span (mm) & $68.3 \pm 0.2$ \\
Plate thickness (mm) & $1.27 \pm 0.05$ \\
Thickness of lateral AG3-NE clad (mm) & 0.1 \\
Fuel plate involute radius (mm) & 134.855 \\
Moderator gap thickness (mm) & 1.8 \\
\hline
\end{tabular}

\subsubsection{Reflector}

The fuel element is located in the center of a cylindrical tank filled with $\mathrm{D}_{2} \mathrm{O}$. The tank has a radius of $1.15 \mathrm{~m}$ and a height of $2.2 \mathrm{~m}$. The fuel element is separated from the reflector by a stack. The stack eliminates the possibility of contaminating the entire system with dissolved boron if a leak occurs. The cylindrical tube has an inner radius of $20.217 \mathrm{~mm}$ and is fabricated from AG3-NE aluminum alloy. The wall thickness is $6.1 \mathrm{~mm}$.

\subsubsection{Boron Endplates}

Packages consisting of horizontal borated aluminum plates and pure aluminum plates, each 1-mm thick, were used to simulate boron zones at the upper and lower edges of the FOEHN fuel element. The boron loading in the plates was $5 \times 10^{-3} \mathrm{~g} \mathrm{~B}_{\text {nat }} / \mathrm{cm}^{2}$ (1-mm-thick plate). The packages were attached outside the watertight vessel that contains the fuel element. A drawing of the endplate configuration is shown in Fig. 2.1. The boron loading and the metal-to- $\mathrm{D}_{2} \mathrm{O}$ ratio of the package correspond to those of the Franco-German High Flux Reactor.

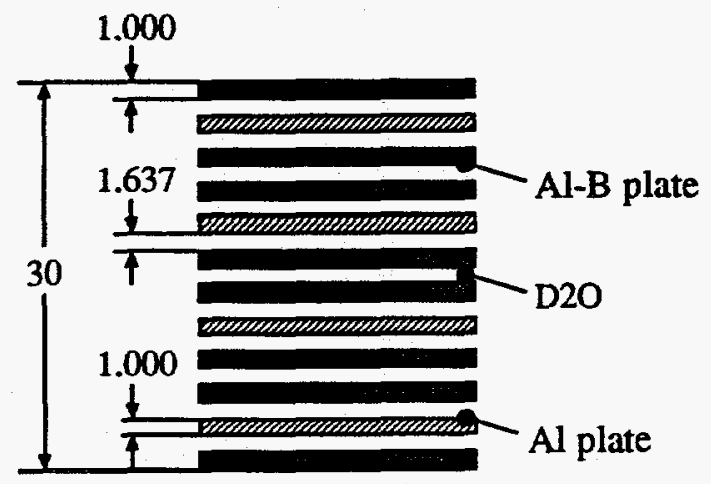

Fig. 2.1. Borated aluminum and aluminum plates in the boron endplate package. (All dimensions are in millimeters.) 


\subsubsection{Reflector Components}

A description of the reflector components is shown Table 2.2. This information is from ref. 7 . The structures are made of an AG3-NE alloy with a thickness of $2 \mathrm{~mm}$. Figure 2.2 shows the location of each of the reflector components. The hot and cold sources were mock-ups of the actual sources. Diagrams of the cold and hot sources are shown in Figs. 2.3 and 2.4, respectively.

Table 2.2. Description of reflector components in the FOEHN experiment

\begin{tabular}{|c|c|c|c|c|c|c|c|c|}
\hline \multirow[t]{2}{*}{ Number } & \multirow[t]{2}{*}{ Description } & \multicolumn{3}{|c|}{$\begin{array}{l}\text { Location of the center of } \\
\text { component }(\mathrm{mm})\end{array}$} & \multicolumn{2}{|c|}{ Orientation } & \multirow{2}{*}{$\begin{array}{l}\text { Length } \\
\text { (mm) }\end{array}$} & \multirow{2}{*}{$\begin{array}{l}\text { Inner } \\
\text { diameter } \\
\text { (mm) }\end{array}$} \\
\hline & & $\mathbf{x}$ & $\mathbf{y}$ & $z$ & $\theta^{\circ}$ & $\phi^{\circ}$ & & \\
\hline 1 & Horizontal beam tube & -278 & -482 & 860 & 159 & $\mathbf{0}$ & 830 & 150 \\
\hline 2 & Horizontal beam tube & -459 & -244 & 860 & 146 & 0 & 765 & 100 \\
\hline 3 & Horizontal beam tube & -429 & 53 & 1360 & 261 & 0 & 1012 & 100 \\
\hline 4 & Horizontal beam tube & -393 & -218 & 1110 & 297 & 0 & 910 & 100 \\
\hline 6 & Horizontal beam tube & 470 & 190 & 1210 & 307 & 0 & 880 & 100 \\
\hline 7 & $\begin{array}{l}\text { Horizontal beam tube to } \\
\text { the hot source }\end{array}$ & 446 & 79 & 1260 & 287 & 0 & 975 & 100 \\
\hline 8 & Horizontal beam tube & $368^{a}$ & $-298^{a}$ & 860 & 40 & 0 & 883 & 100 \\
\hline 9 & Horizontal beam tube & 515 & 402 & 1260 & 28 & 0 & 488 & 100 \\
\hline 10 & Horizontal beam tube & 383 & 496 & 1260 & 94 & 0 & 532 & 100 \\
\hline $11^{b}$ & $\begin{array}{l}\text { Horizonal thermal } \\
\text { neutron conductor }\end{array}$ & -218 & 448 & 910 & 122 & 0 & 588 & $150^{a}$ \\
\hline 13 & $\begin{array}{l}\text { Capture gamma } \\
\text { horizontal tube }\end{array}$ & -486 & -953 & 810 & 30 & 0 & 1784 & 100 \\
\hline 14 & Cold source & -618 & 328 & 1105 & 0 & 90 & 1105 & 200 \\
\hline 15 & Hot source & 375 & 325 & 1010 & 0 & 90 & 1200 & 150 \\
\hline 16 & Pneumatic tube & -522 & 745 & 1110 & 0 & 90 & 1200 & 40 \\
\hline 17 & Pneumatic tube & 39 & 373 & 1310 & 0 & 90 & 1000 & 40 \\
\hline 19 & Slant tube & -310 & -442 & 1360 & 293 & 35 & 800 & 100 \\
\hline 21 & Hot source slant tube & 503 & 193 & 1330 & 314 & 35 & 933 & 100 \\
\hline 22 & Hot source slant tube & -122 & 527 & 1360 & 47 & 35 & 840 & 100 \\
\hline 23 & Vertical electron tube & 375 & -649 & 10 & 0 & 90 & 2200 & 200 \\
\hline 24 & Cold source slant tube & 776 & 137 & 1360 & 230 & 35 & 350 & 100 \\
\hline
\end{tabular}

These values are incorrect in ref. 7 and were corrected based on information from ref. 6.

b This tube has a conical shape. The inner diameter of the cone is $150 \mathrm{~mm}$. The conic angle is $5^{\circ} 30^{\prime \prime}$, making the outer diameter of the cone $253 \mathrm{~mm}$. 


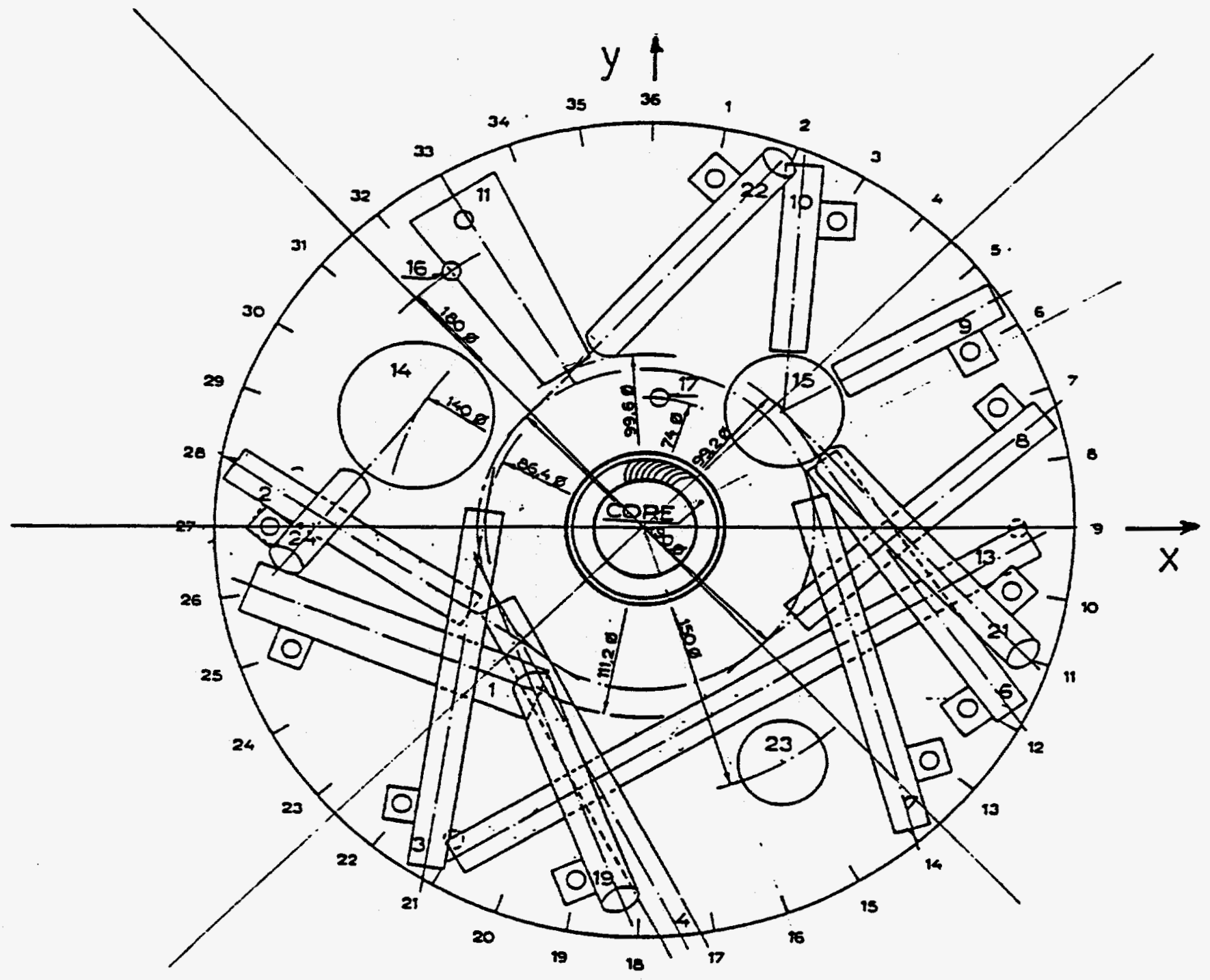

Fig. 2.2. Reflector components in the complex configuration of the FOEHN experiment. 


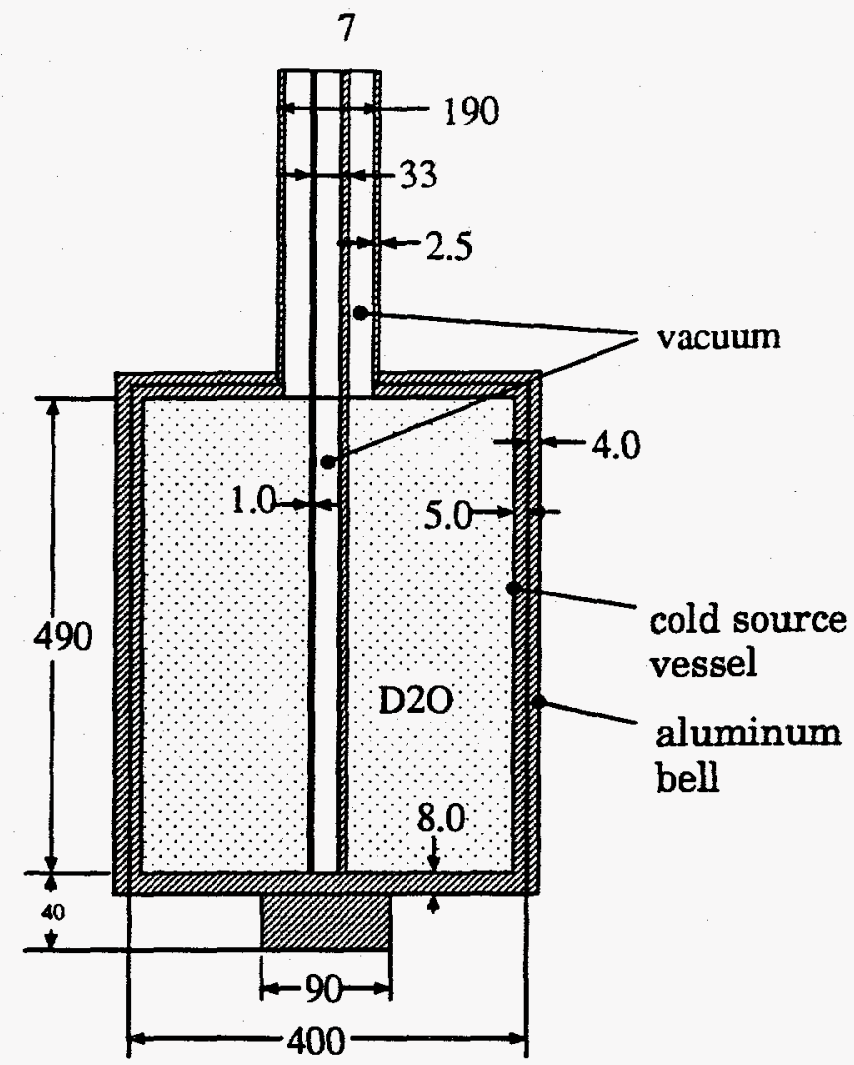

Fig. 2.3. Diagram of the cold source in the FOEHN experiment. (All dimensions are in millimeters.)

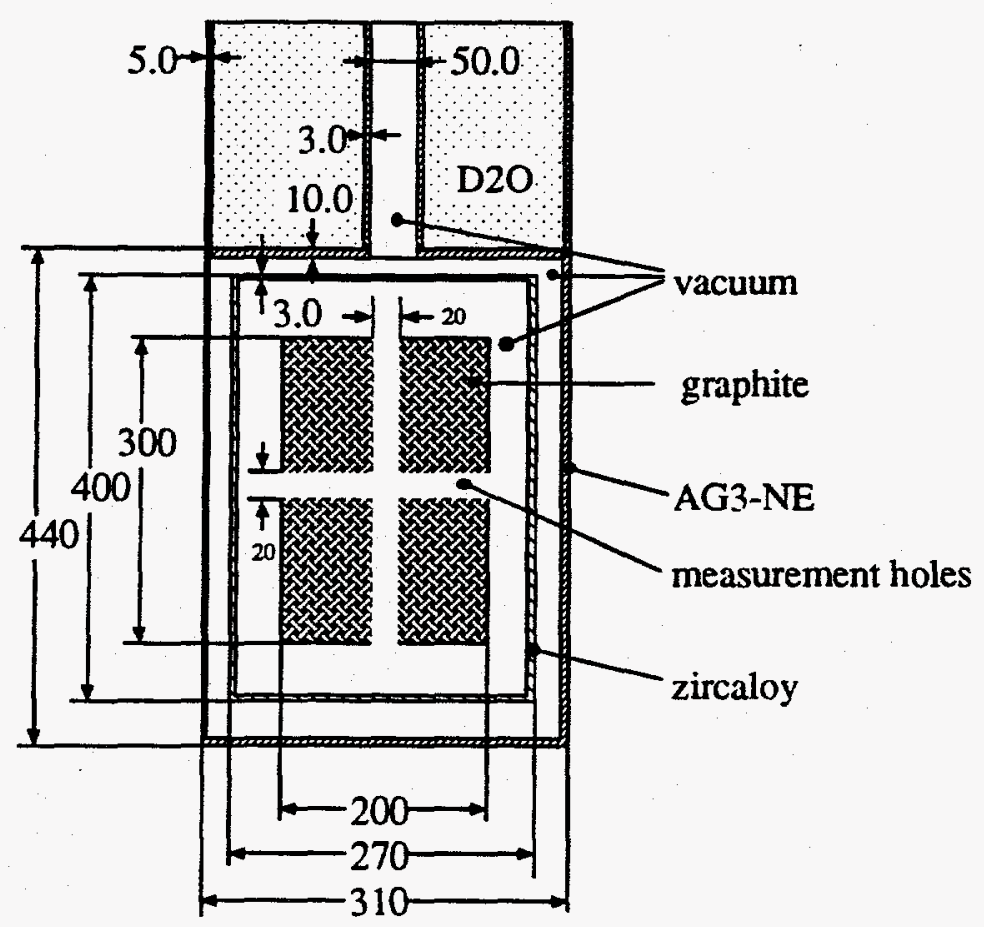

Fig. 2.4. Diagram of the hot source in the FOEHN experiment. (All dimensions are in millimeters.) 


\subsection{MEASURED DATA}

The critical states, power distributions, thermal fluxes, and the rendement are the measured parameters of interest to this report. More detail about the measurement methods can be found in ref. 6. Gamma heating and epithermal and fast flux measurements were also made during the experiment.

\subsubsection{Critical States}

The critical states for the different cases of the configurations were determined by measuring the stable reactor period of various supercritical states. The reactivities for each period are calculated using the Inhour equation and are plotted vs the control element positions. The critical control element position is determined by extrapolation.

\subsubsection{Power Distribution}

Measurements of the power distribution in the fuel element were made with $5 \times 3 \times 1.27$-mm probes. The probes were composed of the same material as the fuel plates. These probes were placed in punched holes of special fuel plates and were calibrated by measurement of their natural gamma activity above $130 \mathrm{keV}$. After irradiation, the gamma activity of the fission products above $511 \mathrm{keV}$ was measured. This activity is proportional to the fission power production that occurred in the probe during irradiation.

\subsubsection{Thermal Flux}

Thermal flux measurements were made at various points in the reflector for each configuration. Manganese probes, or foils, were used to determine the cadmium ratio. Foils with and without cadmium covers were irradiated. The thermal flux can be determined using the measured activities of the irradiated foils.

\subsubsection{Rendement}

The rendement is the ratio of the peak thermal flux in the reflector to the total core power. The rendement $(r)$ was determined using

$$
r=\frac{A_{M n, \max }}{A_{M n, R}} \cdot \frac{v}{v_{0}} \cdot \frac{A_{U, R}}{A_{U, C}} \cdot \frac{1}{\Sigma_{f, t h}^{U} \cdot V_{c} \cdot Q}
$$

where

$A_{M(n, \max } \quad=$ activity of manganese probe at the maximum flux position,

$A_{M, R} \quad=$ activity of manganese probe in the reflector,

$A_{U, R} \quad=$ activity of the uranium probe in the reflector,

$A_{U, C} \quad=$ activity of the uranium probe in the core,

$\Sigma_{f, t h}^{U} \quad=$ thermal macroscopic uranium fission cross section,

$V_{c} \quad=$ the core volume,

$Q \quad=$ the energy per fission. 
The ratio $v \nu_{o}$ and $\Sigma_{f, \text { ah }}^{v}$ were calculated using the THERMOS ${ }^{8}$ code, and $v_{o}$ is given in Eq. 2 . The calculated thermal microscopic uranium fission cross section was 503 barns. In the calculation of the measured rendement in ref. 6 , the energy released per fission, $Q$, was assumed to be $199.73 \mathrm{MeV}$.

$$
v_{0}=\frac{2}{\sqrt{\pi}} \cdot 2200 \frac{m}{\sec }
$$

\subsection{EXPERIMENTAL UNCERTAINTIES}

\subsubsection{Geometrical Uncertainties}

In ref. 6, diagrams of the FOEHN reactor are included that show the location of the different components. However, detailed drawings that include component dimensions are not given in the report. The location of components not described in the text of the report has to be determined using either the diagrams, which do not include dimensions, or the model used for the diffusion theory calculations in the report. One example of these uncertainties is the exact geometry of the control element. It is uncertain whether an aluminum structure is present at the upper edge of the control element.

In Sect. 2.2.1, the difference between the calculated volume and actual volume of borated heavy water in the core region was mentioned. The exact location of this extra $\mathrm{D}_{2} \mathrm{O}$ is not known and was assumed to be at the inner and outer edge of the fuel element. Because the worth of the borated $\mathrm{D}_{2} \mathrm{O}$ is largest for the simple configuration measurements, the location of the borated $\mathrm{D}_{2} \mathrm{O}$ has the largest impact on the measured results of this configuration.

\subsubsection{Material Compositions}

The composition of AG3-NE aluminum alloy is not documented in ref. 6. Furthermore, it is not certain whether some of the components are AG3-NE alloy or pure aluminum. Also, the accuracy of the $\mathrm{D}_{2} \mathrm{O}$ purity or the boron-concentration measurements was not discussed.

\subsection{ERROR ESTIMATES}

\subsubsection{Critical States}

The error associated with the measurement of the critical states depends on the control-element positions and the dissolved boron-concentration measurements. It was reported that the controlelement position could be determined to within $\pm 1 \mathrm{~mm}$. The error in the measurements of the boron concentration was not discussed.

\subsubsection{Power Distribution Measurements}

Reference 6 reports the relative error of the individual measuring points to be less than $1 \%$ for all points except those points on the upper and lower fuel-plate edges. This error is attributed to the uncertainty in the position of the fuel plates containing the probes. The error in the points at the upper 
and lower edges of the fuel element is larger because the plates became somewhat deformed after use. In ref. 9, the errors involved with the power measurements were reevaluated. It is reported that errors in the measurements may be up to $8 \%$ when the probe dimensions, counting statistics, and probe positioning are considered. If the error associated with the probe dimensions is not included, the errors range from 1 to $4.15 \%$. In this report, the error associated with all power distribution measurements is assumed to be $4 \%$.

\subsubsection{Thermal-Flux Measurements}

The error in the thermal-flux measurements was determined to be about $2 \%$ by the FOEHN investigators. ${ }^{6}$ In ref. 9, after evaluation of all the contributing factors, it is stated that the errors may range from 3.3 to $22.8 \%$. In this report, the error in the thermal-flux measurements is assumed to be $4 \%$.

\subsubsection{Rendement}

In ref. 6 , the error in the measurement of the rendement is stated as $\pm 2 \%, \pm 2 \%$, and $\pm 3 \%$ for the simple, intermediate, and complex FOEHN configurations, respectively. The errors are estimated to be between 2.2 and $16.2 \%$ in ref. 9. The upper estimate was determined by accounting for positioning errors and statistical uncertainties.

\subsection{SUMMARY}

The components of the FOEHN experiment have been described in detail. The methods used to obtain the measured data were explained. Some of the uncertainties in the experiment were identified. The errors associated with the measured parameters calculated by the original experimenters and independently in a separate study were presented. 


\section{CALCULATIONAL MODELS OF THE FOEHN EXPERIMENT}

\subsection{INTRODUCTION}

The models of each configuration of the FOEHN experiment are described in this chapter. The methods used to create the cross sections for the 2-D calculations are included. The atom densities for the materials in each configuration are included in Appendix $\mathbf{A}$.

\subsection{MATERIAL COMPOSITIONS}

\subsubsection{Fuel}

The fuel composition was taken from Table 3.1 in ref. 6. These values were the atom densities for the homogenous fuel element. Atom densities for the impurities in the AG3-NE alloy were calculated using the atom density for aluminum from the reference.

\subsubsection{Heavy Water}

The density of the heavy water is $1.105 \mathrm{~g} / \mathrm{cm}^{3}$, which corresponds to a temperature of $20^{\circ} \mathrm{C}$. For each configuration, the amount of light water in the $\mathrm{D}_{2} \mathrm{O}$ was different. The contamination is 0.253 , $0.265,0.263$ at. \% for the simple, intermediate, and complex configurations. ${ }^{6}$ This light water contamination was assumed to be the same in both the core and reflector regions.

\subsubsection{AG3-NE Alloy}

For these calculations, all of the aluminum components in the FOEHN experiment were assumed to be composed of AG3-NE alloy except the borated aluminum and pure aluminum plates used to construct the boron endplate packages. The exact composition of AG3-NE alloy is not documented in ref. 6. The composition assumed for this work is from a mill test ${ }^{10}$ of an AG3-NE sample and is listed in Table 3.1.

\subsection{CROSS SECTION PROCESSING METHODOLOGY}

Cross sections were processed using modules from the AMPX code system. The procedure is outlined in Fig. 3.1. Each step is explained in the following sections. For each case of each FOEHN configuration, 99-group and 20-group neutron cross section working libraries were produced. For each configuration, the ${ }^{2} \mathrm{H}$ and ${ }^{1} \mathrm{H}$ atom densities were changed to account for the fluctuations in the light water contamination during the experiment. The ${ }^{10} \mathrm{~B}$ concentration in the coolant in the core region was set equal to the measured value for each critical state. 


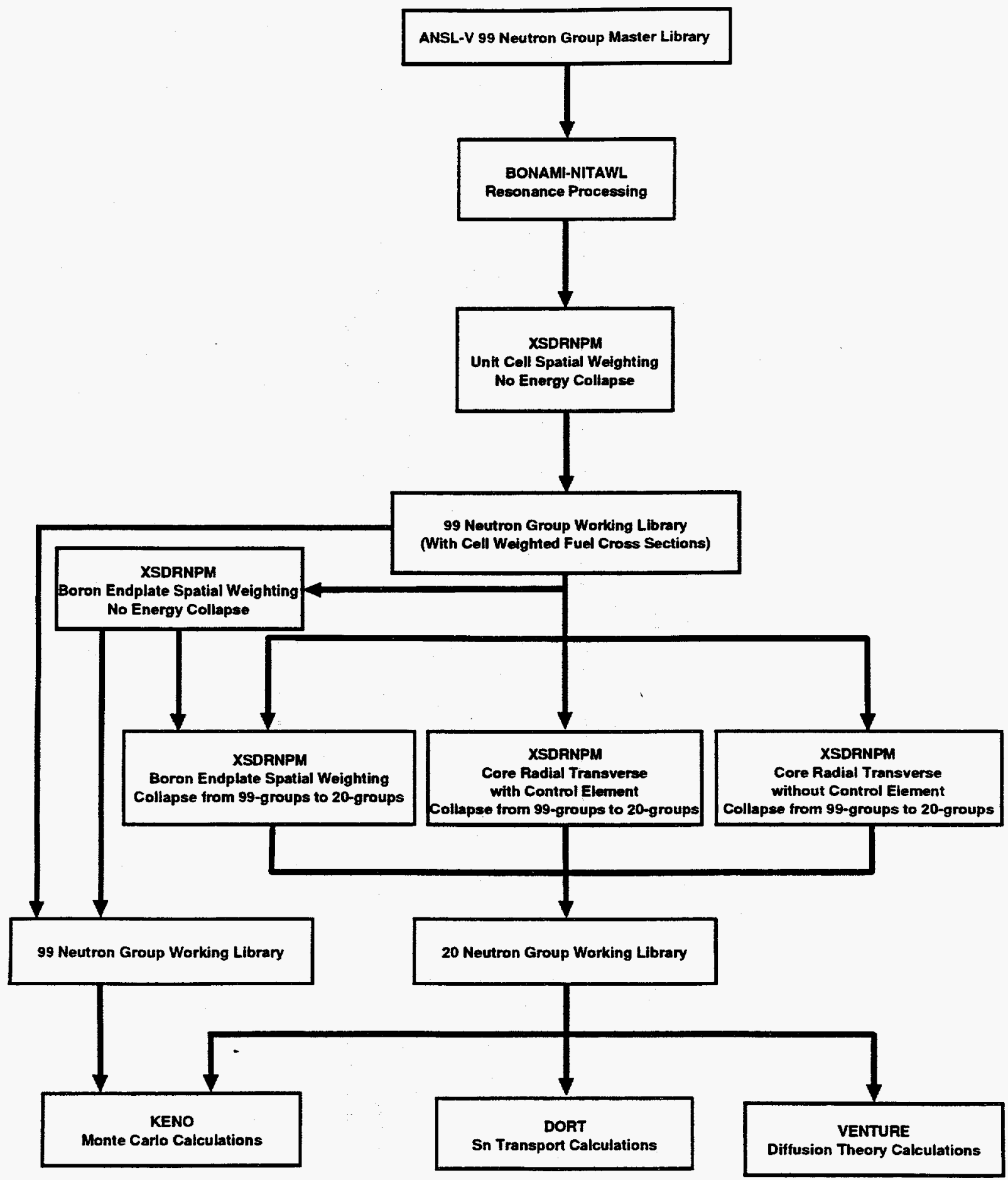

Fig. 3.1. Outline of the procedure used to create multigroup cross sections for the FOEHN calculations. 
Table 3.1. Composition of AG3-NE alloy

\begin{tabular}{lc}
\hline Element & Weight percent \\
\hline $\mathrm{Al}$ & 96.739 \\
$\mathrm{Mg}$ & 2.78 \\
$\mathrm{Fe}$ & 0.26 \\
$\mathrm{Si}$ & 0.15 \\
$\mathrm{Mn}$ & 0.04 \\
$\mathrm{Cr}$ & 0.01 \\
$\mathrm{Ti}$ & 0.01 \\
$\mathrm{Zn}$ & 0.01 \\
$\mathrm{~B}$ & 0.001 \\
$\mathrm{Cu}$ & $70^{a}$ \\
$\mathrm{~Pb}$ & $20^{a}$ \\
$\mathrm{Cd}$ & $1^{a}$ \\
\hline
\end{tabular}

${ }^{a}$ Value has units of ppm.

\subsubsection{Resonance Processing}

\subsubsection{Unresolved Resonance Energy Range}

The BONAMI ${ }^{11}$ module uses Bondarenko factor data in a self-shielding calculation. In the AMPX system, this approach is used in the unresolved energy range. In the ANSL-V library, two isotopes used in these calculations ${ }^{238} \mathrm{U}$ and ${ }^{235} \mathrm{U}$ ) have Bondarenko factor data. A one-dimensional (1-D) slab model of a fuel unit cell was used to allow BONAMI to calculate escape probabilities to account for the interaction between fuel lumps.

\subsubsection{Resolved Resonance Energy Range}

The NITAWL" module was used to process the resolved resonances using the Nordheim Integral Treatment. All nuclides were processed at a temperature of $300 \mathrm{~K}$. The resonance nuclides in the AG3-NE alloy were processed separately for the fuel plates and structural material by changing the lump dimension.

A Dancoff correction factor is required if the interaction between different material lumps must be considered. Calculations were performed using RAFFLE ${ }^{12}$ to determine the Dancoff factors for the resonance processing of the nuclides in the fuel plates and the control element. RAFFLE is a Monte Carlo code that calculates first flight collision probabilities. In the analysis, the involute fuel plates were modeled as concentric circular cylinders. The thickness of the fuel cylinders is $1.27 \mathrm{~mm}$, which is equal to the involute fuel-plate thickness. The moderator gap between the fuel plates is $1.8 \mathrm{~mm}$. Using these dimensions, the FOEHN element model consists of 17 cylindrical fuel rings. For the Dancoff factor calculations, the atom densities of the fuel material were not adjusted to conserve the amount of ${ }^{233} \mathrm{U}$ in the fuel element. The fuel-plate loading was not adjusted because conservation of the actual-fuel plate optical thickness is important in this calculation. 
RAFFLE was used to calculate escape probabilities, $P_{e c c}$, for neutrons born within the fuel and control element regions. $P_{\text {ecc }}$ can be determined using the calculated number of interactions in each material type in the model. The total macroscopic cross sections are required for each material in the model. In the RAFFLE calculations, the $\mathrm{D}_{2} \mathrm{O}$ moderator did not contain dissolved boron or light water contamination. The $P_{\text {ecc }}$ values were then used to calculate the Dancoff correction factor for an infinite slab with the same thickness as the fuel ring. Also, an equivalent slab thickness was calculated. The values determined for the fuel element and the control element are shown in Table 3.2. Either the actual lump dimension and the Dancoff factor or the equivalent lump dimension with a Dancoff factor of zero can be used in NITAWL. Both of these methods result in the same $P_{\text {occ }}$ value for the resonance processing.

Table 3.2. Dancoff correction factors and equivalent slab thicknesses for the FOEHN fuel element and control element

\begin{tabular}{lccc}
\hline \multicolumn{1}{c}{ Region } & $\begin{array}{c}\text { Actual lump } \\
\text { thickness (mm) }\end{array}$ & $\begin{array}{c}\text { Dancoff correction } \\
\text { factor (C) }\end{array}$ & $\begin{array}{c}\text { Equivalent slab thickness } \\
\text { (mm) }\end{array}$ \\
\hline Fuel element & 1.27 & 0.8115 & 7.09 \\
Nickel control element & 5.00 & 0.0127 & 5.08 \\
\hline
\end{tabular}

\subsubsection{Unit Cell Calculation}

After resonance processing, the XSDRNPM $S_{n}$ transport code was used to calculate 99-group fluxes over the fuel unit cell shown in Fig. 3.2. These fluxes were then used to create spatially homogenized 99-group unit cell cross sections. The weighted cross sections account for the flux depression in the fuel plate and can be used in homogenous representations of the fuel region.

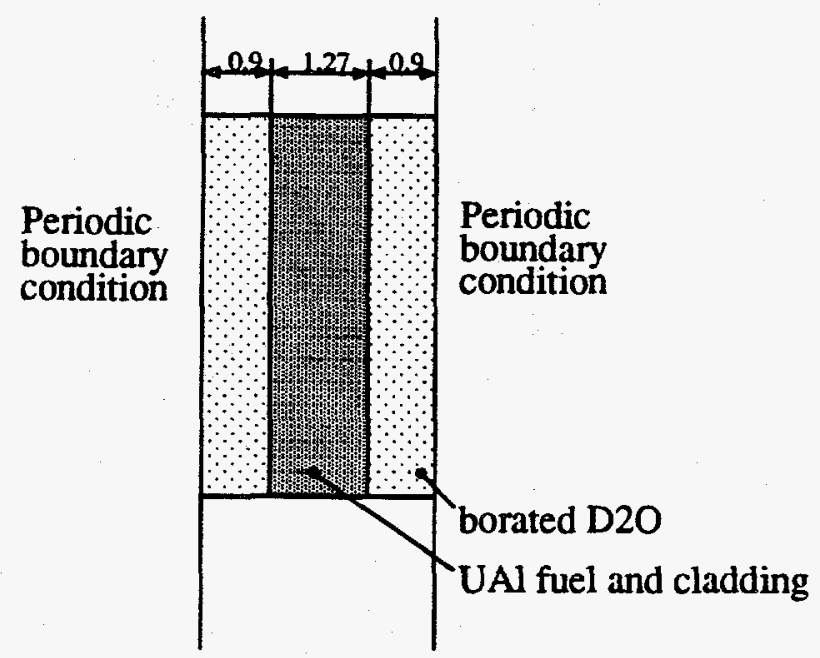

Fig. 3.2. Unit cell model of a fuel plate in the FOEHN element. (All dimensions are in millimeters.) 


\subsubsection{Core Radial Transverse Models}

The cell-weighted 99-group fuel cross sections were used in an XSDRNPM model of the radial transverse at the midplane of the FOEHN reactor. The dimensions of the model are shown in Fig. 3.3. The height of the fuel element, $800 \mathrm{~mm}$, was used to determine the buckling correction and to calculate the axial leakage from the system. Two models were evaluated: a controlled model that included the nickel control element and an uncontrolled model that did not include the control element.

The calculated 99-group fluxes were used to collapse the 99 energy group cross sections to a 20 energy group structure. The energy group boundaries of the 20-group cross sections are shown in Table 3.3. One cross section set was created for the fuel region. Several cross section sets were created for the AG3-NE alloy and the heavy water in the reflector to account for the changes in the energy spectrum at different positions in the reactor. Trace amounts of the nuclides that make up AG3-NE alloy were added to the reflector region to create 20-group cross sections for the reflector components.

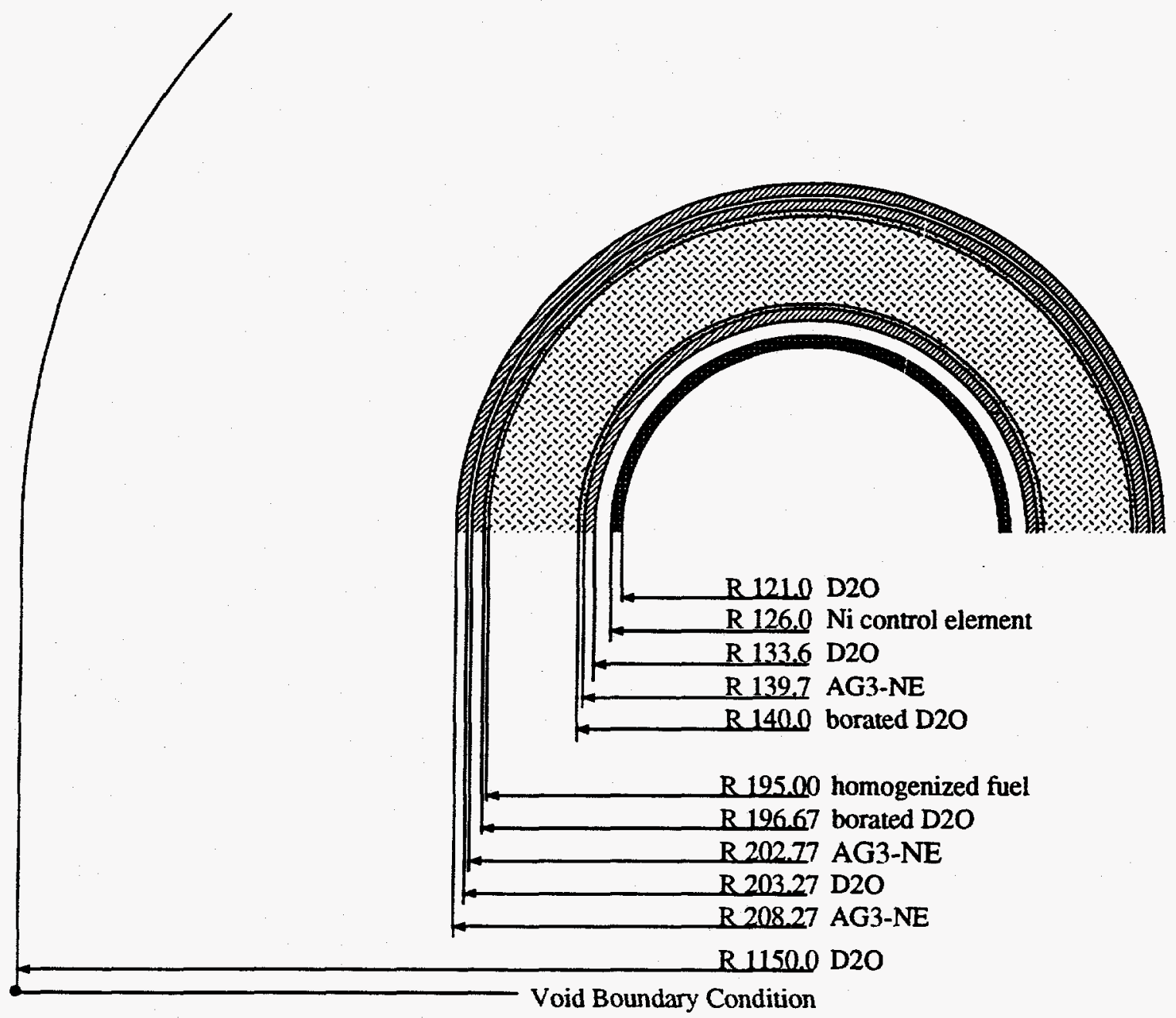

Fig. 3.3. XSDRNPM model of the radial transverse at the midplane of the FOEHN fuel element. (All dimensions are in millimeters.) 
Table 3.3. Energy structure of 20 -group cross sections collapsed from the 99 energy group structure

\begin{tabular}{|c|c|c|c|c|c|c|c|}
\hline & \multirow{2}{*}{$\begin{array}{l}\text { Upper } \\
\text { ewergy } \\
\text { (eV) }\end{array}$} & \multicolumn{2}{|c|}{ Energy groups } & & \multirow{2}{*}{$\begin{array}{l}\text { Upper } \\
\text { enerby } \\
\text { (ev) }\end{array}$} & \multicolumn{2}{|c|}{ Energy groups } \\
\hline & & 99-group & 20-group & & & 99-group & 20-group \\
\hline 1 & $2.0000 \mathrm{E}+07$ & 1 & 1 & 51 & $5.5000 \mathrm{E}+\infty 2$ & 51 & \\
\hline 2 & $1.5941 \mathrm{E}+07$ & 2 & & 52 & $3.9110 \mathrm{E}+02$ & 52 & \\
\hline 3 & $3.2706 \mathrm{E}+07$ & 3 & & 53 & $2.7811 E+02$ & 53 & \\
\hline 4 & $1.0127 \mathrm{E}+07$ & 4 & & 54 & $1.9776+02$ & 54 & \\
\hline 5 & $8.0722 \mathrm{E}+06$ & 5 & & 55 & $1.4063 \mathrm{E}+02$ & 55 & \\
\hline 6 & $6.4340 \mathrm{E}+06$ & 6 & & 56 & $1.0000 \mathrm{E}+02$ & 56 & 7 \\
\hline 7 & $5.5234 \mathrm{E}+06$ & 7 & & 57 & $7.8600 \mathrm{E}+01$ & 57 & \\
\hline 8 & $4.7417 \mathrm{E}+\infty 6$ & 8 & & 58 & $6.1700 \mathrm{z}+01$ & 58 & \\
\hline 9 & $4.0707 \mathrm{E}+06$ & 9 & & 59 & $4.8559 \mathrm{E}+01$ & 59 & \\
\hline 10 & $3.4946 \mathrm{E}+06$ & 10 & & 60 & $3.8168 \mathrm{E}+01$ & 60 & \\
\hline 11 & $3.0000 \mathrm{E}+06$ & 11 & 2 & 61 & $3.0000 \mathrm{E}+01$ & 61 & 8 \\
\hline 12 & $2.7235 \mathrm{E}+06$ & 12 & & 62 & $2.4082 E+01$ & 62 & \\
\hline 13 & $2.4725 \mathrm{E}+06$ & 13 & & 63 & $1.9332 E+01$ & 63 & \\
\hline 14 & $2.2447 \mathrm{E}+06$ & 14 & & 64 & $1.5518 \mathrm{E}+01$ & 64 & \\
\hline 15 & $2.0378 \mathrm{E}+\infty 6$ & 15 & & 65 & $1.2457 \mathrm{E}+01$ & 65 & \\
\hline 16 & $1.8500 \mathrm{E}+06$ & 16 & 3 & 66 & $1.0000 \mathrm{E}+01$ & 66 & 9 \\
\hline 17 & $1.7497 \mathrm{E}+06$ & 17 & & 67 & $7.8600 \mathrm{E}+\infty 0$ & 67 & \\
\hline 18 & $1.6548 \mathrm{E}+06$ & 18 & & 68 & $6.1780 \mathrm{E}+\infty$ & 68 & \\
\hline 19 & $1.5651 E+06$ & 19 & & 69 & $4.8559 E+\infty$ & 69 & \\
\hline 20 & $1.4803 \mathrm{E}+06$ & 20 & & $x$ & $3.8168 \mathrm{E}+\infty$ & $x$ & \\
\hline 21 & $1.4000 \mathrm{E}+06$ & 21 & & 71 & $3.0000 \mathrm{E}+\infty 0$ & 71 & 10 \\
\hline 22 & $1.2816 \mathrm{E}+06$ & 22 & & 72 & $2.6996 \mathrm{E}+\infty 0$ & 72 & \\
\hline 23 & $1.1732 \mathrm{E}+06$ & 23 & & 73 & $2.4292 B+\infty$ & 73 & \\
\hline 24 & $1.0740 E+06$ & 24 & & 74 & $2.1859 \mathrm{E}+\infty$ & 74 & \\
\hline 25 & $9.8315 E+05$ & 25 & & 75 & $1.9670 \mathrm{E}+\infty$ & 75 & \\
\hline 26 & $9.0000 \mathrm{E}+05$ & 26 & 4 & 76 & $1.7 n 00 \mathrm{E}+\infty$ & 76 & 11 \\
\hline 27 & $7.6525 \mathrm{E}+05$ & 27 & & $n$ & $1.3000 E+\infty$ & 77 & \\
\hline 28 & $6.5068 \mathrm{E}+05$ & 28 & & 78 & $1.0000 \mathrm{E}+\infty 0$ & 78 & 12 \\
\hline 29 & $5.5326 \mathrm{E}+05$ & 29 & & 79 & $7.6500 \mathrm{E}-01$ & 79 & \\
\hline 30 & 4.7043E+05 & 30 & & 80 & $6.2500 E-01$ & $\mathbf{8 0}$ & 13 \\
\hline 31 & $4.0000 E+05$ & 31 & & 81 & $4.7900 E-01$ & 81 & \\
\hline 32 & $3.0314 E+05$ & 32 & & 82 & $3.9700 \mathrm{E}-01$ & 82 & 14 \\
\hline 33 & $2.2974 E+05$ & 33 & & 83 & $3.3000 E-01$ & 83 & \\
\hline 34 & $1.7411 E+05$ & 34 & & 84 & $2.7000 \mathrm{E}-01$ & 84 & 15 \\
\hline 35 & $1.3195 E+05$ & 35 & & 85 & $2.1500 \mathrm{E}-01$ & 85 & \\
\hline 36 & $1.0000 \mathrm{E}+05$ & 36 & 5 & 86 & $1.6200 \mathrm{E}-01$ & 86 & 16 \\
\hline 37 & $7.0160 E+04$ & 37 & & 87 & $1.0400 \mathrm{E}-01$ & 87 & \\
\hline 38 & $4.9224 E+04$ & 38 & & 88 & $5.0000 \mathrm{E}-02$ & 88 & 17 \\
\hline 39 & $3.4536 E+04$ & 39 & & 89 & $3.0000 \mathrm{E}-02$ & 89 & \\
\hline 40 & $2.4230 \mathrm{E}+04$ & 40 & & 90 & $1.0000 \mathrm{E}-02$ & 90 & 18 \\
\hline 41 & $1.7000 E+04$ & 41 & & 91 & $4.4500 \mathrm{E}-03$ & 91 & \\
\hline 42 & $1.2017 \mathrm{E}+04$ & 42 & & 92 & $3.2500 \mathrm{E}-03$ & 92 & 19 \\
\hline 43 & $8.4941 E+03$ & 43 & & 93 & $2.6000 \mathrm{E}-\infty 3$ & 93 & \\
\hline 44 & $6.0042 \mathrm{E}+03$ & 44 & & 94 & $2.1500 \mathrm{E}-03$ & 94 & 20 \\
\hline 45 & $4.2441 E+03$ & 45 & & 95 & $1.8000 \mathrm{E}-03$ & 95 & \\
\hline 46 & $3.0000 E+03$ & 46 & 6 & 96 & $1.4500 E-03$ & 9 & \\
\hline 47 & $2.1368 E+03$ & 47 & & 97 & $1.1500 \mathrm{E}-\infty 3$ & 97 & \\
\hline 48 & $1.5220 \mathrm{E}+03$ & 48 & & 98 & $8.5000 E-04$ & 98 & \\
\hline 49 & $1.0841 E+03$ & 49 & & 99 & $5.5000 \mathrm{E}-04$ & 99 & \\
\hline so & $7.721 \pi+02$ & 50 & & & $1.0000 \mathrm{E}-0 \mathrm{~s}$ & & \\
\hline
\end{tabular}




\subsubsection{Boron Endplate Model}

Spatially weighted cross sections were created for the boron endplate regions using the 1-D slab XSDRNPM model shown in Fig. 3.4. This model accurately accounts for the effects of thermal neutrons returning from the $\mathrm{D}_{2} \mathrm{O}$ above the fuel element. The spatially weighted 99-group cross sections from the unit cell calculation described in Sect. 3.3.2 were used in the homogenized fuel region. The width of the fuel element $(55 \mathrm{~mm})$ was used as the slab width, and the slab was assumed to be infinitely thick. The fluxes from this calculation were used to obtain spatially homogenized 99group and 20-group cross sections for the boron endplate regions.

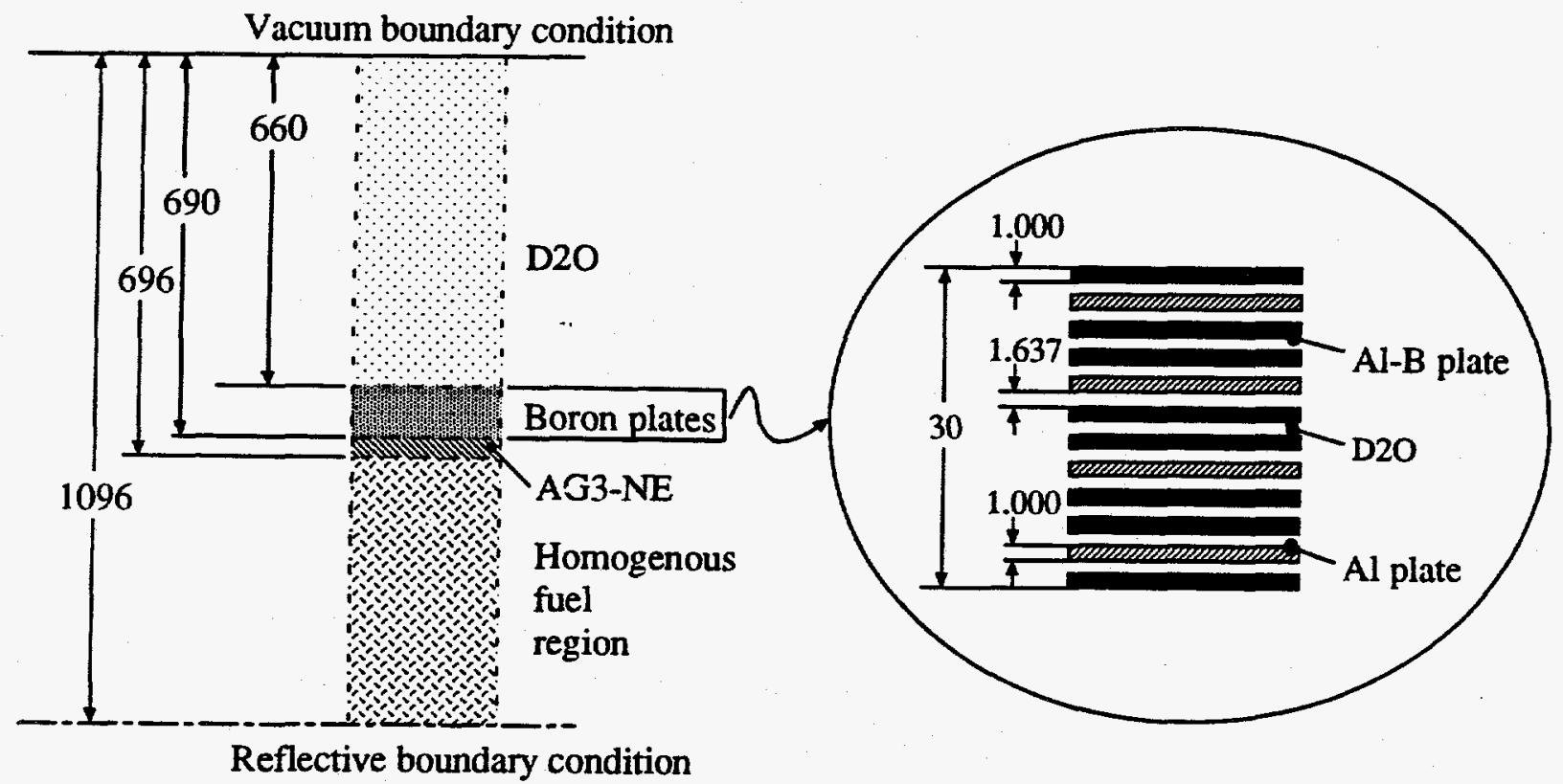

Fig. 3.4. XSDRNPM model used to calculate weighted cross sections for the boron endplate regions. (All dimensions are in millimeters.)

\subsection{TWO-DIMENSIONAL (R-Z) MODEL DESCRIPTIONS}

\subsubsection{Simple Configuration}

The simple configuration model is shown in Fig. 3.5. The radial dimensions are the same as those used in the 1-D model shown in Fig. 3.3. The boron endplate regions at the upper and lower edges of the fuel element contain heavy water in this configuration. 


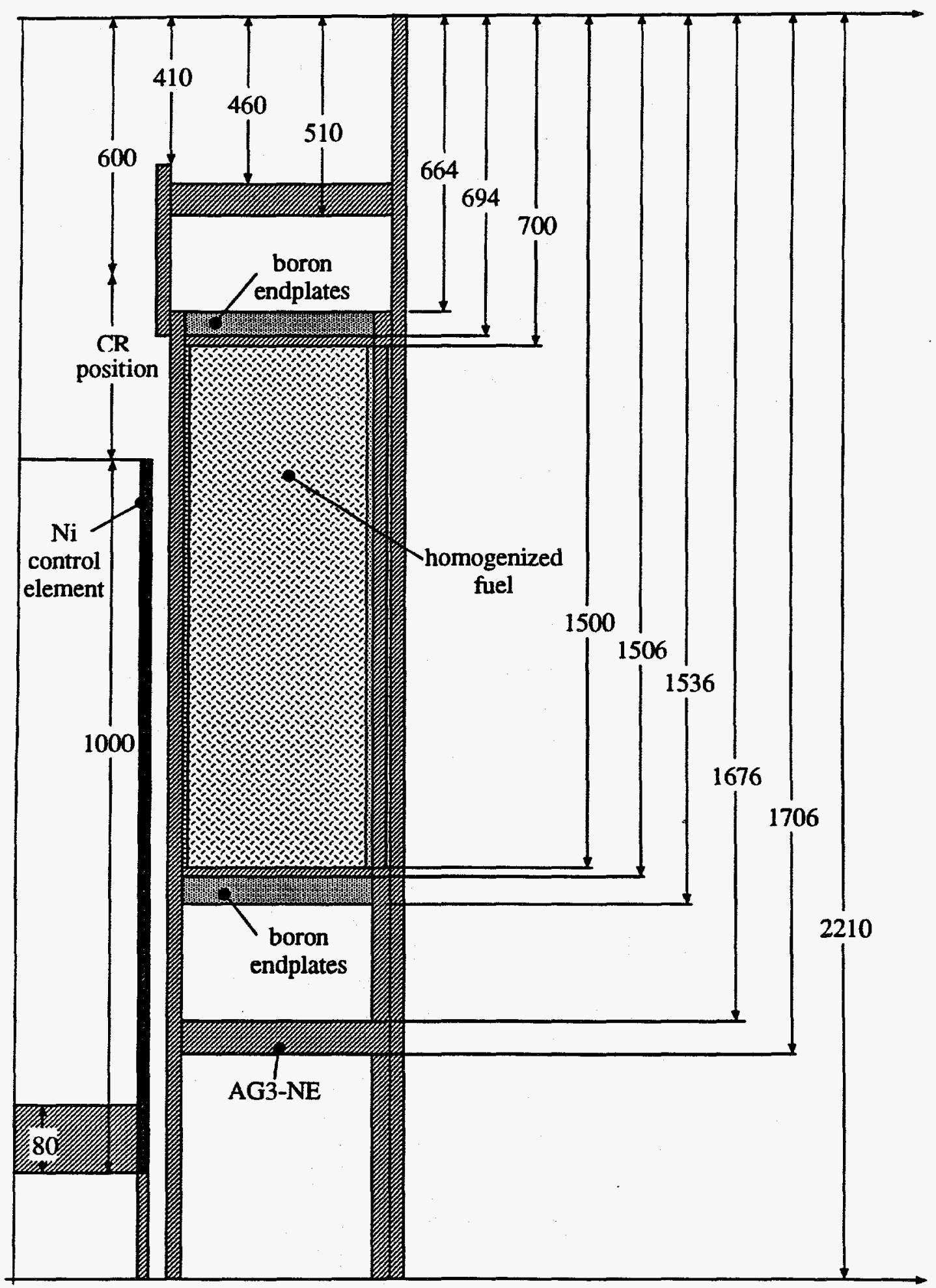

Fig. 3.5. R-Z geometry FOEHN model used in the KENO, DORT, and VENTURE calculations. (All dimensions are in millimeters.) 


\subsubsection{Intermediate Configuration}

The intermediate configuration model is identical to the simple configuration model except that the boron endplates are included at the upper and lower edges of the fuel element. These endplate regions are represented by homogenous material using spatially weighted cross sections (see Sect. 3.3.4).

\subsubsection{Complex Configuration}

The complex configuration model is identical to the intermediate configuration model except that components are included in the reflector pool. Three different reflector component descriptions were examined. These descriptions evaluate different ways of modeling the complex shapes of the reflector components in an $R-Z$ geometric model.

\subsubsection{Void in the Reflector Components}

In this approximate model, Monte Carlo methods were used to determine the amount of material in each region of the R-Z model. The MOVI computer code was used for this calculation. Each reflector component is modeled using basic geometry shapes (cylinders, spheres, cones, etc.). MOVI reads the VENTURE geometry file to determine the mesh structure of the problem. The amount of material in each coarse mesh interval is found by calculating the volume of each component using Monte Carlo methods. After each component has been considered, MOVI creates a modified VENTURE input deck that has a new zone map and the atom densities for the zones containing smeared component materials.

\subsubsection{Aluminum in the Void Regions of the Reflector Components}

In this model, aluminum was artificially added to the void regions of the reflector components. This substitution increases the absorption in the reflector and offsets the streaming effects from the void regions in the reflector components that cannot be modeled in R-Z geometry. Again, MOVI was used to create the VENTURE input deck.

\subsubsection{Constant Aluminum Density in the Reflector}

This model examined the use of a constant aluminum density in the reflector to correct for the reactivity effects of the reflector components. The model is much simpler than the smeared model generated by the MOVI code. Aluminum was added in the reflector from a radius of $30 \mathrm{~cm}$ to the outer edge of the reflector at $1.150 \mathrm{~m}$ over the entire height of the model.

\subsection{COMPUTER CODES USED FOR THE TWO-DIMENSIONAL CALCULATIONS}

\subsubsection{KENO}

KENO is a multigroup Monte Carlo transport code used for criticality analysis. The $\mathrm{R}-\mathrm{Z}$ geometry model was constructed using cylinders and units. The zone structure in the KENO models was identical to the zone structure used in the DORT and VENTURE models. Calculations were performed using 99-group and 20-group cross sections with $\mathrm{P}_{3}$ scattering order. 


\subsubsection{DORT}

DORT is a multigroup discrete ordinates transport code. The DORT $\mathrm{S}_{4} \mathrm{P}_{1}$ calculations were performed using 20-group cross sections. The eigenvalue convergence criterion was $1.0 \mathrm{E}-5$, and the flux convergence criterion was $1.0 \mathrm{E}-4$. The DORT calculations were performed using the same number of mesh points as in the VENTURE model. DORT mesh points are at the center of each mesh region.

\subsubsection{VENTURE}

VENTURE is a multigroup finite difference diffusion theory code. The VENTURE calculations were performed using 20 -group cross sections. The eigenvalue convergence criterion was $1.0 \mathrm{E}-5$ and the flux convergence criterion was $1.0 \mathrm{E}-5$. The number of mesh points was increased until no change occurred in the calculated $k_{e f f}$ value. VENTURE mesh points are at the centroid of each mesh region.

\subsection{DETERMINATION OF CALCULATED QUANTITIES}

\subsubsection{Multiplication Factors}

In the KENO eigenvalue calculations, 320 batches with 500 source particles per batch were used. The statistical uncertainty of all the reported eigenvalues is two standard deviations. The eigenvalues calculated for the first 119 active batches were not used in the determination of the final $k_{\text {eff }}$ value to allow convergence of the fission source. The DORT and VENTURE eigenvalues are the values reported at the final iteration where all the convergence criteria have been met.

\subsubsection{Power Distribution}

For the KENO power distribution calculations, 550 batches with 10,000 source particles per batch were used. The first 50 batches were not tallied to allow convergence of the fission source. Statistical uncertainties of two sigma are reported for each power density value. The tally regions have a height of $5 \mathrm{~mm}$ and a radial thickness of $3 \mathrm{~mm}$. The DORT and VENTURE power density values are point power density values calculated by each code. In the calculation of the power distributions, the energy per fission $(Q)$ was assumed to be $202.47 \mathrm{MeV} /$ fission, which is from ENDF/B-V cross section files for ${ }^{25} \mathrm{U}$. This value assumes that the gamma radiation produced by the fuel is absorbed in the fuel region.

\subsubsection{Thermal Flux}

Thermal flux values are reported from DORT and VENTURE calculations. The values are normalized to the total core power of $1 \mathrm{~W}$. In determining the thermal flux, the upper energy boundary was set at the cadmium cutoff energy $(0.625 \mathrm{eV})$. 


\subsubsection{Rendement}

The rendement $(r)$ was determined using

$$
r=\frac{\phi_{\text {thpeak }}}{P}
$$

where

$\phi_{\text {th,peak }}=$ peak thermal flux in the reflector,

$\mathbf{P} \quad=$ the core power.

The peak thermal flux is the largest thermal flux in the reflector calculated by DORT and VENTURE. In these calculations, the energy per fission, $Q$, was assumed to be $202.47 \mathrm{MeV}$. A value of $199.73 \mathrm{MeV}$ was used to determine the measured rendement values reported in ref. 6. Each calculated rendement value was multiplied by $202.47 \mathrm{MeV}$ then divided by $199.73 \mathrm{MeV}$. This renormalization was done only in the determination of the rendement so that the calculated values could be directly compared to the measured rendement values presented in ref. 6 .

\subsection{SUMMARY}

The models used for the evaluation of each of the FOEHN critical experiment configurations have been described. Necessary assumptions have been discussed. Several of the parameters used in the KENO, DORT, and VENTURE calculations were presented. 



\section{RESULTS}

\subsection{INTRODUCTION}

Results for each of the FOEHN configurations are discussed in this chapter. The differences between the calculated and the measured values are presented. These differences are the percent difference between the measured and calculated results determined by subtracting the measured value from the calculated value and then dividing by the measured value. The average percent differences were determined by taking the average of the absolute values of the percent differences. Tables of the measured data taken from ref. 6 are included in Appendix B along with tables of the power density and thermal flux values calculated using KENO, DORT, and VENTURE. Some of the calculated results are compared to values determined in refs. 9, 13, and 14. The known differences between the calculational models used in this report and the work in these references are documented in Appendix C.

\subsection{SIMPLE CONFIGURATION}

\subsubsection{Multiplication Factors}

Table 4.1 shows the eigenvalues calculated for the eleven critical states of the simple configuration. These results are shown graphically in Figs. 4.1 and 4.2. All of the 99-group KENO results lie within three sigma of unity, and only one value is not within two sigma. The values show a trend of slightly overestimating unity. This bias may be the result of geometrical uncertainties as discussed in Sect. 2.4.1. The $k_{\text {eff }}$ values from the 20-group calculations are larger than the 99-group results. The KENO and DORT 20-group results match well. The eigenvalues calculated with VENTURE (diffusion theory) are larger than those calculated using Monte Carlo techniques and $S_{n}$ transport theory. The average multiplication factor for the simple configuration obtained in an independent analysis using Monte Carlo methods is $0.9982 \pm 0.0017 .{ }^{13}$

\subsubsection{Power Distributions}

Power distributions were measured for case 6 of Table 4.1. For this case, the control element was positioned at $601 \mathrm{~mm}$, and the dissolved boron concentration was $0.4509 \mathrm{~g}{ }^{10} \mathrm{~B} / \mathrm{L}$. Power distributions were calculated using KENO, DORT, and VENTURE. Table 4.2 shows the average and maximum differences between the calculated and measured values. The average difference is smallest for the results calculated with KENO using 99-group cross sections. The average statistical uncertainty in the KENO power density values is $3.20 \%$. Table 4.3 shows the nonmatching points for the simple configuration power densities. A nonmatching point is a point where the experimental error and the two-sigma statistical uncertainty of the calculated result do not overlap. The error in the measured data is assumed to be $4 \%$. Seventeen of the 122 data points (13.9\%) are nonmatching points. If the three points near the control element are not included (see Sect. 2.4.1), the number of nonmatching points drops to $11.5 \%$. Tables $4.4-4.6$ show the differences between the measured and calculated values. Figures 4.3-4.8 show radial and axial traces of the KENO, DORT, and VENTURE calculated and measured power density values. All of the calculations underestimate the measured values for the radial trace at the top of the fuel element $(\mathrm{h}=797.5 \mathrm{~mm})$. The deviation trend in the axial trace at a radius of $143.5 \mathrm{~mm}$ was seen in all previous calculations. ${ }^{6,9,14}$ 


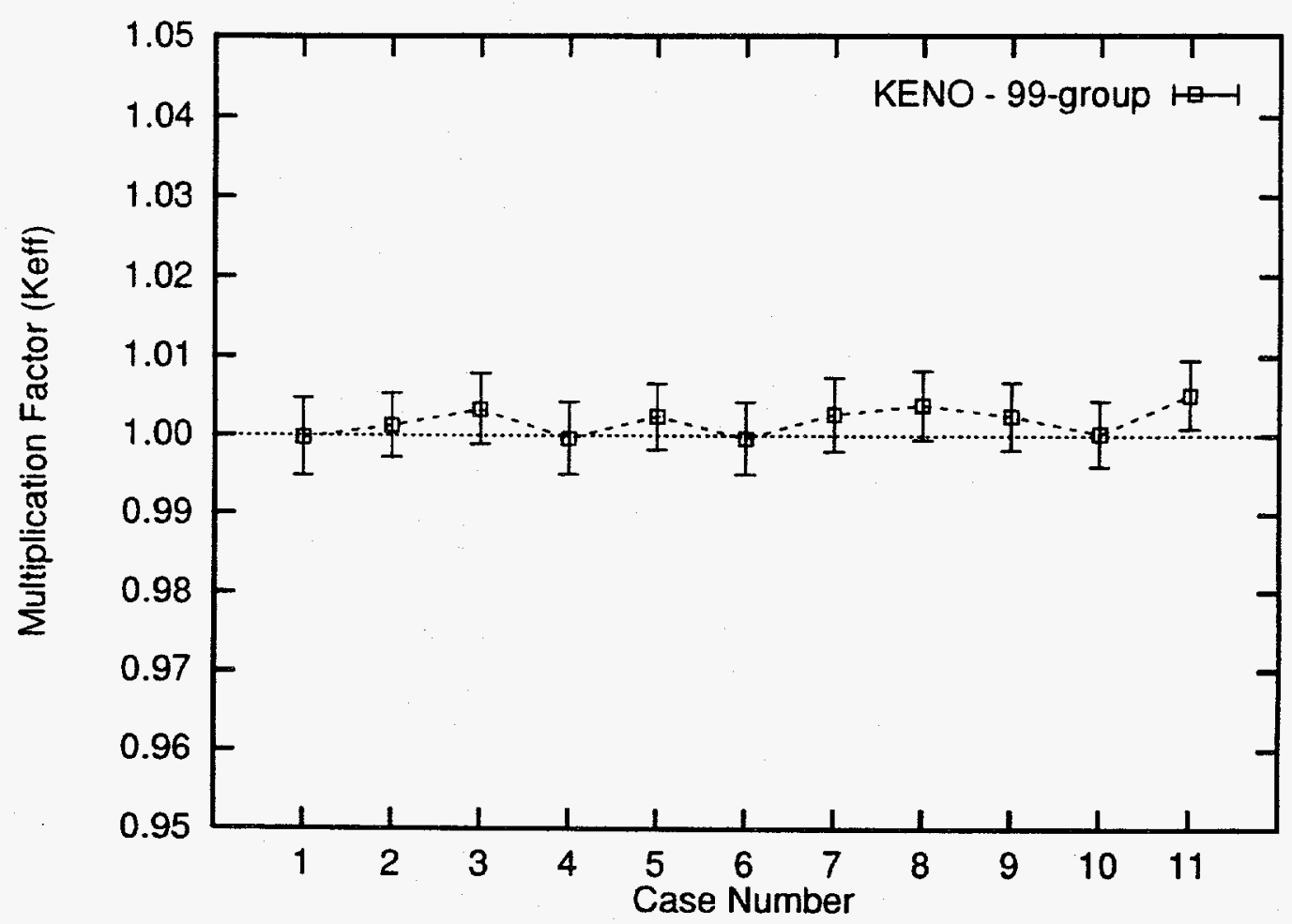

Fig. 4.1. $K_{\text {ef }}$ values for the simple FOEHN configuration calculated with KENO using 99-group cross sections.

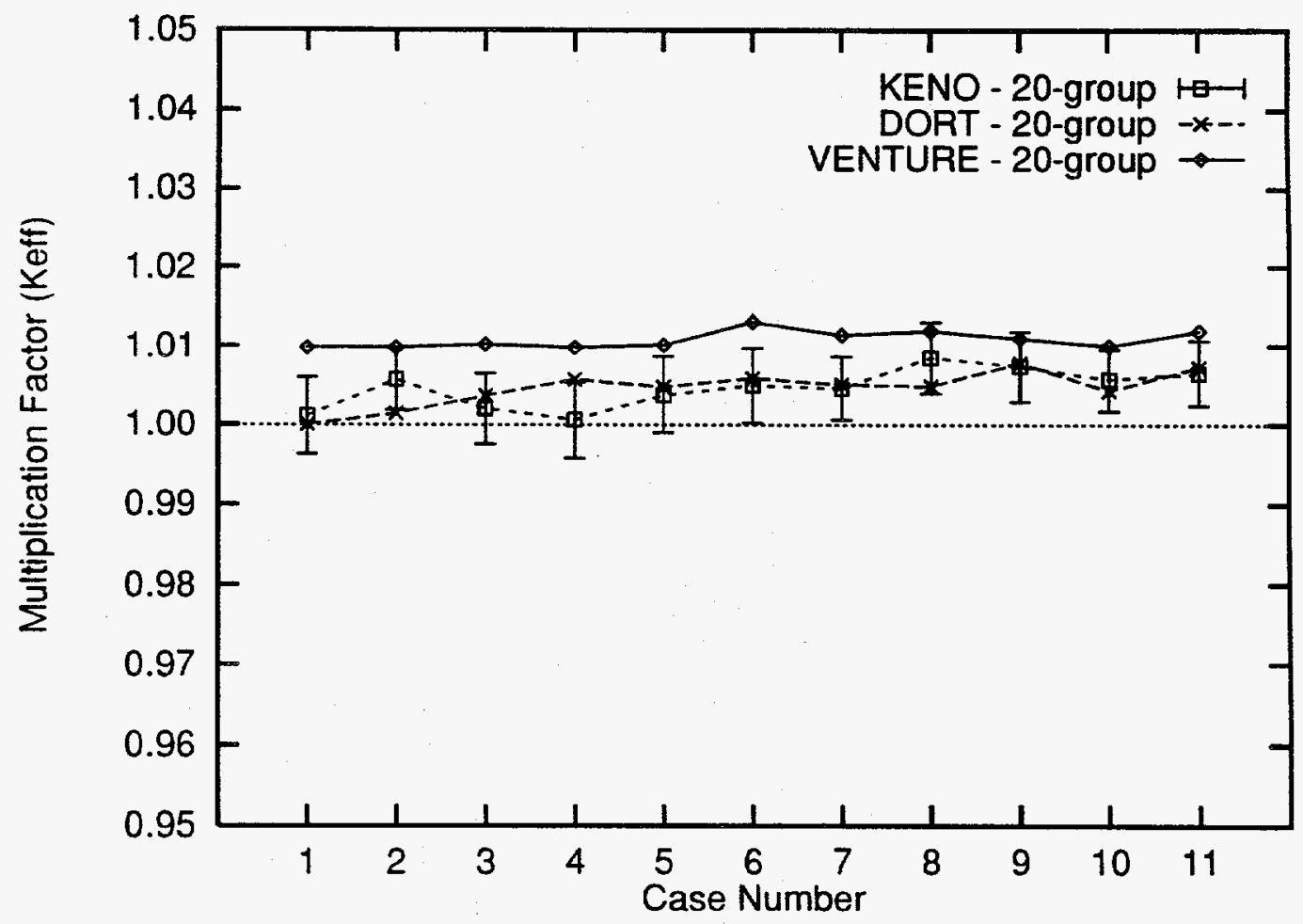

Fig. 4.2. Comparison of $k_{\text {ef }}$ values for the simple FOEHN configuration calculated with different computer codes using 20-group cross sections. 
Table 4.1. Comparison of eigenvalues for the simple FOEHN configuration cases using different calculational methods

\begin{tabular}{|c|c|c|c|c|c|c|}
\hline \multirow[t]{2}{*}{ Case } & \multirow{2}{*}{$\begin{array}{c}\text { Control } \\
\text { element } \\
\text { position } \\
(\mathrm{mm})\end{array}$} & \multirow{2}{*}{$\begin{array}{c}\text { Boron-10 } \\
\text { concentration } \\
\left(\mathrm{g}{ }^{10} \mathrm{~B} / \mathrm{L}\right)\end{array}$} & \multicolumn{2}{|c|}{ KENO } & \multirow{2}{*}{$\begin{array}{c}\text { DORT } \\
\text { 20-group }\end{array}$} & \multirow{2}{*}{$\begin{array}{l}\text { VENTURE } \\
\text { 20-group }\end{array}$} \\
\hline & & & 99-group & 20-group & & \\
\hline 1 & 172.0 & 0.2477 & $0.9997 \pm 0.0050$ & $1.0012 \pm 0.0049$ & 1.0000 & 1.0098 \\
\hline 2 & 357.0 & 0.3349 & $1.0012 \pm 0.0040$ & $1.0057 \pm 0.0040$ & 1.0014 & 1.0098 \\
\hline 3 & 455.0 & 0.3863 & $1.0033 \pm 0.0045$ & $1.0020 \pm 0.0045$ & 1.0037 & 1.0102 \\
\hline 4 & 467.3 & 0.3855 & $0.9996 \pm 0.0046$ & $1.0006 \pm 0.0048$ & 1.0057 & 1.0098 \\
\hline 5 & 596.0 & 0.4501 & $1.0024 \pm 0.0042$ & $1.0038 \pm 0.0048$ & 1.0048 & 1.0101 \\
\hline 6 & 601.0 & 0.4509 & $0.9996 \pm 0.0046$ & $1.0050 \pm 0.0047$ & 1.0059 & 1.0130 \\
\hline 7 & 602.0 & 0.4536 & $1.0027 \pm 0.0047$ & $1.0046 \pm 0.0041$ & 1.0051 & 1.0114 \\
\hline 8 & 661.0 & 0.4791 & $1.0039 \pm 0.0044$ & $1.0085 \pm 0.0045$ & 1.0049 & 1.0119 \\
\hline 9 & 857.0 & 0.5268 & $1.0025 \pm 0.0043$ & $1.0074 \pm 0.0044$ & 1.0078 & 1.0110 \\
\hline 10 & 890.0 & 0.5386 & $1.0002 \pm 0.0042$ & $1.0057 \pm 0.0039$ & 1.0043 & 1.0100 \\
\hline 11 & 896.0 & 0.5386 & $1.0052 \pm 0.0043$ & $1.0065 \pm 0.0042$ & 1.0073 & 1.0119 \\
\hline Average & - & - & $1.0018 \pm 0.0013$ & $1.0046 \pm 0.0013$ & 1.0046 & 1.0108 \\
\hline
\end{tabular}

Table 4.2. Average and maximum power density percent differences for the simple FOEHN configuration

\begin{tabular}{ccc}
\hline Computer code & \multicolumn{3}{c}{ Percent difference } \\
\cline { 2 - 3 } & Average & Maximum $^{a}$ \\
\hline KENO $^{b}$ & 3.43 & $21.61(9.33)$ \\
DORT $^{c}$ & 3.22 & $18.00(-8.67)$ \\
VENTURE $^{c}$ & 2.94 & $13.17(13.17)$ \\
\hline
\end{tabular}

${ }^{a}$ The maximum values in parentheses were determined without including the points at the inner edge of the fuel element near the tip of the control element (see Sect. 2.4.1).

$b_{99}$ energy groups.

$c_{20}$ energy groups.

\subsubsection{Rendement}

The rendement was calculated using the peak thermal flux values from the DORT and VENTURE calculations. The measured rendement was $2.480 \times 10^{11}$ neutrons $/\left(\mathrm{m}^{2} \mathrm{~s} \mathrm{~W}\right)$. Table 4.7 shows the calculated values. The DORT value overestimates the measured value by $10.23 \%$. This result is very similar to the results obtained in ref. 9 (12\% higher) and ref. 14 (14\% higher). The VENTURE model overestimates the measured rendement by $6.27 \%$. 


\subsubsection{Thermal Flux}

Thermal flux values were measured for case 6 of Table 4.1. Tables 4.8 and 4.9 show the differences between the measured results and values calculated with DORT and VENTURE, respectively. The average difference for the DORT values is $7.66 \%$. For the VENTURE values, the average difference is $4.34 \%$. Figures $4.9-4.12$ show radial and axial thermal flux traces comparing the measured and calculated values. Transport theory overestimates the thermal flux near the fuel element $(r=235 \mathrm{~mm})$. Similar results were seen in the analysis in ref. 9. The diffusion theory results were not expected to show better agreement with the measured values than the transport theory results. The reason for this occurrence remains to be investigated.

Table 4.3. Nonmatching points for power densities calculated with KENO using 99-group cross sections for the simple FOEHN configuration

\begin{tabular}{|c|c|c|c|c|c|c|c|c|c|c|c|}
\hline $\mathrm{H} / \mathrm{r}(\mathrm{mm})$ & 143.5 & 146.5 & 149.5 & 152.5 & 159.0 & 167.5 & 176.0 & 182.5 & 185.5 & 188.5 & 193.95 \\
\hline 797.5 & 0 & $\overline{0}$ & $\overline{0}$ & 1 & 0 & 1 & $\overline{0}$ & 1 & 1 & 0 & 0 \\
\hline 790.6 & 1 & & & & & & & & & & 1 \\
\hline 785.5 & 0 & & & & & 0 & & & & & 0 \\
\hline 780.6 & 0 & & & & & 0 & & & & & 1 \\
\hline 771.5 & 0 & & & & & o & & & & & 0 \\
\hline 750.0 & 0 & 0 & 0 & 0 & 0 & o & 0 & 0 & 0 & 0 & 0 \\
\hline 725.0 & 0 & & & & & 0 & & & & & 0 \\
\hline 200.0 & 0 & & & & & 0 & & & & & 0 \\
\hline 625.0 & 0 & 0 & 0 & o & 0 & 0 & 0 & o & 0 & 0 & 0 \\
\hline 550.0 & 0 & & & & & 0 & & & & & 0 \\
\hline 475.0 & 0 & & & & & 0 & & & & & o \\
\hline 400.0 & 1 & 0 & 1 & 1 & 0 & 0 & 0 & 0 & 0 & 0 & 0 \\
\hline 325.0 & 1 & & & & & 0 & & & & & 0 \\
\hline 250.0 & 1 & & & & & 0 & & & & & 0 \\
\hline 175.0 & 0 & 0 & 0 & 0 & 0 & 0 & 0 & 0 & 0 & 0 & 0 \\
\hline 100.0 & 0 & & & & & 0 & & & & & 0 \\
\hline 75.0 & 0 & & & & & 0 & & & & & o \\
\hline 50.0 & 1 & 0 & 0 & 0 & o & 0 & 0 & 0 & 0 & 0 & 0 \\
\hline 28.5 & 1 & & & & & 0 & & & & & 0 \\
\hline 19.4 & 0 & & & & & 0 & & & & & 0 \\
\hline 14.5 & 0 & & & & & 0 & & & & & \\
\hline 9.4 & 0 & & & & & & & & & & 0 \\
\hline 2.5 & $\mathbf{0}$ & 0 & 0 & 0 & 0 & 1 & $\mathbf{I}$ & 0 & 0 & 0 & 1 \\
\hline
\end{tabular}


Table 4.4. Percent differences between measured power densities and values calculated with KENO using 99-group cross sections for the simple FOEHN configuration

\begin{tabular}{|c|c|c|c|c|c|c|c|c|c|c|c|}
\hline $\mathrm{H} / \mathrm{r}(\mathrm{mm})$ & 143.5 & 146.5 & 149.5 & 152.5 & 159.0 & 167.5 & 176.0 & 182.5 & 185.5 & 188.5 & 193.95 \\
\hline 797.5 & -5.25 & -0.65 & -5.93 & -7.07 & -1.90 & -7.97 & -1.70 & -7.14 & -7.13 & -2.97 & -0.50 \\
\hline 790.6 & -7.58 & & & & & & & & & & -7.58 \\
\hline 785.5 & -0.15 & & & & & -2.85 & & & & & -4.57 \\
\hline 780.6 & -4.00 & & & & & -3.29 & & & & & -8.37 \\
\hline 71.5 & 4.29 & & & & & 4.39 & & & & & -2.88 \\
\hline 750.0 & -3.09 & -1.42 & -2.73 & 1.49 & -0.72 & -0.92 & -1.10 & -3.92 & -5.47 & -3.63 & -5.81 \\
\hline 725.0 & -1.09 & & & & & -3.19 & & & & & -4.70 \\
\hline 700.0 & -1.44 & & & & & -0.44 & & & & & -4.62 \\
\hline 005.0 & 2.69 & 1.16 & -0.23 & 1.45 & 1.95 & -1.79 & -0.32 & -0.40 & -1.69 & 0.44 & -2.85 \\
\hline 550.0 & 3.45 & & & & & -0.71 & & & & & -1.88 \\
\hline 475.0 & 6.75 & & & & & 2.49 & & & & & -2.26 \\
\hline 400.0 & 15.21 & 4.33 & 9.34 & 9.49 & 0.41 & -0.85 & 1.18 & 1.59 & -0.11 & 1.92 & 0.99 \\
\hline 325.0 & 21.61 & & & & & 1.26 & & & & & 0.43 \\
\hline 250.0 & 10.36 & & & & & 5.48 & & & & & -5.29 \\
\hline 175.0 & 7.74 & 0.53 & 5.87 & 5.29 & 0.53 & -0.41 & 3.35 & -2.09 & -2.21 & 1.02 & -2.31 \\
\hline 100.0 & 6.16 & & & & & 3.12 & & & & & -0.66 \\
\hline 75.0 & 3.79 & & & & & -0.36 & & & & & -2.35 \\
\hline 50.0 & 9.33 & 0.68 & 5.55 & 2.92 & 2.14 & & 2.96 & -1.97 & -2.52 & 2.14 & -0.16 \\
\hline 28.5 & 8.98 & & & & & 1.51 & & & & & -1.73 \\
\hline 19.4 & 8.16 & & & & & 1.40 & & & & & -1.31 \\
\hline 14.5 & -1.47 & & & & & 4.28 & & & & & \\
\hline 9.4 & 7.46 & & & & & & & & & & 2.59 \\
\hline 2.5 & 4.44 & 1.83 & 4.73 & 6.21 & 4.19 & 8.31 & 8.58 & 5.64 & 2.61 & 3.80 & 7.78 \\
\hline
\end{tabular}

Table 4.5. Percent differences between measured power densities and values calculated with DORT using 20-group cross sections for the simple FOEHN configuration

\begin{tabular}{|c|c|c|c|c|c|c|c|c|c|c|c|}
\hline $\mathrm{H} / \mathrm{r}(\mathrm{mm})$ & 143.5 & 146.5 & 149.5 & 152.5 & 159.0 & 167.5 & 176.0 & 182.5 & 185.5 & 188.5 & 193.95 \\
\hline 797.5 & -6.36 & -3.08 & -8.67 & -8.28 & -4.97 & -7.95 & -3.86 & -6.96 & -7.99 & -4.68 & -7.42 \\
\hline 790.6 & -7.32 & & & & & & & & & & -6.53 \\
\hline 785.5 & -2.96 & & & & & -6.78 & & & & & -4.41 \\
\hline 780.6 & -3.63 & & & & & -6.55 & & & & & -5.60 \\
\hline 771.5 & -4.06 & & & & & -2.99 & & & & & -3.23 \\
\hline 750.0 & -2.26 & -2.65 & -2.73 & -2.63 & -3.39 & -3.37 & -4.54 & -4.04 & -4.01 & -4.17 & -3.30 \\
\hline 725.0 & -1.60 & & & & & -2.62 & & & & & -1.84 \\
\hline 700.0 & 0.30 & & & & & -1.40 & & & & & -1.51 \\
\hline 625.0 & 2.15 & -0.36 & 0.41 & -0.36 & -0.89 & -0.83 & -1.69 & -0.39 & -3.55 & -0.80 & 1.73 \\
\hline 550.0 & 3.10 & & & & & 0.39 & & & & & 1.52 \\
\hline 475.0 & 7.98 & & & & & 1.39 & & & & & 2.19 \\
\hline 400.0 & 15.90 & 6.48 & 10.33 & 7.19 & 3.28 & 2.77 & 1.90 & 0.92 & -0.27 & 2.17 & 3.78 \\
\hline 325.0 & 18.00 & & & & & 2.66 & & & & & 1.84 \\
\hline 250.0 & 10.87 & & & & & 0.37 & & & & & 0.99 \\
\hline 175.0 & 7.27 & 1.64 & 3.79 & 1.38 & -0.24 & -0.19 & 0.3 & -2.58 & -2.33 & 0.20 & 1.23 \\
\hline 100.0 & 5.51 & & & & & -0.09 & & & & & 1.62 \\
\hline 75.0 & -0.53 & & & & & 0.01 & & & & & 1.05 \\
\hline 50.0 & 5.38 & -0.92 & 2.51 & 0.50 & 1.13 & -0.95 & 0.02 & -2.63 & -1.85 & 1.21 & 2.16 \\
\hline 28.5 & 6.86 & & & & & -0.68 & & & & & 1.79 \\
\hline 19.4 & 4.95 & & & & & -1.76 & & & & & 2.91 \\
\hline 14.5 & -0.77 & & & & & 0.02 & & & & & \\
\hline 9.4 & 5.69 & & & & & & & & & & 0.91 \\
\hline 2.5 & 2.24 & 0.37 & 1.40 & 2.25 & 2.53 & 3.95 & 3.80 & 2.73 & 2.88 & 2.66 & 1.90 \\
\hline
\end{tabular}


Table 4.6. Percent differences between measured power densities and values calculated with VENTURE using 20-group cross sections for the simple FOEHN configuration

\begin{tabular}{|c|c|c|c|c|c|c|c|c|c|c|c|}
\hline $\mathrm{H} / \mathrm{r}(\mathrm{mm})$ & 143.5 & 146.5 & 149.5 & 152.5 & 159.0 & 167.5 & 176.0 & 182.5 & 185.5 & 188.5 & 193.95 \\
\hline 797.5 & -6.32 & -1.59 & -6.54 & -5.67 & -2.05 & -5.03 & $-c . .97$ & -3.75 & -5.25 & -2.57 & -5.26 \\
\hline 790.6 & -1.93 & & & & & & & & & & -2.73 \\
\hline 785.5 & 2.92 & & & & & 1.19 & & & & & -0.09 \\
\hline 780.6 & 1.77 & & & & & -0.89 & & & & & -1.02 \\
\hline 771.5 & 0.23 & & & & & -0.29 & & & & & 0.58 \\
\hline 750.0 & -1.01 & -0.23 & -0.17 & -0.55 & -2.51 & -2.89 & -1.71 & 0.91 & 1.37 & 0.66 & -1.23 \\
\hline 725.0 & -2.27 & & & & & -3.29 & & & & & -1.07 \\
\hline 200.0 & -1.51 & & & & & -3.13 & & & & & -1.45 \\
\hline 625.0 & -1.05 & -2.41 & -1.44 & -2.45 & -3.76 & -3.62 & -2.41 & 0.87 & -1.79 & 0.62 & 0.48 \\
\hline$s 50.0$ & -0.74 & & & & & -2.86 & & & & & -0.11 \\
\hline 475.0 & 3.36 & & & & & -2.28 & & & & & 0.21 \\
\hline 400.0 & 10.88 & 3.19 & 7.26 & 3.99 & -0.81 & -1.27 & 0.14 & 1.25 & 0.54 & 2.65 & 1.78 \\
\hline 325.0 & 21.18 & & & & & -1.49 & & & & & -0.18 \\
\hline 250.0 & 6.61 & & & & & -2.17 & & & & & -0.55 \\
\hline 175.0 & 4.14 & -0.54 & 1.88 & -0.69 & -3.36 & -2.94 & 0.34 & -1.01 & -0.19 & 1.83 & 0.08 \\
\hline 100.0 & 4.72 & & & & & -1.84 & & & & & 1.40 \\
\hline 75.0 & -0.23 & & & & & -0.84 & & & & & 1.37 \\
\hline 50.0 & 7.82 & 1.58 & 4.60 & 1.86 & 1.31 & -0.70 & 2.75 & 1.87 & 2.93 & 5.42 & 3.30 \\
\hline 28.5 & 13.17 & & & & & 1.60 & & & & & 4.04 \\
\hline 19.4 & 12.69 & & & & & 3.61 & & & & & 6.09 \\
\hline 14.5 & 6.77 & & & & & 7.73 & & & & & \\
\hline 9.4 & 12.84 & & & & & & & & & & 3.32 \\
\hline 2.5 & 3.42 & 2.56 & 4.05 & 5.29 & 5.77 & 7.40 & 7.67 & 6.19 & 5.76 & 4.67 & 2.60 \\
\hline
\end{tabular}




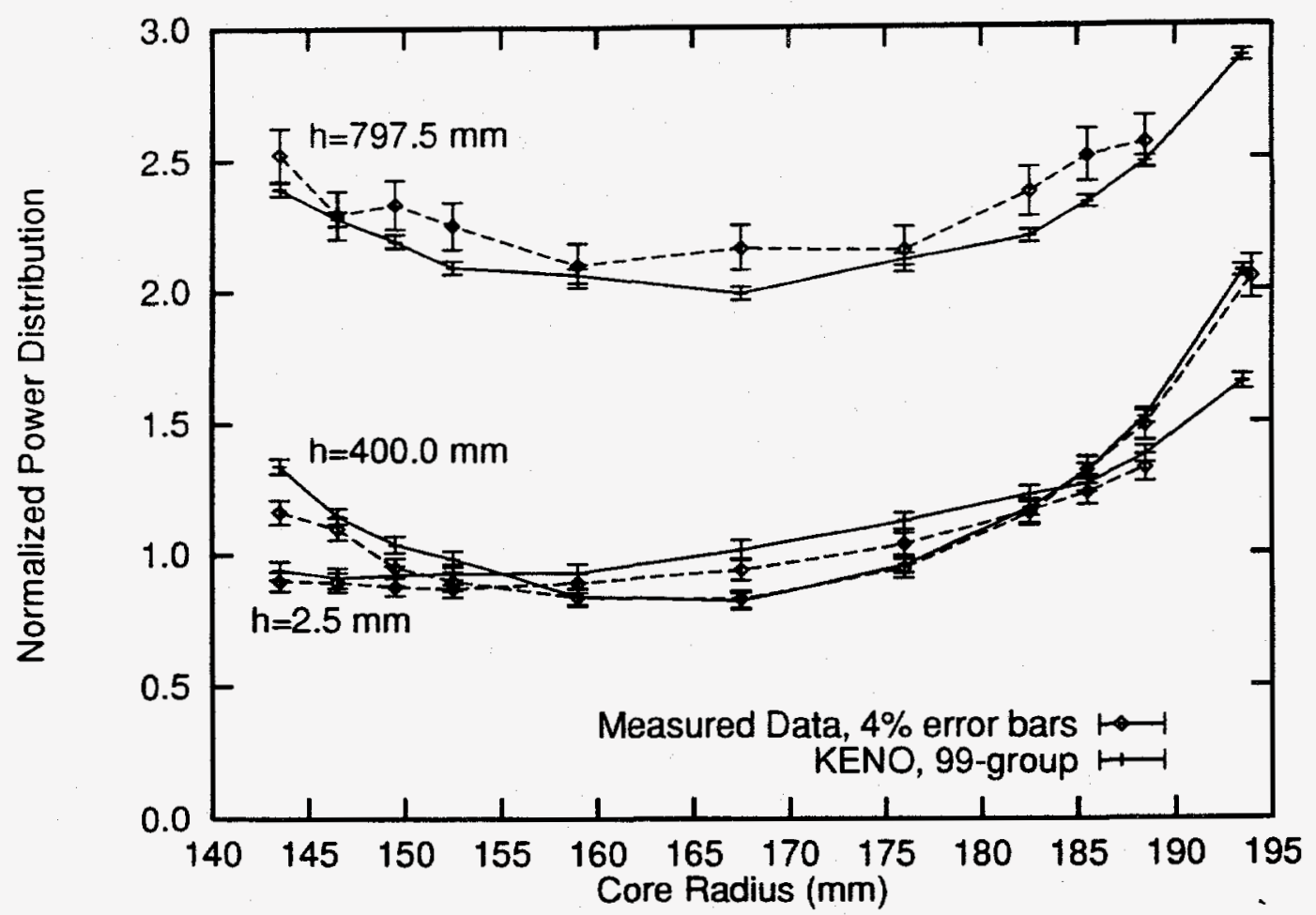

Fig. 4.3. Comparison of experimental radial power density traces and KENO values calculated using 99-group cross sections for the simple FOEHN configuration.

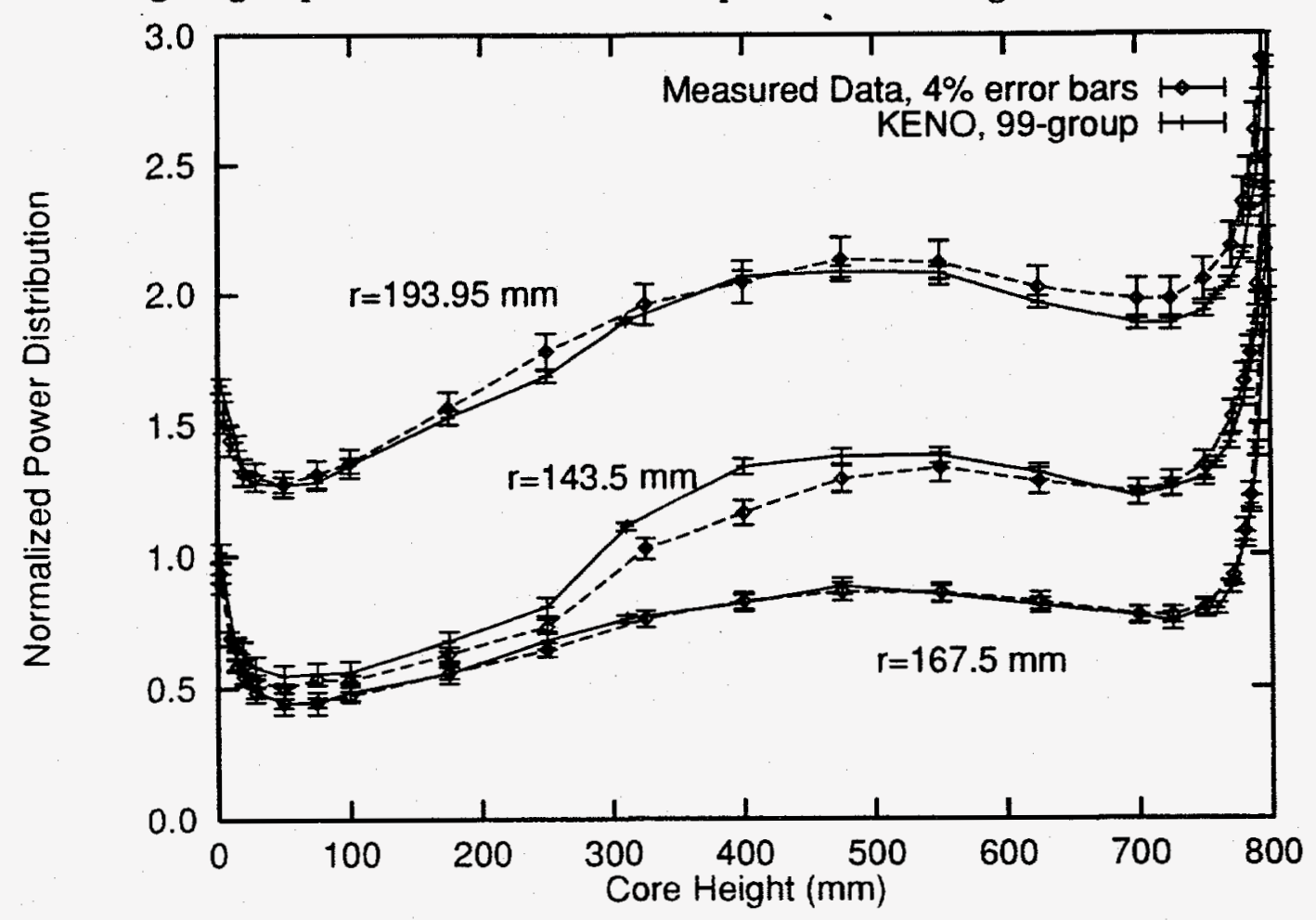

Fig. 4.4. Comparison of experimental axial power density traces and KENO values calculated using 99-group cross sections for the simple FOEHN configuration. 


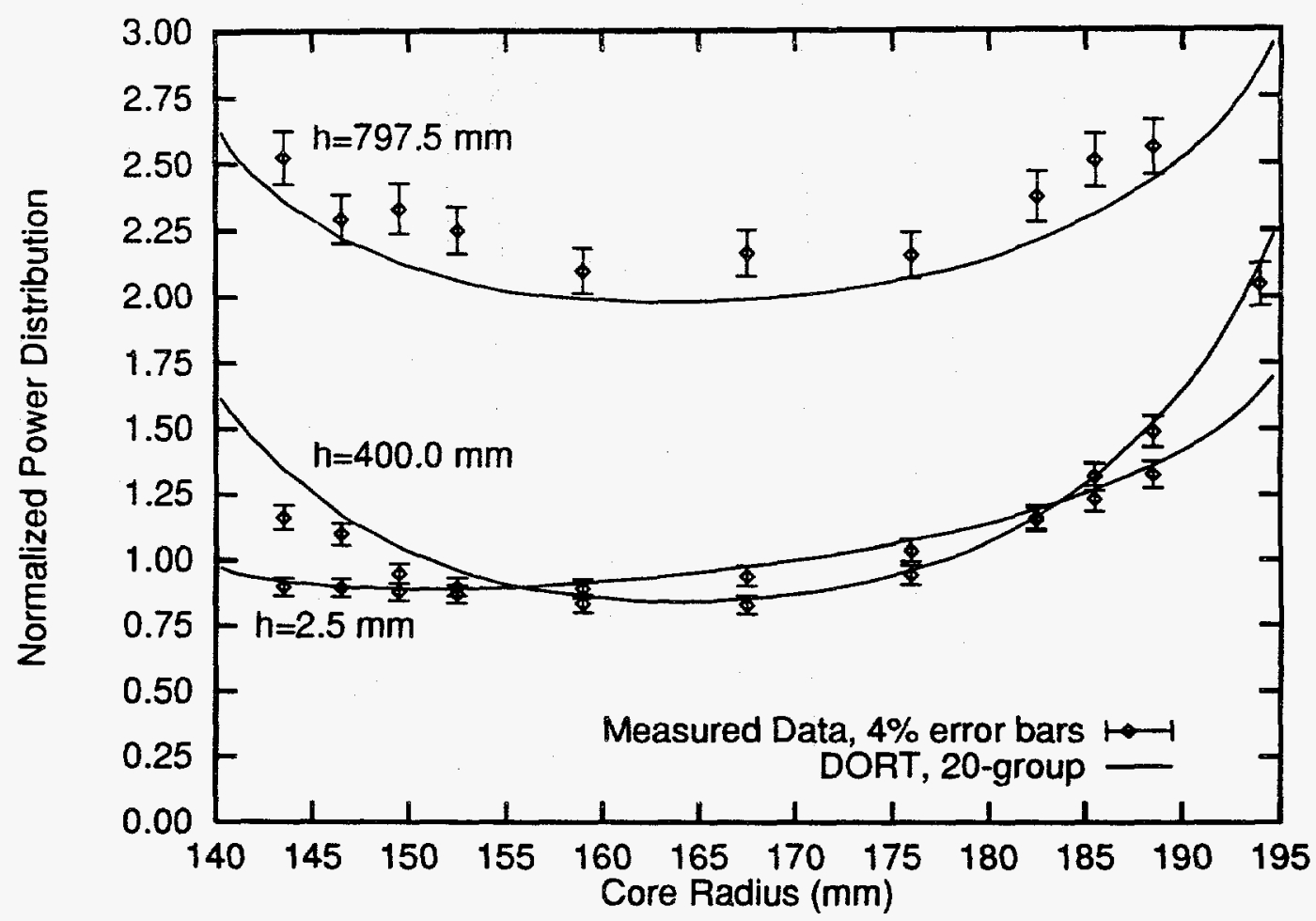

Fig. 4.5. Comparison of experimental radial power density traces and DORT values calculated using 20-group cross sections for the simple FOEFiN configuration.

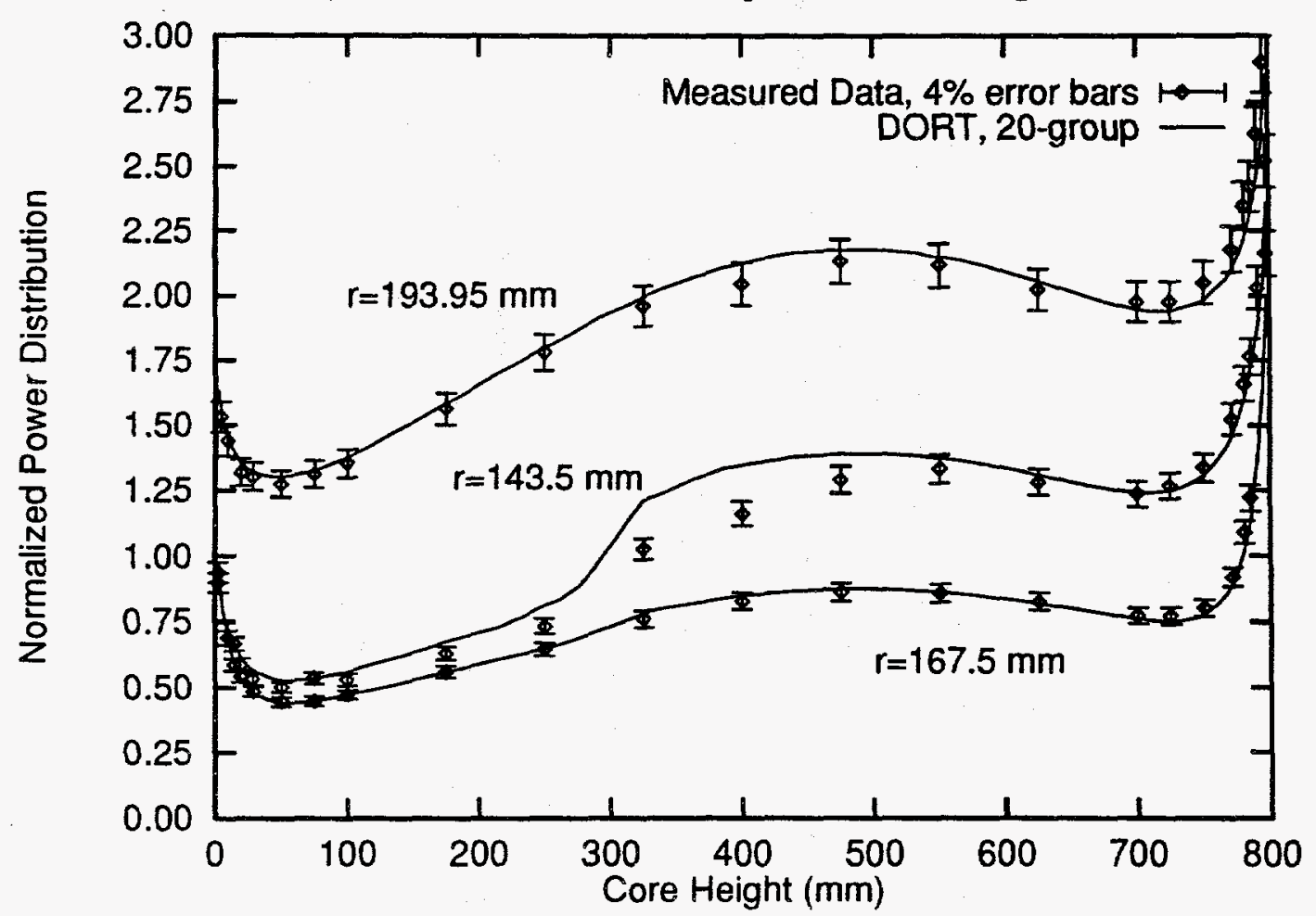

Fig. 4.6. Comparison of experimental axial power density traces and DORT values calculated using 20-group cross sections for the simple FOEHN configuration. 


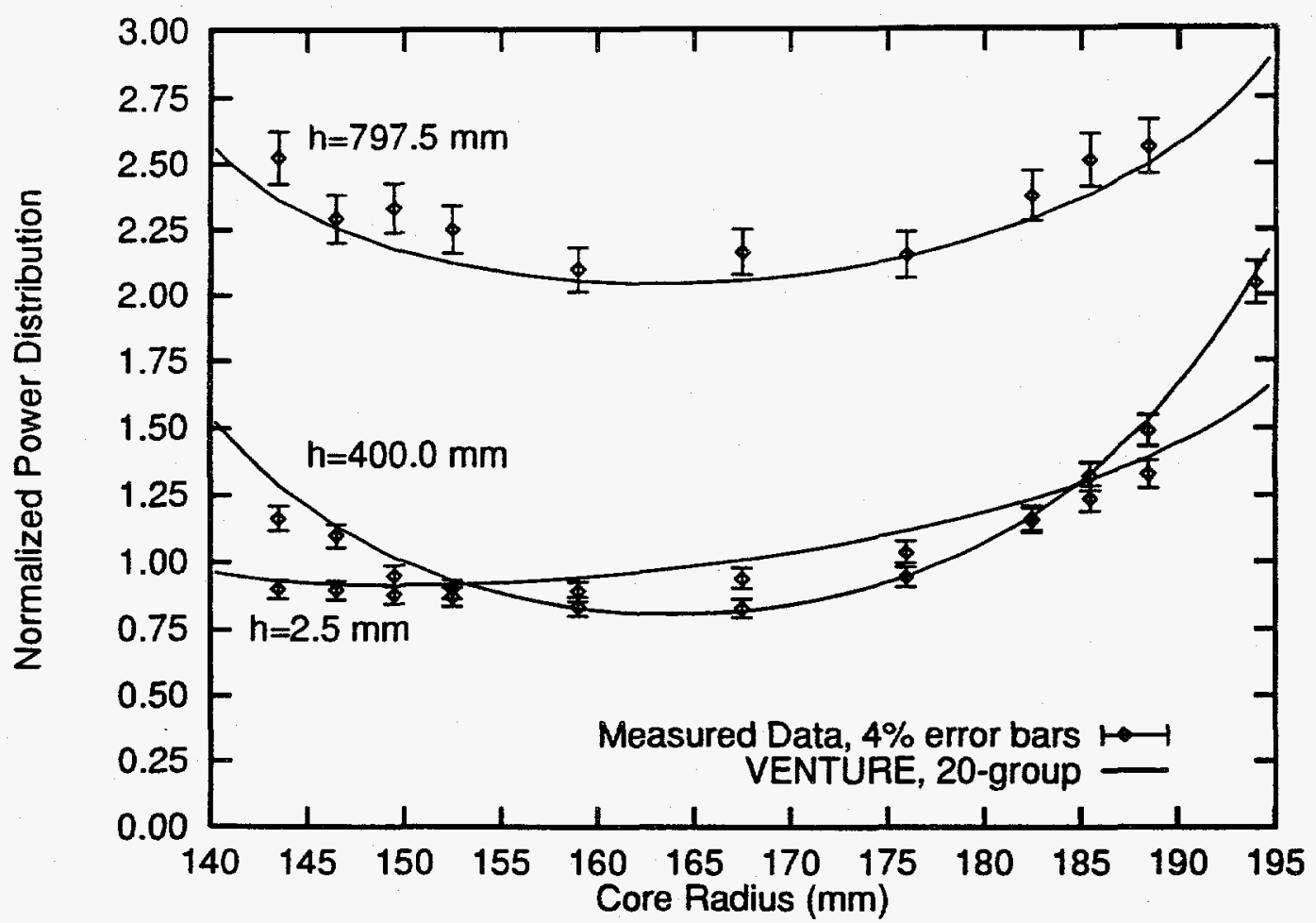

Fig. 4.7. Comparison of experimental radial power density traces and VENTURE values calculated using 20-group cross sections for the simple FOEHN configuration.

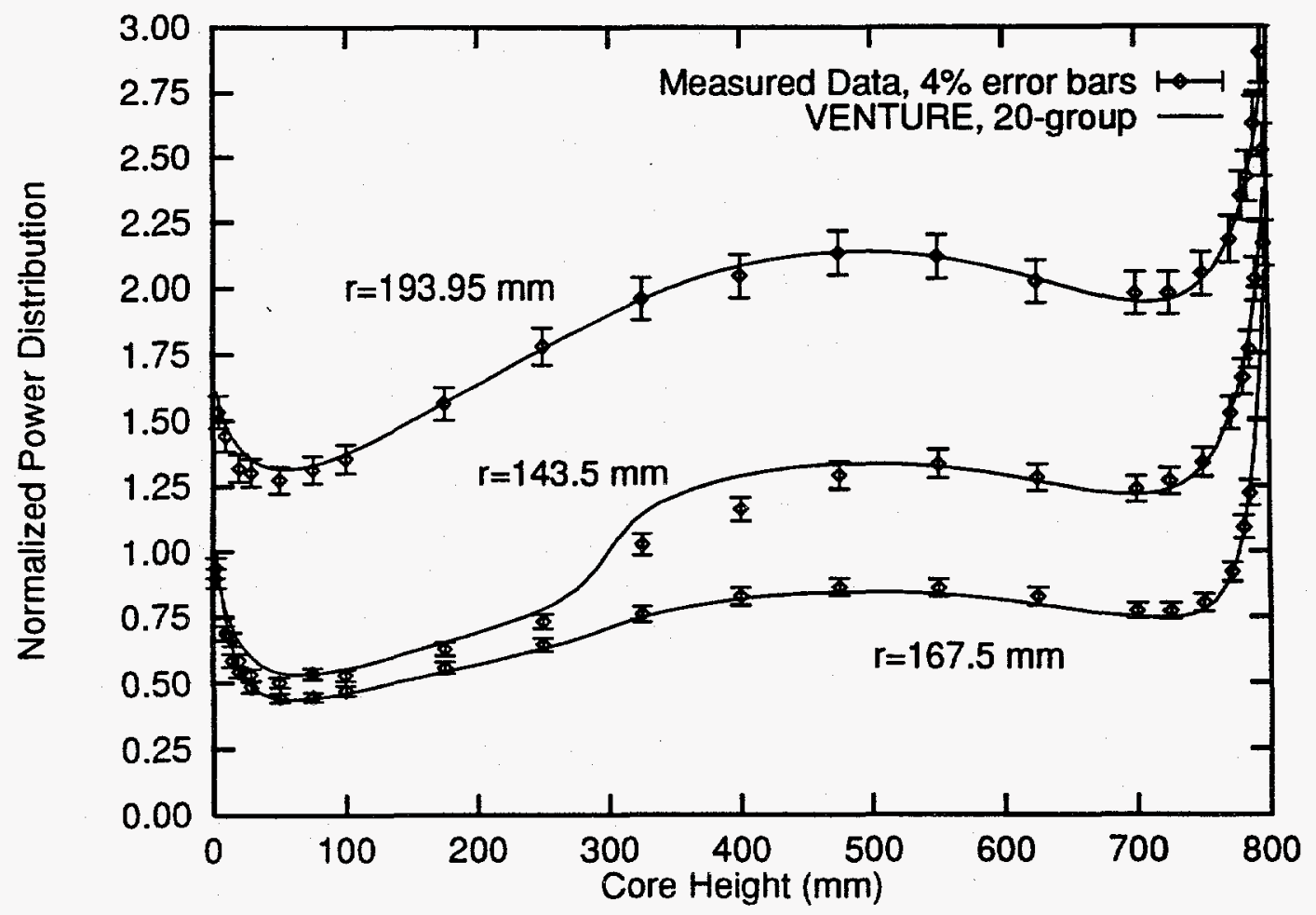

Fig. 4.8. Comparison of experimental axial power density traces and VENTURE values calculated using 20-group cross sections for the simple FOEHN configuration. 
Table 4.7. Rendement values calculated for the simple FOEHN configuration

\begin{tabular}{ccc}
\hline Computer code & $\begin{array}{c}\text { Rendement } \\
\text { neutrons } /\left(\mathrm{m}^{2} \mathrm{~s} \mathrm{~W}\right)\end{array}$ & $\begin{array}{c}\text { Percent } \\
\text { difference }\end{array}$ \\
\hline DORT & 2.7336 & 10.23 \\
VENTURE & 2.6356 & 6.27 \\
\hline
\end{tabular}

Table 4.8. Percent differences between measured thermal fluxes and values calculated with DORT using 20-group cross sections for the simple FOEHN configuration

\begin{tabular}{|c|c|c|c|c|c|c|c|c|c|c|c|c|c|}
\hline $\mathrm{H} / \mathrm{r}(\mathrm{mm})$ & 235 & 255 & 275 & 295 & 315 & 335 & 355 & 395 & 435 & 515 & 635 & 755 & 835 \\
\hline 1825 & -0.64 & -0.21 & 0.13 & -0.06 & 2.75 & & 1.73 & 4.24 & 4.40 & & & & \\
\hline 1675 & -0.30 & 0.60 & 1.15 & 2.93 & 4.68 & & 4.61 & 6.76 & 6.61 & 7.81 & 6.69 & 4.78 & 7.48 \\
\hline 1525 & 5.08 & 0.79 & 2.76 & 4.37 & 4.93 & 5.10 & 5.38 & 7.78 & 8.37 & 8.60 & 7.79 & 4.30 & 7.23 \\
\hline 1425 & 9.73 & 1.85 & 7.05 & 6.29 & 6.38 & 6.34 & 6.90 & 8.32 & 9.34 & 11.32 & 9.05 & 5.80 & 7.96 \\
\hline 1375 & 9.72 & 3.83 & 5.86 & 7.59 & 5.79 & 6.81 & 7.75 & 9.63 & 9.79 & & & & \\
\hline 1325 & 11.20 & 4.35 & 6.94 & 8.22 & 8.48 & 8.93 & 7.76 & y.51 & 9.76 & 10.45 & 9.51 & 6.21 & 7.33 \\
\hline 1275 & 10.28 & 4.74 & 7.68 & 8.81 & 8.04 & 8.39 & 8.92 & 9.87 & 10.31 & 11.39 & 10.73 & & \\
\hline 1225 & 9.96 & 5.17 & 7.89 & 8.78 & 7.08 & 10.18 & 8.75 & 9.49 & 11.44 & 11.05 & 9.30 & 3.73 & 8.05 \\
\hline 1125 & 12.07 & 6.22 & 8.90 & 10.06 & 7.47 & 9.26 & 9.10 & 9.54 & 10.69 & 11.14 & 10.08 & 7.29 & 9.36 \\
\hline 1075 & & 5.15 & & 9.50 & & 9.44 & & & & & & & \\
\hline 975 & 9.45 & 4.76 & 7.53 & 9.58 & 8.47 & 9.91 & 9.98 & 10.06 & 11.13 & $\$ 1.83$ & 10.71 & 8.41 & 8.41 \\
\hline 925 & 9.12 & & 7.59 & & 8.69 & & 10.02 & & & & & & \\
\hline 825 & 7.60 & 3.66 & 7.41 & 9.12 & 8.05 & 9.79 & 8.71 & 9.15 & 11.49 & 12.25 & & 8.50 & 7.93 \\
\hline 725 & 6.47 & 3.89 & 7.90 & 8.91 & 8.15 & & 9.66 & & & & & & \\
\hline 625 & 8.22 & 8.55 & 8.68 & 8.50 & 3.45 & & 11.53 & 10.90 & 9.82 & 15.38 & & & 7.62 \\
\hline 525 & 11.34 & 10.28 & 2.82 & 10.41 & 9.75 & & & & & & & & \\
\hline
\end{tabular}


Table 4.9. Percent differences between measured thermal fluxes and values calculated with VENTURE using

\begin{tabular}{|c|c|c|c|c|c|c|c|c|c|c|c|c|c|}
\hline $\mathbf{H} / \mathrm{r}(\mathrm{mm})$ & 235 & 255 & 275 & 295 & 315 & 335 & 355 & 395 & 435 & 515 & 635 & 755 & 835 \\
\hline 1825 & -1.51 & -1.12 & -0.81 & -1.04 & 1.69 & & 0.59 & 3.00 & 3.08 & & & & \\
\hline 1675 & -3.21 & -2.05 & -1.30 & 0.64 & 2.52 & & 2.69 & 4.93 & 4.83 & 5.99 & 4.90 & 3.15 & 5.94 \\
\hline 1525 & -1.81 & -4.59 & -1.82 & 0.41 & 1.48 & 2.03 & 2.60 & 5.31 & 6.12 & 6.47 & 5.68 & 2.36 & 5.36 \\
\hline 1425 & 2.23 & -4.03 & 1.81 & 1.80 & 2.45 & 2.85 & 3.74 & 5.57 & 6.83 & 8.93 & 6.72 & 3.62 & 5.84 \\
\hline 1375 & 1.67 & -2.46 & 0.43 & 2.85 & 1.71 & 3,15 & 4.42 & 6.72 & 7.16 & & & & \\
\hline 1325 & 2.70 & -2.24 & 1.25 & 3.26 & 4.14 & 5.05 & 4.29 & 6.48 & 7.03 & 7.90 & 6.98 & 3.82 & 5.02 \\
\hline 1275 & 1.63 & -2.05 & 1.79 & 3.68 & 3.58 & 4.40 & 5.30 & 6.73 & 7.46 & 8.72 & 8.07 & & \\
\hline 1225 & 1.21 & -1.76 & 1.87 & 3.54 & 2.55 & 6.03 & 5.04 & 6.27 & 8.48 & 8.31 & 6.61 & 1.23 & 5.54 \\
\hline 1125 & 3.06 & -0.87 & 2.73 & 4.66 & 2.83 & 5.04 & 5.28 & 6.22 & 7.63 & 8.28 & 7.24 & 4.58 & 6.68 \\
\hline 1075 & & -1.83 & & 4.14 & & 5.23 & & & & & & & \\
\hline 975 & 1.08 & -1.90 & 1.72 & 4.43 & 3.98 & 5.83 & 6.26 & 6.80 & 8.10 & 8.93 & 7.79 & 3.58 & 5.64 \\
\hline 925 & 1.03 & & 1.97 & & 4.32 & & 6.40 & & & & & & \\
\hline 825 & 0.34 & -2.14 & 2.29 & 4.59 & 4.08 & 6.14 & 5.39 & 6.19 & 8.67 & 9.46 & & 5.66 & 5.15 \\
\hline 725 & -0.27 & -1.53 & 3.15 & $4 . n$ & 4.51 & & 6.58 & & & & & & \\
\hline 625 & 2.39 & 3.81 & 4.66 & 5.00 & 0.43 & & 8.69 & 8.25 & 7.26 & 12.62 & & & 4.93 \\
\hline 525 & 7.56 & 6.92 & -0.04 & 7.55 & 7.07 & & & & & & & & \\
\hline
\end{tabular}




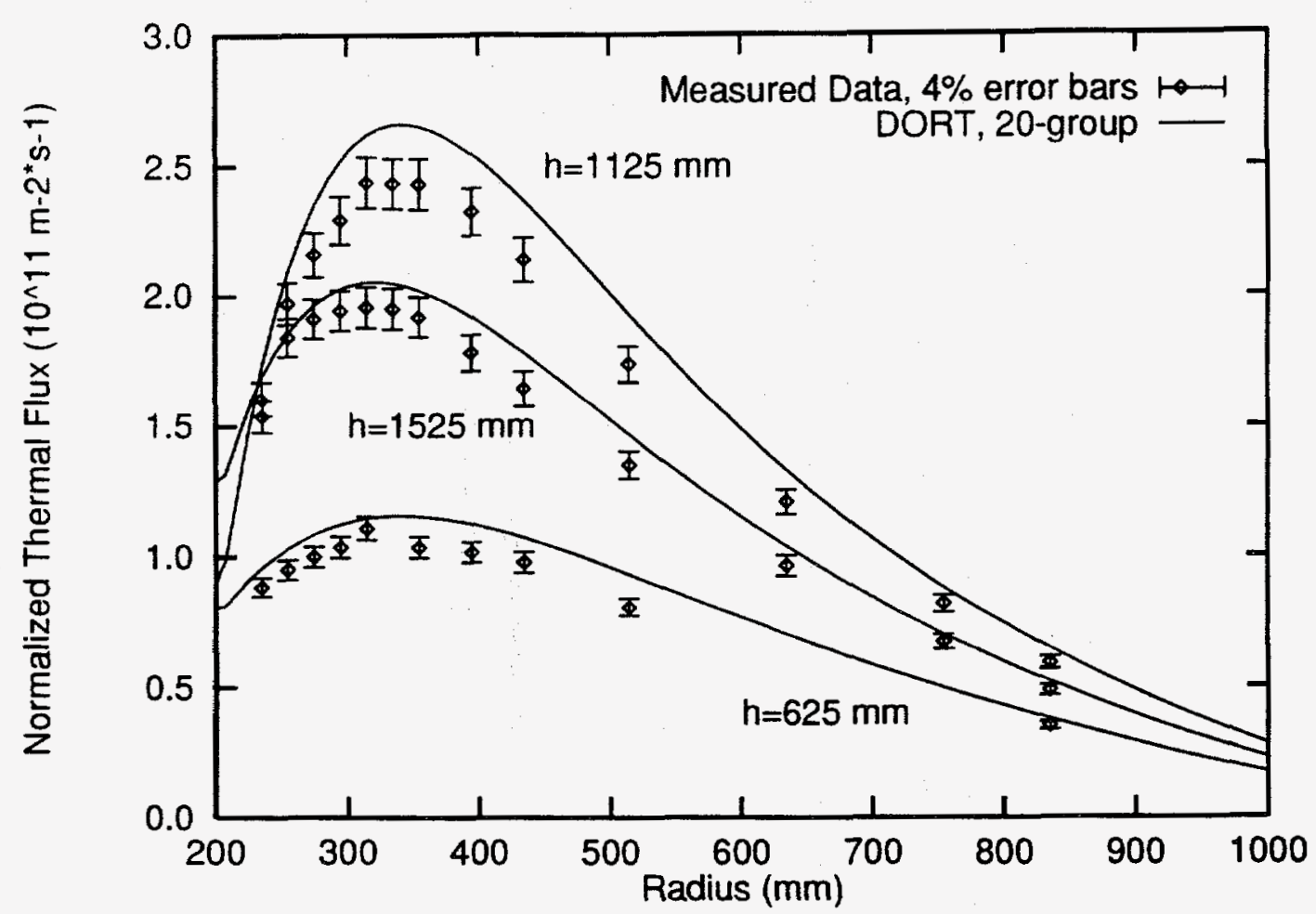

Fig. 4.9. Comparison of experimental radial thermal flux traces with DORT values calculated using 20-group cross sections for the simple FOEHN configuration.

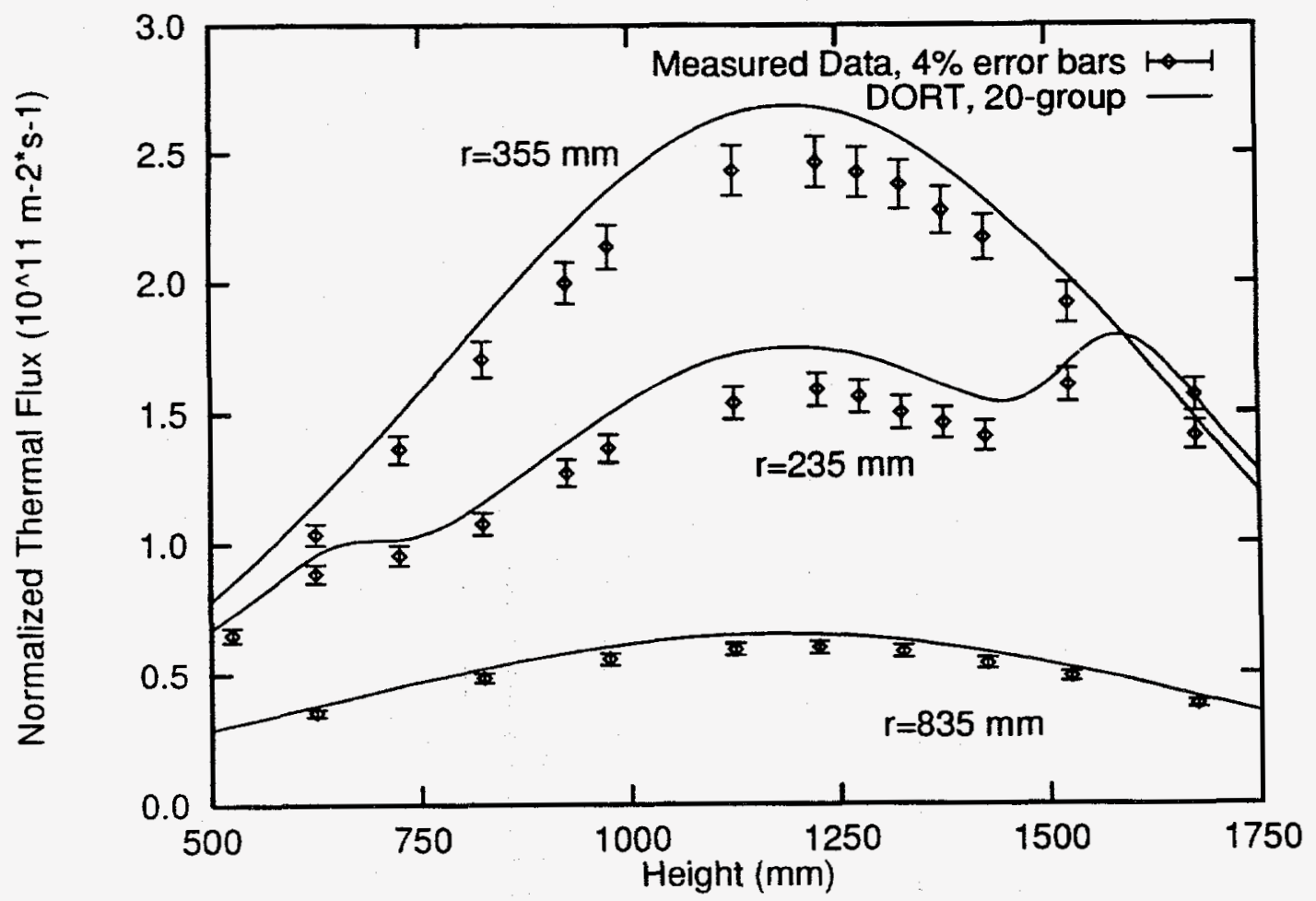

Fig. 4.10. Comparison of experimental axial thermal flux traces with DORT values calculated using 20-group cross sections for the simple FOEHN configuration. 


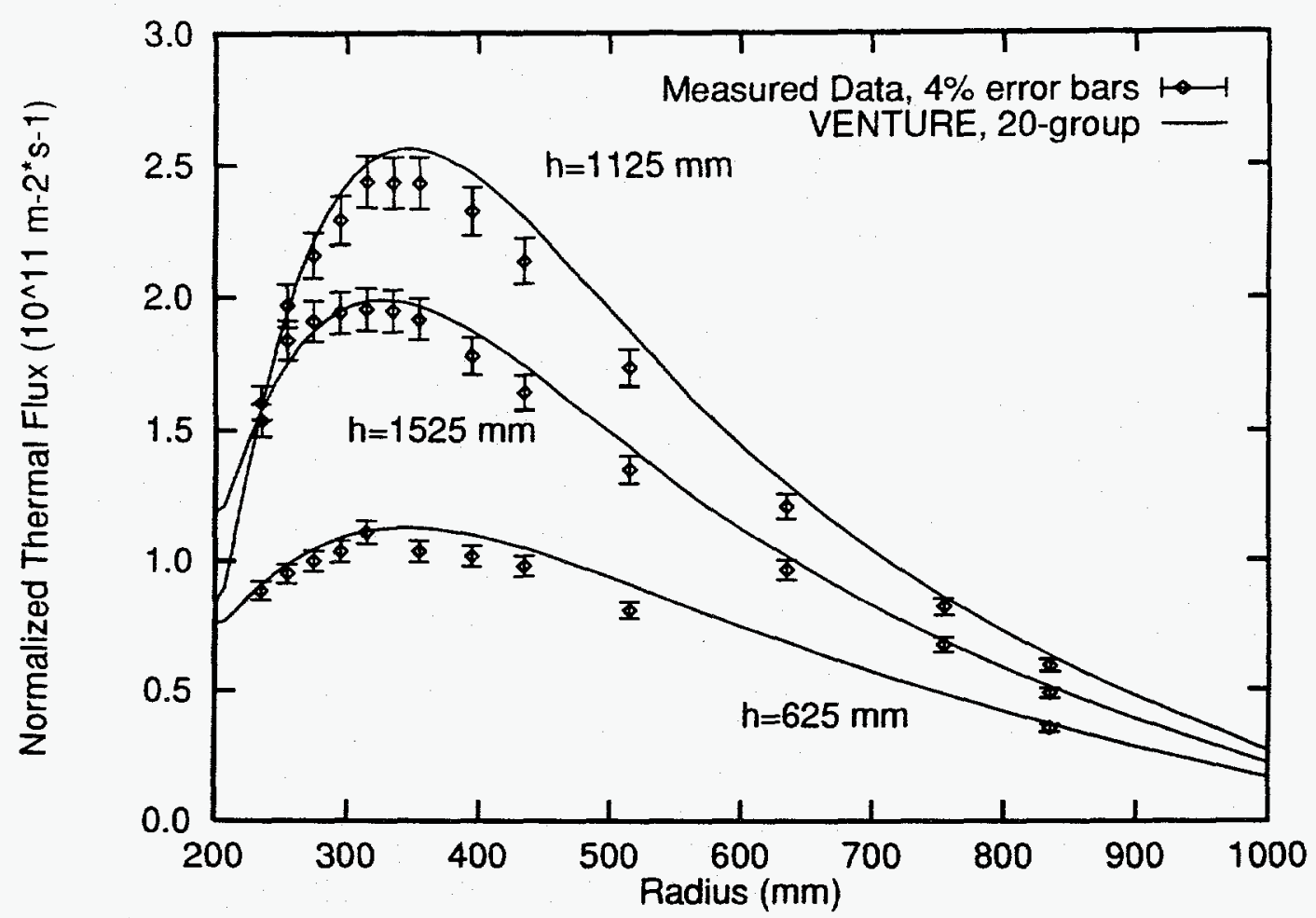

Fig. 4.11. Comparison of experimental radial thermal flux traces with VENTURE values calculated using 20-group cross sections for the simple FOEHN configuration.

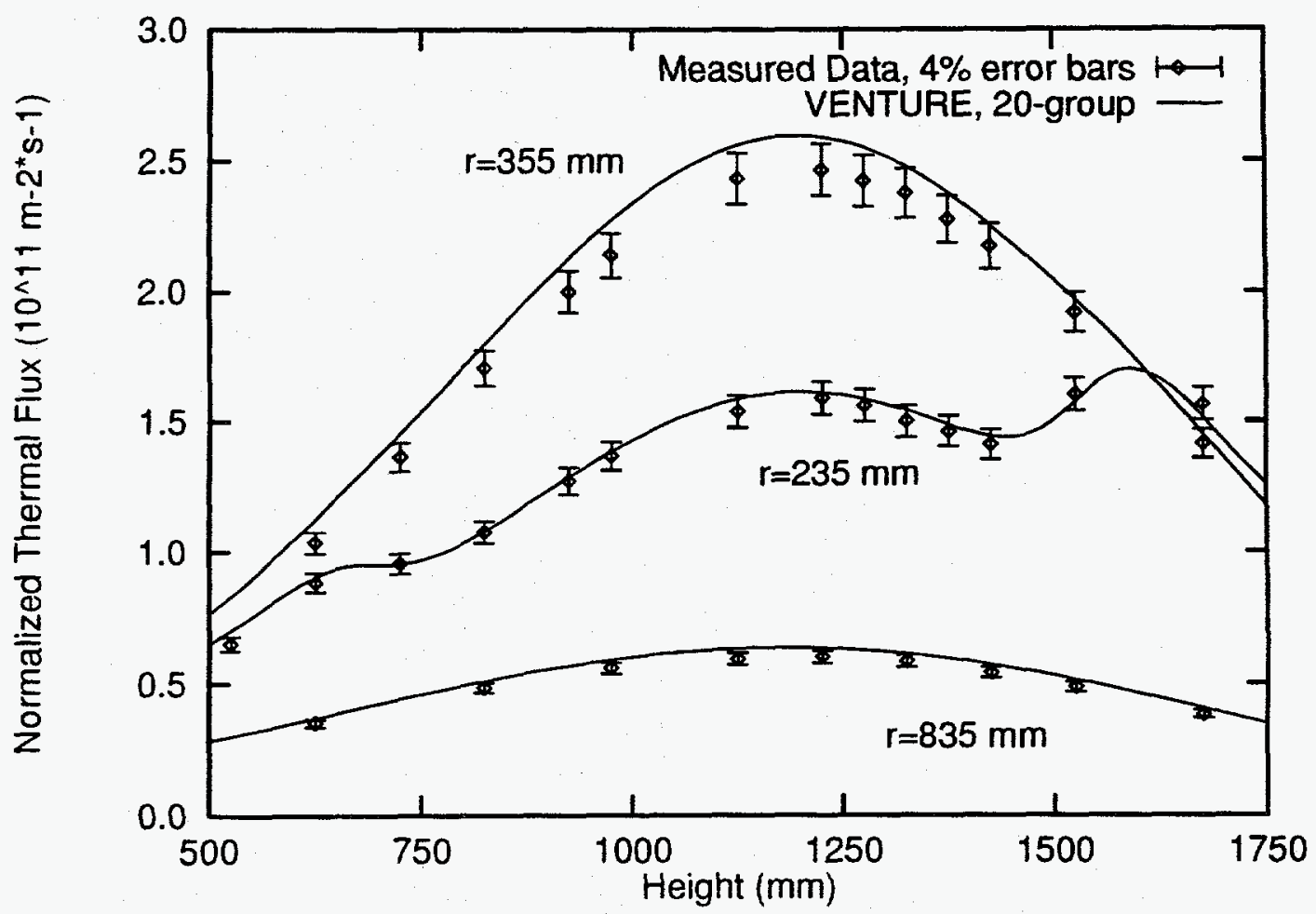

Fig. 4.12. Comparison of experimental axial thermal flux traces with VENTURE values calculated using 20-group cross sections for the simple FOEHN configuration. 


\subsection{INTERMEDIATE CONFIGURATION}

\subsubsection{Multiplication Factors}

Table 4.10 shows the eigenvalues calculated for the six cases of the intermediate FOEHN configuration. All of the values calculated using KENO with 99-group cross sections are within three sigma of unity. Two values are outside two sigma of unity. The average DORT and VENTURE $k_{\text {eff }}$ values overestimate unity by $0.08 \%$ and $0.14 \%$, respectively. The results are shown graphically in Figs. 4.13 and 4.14. The average multiplication factor for the intermediate configuration obtained in an independent analysis using Monte Carlo methods is $0.9951 \pm 0.0021 .^{13}$

Table 4.10. Comparison of eigenvalues for the intermediate FOEHN configuration cases using different calculational methods

\begin{tabular}{|c|c|c|c|c|c|c|}
\hline \multirow[t]{2}{*}{ Case } & \multirow{2}{*}{$\begin{array}{c}\text { Control } \\
\text { element } \\
\text { position } \\
(\mathrm{mm})\end{array}$} & \multirow{2}{*}{$\begin{array}{c}\text { Boron-10 } \\
\text { concentration } \\
\left(\mathrm{g}^{10} \mathrm{~B} / \mathrm{L}\right)\end{array}$} & \multicolumn{2}{|c|}{ KENO } & \multirow{2}{*}{$\begin{array}{c}\text { DORT } \\
\text { 20-group }\end{array}$} & \multirow{2}{*}{$\begin{array}{l}\text { VENTURE } \\
\text { 20-group }\end{array}$} \\
\hline & & & 99-group & 20-group & & \\
\hline 1 & 352.2 & 0.210 & $0.9953 \pm 0.0052$ & $0.9990 \pm 0.0044$ & 0.9975 & 0.9995 \\
\hline 2 & 447.0 & 0.258 & $0.9956 \pm 0.0053$ & $1.0039 \pm 0.0048$ & 1.0009 & 1.0023 \\
\hline 3 & 457.0 & 0.270 & $0.9965 \pm 0.0044$ & $1.0031 \pm 0.0046$ & 0.9987 & 1.0000 \\
\hline 4 & 609.0 & 0.350 & $0.9954 \pm 0.0045$ & $1.0021 \pm 0.0046$ & 1.0013 & 1.0014 \\
\hline 5 & 664.0 & 0.371 & $1.0049 \pm 0.0047$ & $1.0006 \pm 0.0050$ & 1.0033 & 1.0027 \\
\hline 6 & 815.0 & 0.419 & $1.0018 \pm 0.0046$ & $1.0065 \pm 0.0046$ & 1.0030 & 1.0025 \\
\hline Average & - & - & $0.9983 \pm 0.0020$ & $1.0025 \pm 0.0019$ & 1.0008 & 1.0014 \\
\hline
\end{tabular}

\subsubsection{Power Distributions}

Power distributions were measured for case 2 of Table 4.10. For this case, the control element was positioned at $447 \mathrm{~mm}$, and the dissolved boron concentration was $0.258 \mathrm{~g}{ }^{10} \mathrm{~B} / \mathrm{L}$. Table 4.11 shows the average and maximum differences between the calculated and measured values. The maximum differences occur at the upper and lower edges of the fuel element. As stated in Chap. 2, these points have larger experimental errors than the other points because of deformation of the fuel plates. When these points are not considered, the average differences are $2.86 \%, 1.68 \%$, and $1.87 \%$ for the KENO, DORT, and VENTURE results, respectively. Table 4.12 shows the nonmatching points for the power densities calculated with KENO using 99-group cross sections. The error in the measured data is assumed to be $4 \%$. The average statistical uncertainty in the KENO power density values is $3.51 \%$. Twenty-six of the 123 data points $(21.1 \%)$ are nonmatching points. If the points next to the boron endplates are not included (see Sect. 2.5.2), the number of nonmatching points drops to 5.7\%. Tables 4.134 .15 show the differences between the measured and calculated values. Figures 4.15 4.20 show radial and axial traces of the KENO, DORT, and VENTURE calculated and the measured power density values. The figures show that all of the calculated values underestimate the measured values at the upper edge of the fuel element $(\mathrm{h}=797.5 \mathrm{~mm})$. The agreement is better at the lower edge $(\mathrm{h}=2.5 \mathrm{~mm})$. 
Table 4.11. Average and maximum power density percent differences for the intermediate FOEHN configuration

\begin{tabular}{ccc}
\hline Computer code & \multicolumn{2}{c}{ Percent difference } \\
\cline { 2 - 3 } & Average $^{a}$ & Maximum $^{b}$ \\
\hline KENO $^{c}$ & $4.50(2.86)$ & $-20.50(-9.67)$ \\
DORT $^{d}$ & $3.45(1.68)$ & $-19.88(-8.33)$ \\
VENTURE $^{d}$ & $2.45(1.87)$ & $-12.46(-7.66)$ \\
\hline
\end{tabular}

athe average values in parentheses were calculated without including the points at the upper and lower edges of the fuel element (see Sect. 2.5.2).

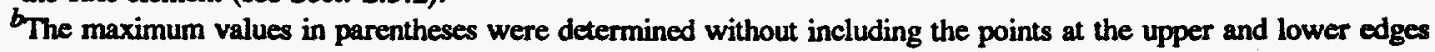
of the fuel element or the points at the inner edge of the fuel element near the tip of the control element (see Sects. 2.4.1 and 2.5.2).

c99 energy groups.

$d_{20}$ energy groups.

\subsubsection{Rendement}

The rendement was calculated using the peak thermal flux from the DORT and VENTURE calculations. The measured rendement was $2.56 \times 10^{11}$ neutrons $/\left(\mathrm{m}^{2} \mathrm{~s} \mathrm{~W}\right)$. Table 4.16 shows the calculated values. The DORT value overestimates the calculated value by $9.19 \%$. This result is very similar to the results obtained in ref. 9 (11.5\% higher) and ref. 14 (13\% higher). The VENTURE model overestimates the measured rendement by $5.82 \%$. 


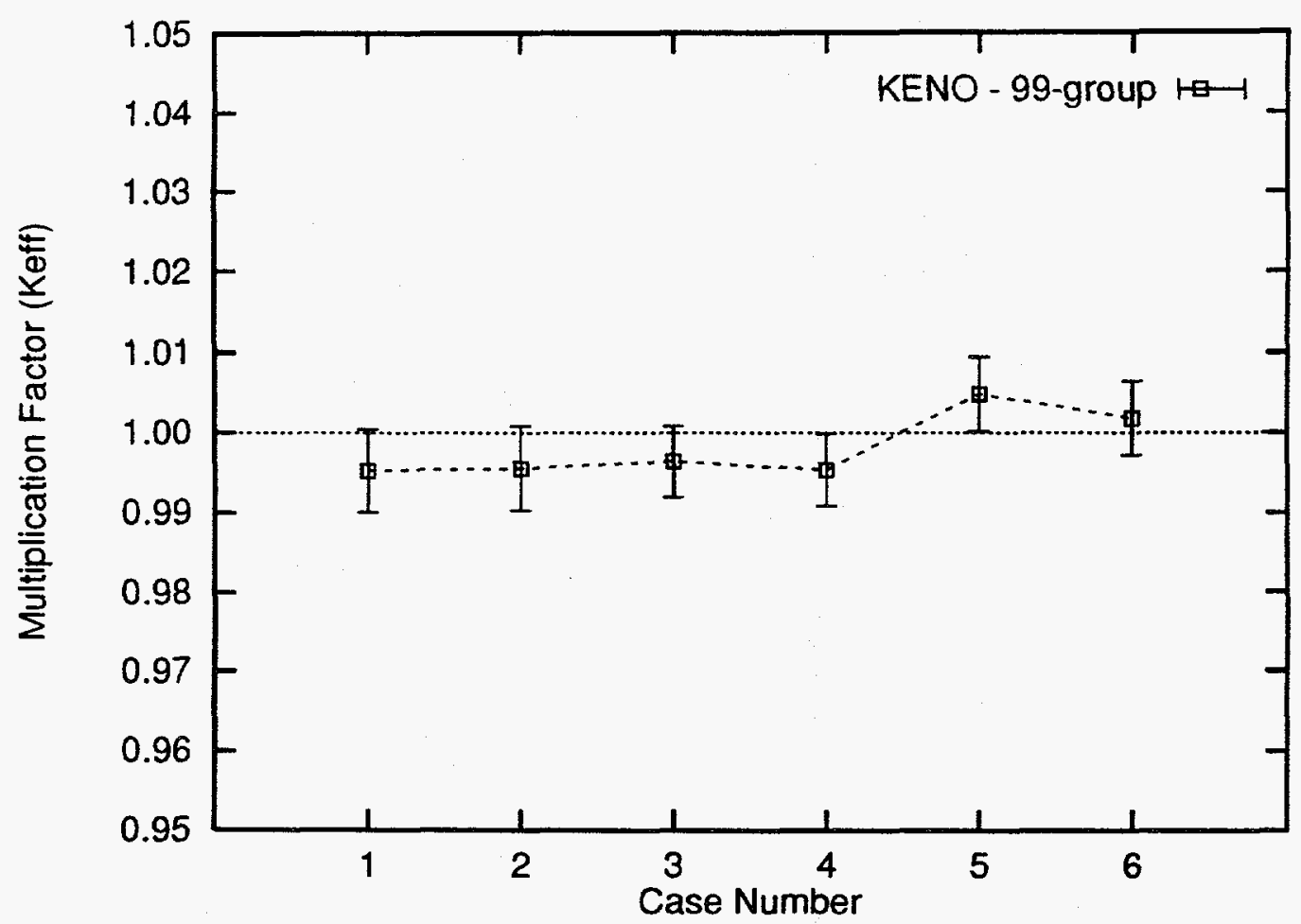

Fig. 4.13. $K_{\text {egf }}$ values for the intermediate FOEHN configuration calculated with KENO using 99-group cross sections.

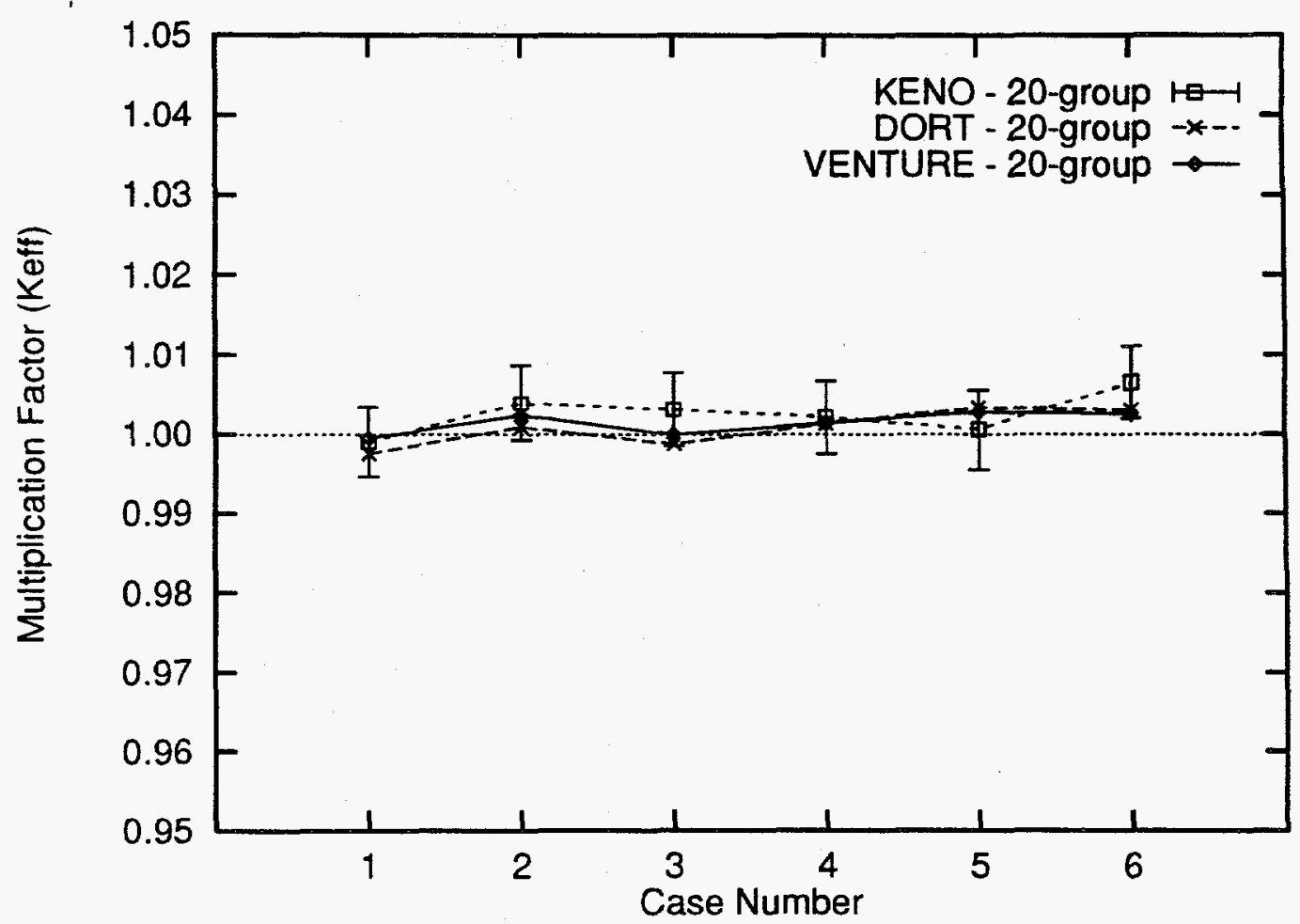

Fig. 4.14. Comparison of $k_{e f f}$ values for the intermediate FOEHN configuration calculated with different computer codes using 20-group cross sections. 
Table 4.12. Nonmatching points for power densities calculated with KENO using 99-group cross sections for the intermediate FOEHN configuration

\begin{tabular}{|c|c|c|c|c|c|c|c|c|c|c|c|}
\hline \multicolumn{12}{|c|}{$(0=$ match, 1 -nonmatch within two sigma) } \\
\hline$H / r(m m)$ & 143.5 & 146.5 & 149.5 & 152.5 & 159.0 & 167.5 & 176.0 & 182.5 & 185.5 & 188.5 & 193.9 \\
\hline 797.5 & 1 & 1 & 1 & 1 & 1 & 1 & 1 & 1 & 1 & 1 & 1 \\
\hline 790.6 & 1 & & & & & & & & & & 1 \\
\hline 785.5 & 0 & & & & & 1 & & & & & 1 \\
\hline 780.6 & 0 & & & & & 1 & & & & & 0 \\
\hline 771.5 & 0 & & & & & 0 & & & & & 0 \\
\hline 750.0 & 0 & 0 & 0 & 0 & 0 & 0 & o & 0 & 0 & 0 & 0 \\
\hline 725.0 & 0 & & & & & D & & & & & 0 \\
\hline 700.0 & o & & & & & 0 & & & & & 0 \\
\hline 625.0 & $\mathbf{0}$ & o & $\mathbf{0}$ & $\mathbf{0}$ & 0 & 0 & 0 & 0 & 0 & 0 & 0 \\
\hline 550.0 & 1 & & & & & 0 & & & & & 0 \\
\hline 475.0 & 0 & & & & & 0 & & & & & 0 \\
\hline 400.0 & 0 & 0 & 0 & 0 & 0 & 0 & 0 & 0 & 0 & 0 & 0 \\
\hline 325.0 & 0 & & & & & 0 & & & & & 0 \\
\hline 250.0 & 0 & & & & & 0 & & & & & 0 \\
\hline 175.0 & 0 & 0 & 0 & 0 & 0 & 0 & 0 & 0 & 0 & 0 & 0 \\
\hline 100.0 & 0 & & & & & 0 & & & & & 0 \\
\hline 75.0 & 0 & & & & & 0 & & & & & 0 \\
\hline so.0 & 0 & $\mathbf{0}$ & 0 & 0 & 0 & $\mathbf{0}$ & $\mathbf{0}$ & 0 & 0 & $\mathbf{0}$ & $\mathbf{0}$ \\
\hline 28.5 & 0 & & & & & 0 & & & & & 0 \\
\hline 19.4 & 0 & & & & & 0 & & & & & 1 \\
\hline 14.5 & 0 & & & & & 0 & & & & & 0 \\
\hline 9.4 & 0 & & & & & & & & & & 0 \\
\hline 2.5 & 1 & 0 & 1 & 1 & 1 & 1 & 1 & $\mathbf{0}$ & 1 & 1 & 0 \\
\hline
\end{tabular}

Table 4.13. Percent differences between measured power densities and values calculated with KENO using 99-group cross sections for the intermediate FOEFN configuration

\begin{tabular}{|c|c|c|c|c|c|c|c|c|c|c|c|}
\hline$H / r(m m)$ & 143.5 & 146.5 & 149.5 & 152.5 & 159.0 & 167.5 & 176.0 & 182.5 & 185.5 & 188.5 & 193.9 \\
\hline 797.5 & -10.96 & -14.74 & -20.13 & -17.50 & -20.50 & -19.66 & -16.19 & -14.15 & -10.27 & -7.01 & -7.74 \\
\hline 790.6 & -8.56 & & & & & & & & & & -7.36 \\
\hline 785.5 & -0.59 & & & & & -8.66 & & & & & -9.19 \\
\hline 780.6 & 1.92 & & & & & -9.67 & & & & & -6.13 \\
\hline 771.5 & -5.77 & & & & & -2.67 & & & & & -3.89 \\
\hline 750.0 & -1.86 & -5.73 & -3.11 & -1.26 & -1.72 & -4.21 & -2.18 & -2.28 & -4.86 & 0.50 & -4.72 \\
\hline 725.0 & -1.45 & & & & & -0.86 & & & & & -3.38 \\
\hline 700.0 & -4.08 & & & & & 2.13 & & & & & -4.15 \\
\hline 625.0 & 0.46 & -0.90 & 0.98 & 1.48 & 0.64 & -3.86 & -0.44 & -1.53 & -2.41 & -0.62 & -4.01 \\
\hline 550.0 & 8.22 & & & & & 1.81 & & & & & -2.90 \\
\hline 475.0 & 5.72 & & & & & 1.90 & & & & & -3.32 \\
\hline 400.0 & 1.08 & 1.77 & 0.98 & 0.70 & 3.17 & 3.64 & 1.21 & -0.53 & 0.77 & -1.57 & -1.76 \\
\hline 325.0 & 0.98 & & & & & 0.84 & & & & & -4.58 \\
\hline 250.0 & 2.94 & & & & & 0.39 & & & & & -2.41 \\
\hline 175.0 & -6.66 & -1.39 & -2.75 & -0.43 & -0.72 & 0.06 & 1.70 & -0.47 & -0.22 & -4.75 & -4.59 \\
\hline 100.0 & -0.83 & & & & & -0.53 & & & & & -3.90 \\
\hline 75.0 & -5.01 & & & & & -1.84 & & & & & -3.32 \\
\hline 50.0 & -5.48 & -5.12 & 0.04 & 0.64 & -4.35 & -0.27 & -2.10 & -1.08 & 0.46 & -3.06 & -1.40 \\
\hline 28.5 & -0.83 & & & & & -3.86 & & & & & -5.94 \\
\hline 19.4 & -5.57 & & & & & -0.26 & & & & & -7.04 \\
\hline 14.5 & 1.13 & & & & & -3.70 & & & & & -4.30 \\
\hline 9.4 & -4.79 & & & & & & & & & & -4.95 \\
\hline 2.5 & -9.69 & -7.10 & -12.17 & -11.21 & -12.52 & -13.64 & -9.39 & -7.21 & -9.22 & -8.96 & -5.27 \\
\hline
\end{tabular}


Table 4.14. Percent differences between measured power densities and values calculated with DORT using 20-group cross sections for the intermediate FOEHN configuration

\begin{tabular}{|c|c|c|c|c|c|c|c|c|c|c|c|}
\hline $\mathrm{H} / \mathrm{r}(\mathrm{mm})$ & 143.5 & 146.5 & 149.5 & 152.5 & 159.0 & 167.5 & 176.0 & 182.5 & 185.5 & 188.5 & 193.9 \\
\hline 797.5 & -11.95 & -14.60 & -19.83 & -19.79 & -19.88 & -18.77 & -14.88 & -13.75 & -10.56 & -7.01 & -5.97 \\
\hline 790.6 & -6.80 & & & & & & & & & & -5.06 \\
\hline 785.5 & -3.78 & & & & & -8.33 & & & & & -3.38 \\
\hline 780.6 & 3.58 & & & & & -7.64 & & & & & -2.87 \\
\hline 71.5 & -3.72 & & & & & -4.10 & & & & & -3.03 \\
\hline 750.0 & -1.09 & -2.47 & -3.42 & -2.09 & -1.08 & -0.59 & -0.85 & -2.42 & -2.12 & -0.19 & -1.53 \\
\hline 725.0 & -0.38 & & & & & 0.85 & & & & & 0.27 \\
\hline 200.0 & 1.60 & & & & & 0.49 & & & & & -0.34 \\
\hline 625.0 & 4.55 & 2.28 & 2.24 & 2.59 & 1.25 & 1.05 & 0.96 & -0.76 & 0.59 & 0.95 & 0.10 \\
\hline $\mathbf{5 5 0 . 0}$ & 8.63 & & & & & 2.71 & & & & & 0.90 \\
\hline 475.0 & -1.55 & & & & & 0.15 & & & & & -0.17 \\
\hline 400.0 & 0.86 & -1.38 & -0.19 & 0.18 & 0.64 & 0.27 & 0.13 & -1.20 & 0.21 & 0.94 & 0.16 \\
\hline 325.0 & 0.04 & & & & & 0.02 & & & & & -0.01 \\
\hline 250.0 & 1.05 & & & & & 0.17 & & & & & 0.05 \\
\hline 175.0 & 0.59 & -0.28 & -1.12 & 0.20 & -0.13 & 0.08 & -0.26 & -1.30 & -0.86 & -0.62 & -0.72 \\
\hline 100.0 & 0.52 & & & & & 0.63 & & & & & 0.40 \\
\hline 75.0 & -1.46 & & & & & 0.09 & & & & & 0.48 \\
\hline 50.0 & -1.44 & -2.71 & -2.73 & -1.74 & -0.67 & -0.74 & -0.67 & -0.50 & -0.94 & 0.47 & 0.60 \\
\hline 28.5 & -2.78 & & & & & -3.58 & & & & & -1.18 \\
\hline 19.4 & -2.89 & & & & & -4.39 & & & & & -0.42 \\
\hline 14.5 & -3.32 & & & & & -6.28 & & & & & -1.85 \\
\hline 9.4 & -4.82 & & & & & & & & & & -2.24 \\
\hline 2.5 & -8.14 & -10.66 & -11.51 & -12.52 & -12.02 & -10.65 & -9.86 & -8.87 & -7.08 & -4.84 & -1.87 \\
\hline
\end{tabular}

Table 4.15. Percent differences between measured power densities and values calculated with VENTURE using 20-group cross sections for the intermediate FOEHN configuration

\begin{tabular}{|c|c|c|c|c|c|c|c|c|c|c|c|}
\hline $\mathrm{H} / \mathrm{r}(\mathrm{mm})$ & 143.5 & 146.5 & 149.5 & 152.5 & 159.0 & 167.5 & 176.0 & 182.5 & 185.5 & 188.5 & 193.9 \\
\hline 797.5 & -11.90 & -10.49 & -12.46 & -10.10 & -8.44 & -6.94 & -2.85 & -4.40 & -4.30 & -4.64 & -9.80 \\
\hline 790.6 & -7.45 & & & & & & & & & & -7.66 \\
\hline 785.5 & -5.39 & & & & & -0.79 & & & & & -5.80 \\
\hline 780.6 & 1.55 & & & & & -2.59 & & & & & -5.09 \\
\hline 771.5 & -5.24 & & & & & -2.50 & & & & & -4.90 \\
\hline 750.0 & -3.47 & -3.81 & -4.42 & -3.45 & -3.25 & -2.29 & -1.20 & -0.88 & -0.37 & 1.02 & -3.23 \\
\hline 725.0 & -3.55 & & & & & -2.02 & & & & & -1.41 \\
\hline 700.0 & -2.01 & & & & & -2.44 & & & & & -2.06 \\
\hline 625.0 & 0.41 & -0.74 & -0.33 & 0.06 & -1.79 & -1.85 & 0.04 & -0.06 & 1.75 & 1.68 & -1.84 \\
\hline 550.0 & 4.25 & & & & & -0.35 & & & & & -0.98 \\
\hline 475.0 & -4.04 & & & & & -2.05 & & & & & -1.56 \\
\hline 400.0 & -0.35 & -2.51 & -1.65 & -1.63 & -1.84 & -1.67 & 0.27 & 0.55 & 2.32 & 2.47 & -1.10 \\
\hline 325.0 & -1.56 & & & & & -1.60 & & & & & -0.98 \\
\hline 250.0 & -0.88 & & & & & -1.33 & & & & & -0.73 \\
\hline 175.0 & -0.90 & -1.13 & -2.10 & -1.06 & -1.87 & -1.20 & 0.66 & 1.18 & 2.06 & 1.74 & -1.12 \\
\hline 100.0 & -0.37 & & & & & -0.43 & & & & & 0.16 \\
\hline 75.0 & -1.80 & & & & & -0.76 & & & & & 0.43 \\
\hline 50.0 & -0.72 & -1.55 & -1.77 & -1.20 & -1.03 & -0.46 & 1.17 & 3.04 & 2.64 & 3.39 & 0.48 \\
\hline 28.5 & -0.28 & - & & & & -0.48 & & & & & -1.65 \\
\hline 19.4 & -0.10 & & & & & 2.30 & & & & & -1.08 \\
\hline 14.5 & -0.08 & & & & & 2.67 & & & & & -2.78 \\
\hline 9.4 & -0.42 & & & & & & & & & & -3.57 \\
\hline 2.5 & -1.54 & -1.04 & 1.03 & 1.79 & 3.96 & 4.87 & $4 ! 6$ & 2.27 & 0.95 & -0.66 & -3.05 \\
\hline
\end{tabular}




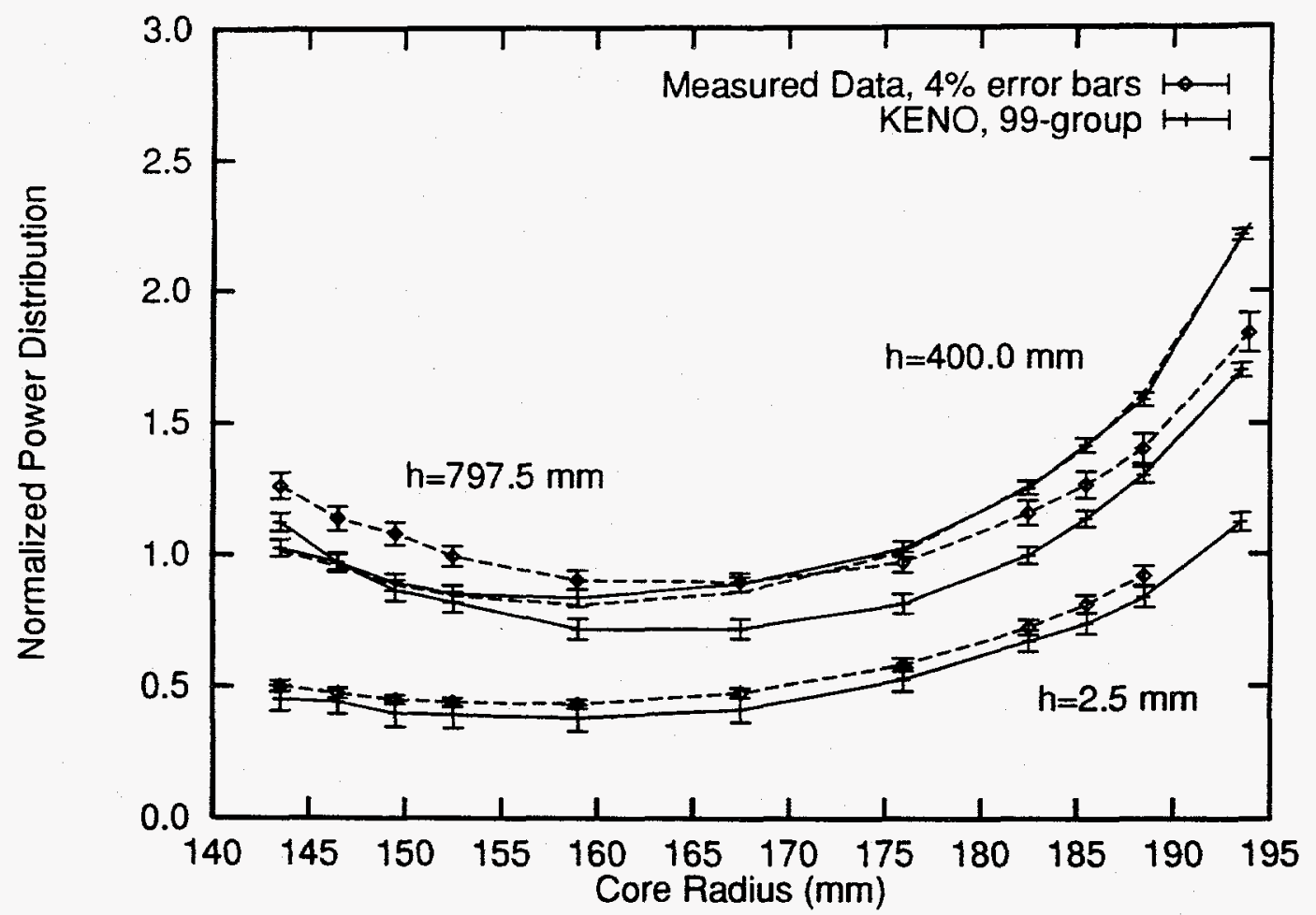

Fig. 4.15. Comparison of experimental radial power density traces and KENO values calculated using 99-group cross sections for the intermediate FOEHN configuration.

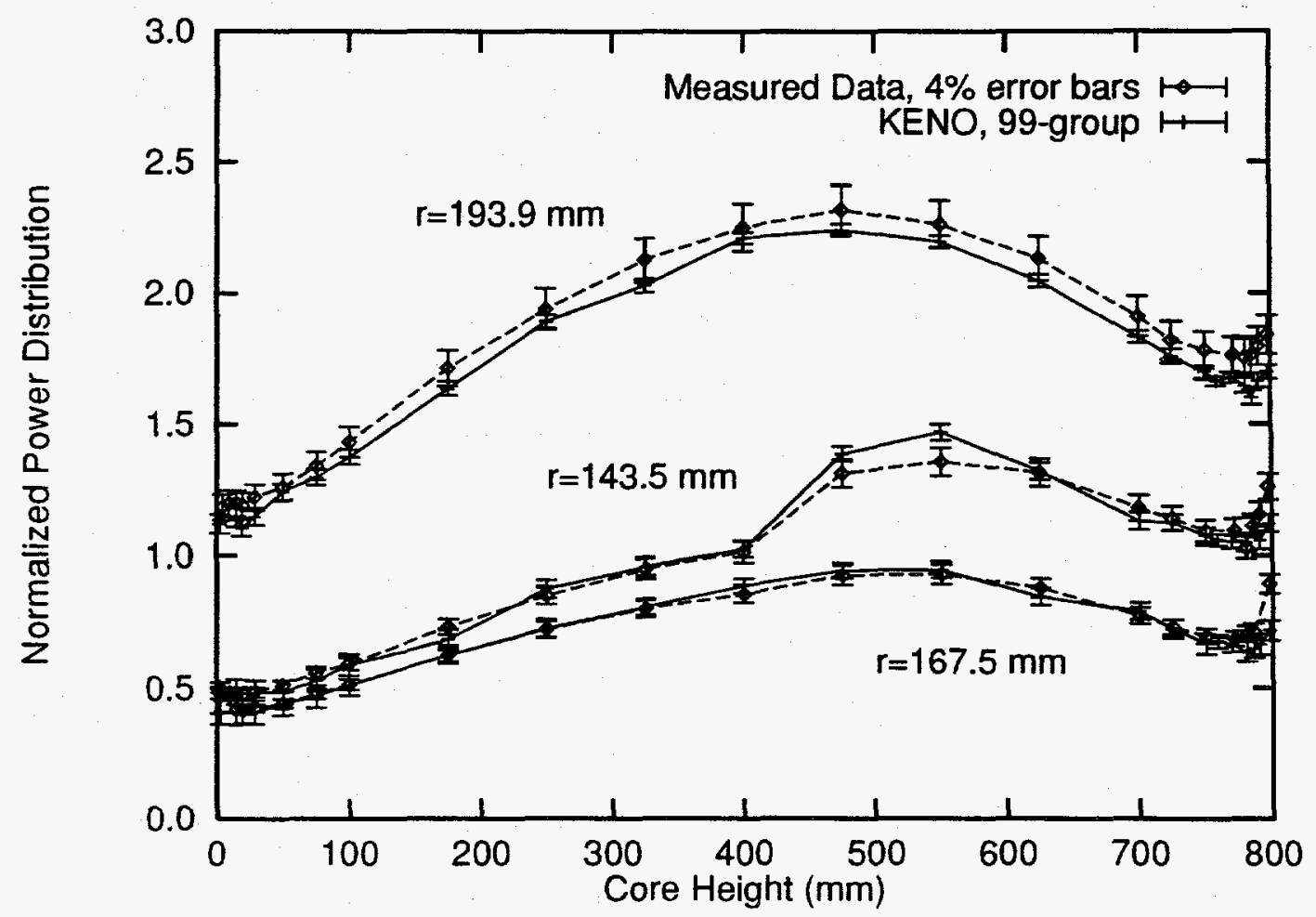

Fig. 4.16. Comparison of experimental axial power density traces and KENO values calculated using 99-group cross sections for the intermediate FOEHN configuration. 


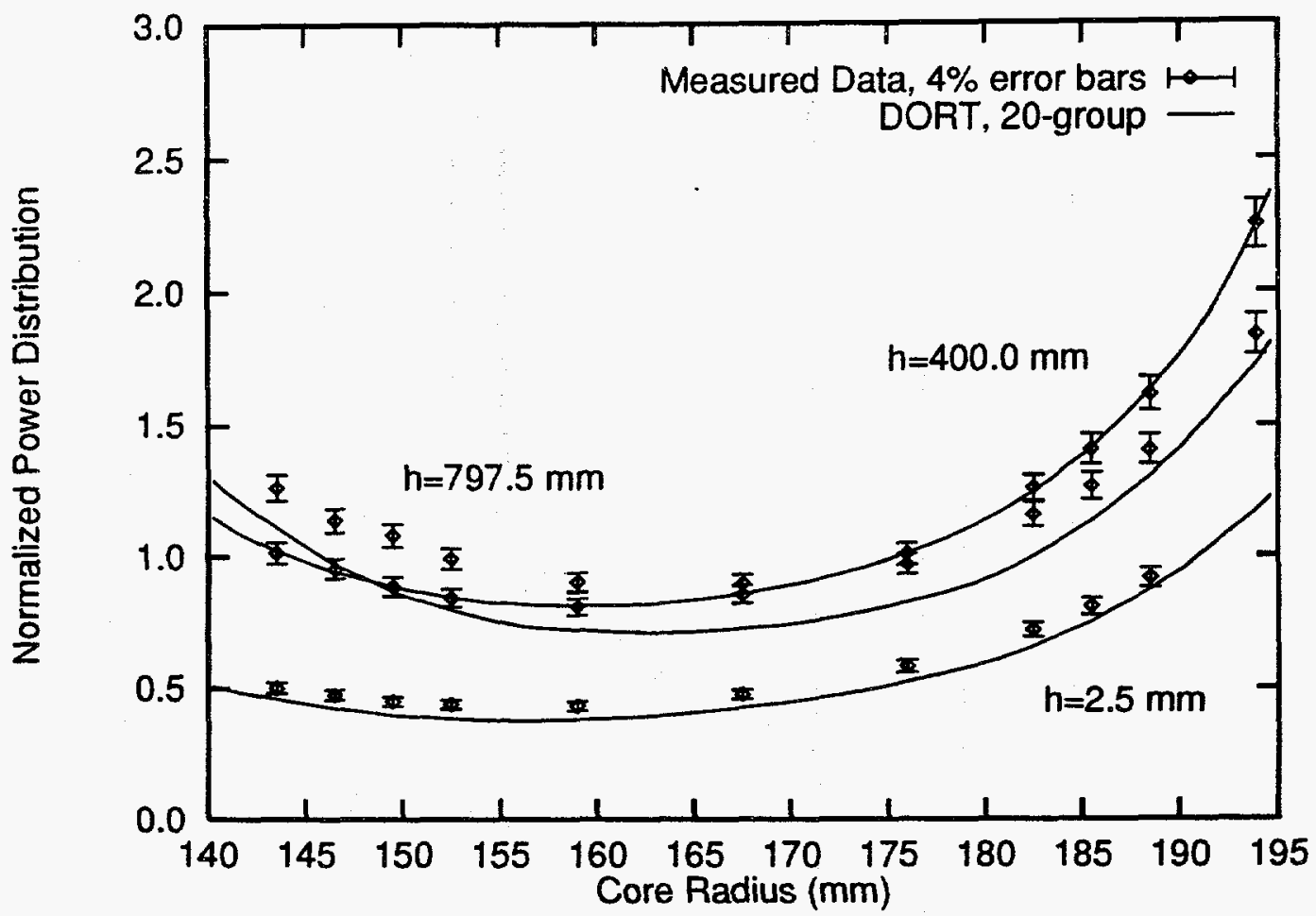

Fig. 4.17. Comparison of experimental radial power density traces and DORT values calculated using 20-group cross sections for the intermediate FOEHN configuration.

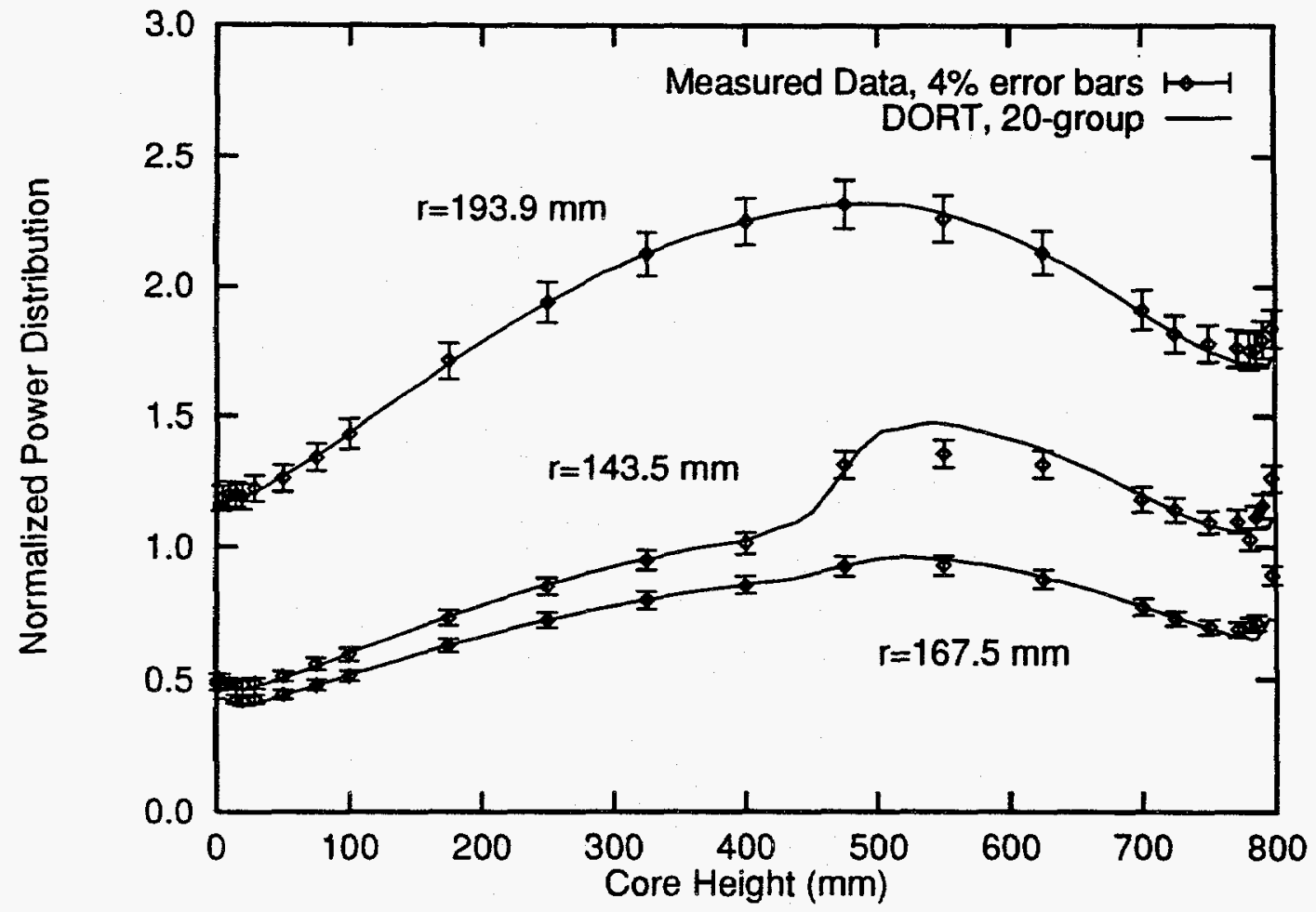

Fig. 4.18. Comparison of experimental axial power density traces and DORT values calculated using 20-group cross sections for the intermediate FOEHN configuration. 


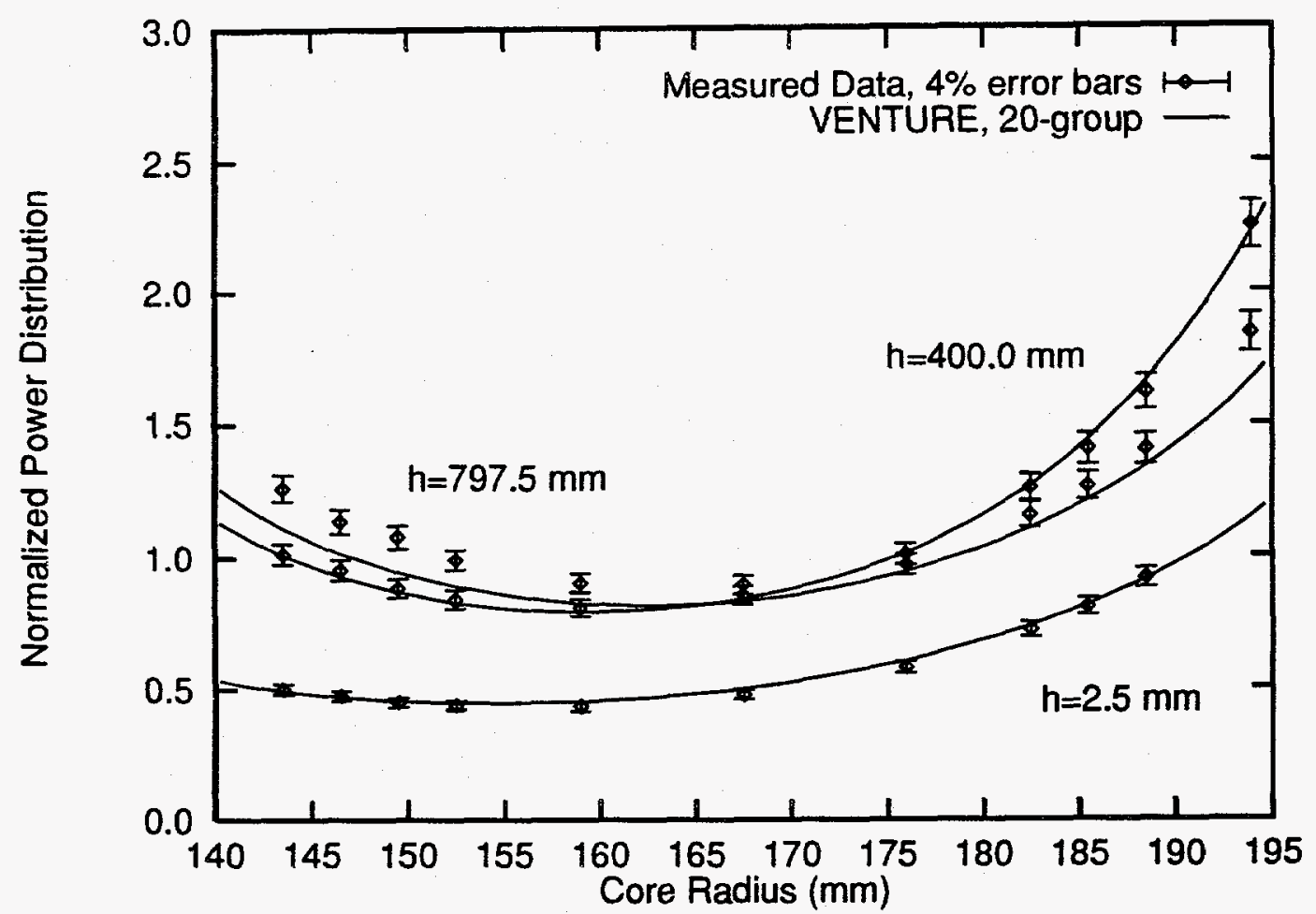

Fig. 4.19. Comparison of experimental radial power density traces and VENTURE values calculated using 20-group cross sections for the intermediate FOEHN configuration.

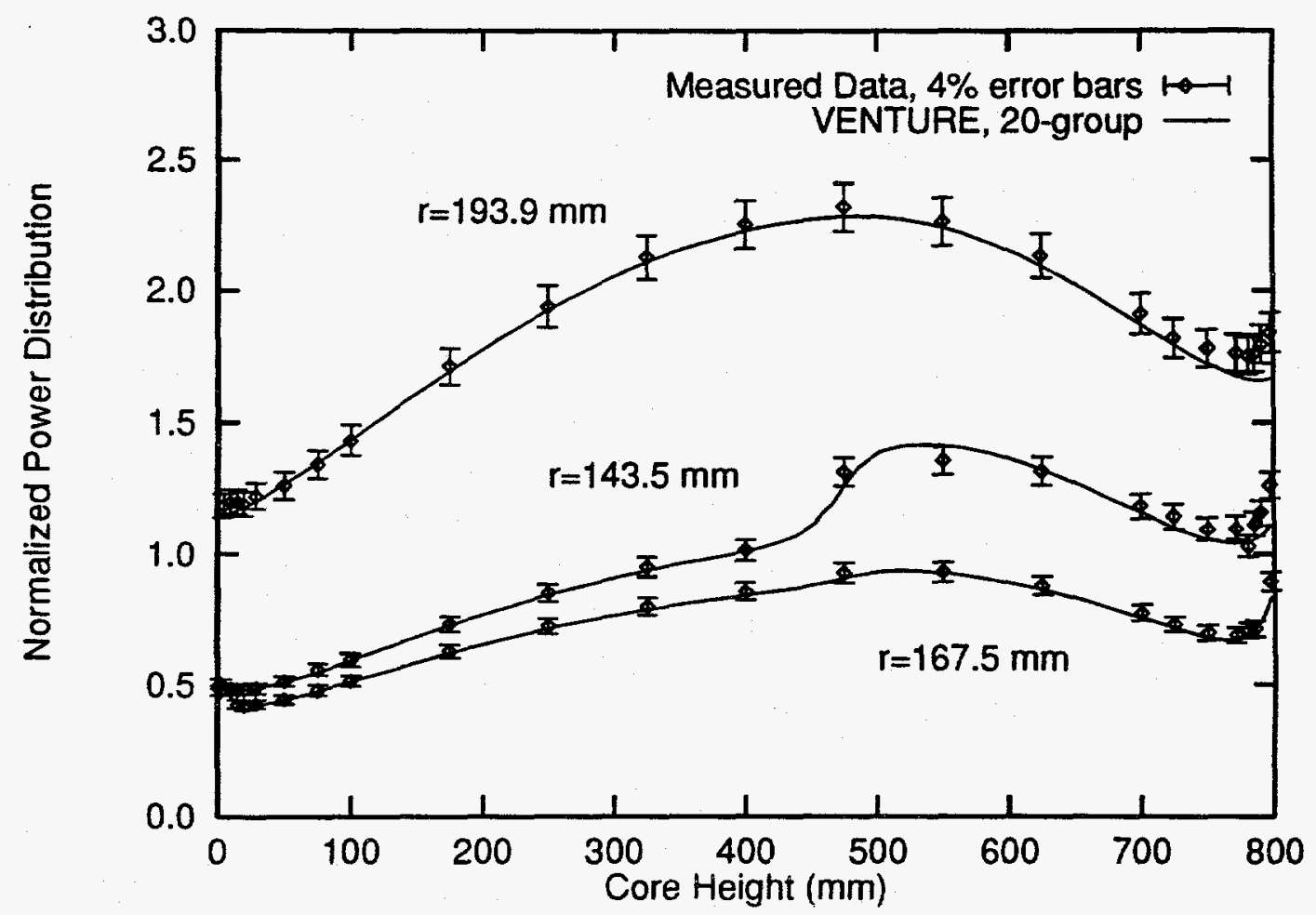

Fig. 4.20. Comparison of experimental axial power density traces and VENTURE values calculated using 20-group cross sections for the intermediate FOEHN configuration. 
Table 4.16. Rendement values calculated for the intermediate FOEHN configuration

\begin{tabular}{ccc}
\hline Computer code & $\begin{array}{c}\text { Rendement } \\
\text { neutrons } /\left(\mathrm{m}^{2} \mathrm{~s} \mathrm{~W}\right)\end{array}$ & $\begin{array}{c}\text { Percent } \\
\text { difference }\end{array}$ \\
\hline DORT & 2.7954 & 9.19 \\
VENTURE & 2.7090 & 5.82 \\
\hline
\end{tabular}

\subsubsection{Thermal Flux}

Thermal flux values were measured for case 2 of Table 4.10. Tables 4.17 and 4.18 show the differences between the measured results and values calculated with DORT and VENTURE, respectively. The average difference for the DORT values is $6.27 \%$. For the VENTURE values, the average difference is $4.46 \%$. Figures $4.21-4.24$ show radial and axial thermal flux traces comparing the measured and calculated values. As with the simple configuration, the calculated flux values overestimate the measured values near the peak in the reflector. Again, the diffusion theory results were not expected to show better agreement with the measured values than the transport theory results; the reason for this occurrence remains to be investigated. 
Table 4.17. Percent differences between measured thermal fluxes and values calculated with DORT using 20-group cross sections for the intermediate FOEHN configuration

\begin{tabular}{|c|c|c|c|c|c|c|c|c|c|c|c|c|c|c|}
\hline $\mathrm{H} / \mathrm{r}(\mathrm{mm})$ & 235 & 275 & 315 & 335 & 355 & 375 & 395 & 435 & 515 & 675 & 755 & 835 & 915 & 955 \\
\hline 1810 & -6.18 & -2.79 & 0.46 & & 2.62 & & & & & & & & & \\
\hline 1710 & -8.69 & -1.68 & 0.75 & & 3.91 & & 3.89 & & & & & & & \\
\hline 1610 & -0.95 & 2.40 & 3.54 & & 4.93 & & 5.24 & 6.37 & & & & 3.60 & & \\
\hline 1510 & -0.16 & 3.37 & 4.36 & & 5.57 & & 5.37 & 7.97 & & & 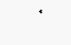 & 4.91 & & \\
\hline 1410 & 1.14 & 5.29 & 6.14 & & 8.00 & 8.25 & 7.26 & 8.84 & 8.53 & & & 5.36 & & \\
\hline 1310 & 2.39 & 6.68 & 6.62 & & 7.65 & 8.98 & 7.34 & 9.24 & 9.16 & 6.72 & 6.13 & 5.55 & & \\
\hline 1200 & & & & 8.68 & 6.99 & 8.27 & 7.88 & & & & & & & \\
\hline 1210 & 1.50 & 6.07 & 6.80 & 8.29 & 7.95 & 8.53 & 8.26 & 8.31 & 9.18 & 7.36 & 6.75 & 5.67 & 2.31 & 2.73 \\
\hline 1160 & & & & 8.56 & 7.02 & 8.67 & 8.07 & & & & & & & \\
\hline 1110 & 1.21 & 6.26 & 6.99 & 8.02 & 8.48 & 8.19 & 8.53 & 8.21 & 9.38 & 7.63 & 6.45 & 5.65 & 2.31 & 2.04 \\
\hline 1060 & & & & 8.29 & & 8.47 & & & & & & & & \\
\hline 1010 & 1.73 & 6.39 & 8.05 & 8.15 & 7.78 & 7.78 & 7.75 & 8.17 & 8.78 & 7.74 & 6.02 & 6.09 & 3.38 & 2.04 \\
\hline 910 & 0.13 & 6.13 & 6.67 & & 7.65 & 8.22 & 7.80 & 7.09 & 8.54 & 7.91 & 6.21 & 6.01 & & \\
\hline 810 & 1.19 & 7.22 & 7.12 & & 7.29 & & 8.25 & 9.01 & 8.64 & 7.01 & 6.76 & 3.7 & & \\
\hline 710 & 1.71 & 6.72 & 7.40 & & 7.74 & & & 7.99 & 8.79 & & & & 5.75 & \\
\hline 610 & -0.45 & 4.89 & 7.51 & & 8.44 & & & 10.13 & & & & & & \\
\hline 510 & 5.78 & 8.05 & 10.48 & & 10.26 & & & & & & & & & \\
\hline
\end{tabular}

Table 4.18. Percent differences between measured thermal fluxes and values calculated with VENTURE using

\begin{tabular}{|c|c|c|c|c|c|c|c|c|c|c|c|c|c|c|}
\hline $\mathrm{H} / \mathrm{s}(\mathrm{mm})$ & 235 & 275 & 315 & 335 & 335 & 375 & 395 & 435 & 515 & 675 & 755 & 835 & 915 & 955 \\
\hline 1810 & -8.45 & -5.06 & -1.83 & & 0.33 & & & & & & & & & \\
\hline 1710 & -12.04 & -4.84 & -2.12 & & 1.19 & & 1.32 & & & & & & & \\
\hline 1610 & -7.24 & -2.20 & -0.14 & & 1.77 & & 2.41 & 3.71 & & & & 1.94 & & \\
\hline 1510 & -7.80 & -1.96 & 0.29 & & 2.21 & & 2.46 & 3.26 & & & & 3.08 & & \\
\hline 1410 & -6.48 & -0.27 & 1.92 & & 4.35 & 5.07 & 4.33 & 6.17 & 6.09 & & & 3.43 & & \\
\hline 1310 & -5.46 & 1.01 & 2.40 & & 4.28 & 5.87 & 4.19 & 6.66 & 6.80 & 4.49 & 4.00 & 3.58 & & \\
\hline 1260 & & & & 4.96 & 3.71 & 5.25 & 5.09 & & & & & & & \\
\hline 1210 & -6.12 & 0.61 & 2.74 & 4.67 & 4.72 & 5.58 & 5.53 & 3.89 & 6.92 & 5.15 & 4.63 & 3.69 & 0.54 & 1.04 \\
\hline 1160 & & & & 5.04 & 3.92 & 5.81 & 5.43 & & & & & & & \\
\hline 1110 & -5.97 & 1.11 & 3.19 & 4.65 & 5.46 & 5.45 & 5.99 & 5.95 & 7.24 & 5.49 & 4.39 & 3.71 & 0.56 & 0.37 \\
\hline 1050 & & & & 5.06 & & 5.84 & & & & & & & & \\
\hline 1010 & -5.14 & 1.55 & 4.47 & 5.03 & 5.02 & 5.27 & 5.43 & 6.09 & 6.80 & 5.69 & 4.05 & 4.21 & 1.68 & 0.42 \\
\hline 910 & -6.30 & 1.59 & 3.40 & & 5.10 & 5.90 & 5.67 & 5.19 & 6.69 & 5.96 & 4.33 & 4.22 & & \\
\hline 810 & -4.88 & 2.97 & 4.10 & & 4.96 & & 6.27 & 7.20 & 6.89 & 5.19 & 4.99 & 4.11 & & \\
\hline 710 & -4.32 & 2.82 & 4.64 & & 5.59 & & 6.15 & 7.08 & & & & 4.24 & & \\
\hline 610 & -5.54 & 1.61 & 5.10 & & 6.47 & & 8.36 & & & & & & & \\
\hline 510 & 2.43 & 5.63 & 8.50 & & 8.51 & & & & & & & & & \\
\hline
\end{tabular}




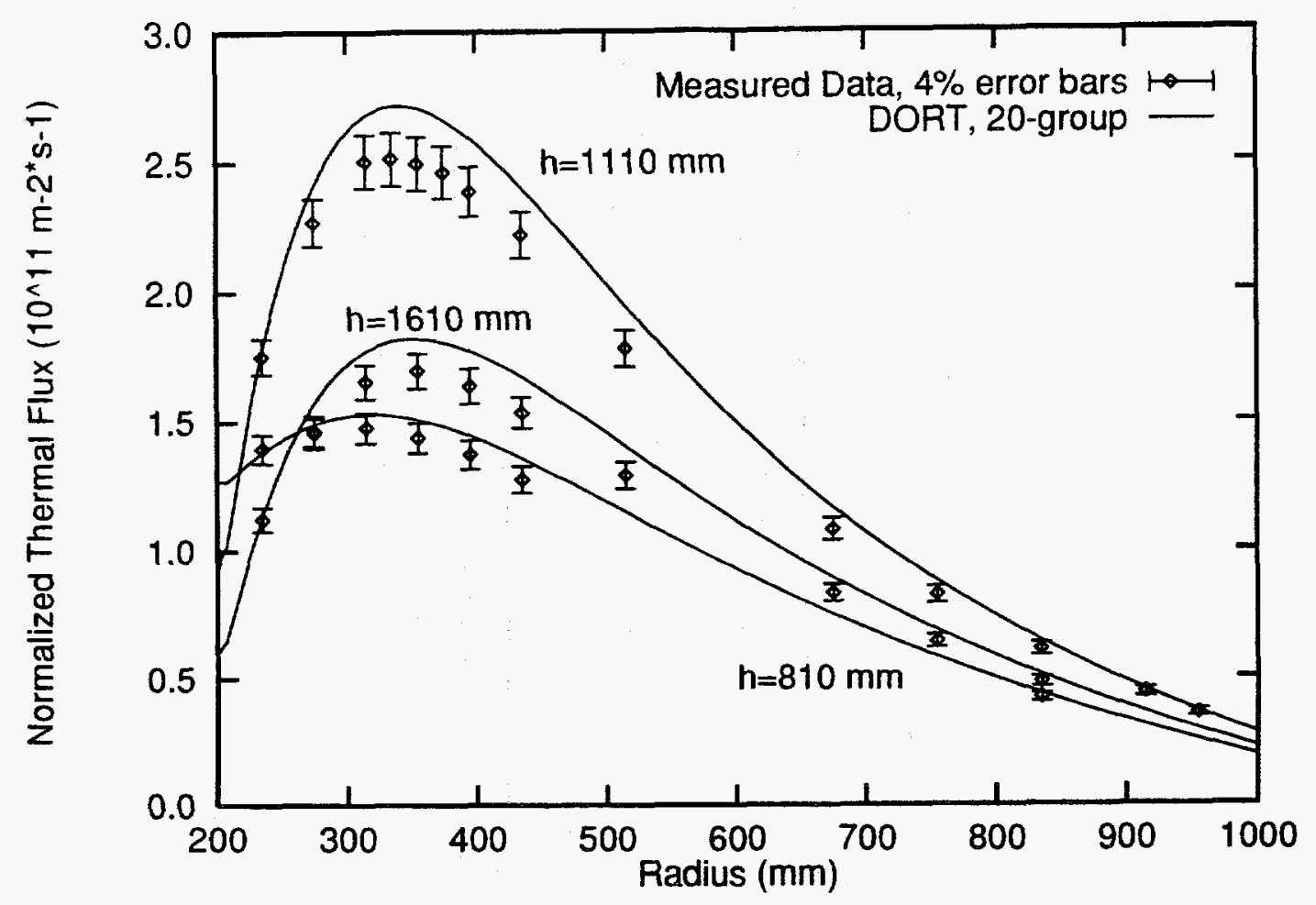

Fig. 4.21. Comparison of experimental radial thermal flux traces with DORT values calculated using 20-group cross sections for the intermediate FOEHN configuration.

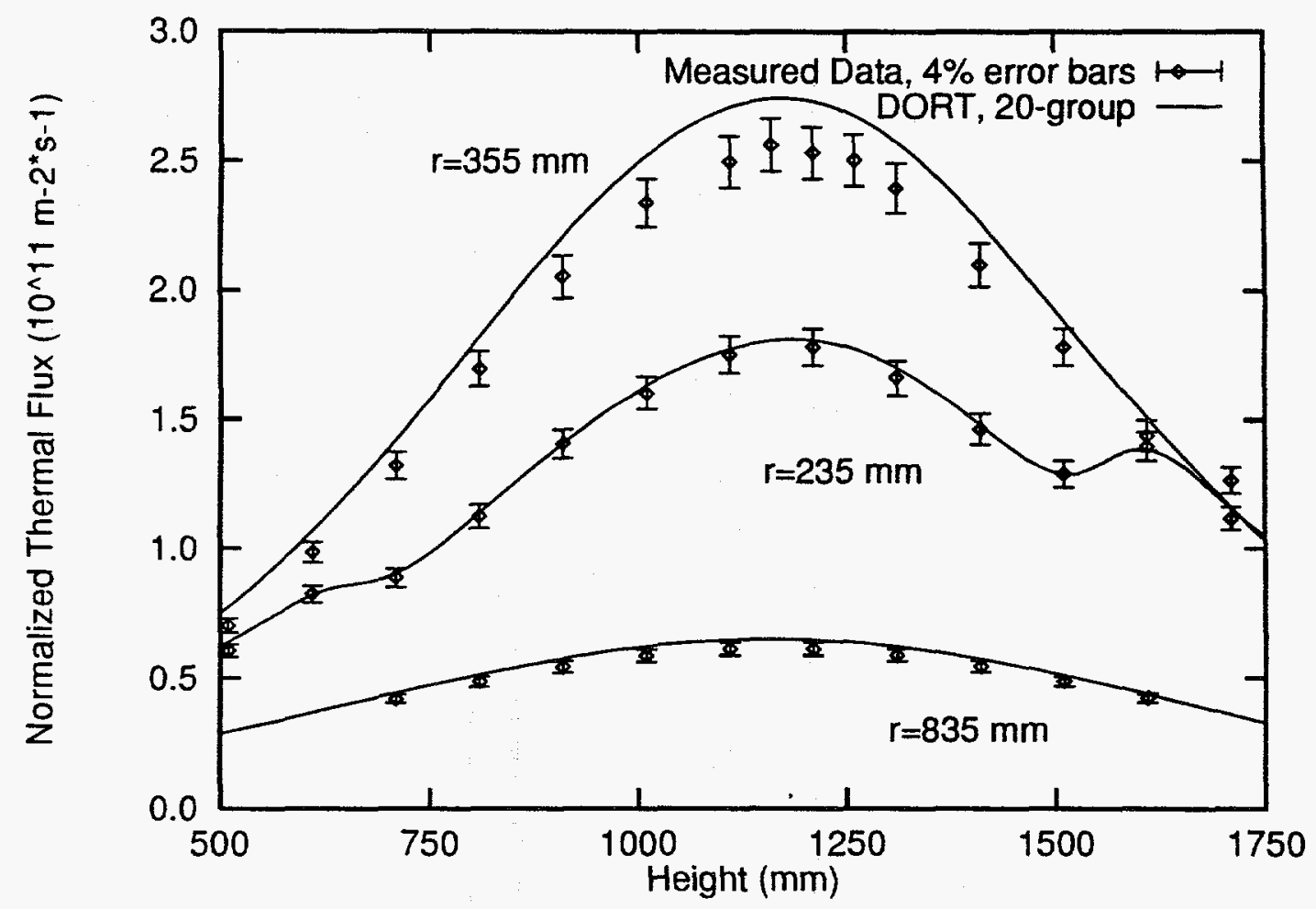

Fig. 4.22. Comparison of experimental axial thermal flux traces with DORT values calculated using 20-group cross sections for the intermediate FOEHN configuration. 


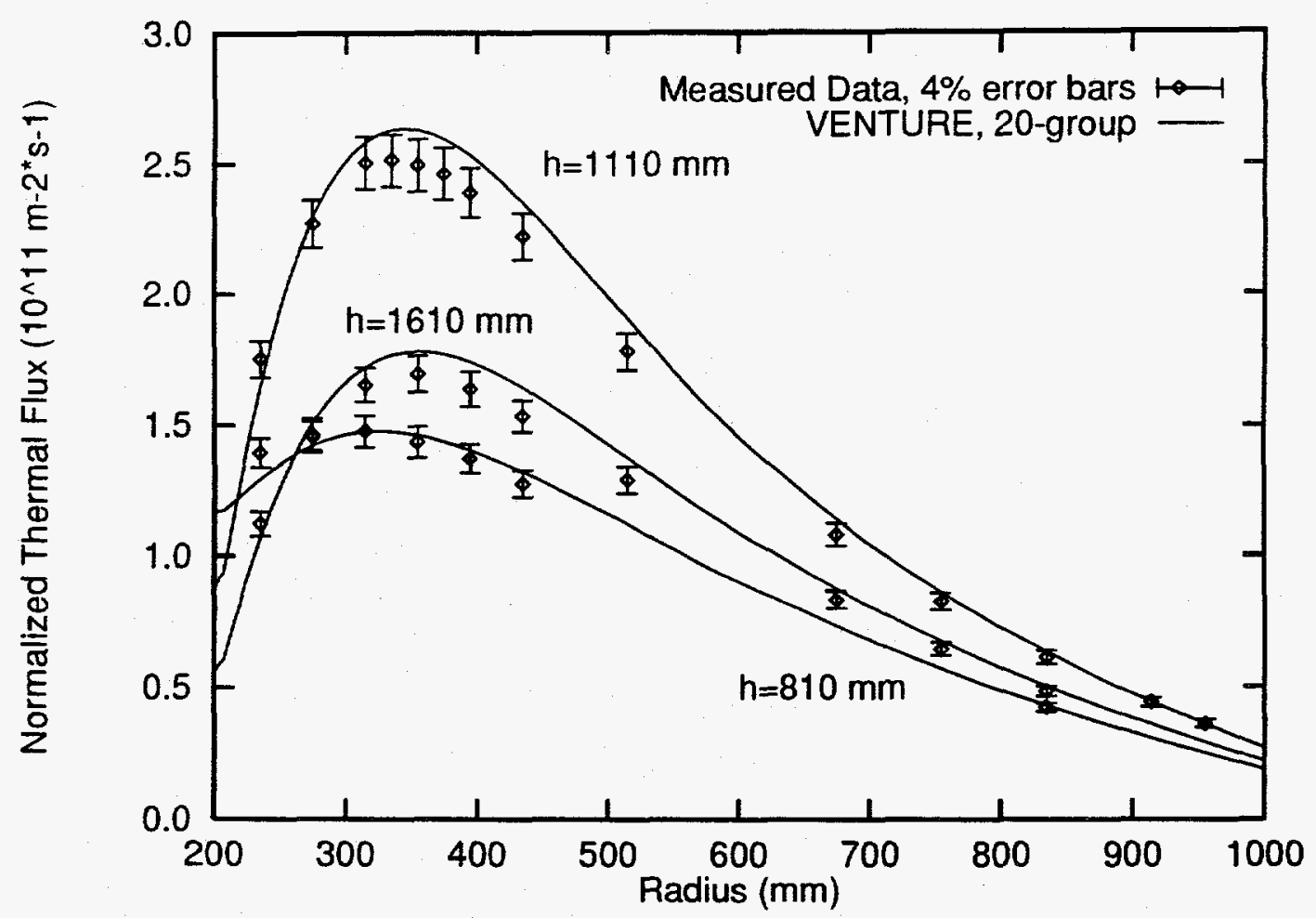

Fig. 4.23. Comparison of experimental radial thermal flux traces with VENTURE values calculated using 20-group cross sections for the intermediate FOEHN configuration.

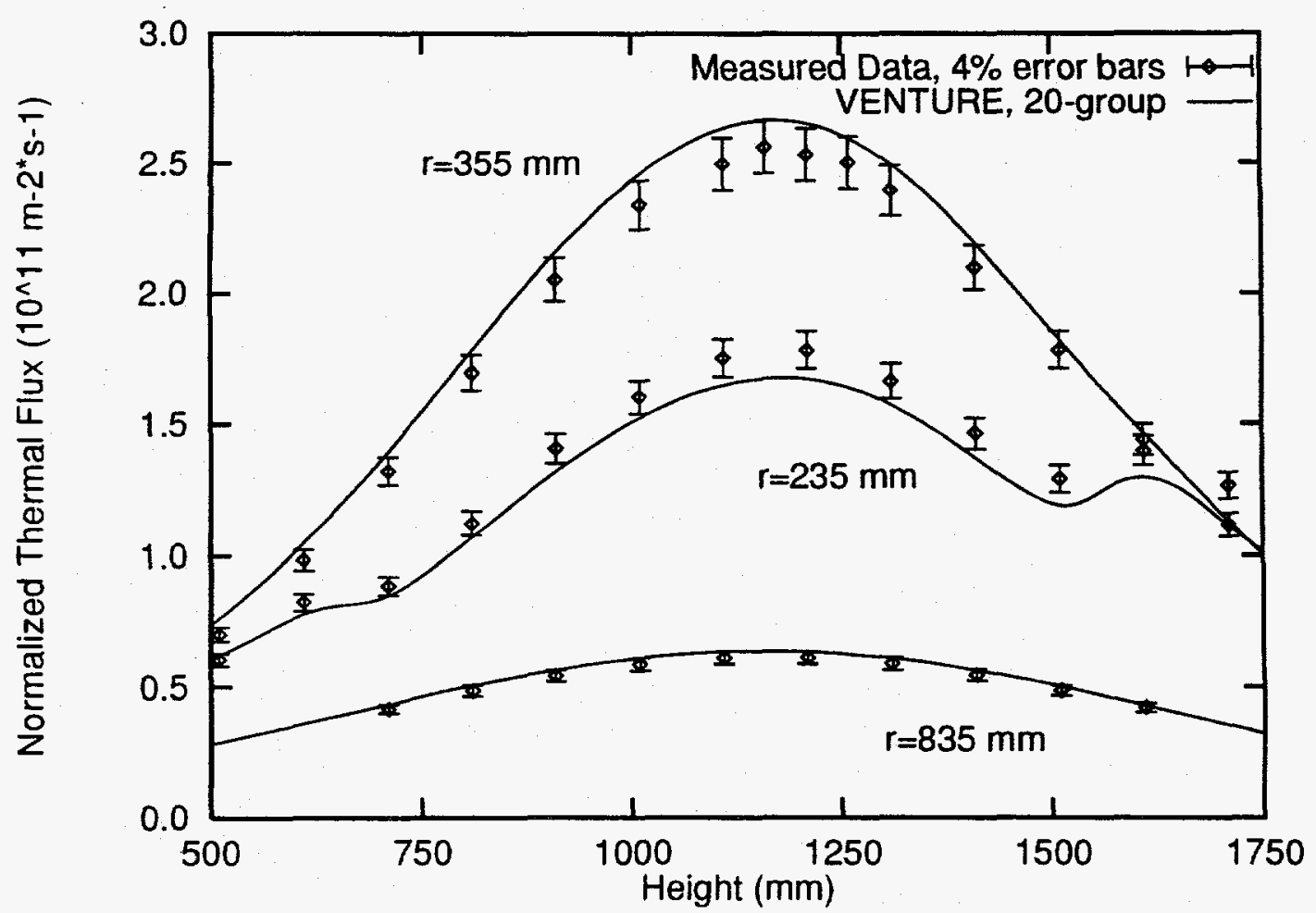

Fig. 4.24. Comparison of experimental axial thermal fux traces with VENTURE values calculated using 20-group cross sections for the intermediate FOEHN configuration. 


\subsection{COMPLEX CONFIGURATION}

\subsubsection{Multiplication Factors}

Three different complex FOEHN configuration models were evaluated. The eigenvalue results are shown in Tables 4.19-4.21. The results are shown graphically in Figs. 4.25-4.30. The smeared model with void in the reflector components overestimates the critical states by approximately $1.6 \%$. The streaming effects of the void regions cannot be correctly treated in the smeared $\mathrm{R}-\mathrm{Z}$ model.

The models that have aluminum in the void region of the reflector components and a constant aluminum density in the reflector were forced to yield $k_{\text {eff }}$ values near unity. These corrected models demonstrate methods of obtaining equivalent reflector component models. The comparisons with the measured critical states and power distributions will indicate how well such a model will perform under varying conditions. For both models, the amount of aluminum in the reflector was adjusted until the $k_{\text {eff }}$ value calculated with KENO using 99-group cross sections was within two sigma of unity for the case with the control element at $804 \mathrm{~mm}$ and a boron concentration of $0.347 \mathrm{~g}{ }^{10} \mathrm{~B} / \mathrm{L}$. The density of the aluminum in the void regions was determined to be $1.08 \mathrm{~g} / \mathrm{cm}^{3}$, or $40 \%$ of $2.7 \mathrm{~g} / \mathrm{cm}^{3}$ (the density of pure aluminum). The aluminum density that yields a multiplication factor near unity for the model with a constant aluminum density in the reflector is $0.0567 \mathrm{~g} / \mathrm{cm}^{3}$, or $2.1 \%$ of $2.7 \mathrm{~g} / \mathrm{cm}^{3}$.

For the two corrected models, all of the KENO 99-group eigenvalues are within three sigma of unity. Three of the values are just outside two sigma of unity. The results for the corrected models using 20 -group calculations overestimate unity by 0.03 to $0.05 \%$. The average multiplication factor obtained in the analysis of the complex configuration using an explicit representation of the reflector components is $0.9923 \pm 0.0021 .^{13}$

\subsubsection{Power Distributions}

Power distributions were measured with the control element positioned at $471 \mathrm{~mm}$ and the dissolved boron concentration equal to $0.177 \mathrm{~g}{ }^{10} \mathrm{~B} / \mathrm{L}$. Table 4.22 shows the average and maximum differences between the calculated and measured values. The average values calculated without including the points at the upper and lower edges of the fuel element are also included. Tables 4.23-4.28 show the differences between the measured and calculated values. Figs. 4.31-4.34 show radial and axial traces of the DORT and VENTURE calculated and the measured power density values. The figures show that the distributions calculated with the three different models vary only slightly at the outer edge of the fuel element $(r=193.9 \mathrm{~mm})$.

\subsubsection{Rendement}

The rendement was calculated using the peak thermal flux from the DORT and VENTURE calculations. The measured rendement is $2.30 \times 10^{11}$ neutrons $/\left(\mathrm{m}^{2} \mathrm{~s} \mathrm{~W}\right)$. Table 4.29 shows the calculated values. The model with void in the reflector components yields the largest rendement. The values calculated using VENTURE are smaller than the DORT results. These results are slightly larger than the rendement obtained in ref. 9 which is $4.84 \%$ higher than the measured value. The complex FOEHN configuration model for the calculations in ref. 9 included explicit reflector components. 
Table 4.19. Comparison of eigenvalues for the complex FOEHN configuration cases using different calculational methods with void in the reflector components

\begin{tabular}{|c|c|c|c|c|c|c|}
\hline \multirow[t]{2}{*}{ Case } & \multirow{2}{*}{$\begin{array}{c}\text { Control } \\
\text { element } \\
\text { position } \\
(\mathrm{mm})\end{array}$} & \multirow{2}{*}{$\begin{array}{c}\text { Boron-10 } \\
\text { concentration } \\
\left(g{ }^{10} \mathrm{~B} / \mathrm{L}\right)\end{array}$} & \multicolumn{2}{|c|}{ KENO } & \multirow{2}{*}{$\begin{array}{c}\text { DORT } \\
20 \text {-group }\end{array}$} & \multirow{2}{*}{$\begin{array}{l}\text { VENTURE } \\
20 \text {-group }\end{array}$} \\
\hline & & & 99-group & 20-group & & \\
\hline 1 & 804 & 0.347 & $1.0166 \pm 0.0045$ & $1.0176 \pm 0.0046$ & 1.0175 & 1.0173 \\
\hline 2 & 711 & 0.311 & $1.0146 \pm 0.0049$ & $1.0234 \pm 0.0046$ & 1.0212 & 1.0208 \\
\hline 3 & 596 & 0.260 & $1.0167 \pm 0.0048$ & $1.0226 \pm 0.0049$ & 1.0212 & 1.0217 \\
\hline 4 & 579 & 0.248 & $1.0209 \pm 0.0048$ & $1.0219 \pm 0.0049$ & 1.0216 & 1.0231 \\
\hline 5 & 503 & 0.210 & $1.0167 \pm 0.0046$ & $1.0179 \pm 0.0051$ & 1.0196 & 1.0217 \\
\hline 6 & 385 & 0.143 & $1.0154 \pm 0.0045$ & $1.0237 \pm 0.0049$ & 1.0172 & 1.0206 \\
\hline 7 & 249 & 0.078 & $1.0124 \pm 0.0050$ & $1.0162 \pm 0.0051$ & 1.0150 & 1.0189 \\
\hline Average & - & - & $1.0162 \pm 0.0018$ & $1.0205 \pm 0.0018$ & 1.0190 & 1.0206 \\
\hline
\end{tabular}

Table 4.20. Comparison of eigenvalues for the complex FOEHN configuration cases using different calculational methods with aluminum in the void regions of the reflector components

\begin{tabular}{|c|c|c|c|c|c|c|}
\hline \multirow[t]{2}{*}{ Case } & \multirow{2}{*}{$\begin{array}{l}\text { Control } \\
\text { clement } \\
\text { position } \\
(\mathrm{mm})\end{array}$} & \multirow{2}{*}{$\begin{array}{c}\text { Boron-10 } \\
\text { concentration } \\
\left(\mathrm{g}^{10} \mathrm{~B} / \mathrm{L}\right)\end{array}$} & \multicolumn{2}{|c|}{ KENO } & \multirow{2}{*}{$\begin{array}{c}\text { DORT } \\
\text { 20-group }\end{array}$} & \multirow{2}{*}{$\begin{array}{l}\text { VENTURE } \\
\text { 20-group }\end{array}$} \\
\hline & & & 99-group & 20-group & & \\
\hline 1 & 804 & 0.347 & $0.9971 \pm 0.0047$ & $0.9996 \pm 0.0051$ & 1.0033 & 1.0016 \\
\hline 2 & 711 & 0.311 & $1.0045 \pm 0.0049$ & $1.0060 \pm 0.0048$ & 1.0049 & 1.0049 \\
\hline 3 & 596 & 0.260 & $1.0022 \pm 0.0045$ & $1.0048 \pm 0.0045$ & 1.0033 & 1.0053 \\
\hline 4 & 579 & 0.248 & $1.0009 \pm 0.0046$ & $1.0101 \pm 0.0045$ & 1.0101 & 1.0066 \\
\hline 5 & 503 & 0.210 & $1.0015 \pm 0.0048$ & $1.0029 \pm 0.0050$ & 1.0028 & 1.0049 \\
\hline 6 & 385 & 0.143 & $0.9947 \pm 0.0050$ & $1.0061 \pm 0.0048$ & 1.0002 & 1.0031 \\
\hline 7 & 249 & 0.078 & $0.9943 \pm 0.0050$ & $0.9997 \pm 0.0052$ & 0.9965 & 1.0007 \\
\hline Average & - & - & $0.9993 \pm 0.0018$ & $1.0042 \pm 0.0018$ & 1.0030 & 1.0039 \\
\hline
\end{tabular}


Table 4.21. Comparison of eigenvalues for the complex FOEHN configuration cases using different calculational methods with a constant aluminum density in the reflector

\begin{tabular}{|c|c|c|c|c|c|c|}
\hline \multirow[t]{2}{*}{ Case } & \multirow{2}{*}{$\begin{array}{c}\text { Control } \\
\text { element } \\
\text { position } \\
(\mathrm{mm})\end{array}$} & \multirow{2}{*}{$\begin{array}{c}\text { Boron-10 } \\
\text { concentration } \\
\left(\mathrm{g}{ }^{10} \mathrm{~B} / \mathrm{L}\right)\end{array}$} & \multicolumn{2}{|c|}{ KENO } & \multirow{2}{*}{$\begin{array}{c}\text { DORT } \\
20 \text {-group }\end{array}$} & \multirow{2}{*}{$\begin{array}{l}\text { VENTURE } \\
\text { 20-group }\end{array}$} \\
\hline & & & 99-group & 20-group & & \\
\hline 1 & 804 & 0.347 & $0.9987 \pm 0.0047$ & $1.0005 \pm 0.0052$ & 1.0031 & 1.0022 \\
\hline 2 & 711 & 0.311 & $0.9978 \pm 0.0052$ & $1.0056 \pm 0.0050$ & 1.0068 & 1.0057 \\
\hline 3 & 596 & 0.260 & $1.0013 \pm 0.0047$ & $1.0064 \pm 0.0044$ & 1.0048 & 1.0063 \\
\hline 5 & 503 & 0.210 & $1.0008 \pm 0.0050$ & $1.0049 \pm 0.0051$ & 1.0053 & 1.0059 \\
\hline 6 & 385 & 0.143 & $0.9997 \pm 0.0046$ & $1.0011 \pm 0.0046$ & 1.0013 & 1.0041 \\
\hline 7 & 249 & 0.078 & $0.9946 \pm 0.0050$ & $0.9974 \pm 0.0054$ & 0.9971 & 1.0013 \\
\hline Average & - & - & $0.9996 \pm 0.0018$ & $1.0030 \pm 0.0019$ & 1.0035 & 1.0047 \\
\hline
\end{tabular}

Table 4.22. Average and maximum power density percent differences for

\begin{tabular}{lccc}
\hline & Model & Computer code & \multicolumn{2}{c}{ Percent difference } \\
\cline { 3 - 4 } & & Average $^{a}$ & Maxinum $^{b}$ \\
\hline Void in the reflector components & DORT & $4.82(2.92)$ & $-23.17(-12.28)$ \\
& VENTURE & $3.37(2.91)$ & $-15.42(-8.39)$ \\
Aluminum in the void regions of the & DORT & $5.11(3.15)$ & $-22.90(-12.98)$ \\
reflector components & VENTURE & $3.51(2.96)$ & $-14.88(-8.06)$ \\
Constant aluminum density in the & DORT & $5.74(3.73)$ & $-22.57(-15.11)$ \\
reflector & VENTURE & $4.12(3.45)$ & $-14.72(-10.27)$ \\
\hline
\end{tabular}

a The average values in parentheses were calculated without including the points at the upper and lower edges of the fuel element (see Sect. 2.5.2).

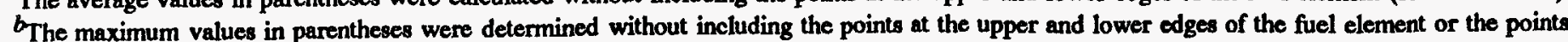
at the inner edge of the fuel element near the tip of the control element (see Sects. 2.4.1 and 2.5.2). 


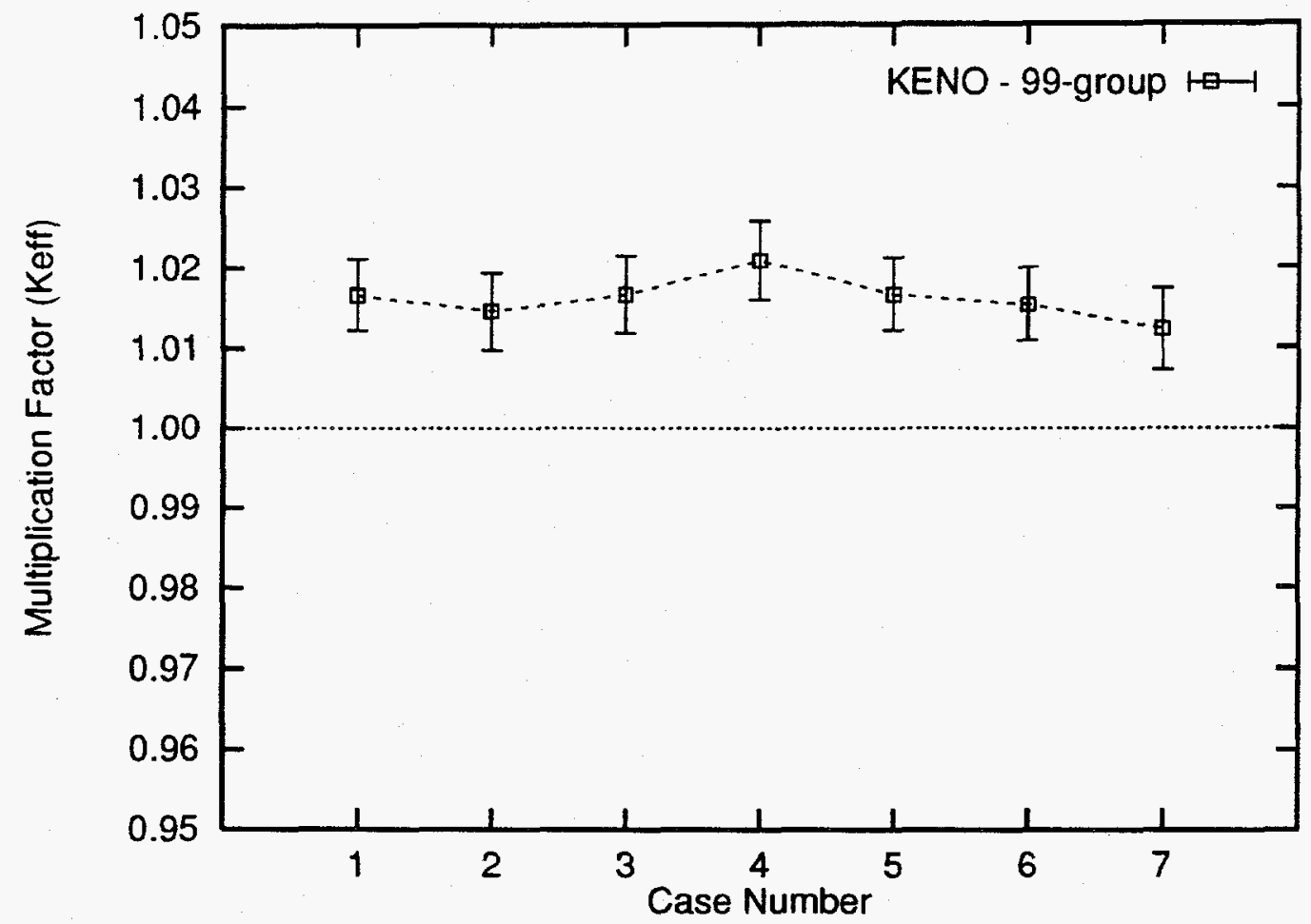

Fig. 4.25. $K_{\text {eg }}$ values for the complex FOEHN configuration calculated with KENO using 99-group cross sections and void in the reflector components.

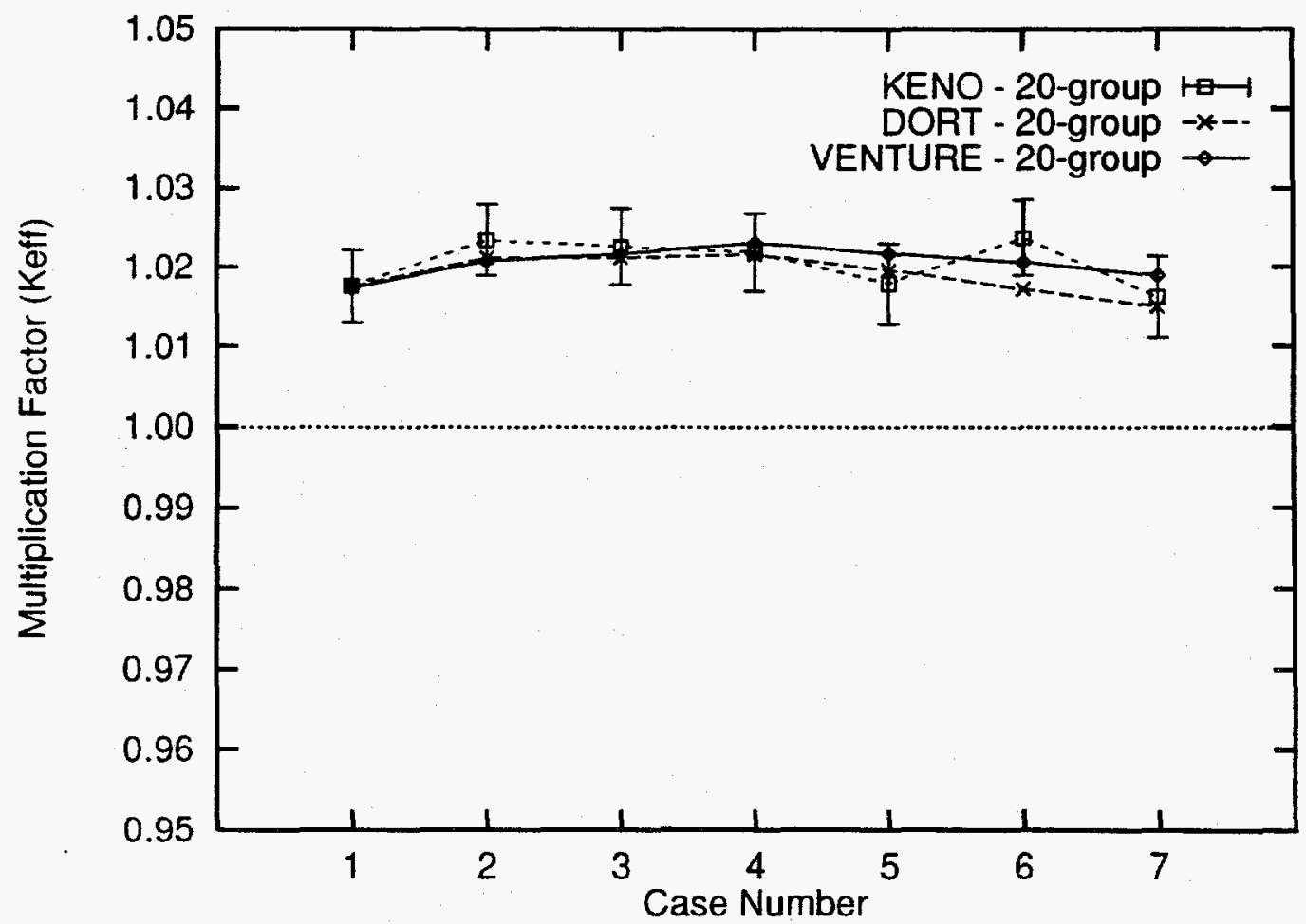

Fig. 4.26. Comparison of $k_{e f f}$ values for the complex FOEHN configuration calculated with different computer codes using 20-group cross sections and void in the reflector components. 


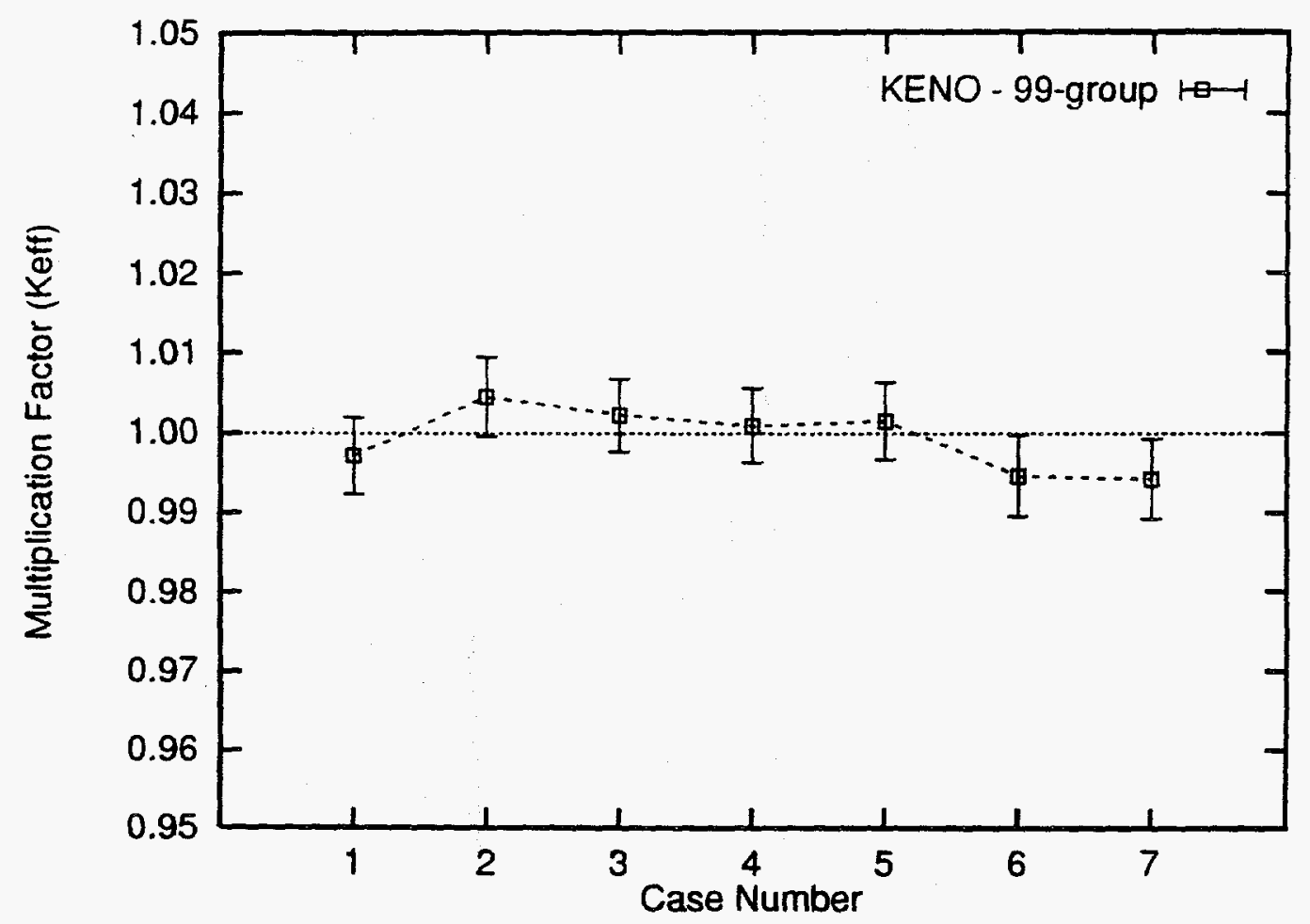

Fig. 4.27. $K_{\text {eff }}$ values for the complex FOEHN configuration calculated with KENO using 99-group cross sections and aluminum in the void regions of the reflector components.

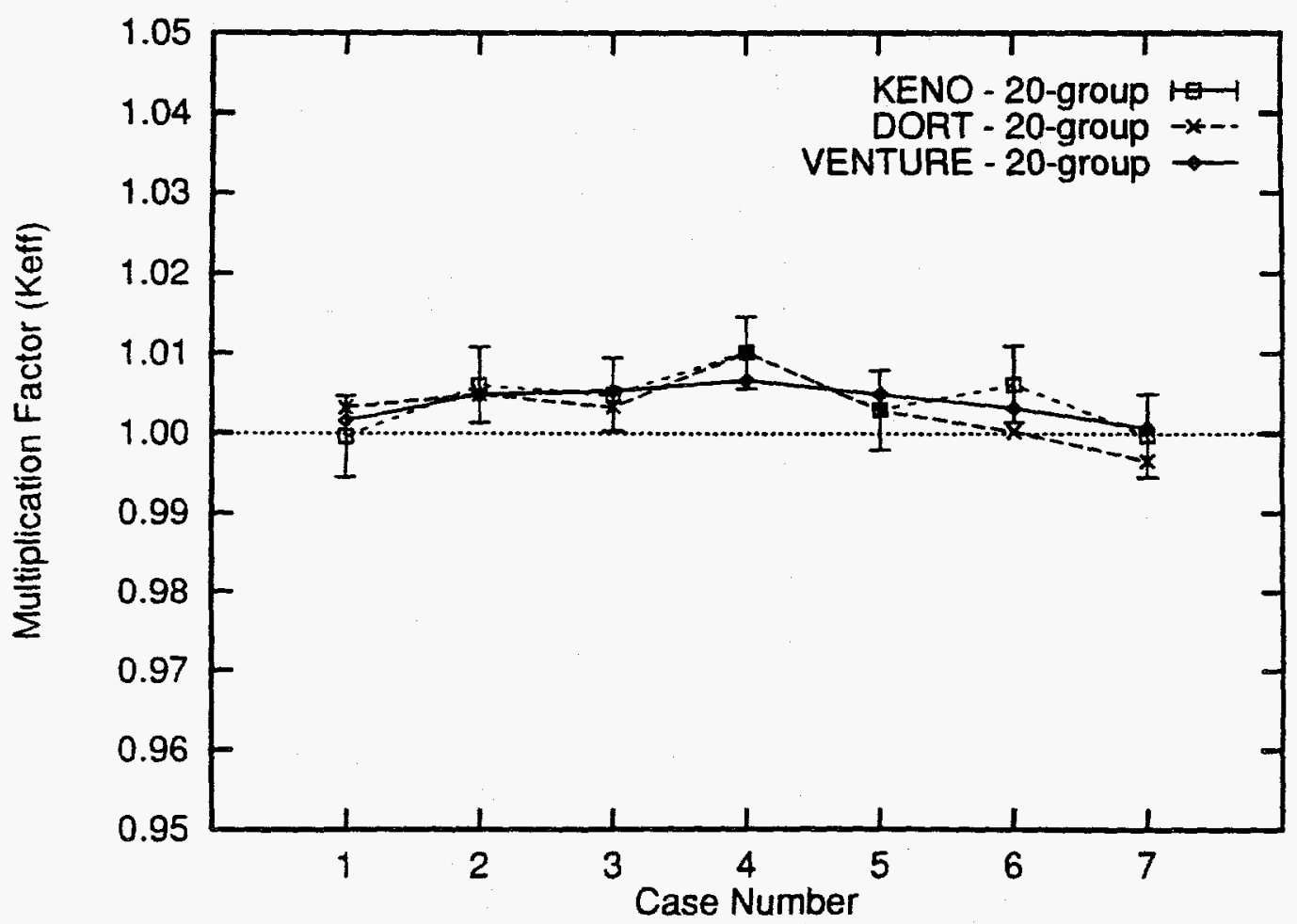

Fig. 4.28. Comparison of $k_{\text {eg }}$ values for the complex FOEHN configuration calculated with different computer codes using 20-group cross sections and aluminum in the void regions of the reflector components. 
53

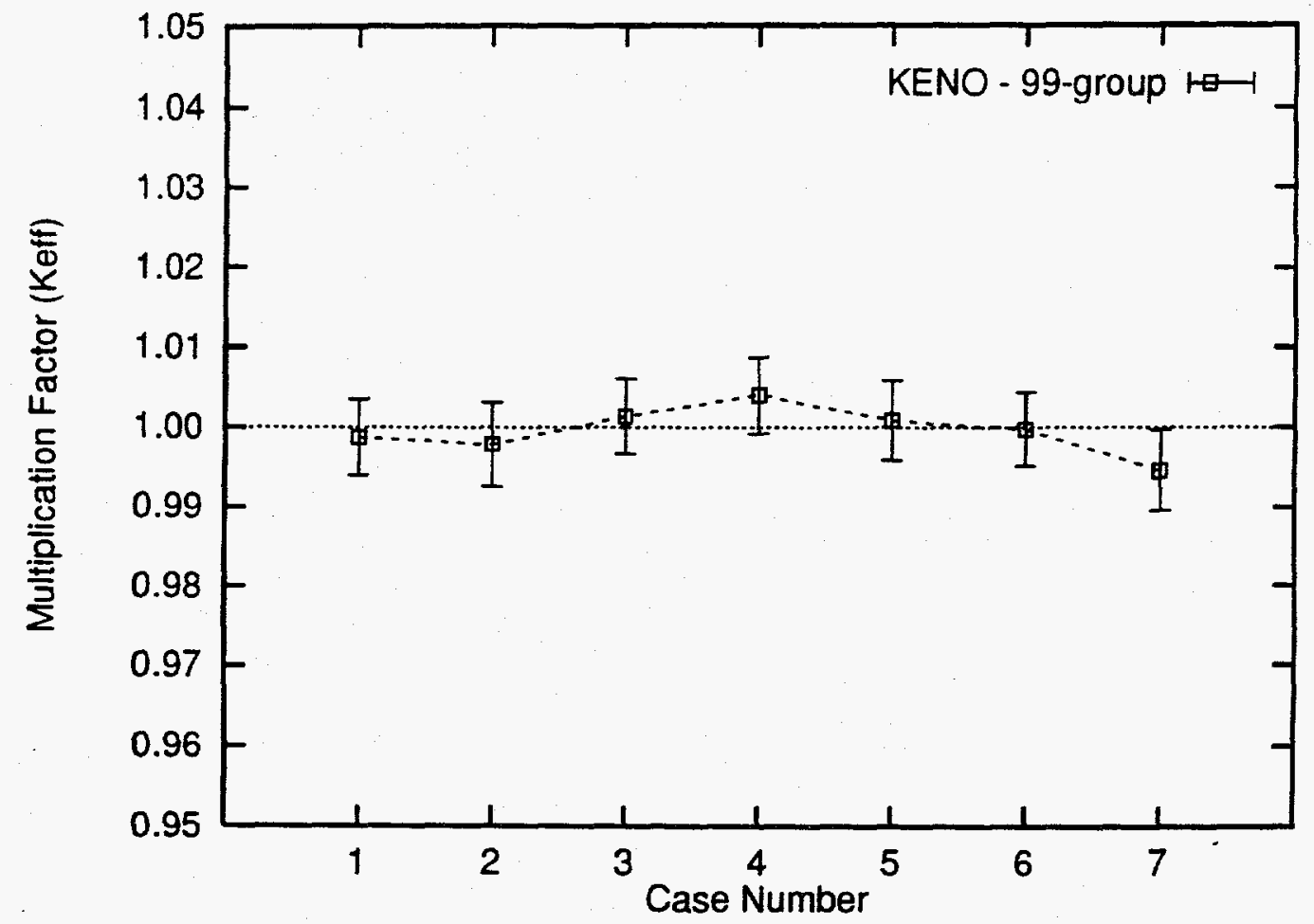

Fig. 4.29. $K_{a, g}$ values for the complex FOEHN configuration calculated with KENO using 99-group cross sections and a constant aluminum density in the reflector.

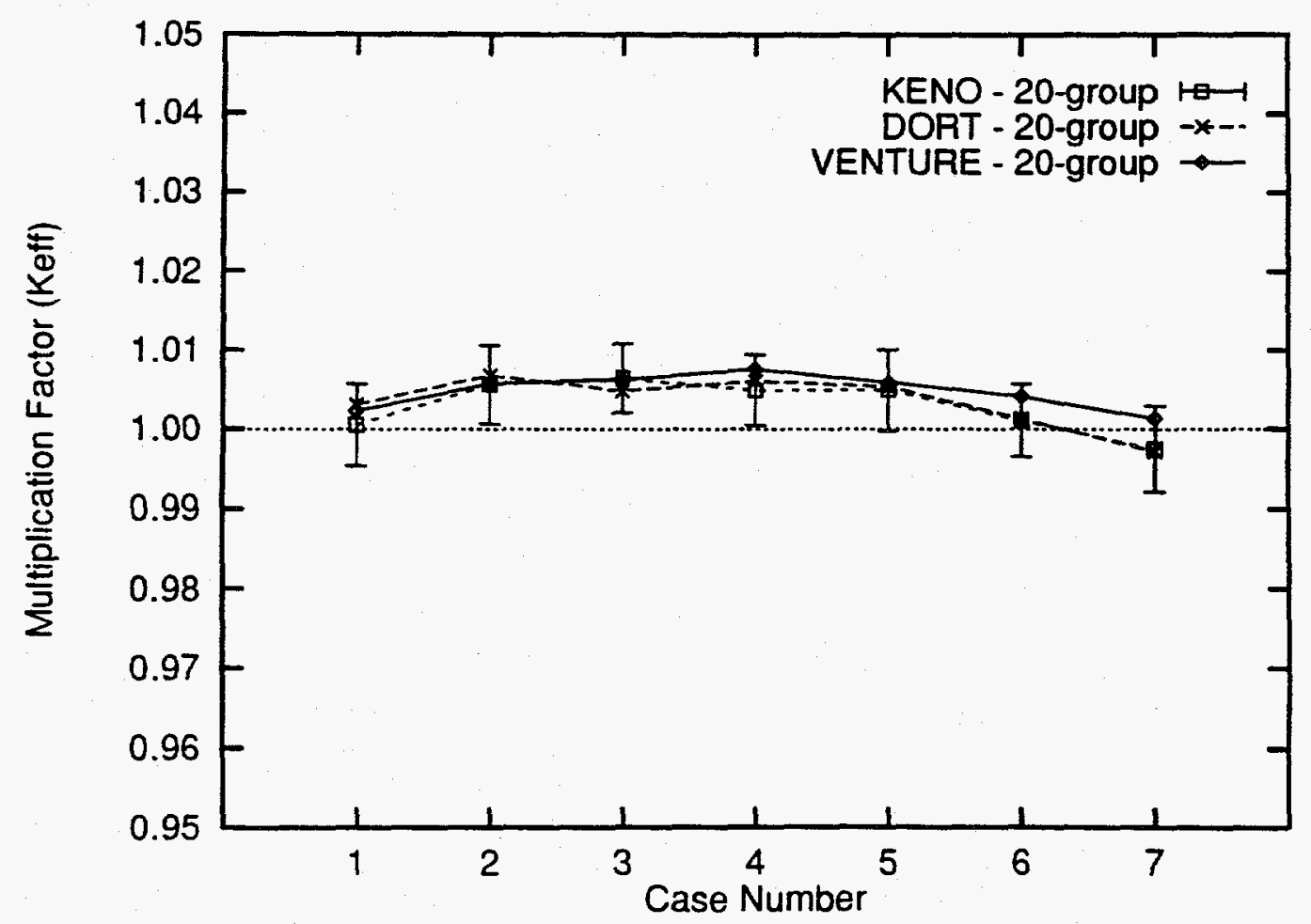

Fig. 4.30. Comparison of $k_{e g}$ values for the complex FOEHN configuration calculated with different computer codes using 20-group cross sections and a constant aluminum density in the reflector. 
Table 4.23. Percent differences between measured power densities and values calculated with DORT using 20-group cross sections for the complex FOEHN configuration with void in the reflector components

\begin{tabular}{|c|c|c|c|c|c|c|c|c|c|c|c|}
\hline $\mathrm{H} / \mathrm{t}(\mathbf{m})$ & 143.5 & 146.5 & 149.5 & 152.5 & 159.0 & 167.5 & 176.0 & 182.5 & 185.5 & 188.5 & 193.9 \\
\hline 791.5 & -16.12 & -17.67 & -19.83 & -23.17 & -21.86 & -16.99 & -15.68 & -15.55 & & -6.86 & -8.03 \\
\hline 795.0 & & & & & & & & & & & -3.71 \\
\hline 790.6 & -7.79 & & & & & & & & & & -3.05 \\
\hline 785.5 & -6.76 & & & & & -10.55 & & & & & -2.85 \\
\hline 700.6 & -7.30 & & & & & -10.68 & & & & & -1.75 \\
\hline$m . s$ & -5.07 & & & & & -2.07 & & & & & -0.69 \\
\hline 750.0 & -4.58 & -4.69 & -3.54 & -5.74 & -3.67 & -2.38 & -1.83 & -5.06 & -1.44 & -0.21 & -0.81 \\
\hline 75.0 & -3.74 & & & & & -1.43 & & & & & 0.69 \\
\hline 700.0 & -2.91 & & & & & -3.65 & & & & & 1.07 \\
\hline 625.0 & 0.35 & -1.15 & 0.14 & -1.74 & -1.71 & -0.81 & -1.11 & -2.66 & -1.47 & 0.62 & 1.41 \\
\hline 550.0 & 1.82 & & & & & 0.51 & & & & & 2.33 \\
\hline 475.0 & 8.13 & & & & & 1.16 & & & & & 2.73 \\
\hline 400.0 & 3.53 & 1.59 & 1.40 & -1.59 & -0.79 & -0.62 & -1.01 & -2.79 & -0.89 & 0.26 & 0.55 \\
\hline 325.0 & -0.79 & & & & & -1.55 & & & & & 1.13 \\
\hline 250.0 & -0.98 & & & & & -2.38 & & & & & -0.08 \\
\hline 175.0 & -1.56 & -2.19 & -3.34 & -4.44 & -2.67 & -2.81 & -3.38 & -4.01 & -3.89 & -2.80 & -1.19 \\
\hline 100.0 & -4.79 & & & & & -3.44 & & & & & -0.79 \\
\hline 75.0 & -0.81 & & & & & -4.89 & & & & & -1.29 \\
\hline So.0 & -2.10 & -2.06 & -5.47 & -5.27 & -4.50 & -4.40 & -4.63 & -2.90 & -3.41 & -2.56 & -0.89 \\
\hline 28.5 & -6.03 & & & & & -5.10 & & & & & -0.69 \\
\hline 19.4 & -6.45 & & & & & -7.79 & & & & & -1.56 \\
\hline 14.5 & -1.70 & & & & & -12.28 & & & & & -2.03 \\
\hline 9.4 & & & & & & & & & & & $-2 \pi$ \\
\hline 5.0 & & & & & & & & & & & -3.85 \\
\hline 2.5 & -10.70 & -11.74 & -13.91 & -15.82 & -15.69 & -14.71 & -13.74 & -12.99 & -10.98 & -8.45 & \\
\hline
\end{tabular}

Table 4.24. Percent differences between measured power densities and values calculated with DORT using 20-group cross sections for the complex FOEHN configuration with

aluminum in the void regions of the refluctor components

\begin{tabular}{|c|c|c|c|c|c|c|c|c|c|c|c|}
\hline$W / t(\operatorname{mm})$ & 143.5 & 146.5 & 149.5 & 152.5 & 159.0 & 167.5 & 176.0 & 182.5 & 185.5 & 188.5 & 193.9 \\
\hline 797.5 & -15.75 & -17.31 & -19.49 & -22.90 & -21.74 & -17.19 & -16.28 & -16.42 & & -8.09 & -9.43 \\
\hline 795.0 & & & & & & & & & & & -5.15 \\
\hline 790.6 & -7.27 & & & & & & & & & & -4.47 \\
\hline 785.5 & -6.17 & & & & & -10.56 & & & & & -4.25 \\
\hline 780.6 & -6.65 & & & & & -10.67 & & & & & -3.15 \\
\hline 771.5 & -4.27 & & & & & -1.97 & & & & & -2.08 \\
\hline 750.0 & -3.59 & -3.74 & -2.64 & -4.92 & -3.05 & -2.16 & -2.09 & -5.69 & -2.26 & -1.22 & -2.11 \\
\hline 725.0 & -2.60 & & & & & -1.09 & & & & & -0.54 \\
\hline 200.0 & -1.67 & & & & & -3.22 & & & & & -0.10 \\
\hline 625.0 & 1.78 & 0.23 & 1.47 & -0.51 & -0.71 & -0.21 & -1.01 & -2.96 & -1.96 & -0.06 & 0.40 \\
\hline 550.0 & 3.34 & & & & & 1.20 & & & & & 1.41 \\
\hline 475.0 & 9.74 & & & & & 1.85 & & & & & 1.85 \\
\hline 400.0 & 4.98 & 2.95 & 2.68 & -0.43 & 0.14 & -0.09 & -0.93 & -3.08 & -1.34 & -0.37 & -0.37 \\
\hline 325.0 & 0.48 & & & & & -1.15 & & & & & 0.11 \\
\hline 250.0 & 0.17 & & & & & -2.14 & & & & & -1.25 \\
\hline 175.0 & -0.59 & -1.30 & -2.55 & -3.75 & -2.22 & -2.79 & -3.81 & -4.80 & -4.83 & -3.91 & -2.60 \\
\hline 100.0 & -4.07 & & & & & -3.70 & & & & & -2.53 \\
\hline 75.0 & -0.15 & & & & & -5.26 & & & & & -3.14 \\
\hline 50.0 & -1.57 & -1.61 & -5.13 & -5.03 & -4.56 & -4.91 & -5.62 & -4.27 & -4.94 & -4.26 & -2.88 \\
\hline 28.5 & -5.65 & & & & & -5.74 & & & & & -2.81 \\
\hline 19.4 & -6.20 & & & & & -8.49 & & & & & -3.71 \\
\hline 14.5 & -1.50 & & & & & -12.98 & & & & & -4.20 \\
\hline 9.4 & & & & & & & & & & & -4.89 \\
\hline 5.0 & & & & & & & & & & & -6.04 \\
\hline 2.5 & -10.65 & -11.76 & -14.00 & -16.01 & -16.16 & -15.62 & -15.06 & -14.60 & -12.75 & -10.39 & \\
\hline
\end{tabular}


Table 4.25. Percent differences between measured power densities and values calculated with DORT using 20-group cross sections for the complex FOEHN configuration with

a constant aluminum density in the reflector

\begin{tabular}{|c|c|c|c|c|c|c|c|c|c|c|c|}
\hline$H_{r}(\operatorname{mon})$ & 143.5 & 146.5 & 149.5 & 152.5 & 159.0 & 167.5 & 176.0 & 182.5 & 185.5 & 188.5 & 193.9 \\
\hline 7975 & -15.44 & -17.00 & -19.17 & -22.57 & -21.39 & -16.79 & -15.82 & -15.93 & & -7.55 & -8.86 \\
\hline 795.0 & & & & & & & & & & & -4.52 \\
\hline 790.6 & -6.90 & & & & & & & & & & -3.79 \\
\hline 785.5 & -5.77 & & & & & -10.03 & & & & & -3.51 \\
\hline 780.6 & -6.24 & & & & & -10.11 & & & & & -2.35 \\
\hline 771.5 & -3.82 & & & & & -1.32 & & & & & -1.18 \\
\hline 750.0 & -3.09 & -3.22 & -2.09 & -4.37 & -2.43 & -1.42 & -1.24 & -4.79 & -1.30 & -0.20 & -1.04 \\
\hline 725.0 & -2.07 & & & & & -0.27 & & & & & 0.70 \\
\hline$x 00.0$ & -1.12 & & & & & -2.40 & & & & & 1.25 \\
\hline 625.0 & 2.31 & 0.76 & 2.04 & 0.08 & -0.03 & 0.63 & -0.01 & -1.84 & -0.76 & 1.21 & 1.79 \\
\hline 550.0 & 3.73 & & & & & 1.86 & & & & & 2.57 \\
\hline 475.0 & 9.94 & & & & & 2.24 & & & & & 200 \\
\hline 40.0 & 4.91 & 2.89 & 2.64 & -0.46 & 0.14 & -0.03 & -0.80 & -2.90 & -1.14 & -0.14 & -0.10 \\
\hline 325.0 & 0.08 & & & & & -1.50 & & & & & -0.14 \\
\hline 250.0 & -0.58 & & & & & -2.89 & & & & & $-20 \mathrm{r}$ \\
\hline 175.0 & -1.67 & -2.38 & -3.63 & -4.83 & -3.35 & -3.94 & -4.9 & -5.97 & -6.02 & -5.11 & -3.84 \\
\hline 100.0 & -5.46 & & & & & -5.30 & & & & & -4.38 \\
\hline 75.0 & -1.73 & & & & & -7.00 & & & & & -5.24 \\
\hline 50.0 & -3.29 & -3.36 & -6.84 & -6.78 & -6.40 & -6.88 & -7.70 & -6.48 & -7.17 & -6.55 & -5.28 \\
\hline 28.5 & -7.45 & & & & & -7.89 & & & & & -5.48 \\
\hline 19.4 & -8.08 & & & & & -10.67 & & & & & -6.49 \\
\hline 14.5 & -3.54 & & & & & -15.11 & & & & & -7.03 \\
\hline 9.4 & & & & & & & & & & & $-7 . n$ \\
\hline 5.0 & & & & & & & & & & & -8.97 \\
\hline 2.5 & -12.62 & -13.74 & -15.96 & -17.97 & -18.23 & -17.88 & -17.51 & -17.16 & -15.42 & -13.19 & \\
\hline
\end{tabular}

Table 4.26. Percent differences between measured power densities and values calculated with VENTURE using 20-group cross sections for the complex FOEHN configuration with void in the reflector components

\begin{tabular}{|c|c|c|c|c|c|c|c|c|c|c|c|}
\hline H/r(m) & 143.5 & 146.5 & 149.5 & 152.5 & 159.0 & 167.5 & 176.0 & 182.5 & 185.5 & 188.5 & 193.9 \\
\hline 797.5 & -15.42 & -12.83 & -11.49 & -13.91 & -11.04 & -4.75 & -3.58 & -5.64 & & -3.19 & -11.38 \\
\hline 795.0 & & & & & & & & & & & -6.37 \\
\hline 790.6 & -8.39 & & & & & & & & & & -5.66 \\
\hline 785.5 & -8.22 & & & & & -2.16 & & & & & -5.49 \\
\hline 780.6 & -8.94 & & & & & -6.03 & & & & & -4.18 \\
\hline 771.5 & -6.38 & & & & & -0.28 & & & & & -2.73 \\
\hline 750.0 & -6.78 & -5.89 & -4.55 & -7.29 & -5.56 & -4.03 & -1.34 & -3.39 & 0.93 & 1.85 & -2.68 \\
\hline 725.0 & -6.54 & & & & & -3.68 & & & & & -1.25 \\
\hline 700.0 & -6.00 & & & & & -5.98 & & & & & -0.99 \\
\hline 625.0 & -3.12 & -3.47 & -2.00 & -4.46 & -4.54 & -3.40 & -1.01 & -1.78 & 0.18 & 2.05 & -0.97 \\
\hline 550.0 & -1.76 & & & & & -2.09 & & & & & -0.12 \\
\hline 475.0 & 4.88 & & & & & -1.46 & & & & & 0.41 \\
\hline 400.0 & 1.88 & 0.93 & 0.93 & -2.56 & -2.08 & -1.81 & -0.35 & -1.22 & 1.59 & 2.41 & -1.25 \\
\hline 325.0 & -2.17 & & & & & -2.89 & & & & & -0.25 \\
\hline 250.0 & -2.29 & & & & & -3.33 & & & & & -1.11 \\
\hline 175.0 & -2.48 & -2.58 & -3.81 & -5.48 & -3.89 & -3.45 & -1.74 & -1.12 & -0.27 & 0.48 & -1.84 \\
\hline 100.0 & -5.00 & & & & & -3.57 & & & & & -0.96 \\
\hline 75.0 & -0.52 & & & & & -4.7 & & & & & -1.31 \\
\hline 50.0 & -0.92 & -0.52 & -4.05 & -4.42 & -4.10 & -3.66 & -1.81 & 1.07 & 1.10 & 1.57 & -0.91 \\
\hline 28.5 & -3.31 & & & & & -1.39 & & & & & -1.03 \\
\hline 19.4 & -3.74 & & & & & -1.32 & & & & & -2.24 \\
\hline 14.5 & 1.21 & & & & & -2.78 & & & & & -2.85 \\
\hline 9.4 & & & & & & & & & & & -3.67 \\
\hline 5.0 & & & & & & & & & & & -4.97 \\
\hline 2.5 & -5.00 & -2.73 & -2.02 & -2.93 & -1.20 & -0.13 & -0.11 & -1.76 & -1.92 & -3.44 & \\
\hline
\end{tabular}


Table 4.27. Percent differences between measured power densities and values calculated with VENTURE using 20-group cross sections for the complex FOEHN configuration with aluminum in the void regions of the reflector components

\begin{tabular}{|c|c|c|c|c|c|c|c|c|c|c|c|}
\hline$H / x(m)$ & 143.5 & 146.5 & 149.5 & 152.5 & 159.0 & 167.5 & 176.0 & 182.5 & 185.5 & 188.5 & 193.9 \\
\hline 797.5 & -14.88 & -12.33 & -11.05 & -13.55 & -10.88 & -4.96 & -4.21 & -6.54 & & -4.35 & -12.61 \\
\hline 795.0 & & & & & & & & & & & -7.67 \\
\hline 790.6 & -7.67 & & & & & & & & & & -6.96 \\
\hline 285.5 & -7.41 & & & & & -2.13 & & & & & -6.72 \\
\hline$\pi 0.6$ & -8.06 & & & & & -5.92 & & & & & -5.48 \\
\hline 771.5 & -5.36 & & & & & -0.07 & & & & & -4.03 \\
\hline 750.0 & -5.57 & $-4 . n$ & -3.42 & -6.27 & -4.77 & -3.69 & -1.55 & -4.01 & 0.10 & 0.83 & -3.93 \\
\hline 725.0 & -5.19 & & & & & -3.24 & & & & & -2.45 \\
\hline 200.0 & -4.56 & & & & & -5.48 & & & & & -2.14 \\
\hline 00.0 & -1.51 & -1.93 & -0.51 & -3.09 & -3.43 & -2.75 & -1.51 & -2.11 & -0.35 & 1.32 & -1.97 \\
\hline 550.0 & -0.10 & & & & & -1.38 & & & & & -1.04 \\
\hline 175.0 & 6.63 & & & & & -0.76 & & & & & -0.48 \\
\hline 100.0 & 3.45 & 2.41 & 2.33 & -1.31 & -1.08 & -1.26 & -0.30 & -1.35 & 1.07 & 1.72 & -2.18 \\
\hline 325.0 & -0.79 & & & & & -2.49 & & & & & -1.29 \\
\hline 250.0 & -1.05 & & & & & -3.10 & & & & & -2.32 \\
\hline 175.0 & -1.41 & -1.59 & -2.94 & -4.73 & -3.42 & -3.44 & -2.25 & -2.02 & -1.35 & -0.77 & -3.31 \\
\hline 100.0 & -4.16 & & & & & -3.85 & & & & & -2.79 \\
\hline 75.0 & 0.27 & & & & & -5.16 & & & & & -3.26 \\
\hline 50.0 & -0.27 & 0.04 & -3.62 & -4.11 & -4.11 & -4.18 & -2.90 & -0.47 & -0.61 & -0.30 & -299 \\
\hline 28.5 & -2.86 & & & & & -2.10 & & & & & -3.22 \\
\hline 19.4 & -3.42 & & & & & -2.15 & & & & & -4.44 \\
\hline 14.5 & 1.47 & & & & & -3.68 & & & & & -5.07 \\
\hline 9.4 & & & & & & & & & & & -5.90 \\
\hline 5.0 & & & & & & & & & & & -7.19 \\
\hline 2.5 & -5.02 & -2.87 & -2.28 & -3.32 & -1.94 & -1.36 & -1.7 & -3.68 & -3.95 & -5.54 & \\
\hline
\end{tabular}

Table 4.28. Percent differences between measured power densities and values calculated with VENTURE using 20-group cross sections for the complex FOEHN configuration with a constant aluminum density in the reflector

\begin{tabular}{|c|c|c|c|c|c|c|c|c|c|c|c|}
\hline $\mathrm{H} / \mathrm{r}(\mathrm{mm})$ & 143.5 & 146.5 & 149.5 & 152.5 & 159.0 & 167.5 & 176.0 & 182.5 & 185.5 & 188.5 & 193.9 \\
\hline 797.5 & -14.72 & -12.15 & -10.85 & -13.35 & -10.64 & -4.68 & -3.91 & -6.25 & & -4.05 & -12.33 \\
\hline 795.0 & & & & & & & & & & & -7.34 \\
\hline 790.6 & -7.43 & & & & & & & & & & -6.57 \\
\hline 785.5 & -7.13 & & & & & -1.70 & & & & & -6.27 \\
\hline 780.6 & -7.75 & & & & & -5.47 & & & & & -4.97 \\
\hline 771.5 & -4.98 & & & & & 0.49 & & & & & -3.41 \\
\hline 750.0 & -5.09 & -4.22 & -2.89 & -5.73 & -4.17 & -3.02 & -0.79 & -3.24 & 0.91 & 1.08 & -3.10 \\
\hline 725.0 & -4.63 & & & & & -246 & & & & & -1.43 \\
\hline 700.0 & -3.96 & & & & & -4.65 & & & & & -0.99 \\
\hline 625.0 & -0.88 & -1.27 & 0.18 & -2.40 & -2.67 & -1.87 & -0.49 & -1.02 & 0.80 & 2.53 & -0.74 \\
\hline 550.0 & 0.44 & & & & & -0.64 & & & & & -0.02 \\
\hline 475.0 & 7.02 & & & & & -0.27 & & & & & 0.15 \\
\hline 400.0 & 3.58 & 2.54 & 2.47 & -1.17 & -0.94 & -1.10 & -0.13 & -1.19 & 1.24 & 1.88 & -2.02 \\
\hline 325.0 & -0.98 & & & & & -2.73 & & & & & -1.66 \\
\hline 250.0 & -1.58 & & & & & -3.75 & & & & & -3.20 \\
\hline 175.0 & -2.27 & -2.47 & -3.82 & -5.62 & -4.38 & -4.50 & -3.43 & -3.29 & -2.66 & -2.12 & -4.68 \\
\hline 100.0 & -5.36 & & & & & -5.39 & & & & & -4.80 \\
\hline 75.0 & -1.14 & & & & & -6.86 & & & & & -5.53 \\
\hline 50.0 & -1.85 & -1.58 & -5.20 & -5.74 & -5.86 & -6.13 & -5.10 & -287 & -3.08 & -2.85 & -5.57 \\
\hline 28.5 & -4.60 & & & & & -4.34 & & & & & -6.08 \\
\hline 19.4 & -5.27 & & & & & -4.53 & & & & & -7.39 \\
\hline 14.5 & -0.54 & & & & & -6.11 & & & & & -8.07 \\
\hline 9.4 & & & & & & & & & & & -8.95 \\
\hline 5.0 & & & & & & & & & & & -10.27 \\
\hline 2.5 & -7.12 & -5.07 & -4.56 & -5.64 & -4.45 & -4.11 & -4.74 & -6.73 & -7.05 & -8.63 & \\
\hline
\end{tabular}




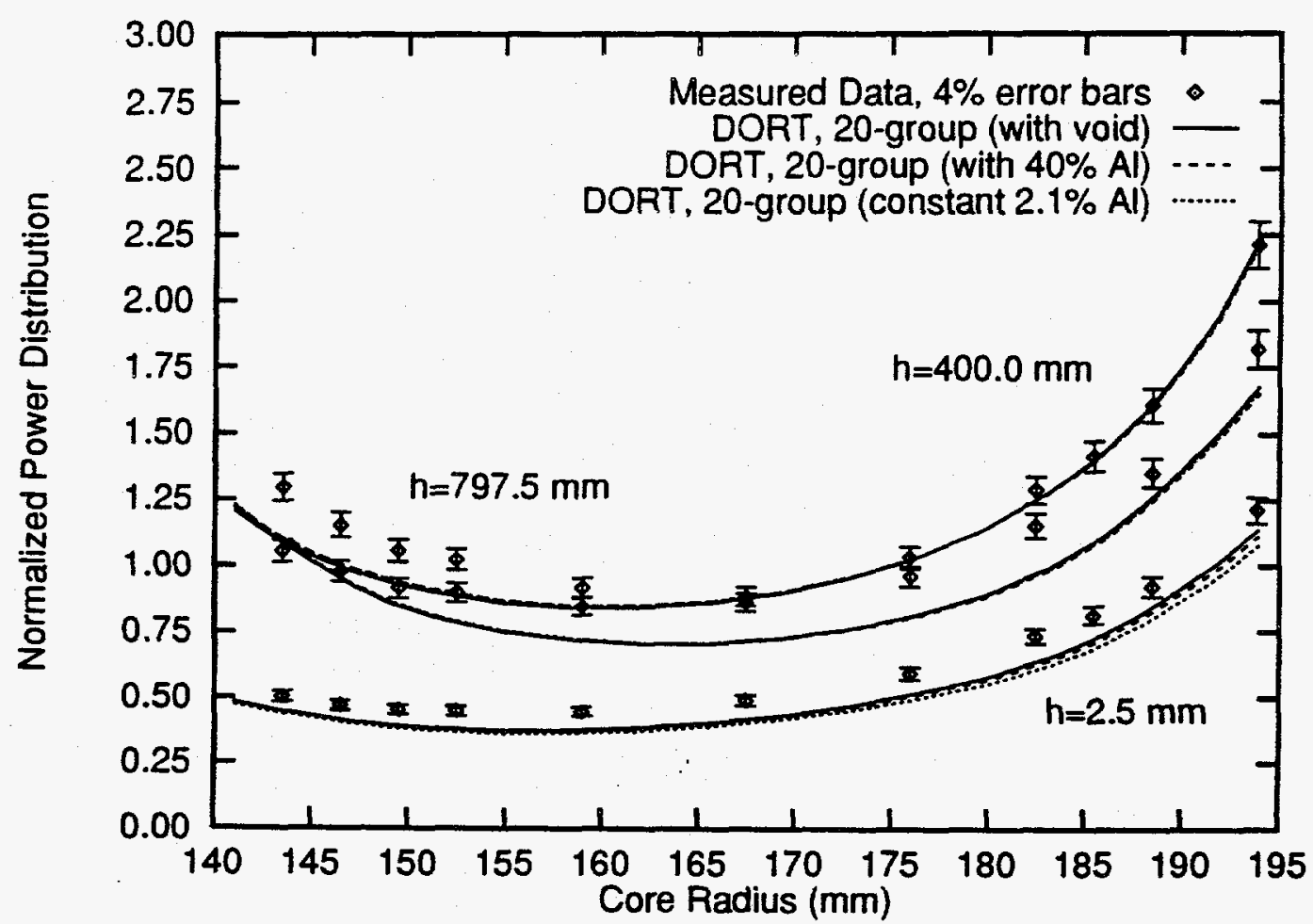

Fig. 4.31. Comparison of experimental radial power density traces and DORT values calculated using 20-group cross sections for the different models of the complex FOEHN configuration.

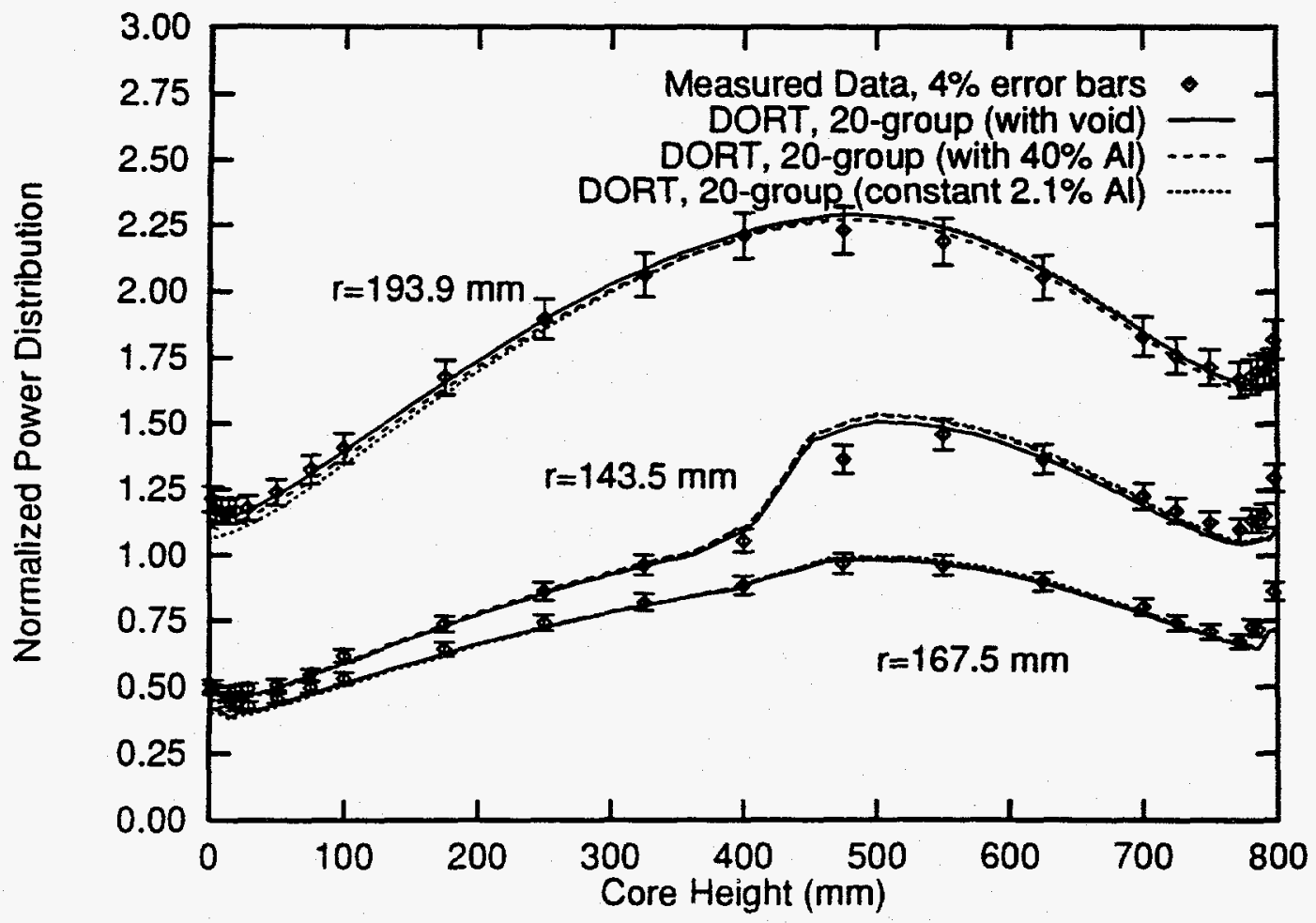

Fig. 4.32. Comparison of experimental axial power density traces and DORT values calculated using 20-group cross sections for the different models of the complex FOEHN configuration. 


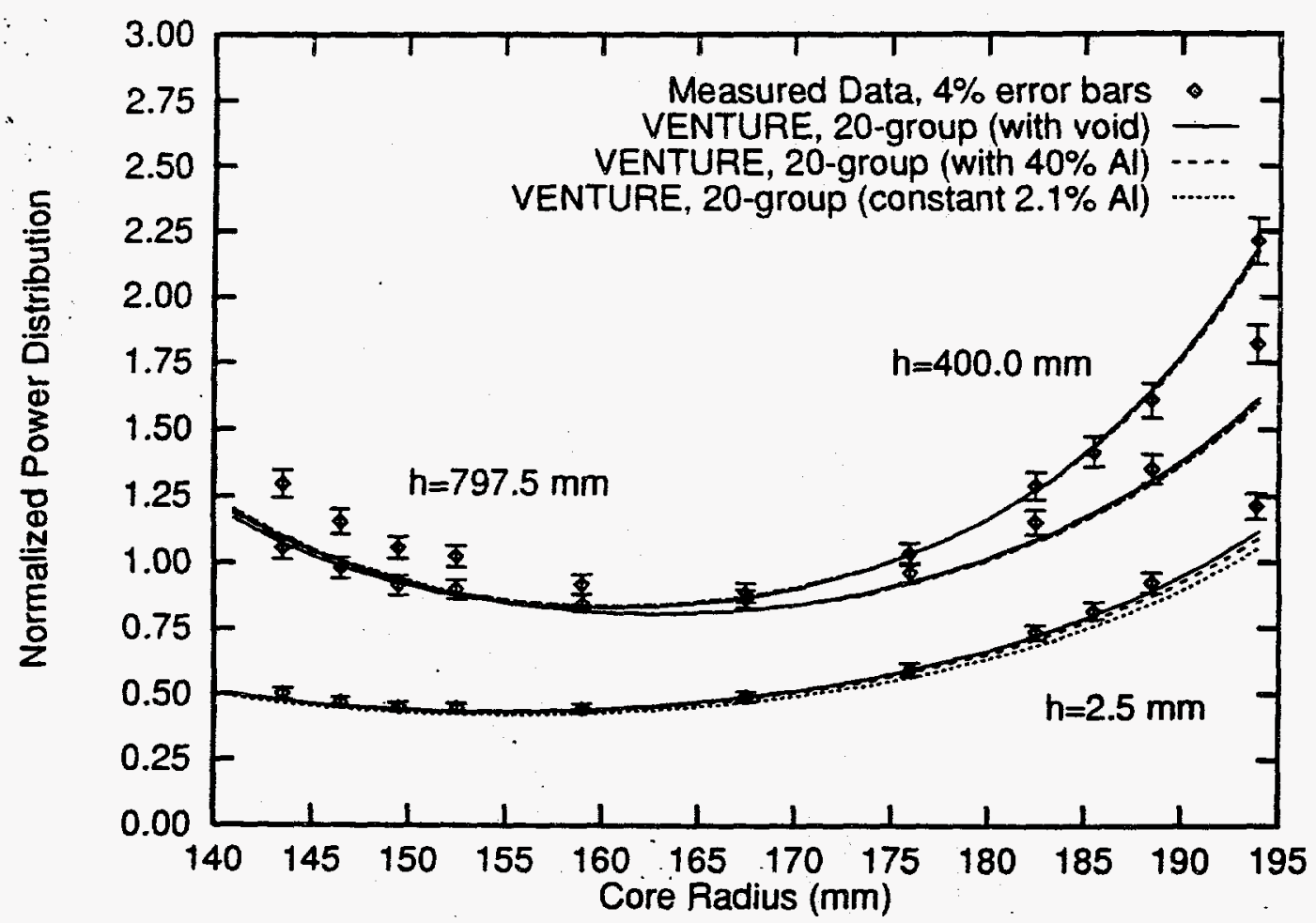

Fig. 4.33. Comparison of experimental radial power density traces and VENTURE values calculated using 20-group cross sections for the different models of the complex FOEHN configuration.

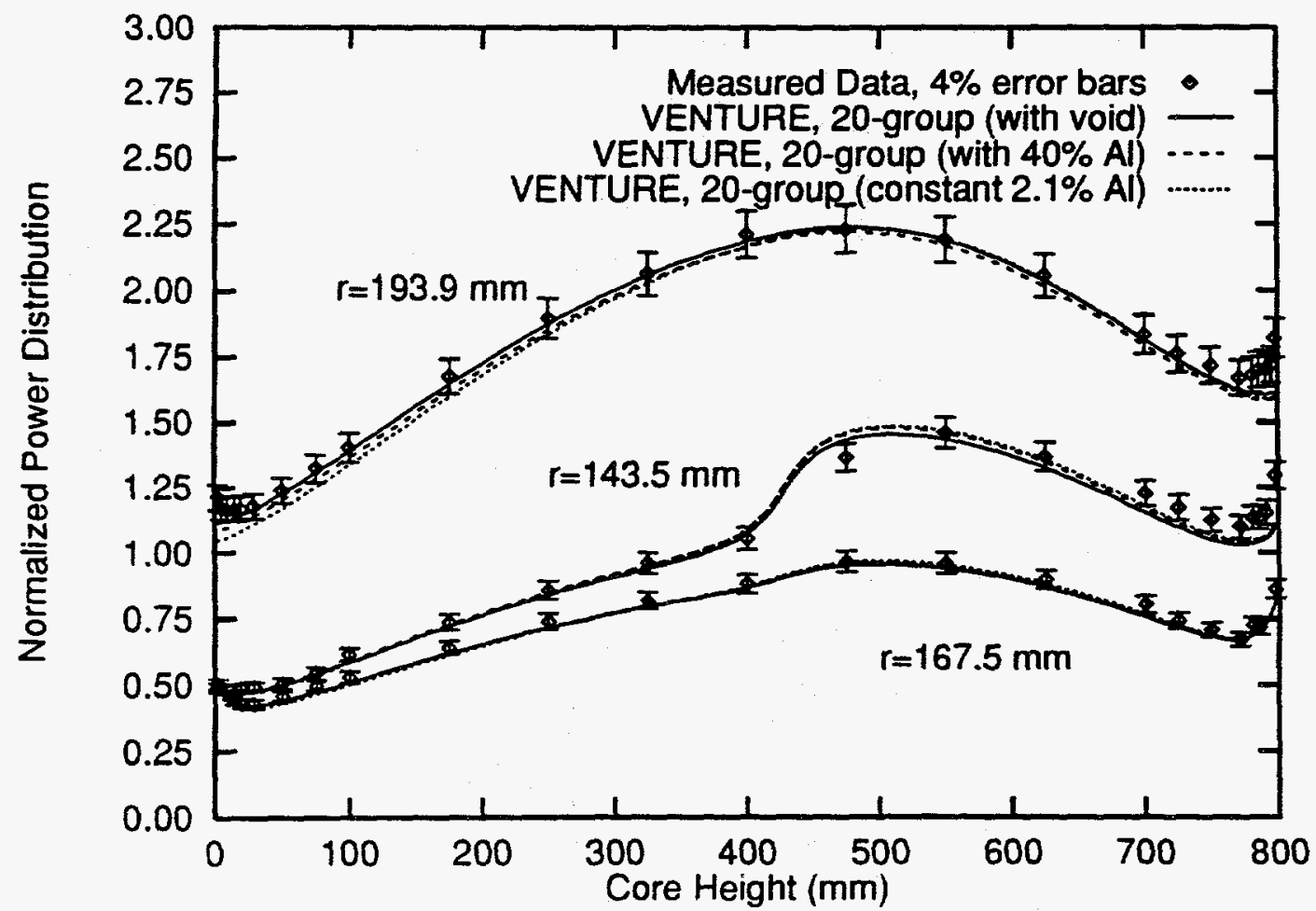

Fig. 4.34. Comparison of experimental axial power density traces and VENTURE values calculated using 20-group cross sections for the different models of the complex FOEHN configuration. 
Table 4.29. Rendement values calculated for the different models of the complex FOEHN configuration

\begin{tabular}{|c|c|c|c|c|}
\hline \multirow{3}{*}{ Model } & \multicolumn{4}{|c|}{ Computer code } \\
\hline & \multicolumn{2}{|c|}{ DORT } & \multicolumn{2}{|c|}{ VENTURE } \\
\hline & $\begin{array}{c}\text { Rendement } \\
10^{11} \text { neutrons } /\left(\mathrm{m}^{2} \mathrm{~s} \mathrm{~W}\right)\end{array}$ & $\begin{array}{l}\text { Percent } \\
\text { difference }\end{array}$ & $\begin{array}{c}\text { Rendement } \\
10^{11} \text { neutrons } /\left(\mathrm{m}^{2} \& \mathrm{~W}\right)\end{array}$ & $\begin{array}{c}\text { Percent } \\
\text { difference }\end{array}$ \\
\hline $\begin{array}{l}\text { Void in the reflector } \\
\text { components }\end{array}$ & 2.6191 & 13.87 & 2.5676 & 11.63 \\
\hline $\begin{array}{l}\text { Aluminum in the } \\
\text { void regions of the } \\
\text { reflector } \\
\text { components }\end{array}$ & 2.5447 & 10.64 & 2.4826 & 7.94 \\
\hline $\begin{array}{l}\text { Constant aluminum } \\
\text { density in the } \\
\text { reflector }\end{array}$ & 2.5864 & 12.45 & 2.5000 & 8.70 \\
\hline
\end{tabular}

\subsubsection{Thermal Flux}

Table 4.30 shows the average and maximum differences between the calculated and measured thermal flux values for the complex configuration models. The measured values were determined by averaging several points measured at the core midplane and at a specific distance from the core. This allows the data to be compared with values determined from the $R-Z$ models. Tables 4.31 and 4.32 , respectively, show the differences between the measured results and values calculated with DORT and VENTURE. Figures 4.35 and 4.36 show radial flux traces comparing the measured and calculated values. The model with void in the reflector components calculated the largest peak thermal flux. The VENTURE flux results for the two corrected models differ slightly.

\subsection{SUMMARY}

The three configurations of the FOEHN critical experiment have been evaluated using the KENO, DORT, and VENTURE computer codes. Calculated results have been compared to measured data. Some of the differences between the calculated and measured results can be attributed to uncertainties in the exact geometry and material compositions of the components in the experiment. 
Table 4.30. Average and maximum thermal flux percent differences for the different models of the complex FOEHN configuration

\begin{tabular}{lcrc}
\hline & Computer code & \multicolumn{2}{c}{ Percent difference } \\
\cline { 3 - 4 } & & Average & Maximum \\
\hline Void in the reflector components & DORT & 13.13 & 17.78 \\
& VENTURE & 10.86 & 20.64 \\
Aluminum in the void regions of the reflector & DORT & 13.98 & -30.73 \\
components & VENTURE & 8.42 & 13.38 \\
Constant aluminum density in the reflector & DORT & 10.20 & 16.46 \\
& VENTURE & 8.15 & 14.17 \\
\hline
\end{tabular}

Table 4.31. Percent differences between measured thermal fluxes and values calculated with DORT using 20-group cross sections for the different models of the complex FOEHN configuration

\begin{tabular}{cccc}
\hline \multirow{2}{*}{$\begin{array}{c}\text { Radius }^{a} \\
(\mathrm{~mm})\end{array}$} & $\begin{array}{c}\text { Void in the reflector } \\
\text { components }\end{array}$ & $\begin{array}{c}\text { Cluminum in the void } \\
\text { regions of the reflector } \\
\text { components }\end{array}$ & $\begin{array}{c}\text { Constant aluminum } \\
\text { density in the reflector }\end{array}$ \\
\hline 275 & 10.86 & 8.76 & 9.46 \\
315 & 10.78 & 7.79 & 9.16 \\
435 & 17.78 & 11.11 & 16.46 \\
515 & 10.83 & 1.54 & 11.61 \\
675 & -11.52 & -23.96 & -6.11 \\
755 & -17.04 & -30.73 & 8.40 \\
\hline
\end{tabular}

${ }^{a}$ Height $=1110 \mathrm{~mm}$, the midplane of the fuel element.

Table 4.32. Percent differences between measured thermal fluxes and values calculated with VENTURE using 20-group cross sections for different models of the complex FOEHN configuration

\begin{tabular}{cccc}
\hline \multirow{2}{*}{$\begin{array}{c}\text { Radius } \\
(\mathrm{mm})\end{array}$} & $\begin{array}{c}\text { Coid in the reflector } \\
\text { components }\end{array}$ & $\begin{array}{c}\text { Aluminum in the void } \\
\text { regions of the reflector } \\
\text { components }\end{array}$ & $\begin{array}{c}\text { Constant gluminum } \\
\text { density in the reflector }\end{array}$ \\
\cline { 2 - 4 } & 5.38 & 3.21 & 3.44 \\
\hline 275 & 7.83 & 4.74 & 5.09 \\
315 & 20.64 & 13.38 & 14.17 \\
435 & 18.23 & 7.59 & 9.62 \\
515 & 5.97 & -9.97 & --7.39 \\
675 & 7.12 & --11.62 & --9.20 \\
755 & & &
\end{tabular}

${ }^{a}$ Height $=1110 \mathrm{~mm}$, the midplane of the fuel element. 
61

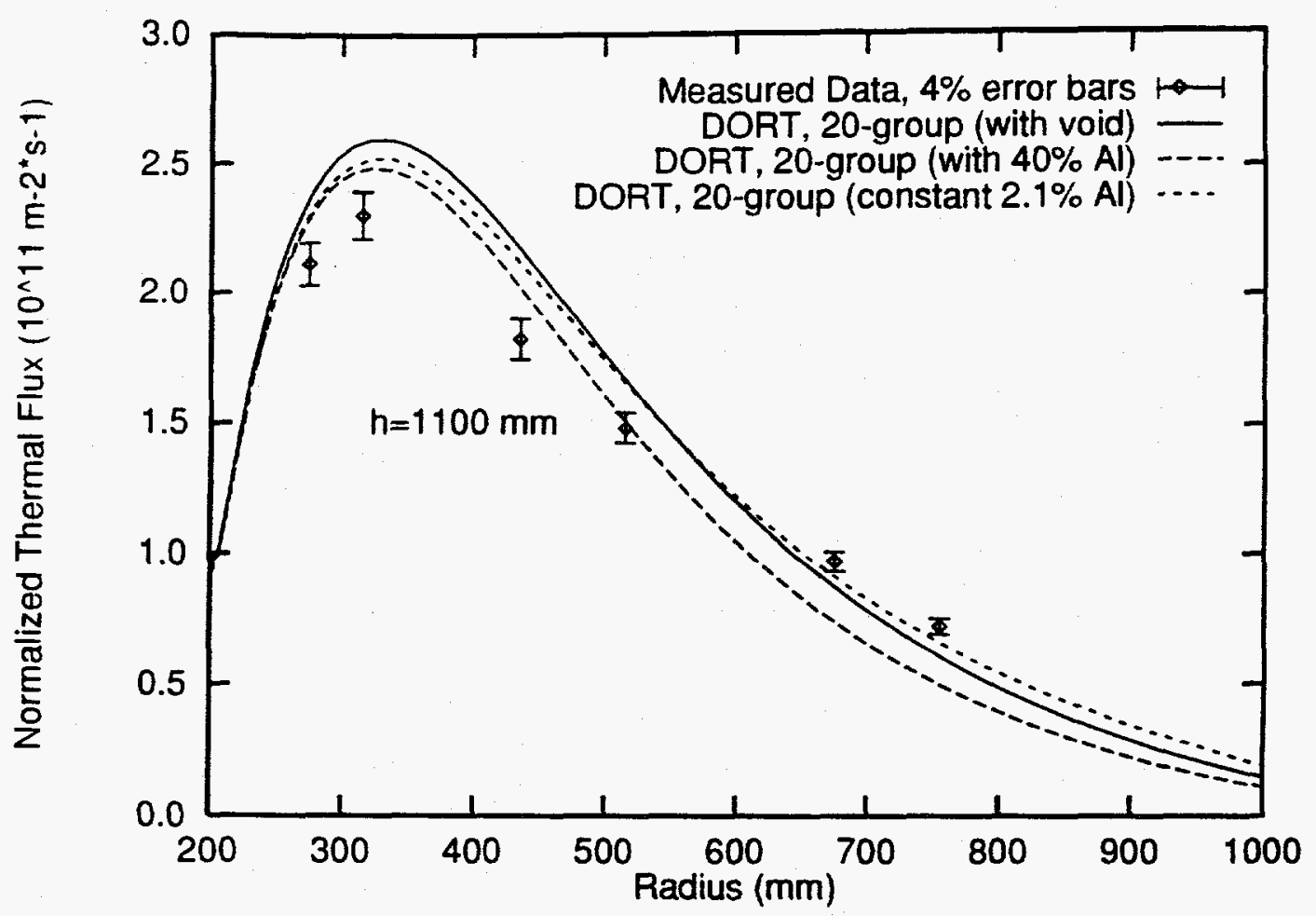

Fig. 4.35. Comparison of experimental radial thermal fux traces with DORT values calculated using 20-group cross sections for the different models of the complex FOEHN configuration.

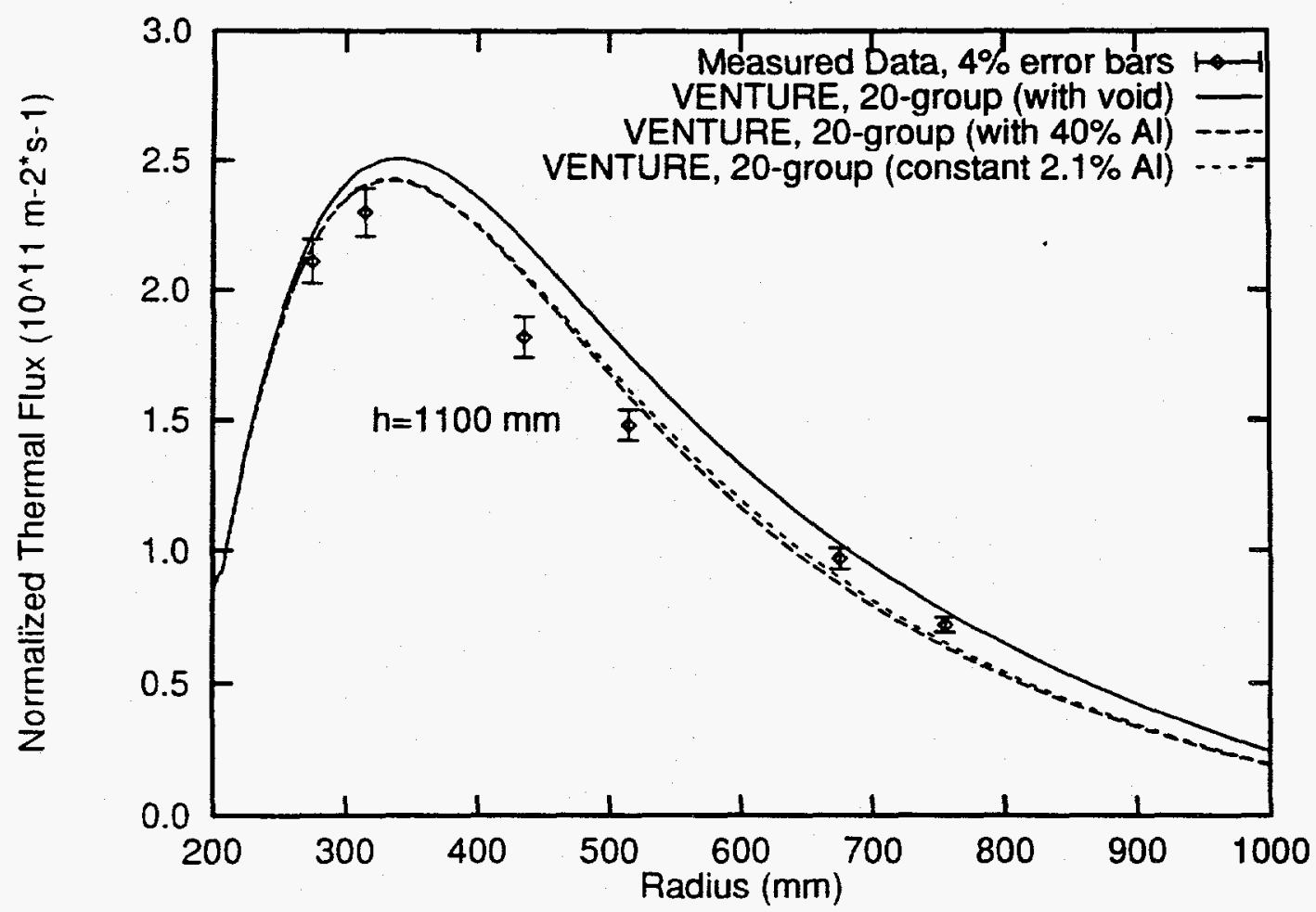

Fig. 4.36. Comparison of experimental radial thermal flux traces with VENTURE values calculated using 20-group cross sections for the different models of the complex FOEHN configuration. 
. 


\section{CONCLUSIONS}

This report documents the analysis of the FOEHN critical experiment using ORNL neutronics codes and multigroup cross sections from the ANSL-V master library. Results from calculations using the KENO Monte Carlo transport code, the DORT discrete ordinates transport code, and the VENTURE diffusion theory code show reasonable agreement with the measured data and are within the experimental errors. Because the simple and intermediate configurations are azimuthally symmetric, the correctness of the models is limited only by the minor geometric and material composition assumptions. The multiplication factors for the simple and intermediate configurations were predicted to within $0.2 \%$ of unity using KENO with 99 -group cross sections. The 20-group transport results were within $0.5 \%$ of unity, while the diffusion theory results are within $1.1 \%$.

The KENO, DORT, and VENTURE calculations yield average power density differences less than $5 \%$ for the simple and intermediate configurations. The results obtained for the power density values at the upper and lower edges of the fuel element do not match the measured data. The error in these measurements cannot be determined quantitatively because the exact position of the boron endplates and the measurement probes is not known. When these points are not considered, the maximum power density differences calculated with KENO and DORT are less than $10 \%$, and less than $14 \%$ when considering the diffusion theory results.

In the evaluation of the complex configuration, three models that approximate the reflector components were developed. The first model smears material of the reflector components into an $\mathrm{R}-\mathrm{Z}$ mesh conserving the amount of material present in the structures. The $k_{\text {eff }}$ values calculated with this model overpredict unity by up to $2.1 \%$ because the streaming in the void regions of the reflector components cannot be accounted for in R-Z geometry. The second model developed examines the artificial addition of aluminum to the void regions of the reflector components. The third model investigates the use of aluminum at a constant density in the reflector region. The aluminum density in the last two models was adjusted until the calculated multiplication factors matched the critical state. The average power density differences calculated using these models are less than $4 \%$ when the points at the upper and lower edges of the fuel element are not considered. The maximum differences are less than $15.2 \%$. The power density distributions for the adjusted models match the measured values well; however, when equivalent models of other systems (such as the ANS) are developed, the results will have to be compared with explicit models analyzed using Monte Carlo techniques.

The work in this report shows that multiplication factors, power distributions, and thermal fluxes for the FOEHN experiment can be calculated within the measurement errors using multigroup cross sections derived from the ANSL-V master cross-section library. The calculated parameters are comparable to those determined in the independent studies documented in refs. 9,13 , and 14. The general trends of overpredicting or underpredicting the measured data are similar. The results show that the calculational methods used in this work accurately predict the measured values of the FOEHN experiment, a highly enriched, heavy water moderated system that has many similarities with the current ANS design. 



\section{REFERENCES}

1. D. L. Selby et. al., The Advanced Neutron Source Research and Development Plan, ORNL/TM-12249/R1, Martin Marietta Energy Systems, Inc., Oak Ridge Natl. Lab., March 1995.

2. L. M. Petrie and N. F. Landers, KENO V.a, An Improved Monte Carlo Criticality Program with Supergrouping, NUREG/CR-0200, (ORNL/NUREG/CSD-2/V1/R2), Oak Ridge Natl. Lab., December 1984.

3. W. A. Rhoades and R. L. Childs, An Updated Version of the DOT 4 One- and TwoDimensional Neutron/Photon Transport Code, ORNL-5851, Oak Ridge Natl. Lab., April 1982.

4. D. R. Vondy et al., The Bold Venture Computation System for Nuclear Reactor Core Analysis, Version III, ORNL-5711, Oak Ridge Nat1. Lab., June 1981.

5. ANSL-V: ENDF/B-V Based Multigroup Cross Section Libraries for Advanced Neutron Source (ANS) Reactor Studies, ORNL-6618, Oak Ridge Natl. Lab., September 1990.

6. K. Scharmer and H. G. Eckert, FOEHN: The Critical Experiment for the Franco-German High Flux Reactor, ORNL/TR-91/23, Martin Marietta Energy Systems, Inc., Oak Ridge Natl. Lab., 1991. English translation of K. Scharmer, H. G. Eckert, FOEHN - Das kritische Experiment für den Deutsch-Französischen Hochflußreaktor, KFK 1064, December 1971.

7. F. X. Gallmeier, Verfizierung des dreidimensionalen Rechencodes MORSE-K durch Nachrechnen des kritischen Experimentes FOEHN, Technische Universität München, January 16, 1991.

8. H. C. Honeck, THERMOS: A Thermalization Transport Theory Code for Reactor Lattice Calculations, BNL-5826, Brookhaven Natl. Lab., September 1961.

9. A. M. Ougouag et al., MCNP Analysis of the FOEHN Critical Experiment, ORNLTM-12466, Oak Ridge Natl. Lab., October 1993.

10. Mill Test Certificate Number 139857 for AG3-NE Alloy, Cegedur Pichiney Company, Paris, France, April 27, 1988.

11. N. M. Greene et al., AMPX-77: A Modular Code System for Generating Coupled Multigroup Neutron-Gamma Cross-Section Libraries from ENDF/B-IV and/or ENDF/B-V, ORNL/CṠD/TM-283, Oak Ridge Natl. Lab., October 1992.

12. O. W. Hermann and R. S. Carlsmith, RAFFLE: A Monte Carlo Code for Calculation of First Flight Collision Probabilities, ORNL/TM-1699, Oak Ridge Natl. Lab., December 1966. 
13. A. M. Ougouag et. al., "MCNP Neutronic Analysis of the FOEHN Franco-German Critical Experiment," pp. 263-272 in Volume III of Proceedings of the 1994 Topical Meeting on Advances in Reactor Physics, Knoxville, Tennessee, April 11-15, 1994.

14. A. Rohrmoser, Verification of Data Generation, Two-Dimensional Transport Calculations and Diffusion and Burnup Calculations for the FRM-II Compact Core, ORNL/OLS-92/12, translated from the German Report No. 00119a issued by the Department of Physics E21, Technische Universität München, July 1991. 


\section{APPENDIX A}

\section{ATOM DENSITIES FOR FOEHN EXPERIMENT MATERIALS}

The atom densities for the materials in each of the three FOEHN configurations are presented in Tables A.1-A.3 of this appendix. The control element positions and boron concentrations for each critical state are documented in Tables A.4-A.6. 
Table A.1. Atom densities for materials in the simple FOEHN configuration model

\begin{tabular}{|c|c|c|c|c|c|c|}
\hline \multirow{2}{*}{ Element } & \multicolumn{6}{|c|}{ Material } \\
\hline & Heavy water & Borated heavy water & AG3-NE alloy & Control element & Fuel plate & $\begin{array}{c}\text { Homogenous core } \\
\text { region }\end{array}$ \\
\hline D & $6.6304-2^{a}$ & $6.6304-2$ & & & & $3.8875-2$ \\
\hline $\mathbf{H}$ & $1.6817-4$ & $1.6817-4$ & & & & $9.8601-5$ \\
\hline o & $3.3236-2$ & $3.3236-2$ & & & & $1.9487-2$ \\
\hline${ }^{233} U$ & & & & & $1.1448-3$ & $4.7360-4$ \\
\hline${ }^{238} \mathrm{U}$ & & & & & $1.1313-4$ & $4.6800-5$ \\
\hline${ }^{10} \mathrm{~B}$ & & $\boldsymbol{b}$ & $2.9811-7$ & & $3.0483-7$ & $b$ \\
\hline${ }^{11} \mathrm{~B}$ & & & $1.1999-6$ & & $1.2269-6$ & $5.0756-7$ \\
\hline $\mathbf{N i}$ & & & & $9.1300-2$ & & \\
\hline Al & & & $5.8061-2$ & & $5.9369-2$ & $2.4560-2$ \\
\hline $\mathbf{M g}$ & & & $1.8523-3$ & & $1.8940-3$ & $7.8353-4$ \\
\hline $\mathbf{M n}$ & & & $1.1791-5$ & & $1.2057-5$ & $4.9876-6$ \\
\hline $\mathrm{Cr}$ & & & $3.1145-6$ & & $3.1847-6$ & $1.3174-6$ \\
\hline $\mathbf{S i}$ & & & $8.6489-5$ & & $8.8438-5$ & $3.6585-5$ \\
\hline $\mathbf{F e}$ & & & $7.5392-5$ & & $7.7091-5$ & $3.1891-5$ \\
\hline $\mathrm{Ti}$ & & & $3.3808-6$ & & $3.4570-6$ & $1.4301-6$ \\
\hline $\mathbf{Z n}$ & & & $2.4769-6$ & & $2.5327-6$ & $1.0477-6$ \\
\hline $\mathrm{Cu}$ & & & $4.2072-6$ & & $4.3020-6$ & 1.7797 .6 \\
\hline $\mathbf{P b}$ & & & 1.2021 .6 & & $1.2292-6$ & $5.0849-7$ \\
\hline
\end{tabular}

${ }^{a_{\text {Read as }}} 6.6304 \times 10^{-2}$. Units are atoms/(bam $\left.\mathrm{cm}\right)$.

${ }^{b}$ Boron-10 atom densities for each critical case are listed in Table A.4. 
Table A.2. Atom densities for materials in the intermediate FOEHN configuration model

\begin{tabular}{|c|c|c|c|c|c|c|c|c|c|c|}
\hline \multirow{2}{*}{ Element } & \multicolumn{10}{|c|}{ Material } \\
\hline & $\begin{array}{l}\text { Heavy } \\
\text { water }\end{array}$ & $\begin{array}{c}\text { Borated heavy } \\
\text { water }\end{array}$ & AG3-NE alloy & $\begin{array}{l}\text { Control } \\
\text { element }\end{array}$ & Fuel plate & $\begin{array}{l}\text { Homogeneous } \\
\text { core region }\end{array}$ & Boron plate & $\begin{array}{l}\text { Aluminum } \\
\text { plate }\end{array}$ & $\begin{array}{c}\text { Homogenous } \\
\text { boron endplate } \\
\text { region }\end{array}$ & \\
\hline D & $6.6296-2^{a}$ & $6.6296-2$ & & & & $3.8871-2$ & & & $3.8624-2$ & \\
\hline $\mathbf{H}$ & $1.7615-4$ & 1.76154 & & & & $1.0328-5$ & & & $1.0262-4$ & \\
\hline 0 & $3.3236-2$ & $3.3236-2$ & & & & $1.9487-2$ & & & $1.9363-2$ & \\
\hline${ }^{233} U$ & & & & & $1.1448-3$ & $4.7360-4$ & & & & \\
\hline${ }^{238} U$ & & & & & 1.13134 & $4.6800-5$ & & & & \\
\hline${ }^{10} \mathrm{~B}$ & & $b$ & $2.9811-7$ & & 3.0483-7 & $b$ & $5.5424-4$ & & $1.5170-4$ & \\
\hline${ }^{11} \mathbf{B}$ & & & $1.1999-6$ & & $1.2269-6$ & $5.0756-7$ & & & & \\
\hline $\mathbf{N i}$ & & & & $9.1300-2$ & & & & & & \\
\hline Al & & & $5.8061-2$ & & $5.9369-2$ & $2.4560-2$ & $6.0265-2$ & $6.0265-2$ & $2.4800-2$ & 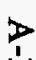 \\
\hline $\mathbf{M g}$ & & & $1.8523-3$ & & $1.8940-3$ & $7.8353-4$ & & & & \\
\hline $\mathbf{M n}$ & & & $1.1791-5$ & & $1.2057-5$ & $4.9876-6$ & & & & \\
\hline Cr & & & $3.1145-6$ & & $3.1847-6$ & $1.3174-6$ & & & & \\
\hline $\mathrm{Si}$ & & & $8.6489-5$ & & $8.8438-5$ & $3.6585-5$ & & & & \\
\hline $\mathrm{Fe}$ & & & $7.5392-5$ & & $7.7091-5$ & $3.1891-5$ & & & & \\
\hline $\mathrm{Ti}$ & & & $3.3808-6$ & & $3.4570-6$ & $1.4301-6$ & & & & \\
\hline $\mathrm{Zn}_{\mathbf{n}}$ & & & $2.4769-6$ & & $2.5327-6$ & $1.0477-6$ & & & & \\
\hline $\mathrm{Cu}$ & & & $4.2072-6$ & & $4.3020-6$ & $1.7797-6$ & & & & \\
\hline $\mathrm{Pb}$ & & & $1.2021-6$ & & $1.2292-6$ & $5.0849-7$ & & & & \\
\hline
\end{tabular}

${ }^{a}$ Read as $6.6296 \times 10^{-2}$. Units are atoms/(bam $\left.\mathrm{cm}\right)$.

${ }^{b}$ Boron-10 atom densities for each critical case are listed in Table A.5. 
Table A.3. Atom densities for materials in the complex FOEHN configuration model

\begin{tabular}{|c|c|c|c|c|c|c|c|c|c|c|c|c|}
\hline \multirow{2}{*}{ Element } & \multicolumn{12}{|c|}{ Melerial } \\
\hline & Heavy walex & $\begin{array}{l}\text { Boralcad } \\
\text { heavy witer }\end{array}$ & AG3-NE alloy & $\begin{array}{l}\text { Conterl } \\
\text { element }\end{array}$ & Fuel plate & $\underset{\text { Hegion }}{\text { Homonomon }}$ & Borven plave & Aluminmm ptance & 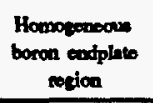 & Grophite & Zireslog-4 & $\begin{array}{l}\text { Suinkess } \\
\text { sloel }\end{array}$ \\
\hline D & $6.6297 \cdot 2^{a}$ & $6.6297-2$ & & & & $3.8871-2$ & & & 3.86242 & & & \\
\hline н & $1.7482-4$ & $1.7482-4$ & & & & $1.0250-4$ & & & $1.0185-4$ & & & \\
\hline 0 & $3.3236-2$ & $3.3236-2$ & & & & $1.9487-2$ & & & $1.9363-2$ & & & \\
\hline$\infty_{U}$ & & & & & $1.1448-3$ & $4.7360-4$ & & & & & & \\
\hline mu & & & & & t.1313-4 & 4.6800-5 & & & & & & 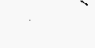 \\
\hline "B & & $b$ & 2.9811 .7 & & $3.0483-7$ & $b$ & $5.5424-4$ & & $1.5170-4$ & & & \\
\hline "B & & & 1.199966 & & 1.22606 & $5.0756-7$ & & & & & & \\
\hline $\mathbf{N i}$ & & & & $9.1300-2$ & & & & & & & $4.7827-6$ & $7.2175-3$ \\
\hline $\mathbf{A}$ & & & $5.8061-2$ & & 5.93692 & 2.4560 .2 & $6.0265-2$ & $6.0265-2$ & $2.4800-2$ & & & \\
\hline $\mathbf{M}_{\mathbf{B}}$ & & & 1.8523 .3 & & $1.8940-3$ & $7.8353-4$ & & & & & & \\
\hline Mn & & & $1.1791-5$ & & 1.2057 .5 & $4.9876-6$ & & & & & & \\
\hline Cr & & & $3.1145-6$ & & $3.1847-6$ & 1.31746 & & & & & 7.6439 .5 & $1.7201-2$ \\
\hline $\mathbf{s i}$ & & & 8.64895 & & $8.8438-5$ & $3.6585-5$ & & & & & & \\
\hline Fo & & & 7.5392 .5 & & 7.7091 .5 & 3.1891 .5 & & & & & 1.42344 & $6.0689-2$ \\
\hline$\pi$ & & & 3.3808 .6 & & 3.45706 & 1.4301 .6 & & & & & & \\
\hline $\mathrm{Zn}$ & & & 2.47696 & & 2.5327 .6 & $1.0477-6$ & & & & & & \\
\hline $\mathrm{Cu}$ & & & $4.2072-6$ & & 4.30206 & $1.797-6$ & & & & & & \\
\hline Pb & & & $1.2021-6$ & & 1.22606 & 5.0849 .7 & & & & & & \\
\hline c & & & & & & & & & & $8.0220-2$ & & \\
\hline $\mathbf{Z r}_{\mathbf{r}}$ & & & & & & & & & & & 4.2753 .2 & \\
\hline Sn & & & & & & & & & & & $5.0230-4$ & \\
\hline
\end{tabular}

${ }^{a}$ Read as $6.6297 \times 10^{-2}$. Units are atoms/(barn $\left.\mathrm{cm}\right)$.

boron-10 atom densities for each critical case are listed in Table A.6. 


\section{A-5}

Table A.4. Boron-10 concentrations and control element positions for the simple FOEHN configuration cases

\begin{tabular}{ccccc}
\hline Case & $\begin{array}{c}\text { Control } \\
\text { element } \\
\text { position } \\
(\mathrm{mm})\end{array}$ & $\begin{array}{c}\text { Boron-10 } \\
\text { concentration } \\
\left(\mathrm{g}{ }^{10 \mathrm{~B} / \mathrm{L})}\right.\end{array}$ & $\begin{array}{c}\text { Boron-10 atom density in } \\
\text { the borated heavy water } \\
\text { atoms/(barn cm) }\end{array}$ & $\begin{array}{c}\text { Boron-10 atom } \\
\text { density in the } \\
\text { homogeneous core } \\
\text { region }\end{array}$ \\
\hline 1 & 172.0 & 0.2477 & $1.4897-5^{a}$ & atoms/(bam cm) \\
\hline 2 & 357.0 & 0.3349 & $2.0142-5$ & $8.8605-6$ \\
3 & 455.0 & 0.3863 & $2.3233-5$ & $1.1936-5$ \\
4 & 467.3 & 0.3855 & $2.3185-5$ & $1.3748-5$ \\
5 & 596.0 & 0.4501 & $2.7070-5$ & $1.3720-5$ \\
$6^{b}$ & 601.0 & 0.4509 & $2.7118-5$ & $1.5998-5$ \\
7 & 602.0 & 0.4536 & $2.7280-5$ & $1.6026-5$ \\
8 & 661.0 & 0.4791 & $2.8814-5$ & $1.6121-5$ \\
9 & 857.0 & 0.5268 & $3.1683-5$ & $1.7020-5$ \\
10 & 890.0 & 0.5386 & $3.2393-5$ & $1.8702-5$ \\
11 & 896.0 & 0.5386 & $3.2393-5$ & $1.9119-5$ \\
\hline
\end{tabular}

${ }^{a}$ Read as $1.4897 \times 10^{-5}$.

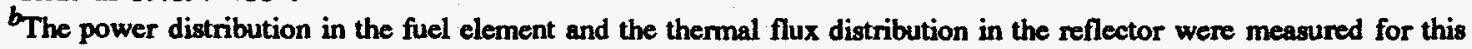
case.

Table A.5. Boron-10 concentrations and control element positions for the intermediate FOEHN configuration cases

\begin{tabular}{ccccc}
\hline Case & $\begin{array}{c}\text { Control } \\
\text { element } \\
\text { position } \\
(\mathrm{mm})\end{array}$ & $\begin{array}{c}\text { Boron-10 } \\
\text { concentration } \\
\left(\mathrm{g}{ }^{10} \mathrm{~B} / \mathrm{L}\right)\end{array}$ & $\begin{array}{c}\text { Boron-10 atom density } \\
\text { in the borated heavy } \\
\text { water } \\
\text { atoms/(barn cm) }\end{array}$ & $\begin{array}{c}\text { Boron-10 atom density } \\
\text { in the homogeneous } \\
\text { core region } \\
\text { atoms/(bam cm) }\end{array}$ \\
\hline 1 & 352.2 & 0.210 & $1.2630-5^{a}$ & $7.5313-6$ \\
$2^{b}$ & 447.0 & 0.258 & $1.5517-5$ & $9.2240-6$ \\
3 & 457.0 & 0.270 & $1.6238-5$ & $9.6468-6$ \\
4 & 609.0 & 0.350 & $2.1050-5$ & $1.2468-5$ \\
5 & 664.0 & 0.371 & $2.2313-5$ & $1.3209-5$ \\
6 & 815.0 & 0.419 & $2.5200-5$ & $1.4901-5$ \\
\hline
\end{tabular}

${ }^{a_{\text {Read as }}} 1.2630 \times 10^{-5}$.

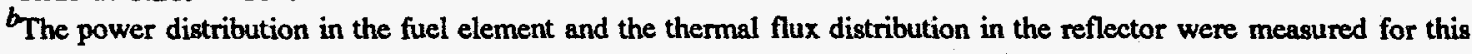
case. 


\section{A-6}

Table A.6. Boron-10 concentrations and control element positions for the complex FOEHN configuration cases

\begin{tabular}{ccccc}
\hline Case & $\begin{array}{c}\text { Control } \\
\text { element } \\
\text { position } \\
(\mathrm{mm})\end{array}$ & $\begin{array}{c}\text { Boron-10 } \\
\text { concentration } \\
\left(\mathrm{g}{ }^{10} \mathrm{~B} / \mathrm{L}\right)\end{array}$ & $\begin{array}{c}\text { Boron-10 atom } \\
\text { density in the borated } \\
\text { heavy water } \\
\text { atoms/(barn cm })\end{array}$ & $\begin{array}{c}\text { Boron-10 atom } \\
\text { density in the } \\
\text { homogeneous core } \\
\text { region } \\
\text { atoms/(barn cm })\end{array}$ \\
\hline 1 & 804.0 & 0.347 & $2.0869-5^{a}$ & $1.2362-5$ \\
2 & 771.0 & 0.311 & $1.8704-5$ & $1.1093-5$ \\
3 & 596.0 & 0.260 & $1.5637-5$ & $9.2944-6$ \\
4 & 579.0 & 0.248 & $1.4915-5$ & $8.8712-6$ \\
5 & 503.0 & 0.210 & $1.2630-5$ & $7.5312-6$ \\
6 & 385.0 & 0.143 & $8.6003-6$ & $5.1686-6$ \\
7 & 249.0 & 0.078 & $4.6911-6$ & $2.8766-6$ \\
$8^{b}$ & 471.0 & 0.177 & $1.0645-5$ & $6.3675-6$ \\
$9^{c}$ & 594.0 & 0.255 & $1.5336-5$ & $9.1179-6$ \\
\hline
\end{tabular}

${ }^{a}$ Read as $2.0869 \times 10^{-5}$.

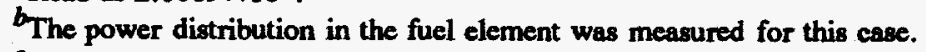

The thermal flux distribution in the reflector was measured for this case. 


\section{APPENDIX B}

\section{TABLES OF MEASURED AND CALCULATED RELATIVE POWER DENSITY AND THERMAL FLUX VALUES}

Tables of the measured and calculated relative power density and thermal flux values are included in this appendix. The measured values in Tables B.1-B.6 are from ref. 6. Values calculated with the KENO, DORT, and VENTURE models of the simple, intermediate, and complex FOEHN configurations are shown in Tables B.7-B.26.

Table B.1. Measured relative power density values for the simple FOEHN configuration

\begin{tabular}{|c|c|c|c|c|c|c|c|c|c|c|c|}
\hline $\mathrm{H} / \mathrm{r}(\mathrm{mm})$ & 143.5 & 146.5 & 149.5 & 152.5 & 159.0 & 167.5 & 176.0 & 182.5 & 185.5 & 188.5 & 193.95 \\
\hline 797.5 & 2.5247 & 2.2931 & 2.3323 & 2.2518 & 2.1002 & 2.1656 & 2.1556 & 2.3767 & 2.5115 & 2.5618 & 2.9004 \\
\hline 790.6 & 2.0302 & & & & & & & & & & 2.6260 \\
\hline 785.5 & 1.7642 & & & & & & 1.20206 & & & & 2.42288 \\
\hline 300.6 & 1.6608 & & & & & & 1.0912 & & & & 2.3470 \\
\hline mi.s & 1.5239 & & & & & & 0.9205 & & & & 2.1803 \\
\hline 750.0 & 1.3380 & 1.1518 & 1.0203 & 0.9272 & 0.8218 & 0.8020 & 0.9149 & 1.1075 & 1.2551 & 1.4642 & 2.0507 \\
\hline 725.0 & 1.2673 & & & & & & 0.7715 & & & & 1.9772 \\
\hline 700.0 & 1.2375 & & & & & & 0.7730 & & & & 1.9769 \\
\hline 625.0 & 1.2020 & 1.1417 & 1.0136 & 0.9871 & 0.8407 & 0.8270 & 0.9440 & 1.1293 & 1.3157 & 1.4818 & 2.0233 \\
\hline 550.0 & 1.3340 & & & & & & 0.8600 & & & & 2.1180 \\
\hline 475.0 & 1.2910 & & & & & & 0.8630 & & & & 2.1315 \\
\hline 400.0 & 1.1620 & 1.0985 & 0.9491 & 0.8971 & 0.8348 & 0.8280 & 0.9442 & 1.1541 & 1.3180 & 1.4889 & 2.0459 \\
\hline 325.0 & 1.02666 & & & & & & 0.7600 & & & & 1.9600 \\
\hline 250.0 & 0.7326 & & & & & & 0.6440 & & & & 1.7007 \\
\hline 175.0 & 0.6279 & 0.6011 & 0.5472 & 0.5335 & 0.5237 & 0.5580 & 0.6627 & 0.8574 & 0.9755 & 1.1134 & 1.5648 \\
\hline 100.0 & 0.5291 & & & & & 0.4706 & & & & & 1.3556 \\
\hline 75.0 & 0.5354 & & & & & 0.4467 & & & & & 1.3130 \\
\hline 50.0 & 0.5015 & 0.4839 & 0.4361 & 0.4241 & 0.4057 & 0.4400 & 0.5312 & 0.6897 & 0.7862 & 0.8977 & 1.2751 \\
\hline 28.5 & 0.5315 & & & & & 0.4836 & & & & & 1.3029 \\
\hline 19.4 & 0.5870 & & & & & 0.5430 & & & & & 1.3195 \\
\hline 14.5 & 0.6646 & & & & & & & & & & \\
\hline 9.4 & 0.6899 & & & & & & & & & & 1.4421 \\
\hline 2.5 & 0.8992 & 0.8945 & 0.8782 & 0.8707 & 0.8902 & 0.9384 & 1.0359 & 1.1621 & 1.2329 & 1.3258 & 1.5329 \\
\hline
\end{tabular}


Table B.2. Measured thermal flux values for the simple FOEHN configuration

\begin{tabular}{|c|c|c|c|c|c|c|c|c|c|c|c|c|c|}
\hline $\mathrm{H} / \mathrm{r}(\mathrm{mm})$ & 235 & 255 & 275 & 295 & 315 & 335 & 355 & 395 & 435 & 515 & 635 & 755 & 835 \\
\hline 1825 & 1.041 & 1.030 & 1.016 & 1.004 & 0.960 & & 0.928 & 0.857 & 0.802 & & & & \\
\hline 1675 & 1.566 & 1.568 & 1.561 & 1.523 & 1.47 & & 1.414 & 1.303 & 1.211 & 1.003 & 0.740 & 0.523 & 0.384 \\
\hline 1525 & 1.604 & 1.840 & 1.912 & 1.943 & 1.957 & 1.950 & 1.919 & 1.782 & 1.644 & 1.351 & 0.963 & 0.674 & 0.488 \\
\hline 1425 & 1.411 & 1.834 & 1.950 & 2.096 & 2.167 & 2.194 & 2.173 & 2.055 & 1.89 & 1.521 & 1.082 & 0.746 & 0.541 \\
\hline 1375 & 1.462 & 1.873 & 2.063 & 2.174 & 2.294 & 2.304 & 2.27 & 2.147 & 1.992 & & & & \\
\hline 1325 & 1.501 & 1.941 & 2.128 & 2.254 & 2.334 & 2.358 & 2.377 & 2.244 & 2.079 & 1.683 & 1.172 & 0.802 & 0.585 \\
\hline 1275 & 1.560 & 1.993 & 2.178 & 2.310 & 2.415 & 2.442 & 2.423 & 2.304 & 2.130 & 1.716 & 1.189 & & \\
\hline 1225 & 1.590 & 2.017 & 2.209 & 2.348 & 2.476 & 2.441 & 2.466 & 2.349 & 2.142 & 1.748 & 1.222 & 0.852 & 0.602 \\
\hline 1125 & 1.538 & 1.970 & 2.160 & 2.292 & 2.438 & 2.434 & 2.432 & 2.326 & 2.139 & 1.736 & 1.209 & 0.822 & 0.594 \\
\hline 1075 & & 1.931 & & 2.239 & & 2.365 & & & & & & & \\
\hline 975 & 1.368 & 1.743 & 1.916 & 2.023 & 2.129 & 2.139 & 2.139 & 2.064 & 1.910 & 1.563 & 1.104 & 0.755 & 0.559 \\
\hline 925 & 1.272 & & 1.781 & & 1.982 & & 2.000 & & & & & & \\
\hline 825 & 1.076 & 1.366 & 1.492 & 1.585 & 1.673 & 1.682 & 1.706 & 1.654 & 1.526 & 1.271 & & 0.644 & 0.484 \\
\hline 725 & 0.956 & 1.154 & 1.230 & 1.298 & 1.356 & & 1.365 & & & & & & \\
\hline 625 & 0.885 & 0.950 & 1.000 & 1.037 & 1.110 & & 1.037 & 1.017 & 0.979 & 0.808 & & & 0.353 \\
\hline 525 & 0.652 & 0.701 & 0.785 & 0.752 & 0.769 & & & & & & & & \\
\hline
\end{tabular}


Table B.3. Measured relative power density values for the intermediate FOEHN configuration

\begin{tabular}{|c|c|c|c|c|c|c|c|c|c|c|c|}
\hline $\mathrm{H} / \mathrm{r}(\mathrm{mm})$ & 143.5 & 146.5 & 149.5 & 152.5 & 159.0 & 167.5 & 176.0 & 182.5 & 185.5 & 188.5 & 193.9 \\
\hline 797.5 & 1.2617 & 1.1367 & 1.0607 & 0.9924 & 0.9023 & 0.8946 & 0.9708 & 1.1586 & 1.2664 & 1.4038 & 1.8400 \\
\hline 790.6 & 1.1577 & & & & & & & & & & 1.7956 \\
\hline 785.5 & 1.1152 & & & & & 0.7138 & & & & & 1.7609 \\
\hline 780.6 & 1.0300 & & & & & 0.7054 & & & & & 1.7518 \\
\hline 77.5 & 1.0978 & & & & & 0.6885 & & & & & 1.7620 \\
\hline 750.0 & 1.0247 & 0.9687 & 0.8770 & 0.7968 & 0.7082 & 0.6666 & 0.8015 & 0.9889 & 1.1146 & 1.2653 & 1.7799 \\
\hline 725.0 & 1.1423 & & & & & 0.7301 & & & & & 1.8183 \\
\hline 700.0 & 1.1813 & & & & & 0.7740 & & & & & 1.5097 \\
\hline 625.0 & 1.3150 & 1.1794 & 1.0616 & 0.9743 & 0.8880 & 0.8800 & 0.9931 & 1.2161 & 1.3458 & 1.5414 & 2.1313 \\
\hline 550.0 & 1.3564 & & & & & 0.9315 & & & & & 2.2630 \\
\hline 475.0 & 1.3118 & & & & & 0.9275 & & & & & 2.3172 \\
\hline 400.0 & 1.0142 & 0.9537 & 0.8855 & 0.8438 & 0.8024 & 0.8560 & 1.0112 & 1.2612 & 1.4062 & 1.6161 & 2.2504 \\
\hline 325.0 & 0.9511 & & & & & 0.8000 & & & & & 2.1266 \\
\hline 250.0 & 0.8502 & & & & & 0.7224 & & & & & 1.9383 \\
\hline 175.0 & 0.7313 & 0.6753 & 0.6400 & 0.6051 & 0.5872 & 0.6257 & 0.7491 & 0.9407 & 1.0623 & 1.2310 & 1.7123 \\
\hline 100.0 & 0.5930 & & & & & 0.5121 & & & & & 1.4317 \\
\hline 75.0 & 0.5567 & & & & & 0.4770 & & & & & 1.3421 \\
\hline 50.0 & 0.5110 & 0.4742 & 0.4459 & 0.4239 & 0.4093 & 0.4420 & 0.5392 & 0.6769 & 0.785 & 0.8976 & 1.2601 \\
\hline 28.5 & 0.4847 & & & & & 0.4245 & & & & & 1.2234 \\
\hline 19.4 & 0.4794 & & & & & 0.4167 & & & & & 1.1911 \\
\hline 14.5 & 0.4794 & & & & & 0.4238 & & & & & 1.2000 \\
\hline 9.4 & 0.4839 & & & & & & & & & & 1.1990 \\
\hline 2.5 & 0.5018 & 0.4759 & 0.4512 & 0.4397 & 0.4338 & 0.4766 & 0.5805 & 0.7211 & 0.8090 & 0.9171 & 1.1850 \\
\hline
\end{tabular}


Table B.4. Measured thermal flux values for the intermediate FOEHN configuration

\begin{tabular}{|c|c|c|c|c|c|c|c|c|c|c|c|c|c|c|}
\hline $\mathrm{H} / \mathrm{r}(\mathrm{mm})$ & 235 & 275 & 315 & 335 & 355 & 375 & 395 & 435 & 515 & 675 & 755 & 835 & 915 & 955 \\
\hline 1810 & 0.9574 & 0.9224 & 0.8768 & & 0.8310 & & & & & & & & & \\
\hline 1710 & 1.2638 & 1.2162 & 1.1836 & & 1.1168 & 1.0672 & & & & & & & & \\
\hline 1610 & 1.3973 & 1.4562 & 1.4784 & & 1.4394 & 1.3761 & 1.2787 & & & & & 0.4229 & & \\
\hline 1510 & 1.2004 & 1.6412 & 1.7851 & & 1.7830 & 1.7232 & 1.5762 & & & & & 0.4879 & & \\
\hline 1410 & 1.4636 & 1.9093 & 2.1072 & & 2.0986 & 2.0637 & 2.0328 & 1.8666 & 1.5366 & & & 0.5460 & & \\
\hline 1310 & 1.6640 & 2.1611 & 2.3967 & & 2.3952 & 2.3266 & 2.3001 & 2.0950 & 1.7026 & 1.0479 & 0.7964 & 0.5892 & & \\
\hline 1260 & & & & 2.4761 & 2.5041 & 2.4317 & 2.3750 & & & & & & & \\
\hline 1210 & 1.7829 & 2.3089 & 2.5402 & 2.5368 & 2.5333 & 2.4760 & 2.4152 & 2.2340 & 1.7928 & 1.0887 & 0.8250 & 0.6118 & 0.4427 & 0.3581 \\
\hline 1160 & & & & 2.5383 & 2.5641 & 2.4823 & 2.4292 & & & & & & & \\
\hline 1110 & 1.7532 & 2.2716 & 2.5066 & 2.5170 & 2.4976 & 2.4631 & 2.3900 & 2.2225 & 1.7824 & 1.0843 & 0.8266 & 0.6117 & 0.4427 & 0.3606 \\
\hline 1060 & & & & 2.4383 & & 2.3901 & & & & & & & & \\
\hline 1010 & 1.6042 & 2.0957 & 2.3018 & 2.3356 & 2.3398 & 2.3056 & 2.2500 & 2.0846 & 1.6920 & 1.0342 & 0.7956 & 0.5858 & 0.4223 & 0.3479 \\
\hline 910 & 1.4069 & 1.8222 & 2.0323 & & 2.0529 & 2.0178 & 1.9817 & 1.8660 & 1.5200 & 0.9437 & 0.7312 & 0.5428 & & \\
\hline 810 & 1.1239 & 1.4658 & 1.6560 & & 1.6981 & & 1.6400 & 1.5362 & 1.2937 & 0.8336 & 0.6438 & 0.4853 & & \\
\hline 710 & 0,8863 & 1.1489 & 1.2847 & & 1.3208 & & 1.2941 & 1.2236 & & & & 0.4176 & & \\
\hline 610 & 0.8242 & 0.9216 & 0.9719 & & 0.9851 & & 0.9560 & & & & & & & \\
\hline 510 & 0.6045 & 0.6648 & 0.6882 & & 0.7016 & & & & & & & & & \\
\hline
\end{tabular}


Table B.5. Measured relative power density values for the complex FOEHN configuration

\begin{tabular}{|c|c|c|c|c|c|c|c|c|c|c|c|}
\hline $\mathrm{H} / \mathrm{r}(\mathrm{mm})$ & 143.5 & 146.5 & 149.5 & 152.5 & 159.0 & 167.5 & 176.0 & 182.5 & 185.5 & 188.5 & 193.95 \\
\hline 797.5 & 1.2958 & 1.1534 & 1.0572 & 1.0238 & 0.9171 & 0.8625 & 0.9632 & 1.1537 & & 1.3556 & 1.8193 \\
\hline 795.0 & & & & & & & & & & & 1.7183 \\
\hline 790.6 & 1.1528 & & & & & & & & & & 1.7021 \\
\hline 785.5 & 1.1344 & & & & & 0.7188 & & & & & 1.6985 \\
\hline 780.6 & 1.1352 & & & & & 0.7285 & & & & & 1.6806 \\
\hline 771.5 & 1.1000 & & & & & 0.6721 & & & & & 1.6685 \\
\hline 750.0 & 1.1257 & 0.9867 & 0.8775 & 0.8289 & 0.7265 & 0.7100 & 0.7993 & 1.0039 & 1.0851 & 1.2325 & 1.7150 \\
\hline 725.0 & 1.1729 & & & & & 0.7442 & & & & & 1.7600 \\
\hline 700.0 & 1.2275 & & & & & 0.8055 & & & & & 1.8327 \\
\hline 625.0 & 1.3661 & 1.2192 & 1.0878 & 1.0273 & 0.9211 & 0.9003 & 1.0106 & 1.2300 & 1.3538 & 1.5147 & 2.0550 \\
\hline 550.0 & 1.4596 & & & & & 0.9621 & & & & & 2.1906 \\
\hline 475.0 & 1.3656 & & & & & 0.9684 & & & & & 2.2314 \\
\hline 400.0 & 1.0555 & 0.9788 & 0.9144 & 0.8984 & 0.8473 & 0.8850 & 1.0357 & 1.2898 & 1.4189 & 1.6113 & 2.2120 \\
\hline 325.0 & 0.9626 & & & & & 0.8191 & & & & & 2.0636 \\
\hline 250.0 & 0.8609 & & & & & 0.7408 & & & & & 1.8965 \\
\hline 175.0 & 0.7386 & 0.6832 & 0.6508 & 0.6328 & 0.6002 & 0.6410 & 0.7650 & 0.9542 & 1.0744 & 1.2272 & 1.6764 \\
\hline 100.0 & 0.6163 & & & & & 0.5283 & & & & & 1.4047 \\
\hline 75.0 & 0.5441 & & & & & 0.4965 & & & & & 1.3249 \\
\hline 50.0 & 0.5061 & 0.4655 & 0.4540 & 0.4359 & 0.4214 & 0.4560 & 0.5526 & 0.6827 & 0.7796 & 0.8979 & 1.2395 \\
\hline 28.5 & 0.4920 & & & & & 0.4270 & & & & & 1.1787 \\
\hline 19.4 & 0.4880 & & & & & 0.4295 & & & & & 1.1697 \\
\hline 14.5 & 0.4629 & & & & & 0.4437 & & & & & 1.1657 \\
\hline 9.4 & & & & & & & & & & & 1.1654 \\
\hline 5.0 & & & & & & & & & & & 1.1739 \\
\hline 2.5 & 0.5033 & 0.4701 & 0.4529 & 0.4492 & 0.4462 & 0.4908 & 0.5958 & 0.7363 & 0.8162 & 0.9236 & \\
\hline
\end{tabular}

Table B.6. Measured thermal flux values for the complex FOEHN configuration

\begin{tabular}{|c|c|}
\hline $\begin{array}{l}\text { Radius }^{a} \\
\text { (mm) }\end{array}$ & $\begin{array}{l}\text { Thermal flux } \\
10^{11} \text { neutrons } /\left(\mathrm{m}^{2} \mathrm{~s}\right)\end{array}$ \\
\hline 275 & 2.11 \\
\hline 315 & 2.30 \\
\hline 435 & 1.82 \\
\hline 515 & 1.48 \\
\hline 675 & 0.97 \\
\hline 755 & 0.72 \\
\hline
\end{tabular}

Height $=1110 \mathrm{~mm}$, the midplane of the fuel element. 
Table B.7. Relative power density values calculated with KENO using 99-group cross sections for the simple FOEHN configuration

\begin{tabular}{|c|c|c|c|c|c|c|c|c|c|c|c|}
\hline $\mathrm{H} / \mathrm{r}(\mathrm{mm})$ & 143.5 & 146.5 & 149.5 & 152.5 & 159.0 & 167.5 & 176.0 & 182.5 & 185.5 & 188.5 & 193.95 \\
\hline 797.5 & 2.3922 & 2.2783 & 2.1940 & 2.0926 & 2.0602 & 1.9931 & 2.1190 & 2.2070 & 2.3325 & 2.4858 & 2.8859 \\
\hline 790.6 & 1.8764 & 1.7324 & 1.5652 & 1.4883 & 1.4068 & 1.4003 & 1.4578 & 1.6245 & 1.7620 & 1.9217 & 2.4270 \\
\hline 785.5 & 1.7615 & 1.5073 & 1.4383 & 1.3110 & 1.1753 & 1.1878 & 1.2660 & 1.4383 & 1.5768 & 1.7425 & 2.3121 \\
\hline 700.6 & 1.5944 & 1.4063 & 1.2637 & 1.1734 & 1.0530 & 1.0553 & 1.1257 & 1.3193 & 1.4763 & 1.6397 & 2.1505 \\
\hline 71.5 & 1.5893 & 1.3725 & 1.1873 & 1.1123 & 0.9859 & 0.9609 & 1.0577 & 1.2596 & 1.3545 & 1.5707 & 2.1176 \\
\hline 750.0 & 1.2966 & 1.1355 & 0.9924 & 0.9410 & 0.8159 & 0.7946 & 0.9048 & 1.0641 & 1.1864 & 1.4110 & 1.9315 \\
\hline 725.0 & 1.2535 & 1.0720 & 0.9553 & 0.8636 & 0.7896 & 0.7469 & 0.8752 & 1.0762 & 1.1651 & 1.3549 & 1.8842 \\
\hline 700.0 & 1.2197 & 1.0540 & 0.9678 & 0.8923 & 0.7821 & 0.7696 & 0.8673 & 1.0452 & 1.1943 & 1.4133 & 1.8856 \\
\hline 625.0 & 1.3165 & 1.1549 & 1.0113 & 0.9507 & 0.8571 & 0.8122 & 0.9410 & 1.1248 & 1.2934 & 1.4883 & 1.9657 \\
\hline 500.0 & 1.3800 & 1.1929 & 1.0836 & 0.9725 & 0.8886 & 0.8539 & 0.9836 & 1.1966 & 1.3429 & 1.5656 & 2.0792 \\
\hline 475.0 & 1.3781 & 1.2197 & 1.1128 & 0.9678 & 0.8775 & 0.8845 & 0.9942 & 1.1980 & 1.3452 & 1.5494 & 2.0834 \\
\hline 400.0 & 1.3387 & 1.1461 & 1.037 & 0.9822 & 0.8382 & 0.8210 & 0.9553 & 1.1725 & 1.3165 & 1.5175 & 20662 \\
\hline 325.0 & 1.2484 & 1.0479 & 0.9474 & 0.8956 & 0.7863 & 0.7696 & 0.894 & 1.1030 & 1.2494 & 1.4175 & 1.9685 \\
\hline 250.0 & 0.8085 & 0.7053 & 0.6761 & 0.6451 & 0.5988 & 0.6793 & 0.7812 & 0.9701 & 1.0655 & 1.2651 & 1.6805 \\
\hline 175.0 & 0.6765 & 0.6043 & 0.5793 & 0.5617 & 0.5365 & 0.5557 & 0.6849 & 0.8395 & 0.9539 & 1.1248 & 1.5286 \\
\hline 100.0 & 0.5617 & 0.5029 & 0.4614 & 0.4635 & 0.4441 & 0.4853 & 0.5659 & 0.7219 & 0.8294 & 0.9655 & 1.3466 \\
\hline 75.0 & 0.5557 & 0.4927 & 0.4541 & 0.4275 & 0.4079 & 0.4451 & 0.5543 & 0.6798 & 0.7937 & 0.9155 & 1.2822 \\
\hline 50.0 & 0.5483 & 0.4872 & 0.4603 & 0.4365 & 0.4144 & 0.4440 & 0.5469 & 0.6761 & 0.7664 & 0.9169 & 1.2730 \\
\hline 28.5 & 0.5793 & 0.5122 & 0.4746 & 0.4746 & 0.4640 & 0.4909 & 0.5524 & 0.7196 & 0.8178 & 0.9641 & 1.2004 \\
\hline 19.4 & 0.6349 & 0.5747 & 0.5339 & 0.5321 & 0.5186 & 0.5506 & 0.6233 & 0.7645 & 0.8446 & 0.9599 & 1.3022 \\
\hline 14.5 & 0.6548 & 0.6191 & 0.5918 & 0.5534 & 0.5742 & 0.6113 & 0.7085 & 0.8196 & 0.9160 & 1.0058 & 1.4355 \\
\hline 9.4 & 0.7414 & 0.7150 & 0.6886 & 0.6520 & 0.6580 & 0.7006 & 0.7766 & 0.9016 & 0.9766 & 1.1095 & 1.4795 \\
\hline 2.5 & 0.9391 & 0.9109 & 0.9197 & 0.9248 & 0.9275 & 1.0164 & 1.1248 & 1.2276 & 1.2651 & 1.3762 & 1.6522 \\
\hline
\end{tabular}

Table B.8. Two sigma standard deviations for the relative power density values calculated with KENO using 99-group cross sections for the simple FOEHN configuration

\begin{tabular}{|c|c|c|c|c|c|c|c|c|c|c|c|}
\hline$H / r(m m)$ & 143.5 & 146.5 & 149.5 & 152.5 & 159.0 & 167.5 & 176.0 & 182.5 & 185.5 & 188.5 & 193.95 \\
\hline 791.5 & 0.0258 & 0.0274 & 0.0262 & 0.0274 & 0.0264 & 0.0256 & 0.0246 & 0.0234 & 0.0228 & 0.0220 & 0.0204 \\
\hline 790.6 & 0.0280 & 0.0288 & 0.0288 & 0.0292 & 0.0278 & $0.0280^{\circ}$ & 0.0270 & 0.0266 & 0.0274 & 0.0250 & 0.0200 \\
\hline 785.5 & 0.0282 & 0.0276 & 0.0292 & 0.0310 & 0.0324 & 0.0314 & 0.0292 & 0.0276 & 0.0262 & 0.0214 & 0.0236 \\
\hline 780.6 & 0.0304 & 0.0296 & 0.0308 & 0.0316 & 0.0312 & 0.0312 & 0.0306 & 0.0296 & 0.0264 & 0.0262 & 0.0228 \\
\hline 771.5 & 0.0330 & 0.0326 & 0.0042 & 0.0344 & 0.0348 & 0.0350 & 0.0330 & 0.0312 & 0.0300 & 0.0276 & 0.0270 \\
\hline 750.0 & 0.0332 & 0.0344 & 0.0346 & 0.0348 & 0.0336 & 0.0336 & 0.0334 & 0.0020 & 0.0290 & 0.0272 & 0.0246 \\
\hline 725.0 & 0.0330 & 0.0328 & 0.0334 & 0.0352 & 0.0334 & 0.0320 & 0.0302 & 0.0306 & 0.0292 & 0.0266 & 0.0252 \\
\hline 200.0 & 0.0328 & 0.0332 & 0.0318 & 0.0322 & 0.0336 & 0.0326 & 0.0296 & 0.0306 & 0.0264 & 0.0276 & 0.0250 \\
\hline 625.0 & 0.0312 & 0.0302 & 0.0312 & 0.0338 & 0.0312 & 0.0294 & 0.0302 & 0.0300 & 0.0270 & 0.0258 & 0.0242 \\
\hline 550.0 & 0.0284 & 0.0310 & 0.0282 & 0.0304 & 0.0306 & 0.0310 & 0.0298 & 0.0284 & 0.0262 & 0.0254 & 0.0244 \\
\hline 475.0 & 0.0296 & 0,0314 & 0.0308 & 0.0294 & 0.0310 & 0.0306 & 0.0284 & 0.0278 & 0.0278 & 0.0242 & 0.0232 \\
\hline 400.0 & 0.0302 & 0.0306 & 0,0316 & 0.0312 & 0.0320 & 0.0316 & 0.0296 & 0.0278 & 0.0260 & 0.0250 & 0.0204 \\
\hline 325.0 & 0.0330 & 0.0328 & 0.0328 & 0.0326 & 0.0316 & 0.0304 & 0.0294 & 0.0288 & 0.0300 & 0.0260 & 0.0238 \\
\hline 250.0 & 0.0352 & 0.0334 & 0.0348 & 0.0346 & 0.0370 & 0.0342 & 0.0332 & 0.0300 & 0.0296 & 0.0288 & 0.0252 \\
\hline 175.0 & 0.0368 & 0.0386 & 0.0378 & 0.0382 & 0.0354 & 0.0370 & 0.0342 & 0.0312 & 0.0302 & 0.0302 & 0.0260 \\
\hline 100.0 & 0.0430 & 0.0440 & 0.0416 & 0.0452 & 0.0428 & 0.0394 & 0.0392 & 0.0358 & 0.0332 & 0.0330 & 0.0292 \\
\hline 75.0 & 0.0422 & 0.0430 & 0.0414 & 0.0442 & 0.0422 & 0.0414 & $0.03: 0$ & 0.0388 & 0.0360 & 0.0328 & 0.0306 \\
\hline 50.0 & 0.0414 & 0.0422 & 0.0418 & 0.0440 & 0.0428 & 0.0410 & 0.0388 & 0.0360 & 0.0372 & 0.0358 & 0.0302 \\
\hline 28.5 & 0.0416 & 0.0432 & 0.0434 & 0.0422 & 0.0442 & 0.0422 & 0.0384 & 0.0380 & 0.0344 & 0.0348 & 0.0302 \\
\hline 19.4 & 0.0418 & 0.0440 & 0.0440 & 0.0444 & 0,0428 & 0.0424 & 0.0406 & 0.0372 & 0.0340 & 0.0324 & 0.0292 \\
\hline 14.5 & 0.0404 & 0.0430 & 0.0426 & 0.0442 & 0.0408 & 0.0382 & 0.0372 & 0.0360 & 0.0342 & 0.0322 & 0.0286 \\
\hline 9.4 & 0.0416 & 0.0408 & 0.0388 & 0.0430 & 0.0392 & 0.0396 & 0.0354 & 0.0334 & 0.0342 & 0.0312 & 0.0288 \\
\hline 2.5 & 0.0368 & 0.0382 & 0.0378 & 0.0386 & 0.0362 & 0.0342 & 0.0314 & 0.0318 & 0.0306 & 0.0302 & 0.0280 \\
\hline
\end{tabular}


Table B.9. Relative power density values calculated with DORT using 20-group cross sections for the simple FOEHN configuration

\begin{tabular}{|c|c|c|c|c|c|c|c|c|c|c|c|}
\hline H/r(mm) & 143.5 & 146.5 & 149.5 & 1525 & 159.0 & 167.5 & 176.0 & 182.5 & 185.5 & 188.5 & 193.95 \\
\hline 797.5 & 2.3642 & 2.2024 & 2.1301 & 2.0652 & 1.9958 & 1.9933 & 2.0724 & 2.2113 & 2.3108 & 2.4420 & 2.6851 \\
\hline 790.6 & 1.8816 & 1.6813 & 1.5576 & 1.4737 & 1.3843 & 1.3708 & 1.4489 & 1.5989 & 1.7212 & 1.8929 & 2.4546 \\
\hline 785.5 & 1.7119 & 1.4963 & 1.3673 & 1.2765 & 1.1646 & 1.1398 & 1.2307 & 1.4056 & 1.5345 & 1.7168 & 2.3160 \\
\hline 700.6 & 1.6005 & 1.3786 & 1.2408 & 1.1550 & 1.0467 & 1.0197 & 1.1152 & 1.2886 & 1.4194 & 1.6083 & 2.2156 \\
\hline 771.5 & 1.4620 & 1.2566 & 1.1153 & 1.0187 & 0.9176 & 0.8930 & 0.9894 & 1.1654 & 1.3002 & 1.5022 & 2.1098 \\
\hline 750.0 & 1.307 & 1.1213 & 0.9925 & 0.9028 & 0.7939 & 0.7749 & 0.8734 & 1.0627 & 1.2048 & 1.4031 & 1.9031 \\
\hline 725.0 & 1.2470 & 1.0746 & 0.9551 & 0.8713 & 0.7689 & 0.7513 & 0.8546 & 1.0440 & 1.1829 & 1.3756 & 1.9409 \\
\hline 700.0 & 1.2412 & 1.0729 & 0.9561 & 0.8742 & 0.7757 & 0.7622 & 0.2644 & 1.0538 & 1.1925 & 1.3850 & 1.9471 \\
\hline 625.0 & 1.3095 & 1.1376 & 1.0177 & 0.9337 & 0.8332 & 0.8201 & 0.9280 & 1.1249 & 1.2690 & 1.4699 & 2.0583 \\
\hline 550.0 & 1.3753 & 1.1934 & 1.0695 & 0.9830 & 0.8788 & 0.8633 & 0.9763 & 1.1809 & 1.3322 & 1.5406 & 21503 \\
\hline 475.0 & 1.3941 & 1.2098 & 1.0831 & 0.9044 & 0.8876 & 0.8750 & 0.9890 & 1.1964 & 1.3492 & 1.5591 & 2.1781 \\
\hline 400.0 & 1.3468 & 1.1697 & 1.0472 & 0.9616 & 0.8621 & 0.8509 & 0.9621 & 1.1647 & 1.3145 & 1.5212 & 2.1232 \\
\hline 325.0 & 1.2114 & 1.0584 & 0.9519 & 0.8765 & 0.7872 & 0.7002 & 0.8997 & 1.0842 & 1.22064 & 1.4215 & 1.9961 \\
\hline 250.0 & 0.8122 & 0.7361 & 0.6828 & 0.6467 & 0.6144 & 0.6464 & 0.7696 & 0.9566 & 1.0904 & 1.2709 & 1.7980 \\
\hline 175.0 & 0.6735 & 0.6109 & 0.5680 & 0.5409 & 0.5204 & 0.5569 & 0.6672 & 0.8352 & 0.9528 & 1.1157 & 1.5841 \\
\hline 100.0 & 0.5582 & 0.5117 & 0.4779 & 0.4542 & 0.4382 & 0.4702 & 0.5688 & 0.7179 & 0.8226 & 0.9656 & 1.3775 \\
\hline 75.0 & 0.5326 & 0.4857 & 0.4531 & 0.4322 & 0.4172 & 0.4468 & 0.5429 & 0.6872 & 0.7989 & 0.9270 & 1.3268 \\
\hline 50.0 & 0.5285 & 0.4795 & 0.4470 & 0.4262 & 0.4103 & 0.4398 & 0.5313 & 0.6716 & 0.7717 & 0.9085 & 1.3027 \\
\hline 28.5 & 0.5600 & 0.5143 & 0.4807 & 0.4602 & 0.4507 & 0.4903 & 0.5699 & 0.6997 & 0.7934 & 0.9276 & 1.3262 \\
\hline 19.4 & 0.6161 & 0.5601 & 0.5285 & 0.5119 & 0.5025 & 0.5335 & 0.6249 & 0.7511 & 0.8401 & 0.9672 & 1.3579 \\
\hline 14.5 & 0.6595 & 0.6078 & 0.5795 & 0.5625 & 0.5541 & 0.5863 & 0.6733 & 0.8019 & 0.8913 & 1.0121 & 1.3984 \\
\hline 9.4 & 0.7292 & 0.6829 & 0.6601 & 0.6499 & 0.6518 & 0.6910 & 0.779 & 0.8897 & 0.9736 & 1.0899 & 1.4552 \\
\hline 2.5 & 0.9194 & 0.8978 & 0.8905 & 0.8903 & 0.9128 & 0.9755 & 1.0753 & 1.1938 & 1.2684 & 1.3611 & 1.5621 \\
\hline
\end{tabular}

Table B.10. Relative power density values calculated with VENTURE using 20-group cross sections for the simple FOEHN configuration

\begin{tabular}{|c|c|c|c|c|c|c|c|c|c|c|c|}
\hline $\mathrm{H} / \mathrm{r}(\mathrm{mm})$ & 143.5 & 146.5 & 149.5 & 152.5 & 159.0 & 167.5 & 176.0 & 182.5 & 185.5 & 188.5 & 193.95 \\
\hline 797.5 & 2.3651 & 2.2567 & 2.1797 & 2.1240 & 2.0571 & 2.0568 & 2.1475 & 2.2877 & 2.3797 & 2.4960 & 2.7480 \\
\hline 790.6 & 1.9911 & 1.8128 & 1.6892 & 1.6029 & 1.5010 & 1.4845 & 1.5806 & 1.7542 & 1.8799 & 20494 & 2.5542 \\
\hline 785.5 & 1.8157 & 1.6190 & 1.4792 & 1.3802 & 1.2611 & 1.2372 & 1.3405 & 1.5344 & 1.6764 & 1.8671 & 2.4207 \\
\hline$\pi 0.6$ & 1.6902 & 1.4883 & 1.3424 & 1.2375 & 1.1093 & 1.0815 & 1.1909 & 1.3990 & 1.5490 & 1.7503 & 23229 \\
\hline 771.5 & 1.5274 & 1.3301 & 1.1849 & 1.0789 & 0.9467 & 0.9178 & 1.0342 & 1.2525 & 1.4096 & 1.6167 & 2.1980 \\
\hline 750.0 & 1.3245 & 1.1492 & 1.0185 & 0.9221 & 0.8012 & 0.7798 & 0.8992 & 1.1176 & 1.2722 & 1.4738 & 2.0255 \\
\hline $\mathbf{2 5 . 0}$ & 1.2385 & 1.0788 & 0.9597 & 0.8718 & 0.7623 & 0.7461 & 0.8660 & 1.0791 & 1.2291 & 1.4241 & 1.9561 \\
\hline 700.0 & 1.2188 & 1.0654 & 0.9511 & 0.8667 & 0.7622 & 0.7488 & 0.8688 & 1.0002 & 1.2288 & 1.4218 & 1.9491 \\
\hline 625.0 & 1.2685 & 1.1141 & 0.9990 & 0.9141 & 0.8091 & 0.7970 & 0.9213 & 1.1391 & 1.2922 & 1.4910 & 2.0329 \\
\hline 550.0 & 1.3241 & 1.1643 & 1.0450 & 0.9570 & 0.8481 & 0.8354 & 0.9640 & 1.1897 & 1.3482 & 1.5542 & 2.1158 \\
\hline 475.0 & 1.3344 & 1.1737 & 1.0537 & 0.9652 & 0.8558 & 0.8433 & 0.9733 & 1.2012 & 1.3612 & 1.5692 & 2.1359 \\
\hline 400.0 & 1.2884 & 1.1335 & 1.0180 & 0.9329 & 0.8280 & 0.8175 & 0.9455 & 1.1686 & 1.3251 & 1.5284 & 2.0823 \\
\hline 325.0 & 1.1414 & 1.0073 & 0.9079 & 0.8353 & 0.7485 & 0.7486 & 0.8756 & 1.0895 & 1.2385 & 1.4315 & 1.9564 \\
\hline 250.0 & 0.7811 & 0.7126 & 0.6628 & 0.6281 & 0.5954 & 0.6300 & 0.7650 & 0.9693 & 1.1085 & 1.2875 & 1.7709 \\
\hline 175.0 & 0.6539 & 0.5979 & 0.5575 & 0.5298 & 0.5061 & 0.5416 & 0.6650 & 0.8488 & 0.9736 & 1.1338 & 1.5660 \\
\hline 100.0 & 0.5541 & 0.5060 & 0.4716 & 0.4482 & 0.4289 & 0.4619 & 0.5725 & 0.7363 & 0.8475 & 0.9900 & 1.3746 \\
\hline 75.0 & 0.5342 & 0.4870 & 0.4532 & 0.4302 & 0.4110 & 0.4429 & 0.5504 & 0.7097 & 0.8178 & 0.9566 & 1.3310 \\
\hline 50.0 & 0.5407 & 0.4915 & $0.4 \$ 61$ & 0.4320 & 0.4110 & 0.4409 & 0.5458 & 0.7026 & 0.8092 & 0.9464 & 1.3172 \\
\hline 28.5 & 0.6015 & 0.5480 & 0.5101 & 0.4846 & 0.4626 & 0.4913 & 0.5926 & 0.7450 & 0.8495 & 0.9850 & 1.3556 \\
\hline 19.4 & 0.6615 & 0.6084 & 0.5721 & 0.5486 & 0.5310 & 0.5626 & 0.6611 & 0.8066 & 0.9066 & 1.0371 & 1.3999 \\
\hline 14.5 & 0.7096 & 0.6597 & 0.6270 & 0.6071 & 0.5956 & 0.6315 & 0.7287 & 0.8675 & 0.9624 & 1.0865 & 1.4365 \\
\hline 9.4 & 0.7785 & 0.7374 & 0.7127 & 0.6995 & 0.6991 & 0.7433 & 0.8408 & $0.9 \% 03$ & 1.0567 & 1.1689 & 1.4900 \\
\hline 2.5 & 0.9299 & 0.9174 & 0.9137 & 0.9167 & 0.9416 & 1.0079 & 1.1154 & 1.2340 & 1.3040 & 1.3878 & 1.5727 \\
\hline
\end{tabular}


Table B.11. Thermal fluxes calculated with DORT using 20-group cross sections for the simple FOEHN configuration

\begin{tabular}{|c|c|c|c|c|c|c|c|c|c|c|c|c|c|}
\hline $\mathrm{H} / \mathrm{r}(\mathrm{mm})$ & 235 & 253 & 275 & 295 & 315 & 335 & 355 & 395 & 435 & 515 & 635 & 755 & 835 \\
\hline 1825 & 1.0344 & 1.0279 & 1.0173 & 1.0034 & 0.9864 & 0.9664 & 0.9441 & 0.8934 & 0.8373 & 0.7180 & 0.5424 & 0.3861 & $\overline{0.2943}$ \\
\hline 1675 & 1.5614 & 1.5775 & 1.5789 & 1.5676 & 1.5461 & 1.5160 & 1.4792 & 1.3911 & 1.2911 & 1.0813 & 0.7895 & 0.5480 & 0.4127 \\
\hline 1525 & 1.6855 & 1.8545 & 1.9647 & 2.0280 & 2.0536 & 2.0495 & 2.0222 & 1.9206 & 1.7815 & 1.4672 & 1.0380 & 0.7030 & 0.5233 \\
\hline 1425 & 1.5483 & 1.8679 & 2.0875 & 2.2279 & 2.3052 & 2.3330 & 2.3229 & 2.2281 & 2.0686 & 1.6932 & 1.1800 & 0.7893 & 0.5840 \\
\hline 1375 & 1.6040 & 1.9448 & 2.1838 & 2.3390 & 2.4267 & 2.4609 & 2.4535 & 2.3338 & 2.1869 & 1.7553 & 1.2375 & 0.8240 & 0.0084 \\
\hline 1325 & 1.6691 & 2.0254 & 2.2758 & 2.4392 & 2.5320 & 2.5685 & 2.3614 & 2.4573 & 2.2820 & 1.8589 & 1.2835 & 0.8518 & 0.6279 \\
\hline 1275 & 1.7204 & 2.0874 & 2.3453 & 2.5136 & 2.6092 & 2.6468 & 2.6392 & 2.5313 & 2.3496 & 1.9115 & 1.3166 & 0.8719 & 0.6420 \\
\hline 1225 & 1.7484 & 2.1212 & 2.3832 & 2.5542 & 2.6512 & 2.6894 & 2.6817 & 2.5719 & 2.3870 & 1.9411 & 1.3357 & 0.8837 & 0.6505 \\
\hline 1125 & 1.7237 & 2.0925 & 2.3523 & 2.5220 & 2.6200 & 2.6594 & 2.6534 & 2.5480 & 2.3676 & 1.9294 & 1.3308 & 0.8830 & 0.6496 \\
\hline 1075 & 1.6711 & 2.0304 & 2.2843 & 2.4516 & 2.5482 & 2.5883 & 2.5843 & 2.4850 & 2.3122 & 1.8891 & 1.3072 & 0.8684 & 0.6404 \\
\hline 975 & 1.4973 & 1.8259 & 2.0602 & 2.2167 & 2.3094 & 2.3510 & 2.3526 & 2.2717 & 2.1225 & 1.7479 & 1.2223 & 0.8185 & 0.0000 \\
\hline 925 & 1.3880 & 1.6957 & 1.9162 & 2.0648 & 2.1542 & 2.1960 & 2.2003 & 2.1304 & 1.9998 & 1.6523 & 1.1637 & 0.7837 & 0.5818 \\
\hline 825 & 1.157 & 1.4100 & 1.6026 & 1.7296 & 1.8077 & 1.8466 & 1.8546 & 1.8053 & 1.2014 & 1.4267 & 1.0232 & 0.6987 & 0.5224 \\
\hline 725 & 1.0179 & 1.1989 & 1.3272 & 1,4137 & 1.4666 & 1.4924 & 1.4969 & 1.4601 & 1.3837 & 1.1783 & 0.8646 & 0.6010 & 0.4532 \\
\hline 625 & 0.9578 & 1.0312 & 1.0868 & 1.1252 & 1.1483 & 1.1580 & $t .1565$ & 1.1278 & 1.0751 & 0.9323 & 0.2030 & 0.4989 & 0.3799 \\
\hline 525 & 0.7260 & 0.7731 & 0.8072 & 0.8303 & 0.8440 & 0.8499 & 0.8492 & 0.832 & 0.7999 & 0.0086 & 0.5506 & 0.3994 & 0.3074 \\
\hline
\end{tabular}

Table B.12. Thermal fluxes calculated with VENTURE using 20-group cross sections for the simple FOEHN configuration

\begin{tabular}{|c|c|c|c|c|c|c|c|c|c|c|c|c|c|}
\hline $\mathrm{H} / \mathrm{r}(\mathrm{mm})$ & 235 & 255 & 275 & 295 & 315 & 335 & 335 & 395 & 435 & 515 & 635 & 755 & 835 \\
\hline 1825 & 1.0253 & 1.0185 & 1.0078 & 0.9936 & 0.9762 & 0.9560 & 0.9334 & 0.8827 & 0.8267 & 0.0084 & 0.5351 & 0.3814 & 0.2912 \\
\hline 1675 & 1.5158 & 1.5358 & 1.5407 & 1.5328 & 1.5142 & 1.4867 & 1.4521 & $1.36 n$ & 1.2695 & 1.0631 & 0.763 & 0.5395 & 0.4068 \\
\hline 1525 & 1.5750 & 1.7555 & 1.872 & 1.9510 & 1.9859 & 1.9895 & 1.9688 & 1.8767 & 1.7446 & 1.4384 & $1.01 n$ & 0.6899 & 0.5141 \\
\hline 1425 & 1.4425 & 1.7601 & 1.9653 & 2.1338 & 2.22000 & 2.2565 & 2.2542 & 2.1695 & 2.0212 & 1.6569 & 1.1547 & 0.730 & 0.5726 \\
\hline 1375 & 1.4864 & $1.82 \pi$ & 2.0719 & 2.2359 & 2.3332 & 2.3766 & 2.3776 & 2.2913 & 2.1346 & 1.7455 & 1.2099 & 0.8062 & 0.5959 \\
\hline 1325 & 1.5415 & 1.8976 & 2.1546 & 2.3275 & 2.4306 & 2.477 & 2.4790 & 2.3895 & 2.2251 & 1.8159 & 1.2536 & 0.8326 & 0.6144 \\
\hline 1275 & 1.5855 & 1.9522 & 2.2169 & 2.3951 & 2.5014 & 2.5495 & 2.5515 & 2.4590 & 2.2899 & 1.8656 & 1.2850 & 0.8516 & 0.6276 \\
\hline 1225 & 1.6002 & 1.9815 & 2.2502 & 2.4311 & 2.5392 & 2.5881 & 2.5902 & 2.4963 & 2.3236 & 1.8932 & 1.3028 & 0.8625 & 0.6353 \\
\hline 1125 & 1.5850 & 1.9528 & 2.2189 & 2.3988 & 2.5069 & 2.5567 & 2.56003 & 2.4706 & 2.3023 & 1.8797 & 1.2965 & 0.8597 & 0.6337 \\
\hline 1075 & 1.5374 & 1.8957 & 2.1555 & 2.3318 & 2.4385 & 2.4886 & 2.4937 & 2.4094 & 2.2481 & 1.8400 & $1.273 t$ & 0.8461 & 0.624 \\
\hline 975 & 1.3828 & 1.7099 & 1.9489 & 2.1127 & 2.2138 & 2.2637 & 2.2728 & 2.2044 & 2.0647 & 1.028 & 1.1900 & 0.7971 & 0.5905 \\
\hline 925 & 1.2851 & 1.5914 & 1.8161 & 1.9712 & 2.0679 & $2.11 \%$ & 2.1279 & 2.0688 & 1.9425 & 1.0090 & 1.1330 & 0.7630 & 0.5668 \\
\hline 825 & 1.0797 & 1.3368 & 1.5261 & 1.657 & 1.7412 & 1.7853 & 1.7900 & 1.7563 & 1.6583 & 1.3912 & 0.9965 & 0.6805 & 0.5089 \\
\hline nS & 0.9534 & 1.1363 & 1.2688 & 1.3599 & 1.417 & 1.470 & 1.4548 & 1.4230 & 1.3504 & 1.1497 & 0.8425 & 0.5855 & 0.4417 \\
\hline 625 & 0.9061 & 0.9662 & 1.0466 & 1.0888 & 1.1148 & 1.1268 & 1.1271 & 1.1009 & 1.0501 & 0.9100 & 0.6853 & 0.4862 & 0.370 \\
\hline 325 & 0.7013 & 0.7495 & 0.7847 & 0.8088 & 0.8234 & 0.8299 & 0.8297 & 0.8135 & 0.7817 & 0.6918 & $0.53 \%$ & 0.3895 & 0.2999 \\
\hline
\end{tabular}




\section{B-9}

Table B.13. Relative power density values calculated with KENO using 99-group cross sections for the intermediate FOEHN configuration

\begin{tabular}{|c|c|c|c|c|c|c|c|c|c|c|c|}
\hline$H / r(m m)$ & 143.5 & 146.5 & 149.5 & 152.5 & 159.0 & 167.5 & 176.0 & 182.5 & 185.5 & 188.5 & 193.9 \\
\hline 797.5 & 1.1234 & 0.9692 & 0.8632 & 0.8187 & 0.7173 & 0.7187 & 0.8136 & 0.9947 & 1.1364 & 1.3054 & 1.6976 \\
\hline 790.6 & 1.0586 & 0.9234 & 0.8053 & 0.7766 & 0.6539 & 0.6659 & 0.7877 & 0.9428 & 1.0595 & 1.2364 & 1.6634 \\
\hline 785.5 & 1.1086 & 0.9127 & 0.8094 & 0.7335 & 0.6747 & 0.6520 & 0.7692 & 0.9322 & 1.057 & 1.1998 & 1.5990 \\
\hline 700.6 & 1.0498 & 0.9465 & 0.7886 & 0.7474 & 0.6645 & 0.6372 & 0.7645 & 0.9359 & 1.0996 & 1.2304 & 1.6444 \\
\hline 771.5 & 1.0345 & 0.8942 & 0.8136 & 0.7506 & 0.6594 & 0.6701 & 0.7525 & 0.9391 & 1.0637 & 1.2285 & 1.6935 \\
\hline 750.0 & 1.0743 & 0.9132 & 0.2497 & 0.7868 & 0.6960 & 0.6673 & 0.7840 & 0.9664 & 1.0604 & 1.2716 & 1.6958 \\
\hline 725.0 & 1.1257 & 0.9493 & 0.8933 & 0.8057 & 0.7238 & 0.7238 & 0.8576 & 1.0239 & 1.1581 & 1.3003 & 1.7569 \\
\hline 200.0 & 1.1331 & 1.0164 & 0.9456 & 0.8446 & 0.7469 & 0.7905 & 0.8451 & 1.0489 & 1.2017 & 1.3656 & 1.8305 \\
\hline 625.0 & 1.3211 & 1.1688 & 1.0720 & 0.9887 & 0.8937 & 0.8460 & 0.9887 & 1.1975 & 1.3133 & 1.5318 & 2.0459 \\
\hline 550.0 & 1.4679 & 1.2934 & 1.2026 & 1.0878 & 0.9627 & 0.9484 & 1.0850 & 1.2938 & 1.4601 & 1.5990 & 2.1963 \\
\hline$\$ 75.0$ & 1.3869 & 1.2387 & 1.1364 & 1.0627 & 0.9493 & 0.9451 & 1.0984 & 1.2952 & 1.4712 & 1.6837 & 2.2400 \\
\hline $\mathbf{4 0 0 . 0}$ & 1.0252 & 0.9706 & 0.8942 & 0.8497 & 0.8340 & 0.8872 & 1.0234 & 1.2545 & 1.4170 & 1.5907 & 2.2107 \\
\hline 325.0 & 0.9604 & 0.8516 & 0.8192 & 0.7840 & 0.7479 & 0.8067 & 0.9655 & 1.1401 & 1.3105 & 1.5207 & 2.0292 \\
\hline 250.0 & 0.8752 & 0.7798 & 0.7344 & 0.6246 & 0.6937 & 0.7252 & 0.8655 & 1.0757 & 1.2151 & 1.3837 & 1.8916 \\
\hline 175.0 & 0.6826 & 0.6659 & 0.6224 & 0.6025 & 0.5830 & 0.6261 & 0.7618 & 0.9363 & 1.0600 & 1.1725 & 1.6337 \\
\hline 100.0 & 0.5881 & 0.5645 & 0.5247 & 0.4765 & 0.4577 & 0.5094 & 0.60085 & 0.7932 & 0.8812 & 0.9947 & 1.3758 \\
\hline 75.0 & 0.5298 & 0.5071 & 0.4649 & 0.4412 & 0.4447 & 0.4682 & 0.5649 & 0.7016 & 0.8178 & 0.9572 & 1.2975 \\
\hline 50.0 & 0.4830 & 0.4499 & 0.4461 & 0.4266 & 0.3915 & 0.4408 & 0.5279 & 0.6696 & 0.7821 & 0.8701 & 1.2424 \\
\hline 28.5 & 0.4807 & 0.4387 & 0.4212 & 0.3781 & 0.3875 & 0.4081 & 0.5103 & 0.6432 & $0.7 m 15$ & 0.8724 & 1.1498 \\
\hline 19.4 & 0.4527 & 0.4160 & 0.3913 & 0.3873 & 0.3660 & 0.4156 & 0.4946 & 0.6409 & 0.7252 & 0.8433 & 1.107 \\
\hline 14.5 & 0.4848 & 0.4308 & 0.3988 & 0.3728 & 0.3715 & 0.4081 & 0.48012 & 0.6224 & 0.6907 & 0.8270 & 1.1484 \\
\hline 9.4 & 0.4607 & 0.4338 & 0.4067 & 0.3687 & 0.3787 & 0.4149 & 0.4876 & 0.6150 & 0.7233 & 0.8238 & 1.1396 \\
\hline 2.5 & 0.4532 & 0.4421 & 0.3963 & 0.3904 & 0.3795 & 0.4116 & 0.5260 & 0.6691 & 0.7344 & 0.8349 & 1.1205 \\
\hline
\end{tabular}

Table B.14. Two sigma standard deviations for the relative power density values calculated with KENO using 99-group cross sections for the intermediate FOEHN configuration.

\begin{tabular}{|c|c|c|c|c|c|c|c|c|c|c|c|}
\hline$H / r(m m)$ & 143.5 & 146.5 & 149.5 & 152.5 & 159.0 & 167.5 & 176.0 & 182.5 & 185.5 & 188.5 & 193.9 \\
\hline 797.5 & 0.0350 & 0.0370 & 0.0388 & 0.0382 & 0.0382 & 0.0370 & 0.0372 & 0.0330 & 0.0318 & 0.0304 & 0.0268 \\
\hline 790.6 & 0.0348 & 0.0368 & 0.0364 & 0.0374 & 0.0090 & 0.0086 & 0.0358 & 0.0040 & 0.0006 & 0.0004 & 0.0264 \\
\hline 785.5 & 0.0376 & 0.0364 & 0.0364 & 0.0380 & 0.0382 & 0.0366 & 0.0348 & 0.0338 & 0.00324 & 0.0296 & 0.0272 \\
\hline 780.6 & 0.0348 & 0.0362 & 0.0404 & 0.0398 & 0.0376 & 0.0368 & 0.0354 & 0.0342 & 0.0308 & 0.0304 & 0.0288 \\
\hline 771.5 & 0.0416 & 0.0412 & 0.0396 & 0.0396 & 0.0420 & 0.0416 & 0.0372 & 0.0372 & 0.0338 & 0.0336 & 0.0312 \\
\hline 750.0 & 0.0344 & 0.0340 & 0.0360 & 0.0358 & 0.0358 & 0.0362 & 0.0316 & 0.0320 & 0.0306 & 0.0308 & 0.0268 \\
\hline 725.0 & 0.0336 & 0.0356 & 0.0346 & 0.0370 & 0.0366 & 0.0354 & 0.0322 & 0.0290 & 0.0290 & 0.0300 & 0.0264 \\
\hline 700.0 & 0.0346 & 0.0340 & 0.0338 & 0.0360 & 0.0334 & 0.0314 & 0.0324 & 0.0294 & 0.0298 & 0.0286 & 0.0244 \\
\hline 625.0 & 0.0326 & 0.0324 & 0.0314 & 0.0326 & 0.0318 & 0.0330 & 0.0290 & 0.0308 & 0.0274 & 0.0260 & 0.0246 \\
\hline 550.0 & 0.0304 & 0.0306 & 0.0288 & 0.0322 & 0.0306 & 0.0304 & 0.0274 & 0.0276 & 0.0258 & 0.0262 & 0.0240 \\
\hline 475.0 & 0.0276 & 0.0290 & 0.0296 & 0.0306 & 0.0288 & 0.0296 & 0.0292 & 0.0262 & 0.0244 & 0.0238 & 0.0224 \\
\hline 400.0 & 0.0310 & 0.0302 & 0.0326 & 0.0320 & 0.0306 & 0.0292 & 0.0294 & 0.0264 & 0.0264 & 0.0258 & 0.0200 \\
\hline 325.0 & 0.0332 & 0.0334 & 0.0334 & 0.0318 & 0.0316 & 0.0314 & 0.0290 & 0.0282 & 0.0262 & 0.0258 & 0.0250 \\
\hline 250.0 & 0.0338 & 0.0358 & 0.0350 & 0.0326 & 0.0354 & 0.0356 & 0.0334 & 0.0298 & 0.0276 & 0.0272 & 0.0248 \\
\hline 175.0 & 0.0380 & 0.0376 & 0.0092 & 0.0362 & 0.0382 & 0.0352 & 0.0350 & 0.0334 & 0.0330 & 0.0314 & 0.0262 \\
\hline 100.0 & 0.0410 & 0.0394 & 0.0410 & 0.0426 & 0.0400 & 0.0384 & 0.0370 & 0.0362 & 0.0334 & 0.0310 & 0.0286 \\
\hline 75.0 & 0.0422 & 0.0432 & 0.0434 & 0.0434 & 0.0400 & 0.0418 & 0.0420 & 0.0380 & 0.0360 & 0.0338 & 0.0306 \\
\hline 50.0 & 0.0450 & 0.0460 & 0.0472 & 0.0434 & 0.0460 & 0.0430 & 0.0428 & 0.0388 & 0.0066 & 0.0356 & 0.0308 \\
\hline 28.5 & 0.0476 & i.0476 & 0.0450 & 0.0498 & 0.0470 & 0.0450 & 0.0396 & 0.0392 & 0.0376 & 0.0348 & 0.0318 \\
\hline 19.4 & 0.0464 & 0.0474 & 0.0494 & 0.0476 & 0.0482 & 0.0472 & 0.0430 & 0.0384 & 0.0372 & 0.0374 & 0.0320 \\
\hline 14.5 & 0.0468 & 0.0512 & 0.0494 & 0.0480 & 0.0448 & 0.0458 & 0.0458 & 0.0376 & 0.0388 & 0.0370 & 0.0330 \\
\hline 9.4 & 0.0478 & 0.0488 & 0.0514 & 0.0500 & 0.0478 & 0.0480 & 0.0436 & 0.0410 & 0.0382 & 0.0362 & 0.0334 \\
\hline 2.5 & 0.0488 & 0.0488 & 0.0494 & 0.0504 & 0.0496 & 0.0470 & 0.0440 & 0.0420 & 0.0394 & 0.0374 & 0.0354 \\
\hline
\end{tabular}


Table B.15. Relative power density values calculated with DORT using 20-group cross sections for the intermediate FOEHN configuration

\begin{tabular}{|c|c|c|c|c|c|c|c|c|c|c|c|}
\hline$H / r(m m)$ & 143.5 & 146.5 & 149.5 & 152.5 & 159.0 & 167.5 & 176.0 & 182.5 & 185.5 & 188.5 & 193.9 \\
\hline 797.5 & 1.1109 & 0.9707 & 0.8664 & 0.7960 & 0.7229 & 0.7267 & 0.8263 & 0.9993 & 1.1327 & 1.3054 & 1.7302 \\
\hline 790.6 & 1.0790 & 0.9422 & 0.8352 & 0.7577 & 0.6823 & 0.6886 & 0.7695 & 0.9374 & 1.0689 & 1.2458 & 1.7047 \\
\hline 785.5 & 1.0731 & 0.9367 & 0.8407 & 0.7594 & 0.6643 & 0.6544 & 0.7514 & 0.9342 & 1.0674 & 1.2388 & 1.7014 \\
\hline 70.6 & 1.0669 & 0.9243 & 0.8277 & 0.7580 & 0.6638 & 0.6515 & 0.7536 & 0.9314 & 1.0639 & 1.2270 & 1.7015 \\
\hline 771.5 & 1.0569 & 0.9218 & 0.8254 & 0.7574 & 0.6729 & 0.6602 & 0.7625 & 0.9395 & 1.0578 & 1.2276 & 1.7086 \\
\hline 750.0 & 1.0828 & 0.9448 & 0.8470 & 0.7802 & 0.7005 & 0.6925 & 0.7947 & 0.9649 & 1.0910 & 1.2628 & 1.7526 \\
\hline 725.0 & 1.1380 & 0.9948 & 0.8936 & 0.8219 & 0.7397 & 0.7363 & 0.8357 & 1.0135 & 1.1417 & 1.3178 & 1.8233 \\
\hline 700.0 & 1.2002 & 1.0494 & 0.9447 & 0.8699 & 0.7837 & 0.7778 & 0.8805 & 1.0647 & 1.1984 & 1.3808 & 1.9031 \\
\hline 625.0 & 1.3749 & 1.2063 & 1.0853 & 0.9995 & 0.8991 & 0.8892 & 1.0026 & 1.2068 & 1.3538 & 1.5560 & 2.1334 \\
\hline 550.0 & 1.4734 & 1.2863 & 1.1586 & 1.0708 & 0.9678 & 0.9568 & 1.0773 & 1.2926 & 1.4514 & 1.6670 & 2.2824 \\
\hline 475.0 & 1.2915 & 1.1498 & 1.0526 & 0.9855 & 0.9133 & 0.9289 & 1.0689 & 1.2990 & 1.4629 & 1.6844 & 2.3133 \\
\hline 400.0 & 1.0230 & 0.9405 & 0.8838 & 0.8453 & 0.8136 & 0.8583 & 1.0126 & 1.2461 & 1.4092 & 1.6312 & 2.2540 \\
\hline 325.0 & 0.9515 & 0.8709 & 0.8213 & 0.7870 & 0.7562 & 0.8001 & 0.9485 & 1.1707 & 1.3270 & 1.5356 & 2.1264 \\
\hline 250.0 & 0.8591 & 0.7845 & 0.7366 & 0.7049 & 0.6817 & 0.7236 & 0.8601 & 1.0632 & 1.2064 & 1.397 & 1.9393 \\
\hline 175.0 & 0.7356 & 0.6734 & 0.6328 & 0.6063 & 0.5864 & 0.6262 & 0.7471 & 0.9285 & 1.0531 & 1.2233 & 1.6999 \\
\hline 100.0 & 0.5961 & 0.5466 & 0.5139 & 0.4932 & 0.4794 & 0.5154 & 0.6196 & 0.7741 & 0.8821 & 1.0271 & 1.4375 \\
\hline 75.0 & 0.5486 & 0.5024 & 0.4727 & 0.4537 & 0.4419 & 0.4774 & 0.5762 & 0.7227 & 0.8244 & 0.9615 & 1.3486 \\
\hline 50.0 & 0.5036 & 0.4613 & 0.4337 & 0.4165 & 0.4065 & 0.4387 & 0.5356 & 0.6735 & 0.7712 & 0.9018 & 1.2677 \\
\hline 28.5 & 0.4712 & 0.4316 & 0.4058 & 0.3902 & 0.3801 & 0.4093 & 0.5022 & 0.6402 & 0.7300 & 0.8559 & 1.2079 \\
\hline 19.4 & 0.4655 & 0.4258 & 0.4010 & 0.3839 & 0.3695 & 0.3984 & 0.4924 & 0.6270 & 0.7226 & 0.8440 & 1.1862 \\
\hline 14.5 & 0.4635 & 0.4277 & 0.4037 & 0.3849 & 0.3698 & 0.3972 & 0.4843 & 0.6222 & 0.7196 & 0.8425 & 1.1778 \\
\hline 9.4 & 0.4606 & 0.4257 & 0.3994 & 0.3823 & 0.3773 & 0.4117 & 0.4903 & 0.6182 & 0.7128 & 0.8401 & 1.1722 \\
\hline 2.5 & 0.4610 & 0.4251 & 0.3993 & 0.3847 & 0.3817 & 0.4259 & 0.5233 & 0.6571 & 0.7517 & 0.8727 & 1.1629 \\
\hline
\end{tabular}

Table B.16. Relative power density values calculated with VENTURE using 20-group cross sections for the intermediate FOEHN configuration

\begin{tabular}{|c|c|c|c|c|c|c|c|c|c|c|c|}
\hline $\mathrm{H} / \mathrm{r}(\mathrm{mm})$ & 143.5 & 146.5 & 149.5 & 152.5 & 159.0 & 167.5 & 176.0 & 182.5 & 185.5 & 188.5 & 193.9 \\
\hline 797.5 & 1.1115 & 1.0175 & 0.9460 & 0.8922 & 0.8262 & 0.8326 & 0.9431 & 1.1076 & 1.2119 & $1.33 \% 6$ & 1.6596 \\
\hline 790.6 & 1.0715 & 0.9586 & 0.8759 & 0.8158 & 0.7442 & 0.7452 & 0.8483 & 1.0138 & 1.1262 & 1.2702 & 1.6581 \\
\hline 785.5 & 1.0551 & 0.9366 & 0.8493 & 0.7859 & 0.7100 & 0.7082 & 0.8109 & 0.9813 & 1.0989 & 1.2508 & 1.6587 \\
\hline 780.6 & 1.0460 & 0.9248 & 0.8350 & 0.7695 & 0.6906 & 0.6872 & 0.7910 & 0.9658 & 1.0871 & 1.2437 & 1.6627 \\
\hline$m 1.5$ & 1.0402 & 0.9170 & 0.8251 & 0.7578 & 0.6759 & 0.6713 & 0.7778 & 0.9585 & 1.0839 & 1.2455 & 1.6756 \\
\hline 750.0 & 1.0567 & 0.9317 & 0.8382 & 0.7693 & 0.6852 & 0.6906 & 0.7919 & 0.9902 & 1.1105 & 1.2782 & 1.7224 \\
\hline 725.0 & 1.1018 & 0.9735 & 0.8774 & 0.8066 & 0.7199 & 0.7154 & 0.8305 & 1.0254 & 1.1602 & 1.3336 & 1.7927 \\
\hline 700.0 & 1.1576 & 1.0244 & 0.9245 & 0.8508 & 0.7605 & 0.7551 & 0.8740 & 1.0757 & 1.2153 & 1.3949 & 1.8704 \\
\hline 625.0 & 1.3204 & 1.1706 & 1.0581 & 0.9749 & 0.8721 & 0.8637 & 0.9935 & 1.2154 & 1.3693 & 1.5674 & 2.0921 \\
\hline 550.0 & 1.4141 & 1.2546 & 1.1348 & 1.0462 & 0.9369 & 0.9283 & 1.0671 & 1.3041 & 1.4694 & 1.6799 & 2.2399 \\
\hline 475.0 & 1.2588 & 1.1316 & 1.0371 & 0.9687 & 0.8909 & 0.9085 & 1.0658 & 1.3157 & 1.4864 & 1.7049 & 2.2009 \\
\hline 400.0 & 1.0107 & 0.9298 & 0.8709 & 0.8301 & 0.7936 & 0.8417 & 1.0139 & 1.2681 & 1.4389 & 1.6561 & 2.2257 \\
\hline 325.0 & 0.9362 & 0.8619 & 0.8080 & 0.7709 & 0.7391 & 0.7872 & 0.9525 & 1.1948 & 1.3573 & 1.5640 & 2.1057 \\
\hline 250.0 & 0.8427 & 0.7761 & 0.7278 & 0.6949 & 0.6672 & 0.7128 & 0.8652 & 1.0878 & 1.2371 & 1.4269 & 1.9242 \\
\hline 175.0 & 0.7247 & 0.6677 & 0.6266 & 0.5987 & 0.5762 & 0.6182 & 0.7541 & 0.9518 & 1.0841 & 1.2524 & 1.6932 \\
\hline 100.0 & 0.5908 & 0.5443 & 0.5110 & 0.4887 & 0.4719 & 0.5099 & 0.6276 & 0.7976 & 0.9113 & 1.0557 & 1.4339 \\
\hline 75.0 & 0.5467 & 0.5035 & 0.4726 & 0.4519 & 0.4369 & 0.4734 & 0.5850 & 0.7460 & 0.8535 & 0.9901 & 1.3479 \\
\hline 50.0 & 0.5073 & 0.4669 & 0.4380 & 0.4188 & 0.4051 & 0.4400 & 0.5455 & 0.6975 & 0.7990 & 0.9280 & 1.2661 \\
\hline 28.5 & 0.4834 & 0.4452 & 0.4182 & 0.4005 & 0.3885 & 0.4225 & 0.5223 & 0.6652 & 0.7609 & 0.8825 & 1.2022 \\
\hline 19.4 & 0.4789 & 0.4426 & 0.4172 & 0.4010 & 0.3914 & 0.4263 & 0.5237 & 0.6613 & 0.7531 & 0.8699 & 1.1782 \\
\hline 14.5 & 0.4790 & 0.444 & 0.4207 & 0.4058 & 0.3985 & 0.4351 & 0.5319 & 0.6661 & 0.7549 & 0.8678 & 1.1666 \\
\hline 9.4 & 0.4819 & 0.4504 & 0.4293 & 0.4166 & 0.4130 & 0.4529 & 0.5508 & 0.6815 & 0.7663 & 0.8732 & 1.1562 \\
\hline 2.5 & 0.4941 & 0.4709 & 0.4559 & 0.4476 & 0.4510 & 0.4998 & 0.6064 & 0.7375 & 0.8167 & 0.9110 & 1.1489 \\
\hline
\end{tabular}


Table B.17. Thermal fluxes calculated with DORT using 20-group cross sections for the intermediate FOEHN configuration

\begin{tabular}{|c|c|c|c|c|c|c|c|c|c|c|c|c|c|c|}
\hline $\mathrm{H} / \mathrm{r}(\mathrm{mm})$ & 235 & 275 & 315 & 335 & 355 & 375 & 395 & 435 & 5 & 678 & 780 & 9 & & \\
\hline 1810 & 0.8983 & 0.8966 & 0.8800 & 0.8681 & 0.8527 & $\overline{0.8351}$ & 0.8153 & 0.710 & 0.6709 & 0.4646 & 0.3699 & 0.2832 & 0.2046 & 0.1681 \\
\hline 1710 & 1.1539 & 1.1958 & 1.1924 & 1.1794 & 1.1605 & 1.1366 & 1.1087 & 1.0441 & 0.8963 & 0.6030 & 0.4748 & 0.3603 & 0.2586 & 0.2120 \\
\hline 1610 & $1.384 !$ & 1.4912 & 1.5308 & 1.5269 & 1.5103 & 1.4833 & 1.4482 & 1.3602 & 1.1506 & 0.7492 & 0.5827 & 0.4381 & 0.3123 & 0.2553 \\
\hline 1510 & 1.2884 & 1.6964 & 1.8630 & 1.8866 & 1.8824 & 1.8569 & 1.8158 & 1.2018 & 1.4181 & 0.8938 & 0.6869 & 0.5118 & 0.3625 & 0.2956 \\
\hline 1410 & 1.4802 & 2.0103 & 2.2365 & 2.2704 & 2.2665 & 2.2339 & 2.1804 & 2.0316 & 1.6676 & 1.0222 & $0 . m 8$ & 0.5752 & 0.4052 & 0.3298 \\
\hline 1310 & 1.7038 & 2.3056 & 2.5554 & 2.5887 & 2.5785 & 2.5355 & 2.4689 & 2.2836 & 1.8585 & 1.1184 & 0.8452 & 0.6219 & 0.4364 & 0.3547 \\
\hline 1260 & 1.748 & 2.3999 & 2.6578 & 2.6911 & 2.6790 & 2.6329 & 2.5621 & 2.3720 & 1.9209 & 1.1499 & 0.8673 & 0.6372 & 0.4467 & 0.3629 \\
\hline 1210 & 1.8097 & 2.4490 & 2.7129 & 2.7470 & 2.7346 & 2.6873 & 2.6146 & 2.4197 & 1.9573 & 1.1688 & 0.8807 & 0.6465 & 0.4529 & 0.3679 \\
\hline 1160 & 1.8000 & 2.4526 & 2.7202 & 2.7556 & 2.7442 & 2.6975 & 2.6253 & 2.4305 & 1.9668 & 1.1746 & 0.8849 & 0.6496 & 0.4550 & 0.3696 \\
\hline 1110 & 1.7745 & 2.4138 & 2.6819 & 2.7188 & 2.0093 & 2.6648 & 2.5949 & 2.4049 & 1.9495 & 1.1670 & 0.8799 & 0.6463 & 0.4529 & 0.3679 \\
\hline 1060 & 1.7147 & 2.3379 & 2.6024 & 2.6405 & 2.6336 & 2.5925 & 2.5266 & 2.3452 & 1.9067 & 1.1467 & 0.8600 & 0.0368 & 0.4467 & 0.3630 \\
\hline 1010 & 1.6320 & 2.2297 & 2.4870 & 2.5260 & 2.5219 & 2.4851 & 2.4243 & 2.2549 & 1.8406 & 1.1143 & 0.8435 & 0.6215 & 0.4366 & 0.3550 \\
\hline 910 & 1.4088 & 1.9338 & 2.1678 & 2.2075 & 2.2099 & 2.1836 & 2.1363 & 1.9984 & 1.6498 & 1.0183 & 0.776 & 0.5754 & 0.4059 & 0.3306 \\
\hline 810 & 1.1372 & 1.5716 & 1.7739 & 1.8130 & 1.8219 & 1.8074 & 1.7754 & 1.6746 & 1.4054 & 0.8921 & 0.6873 & 0.5133 & 0.3642 & 0.2973 \\
\hline 710 & 0.9014 & 1.2261 & 1.3798 & 1.4122 & 1.4230 & 1.4168 & 1.3976 & 1.3311 & 1.1408 & 0.7504 & 0.5856 & 0.4416 & 0.3156 & 0.2583 \\
\hline 610 & 0.8205 & 0.9666 & 1.0449 & 1.0624 & 1.0682 & 1.0644 & 1.0528 & 1.0117 & 0.8870 & 0.6074 & 0.4809 & 0.3666 & 0.2641 & 0.2168 \\
\hline 510 & 0.6395 & 0.7183 & 0.7603 & 0.701 & 0.7736 & 0.7716 & 0.7651 & 0.7411 & 0.0645 & 0.4739 & 0.3807 & 0.2935 & 0.2132 & 0.1755 \\
\hline
\end{tabular}

Table B.18. Thermal fluxes calculated with VENTURE using 20-group cross sections for the intermediate FOEHN configuration

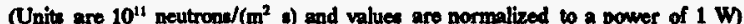

\begin{tabular}{|c|c|c|c|c|c|c|c|c|c|c|c|c|c|c|}
\hline $\bar{H} / \mathrm{s}$ & 235 & 275 & 315 & 335 & 355 & 375 & 395 & 435 & 515 & 675 & 755 & 835 & 915 & 955 \\
\hline 1810 & 0.8765 & 0.8758 & 0.8608 & 0.8486 & 0.8337 & 0.8165 & 0.7974 & 0.7543 & 0.6571 & 0.4567 & 0.3646 & 0.2798 & 0.2027 & 0.1667 \\
\hline 1710 & 1.1117 & 1.1573 & 1.1585 & 1.1473 & 1.1301 & 1.1078 & 1.0813 & 1.0193 & 0.8763 & 0.3916 & 0.4669 & 0.3552 & 0.2536 & 0.2007 \\
\hline 1610 & 1.2962 & 1.4242 & 1.4764 & 1.474 & 1.4649 & 1.4414 & 1.4092 & 1.3262 & $1.12 \mathrm{Al}$ & 0.7341 & 0.5721 & 0.4311 & 0.3000 & 0.2521 \\
\hline 1510 & 1.1898 & 1.6090 & 1.7902 & 1.8207 & 1.8224 & 1.8021 & 1.7656 & 1.6591 & 1.3855 & 0.8751 & 0.6737 & 0.5029 & 0.3569 & 0.2914 \\
\hline 1410 & 1.3687 & 1.9042 & 2.1476 & 2.1901 & 2.1941 & 2.1683 & 2.1208 & 1.9818 & 1.6302 & 1.0006 & 0.7624 & 0.5648 & 0.3986 & 0.3247 \\
\hline 1310 & 1.5731 & 2.1830 & 2.4543 & 2.4984 & 2.4978 & 2.4631 & 2.4034 & 2.2346 & 1.8184 & 1.0949 & 0.8283 & 0.6103 & 0.4290 & 0.3490 \\
\hline 1260 & 1.6394 & 2.2738 & 2.5543 & 2.5988 & 2.5969 & 2.5593 & 2.4958 & 2.3174 & 1.8802 & 1.1259 & 0.8500 & 0.6252 & 0.4390 & 0.3569 \\
\hline 1210 & 1.6738 & 2.3229 & 2.6098 & 2.6552 & 2.6529 & 2.6142 & 2.5488 & 2.3655 & 1.9169 & 1.1448 & 0.8632 & 0.0344 & 0.4451 & 0.3618 \\
\hline 1160 & 1.6758 & 2.3296 & 2.6197 & 2.6602 & 2.6647 & 2.6264 & 2.5612 & 2.3776 & 1.9272 & 1.1507 & 0.8675 & 0.6374 & 0.4472 & 0.3635 \\
\hline 1110 & 1.6486 & 2.2968 & 2.5865 & 2.6340 & 2.6339 & 2.5973 & 2.5341 & 2.3547 & 1.9115 & 1.1438 & 0.8629 & 0.0344 & 0.4452 & 0.3619 \\
\hline 1060 & 1.5963 & 2.2283 & 2.5135 & 2.5616 & 2.5634 & 2.5297 & 2.4700 & 2.2983 & 1.8709 & 1.1243 & 0.8495 & 0.6253 & 0.4392 & 0.3572 \\
\hline 1010 & 1.5218 & 2.1282 & 2.4048 & 2.4531 & 2.4572 & 2.4272 & 2.3721 & 2.2115 & 1.8070 & 1.0930 & 0.8278 & 0.6105 & 0.4294 & 0.3494 \\
\hline 910 & 1.3182 & 1.8512 & 2.1014 & 2.1488 & 2.157 & 2.1369 & 2.0940 & 1.9629 & 1.6217 & 0.9999 & 0.7629 & 0.5657 & 0.3996 & 0.3256 \\
\hline 810 & 1.0091 & 1.5094 & 1.7239 & 1.7687 & 1.7823 & 1.717 & 1.7428 & 1.6468 & 1.3829 & 0.8769 & 0.6759 & 0.5053 & 0.3590 & 0.2932 \\
\hline 710 & 0.8480 & 1.1813 & 1.3443 & 1.3806 & 1.3946 & 1.3909 & $1.3 m 7$ & 1.3102 & 1.1233 & 0.7384 & 0.5766 & 0.4353 & 0.3115 & 0.2552 \\
\hline 610 & 0.7785 & 0.9364 & 1.0215 & 1.0412 & 1.0488 & 1.0403 & 1.0359 & 0.9964 & 0.8737 & 0.5984 & 0.4742 & 0.3620 & 0.2612 & 0.2146 \\
\hline 510 & 0.6192 & 0.022 & 0.7467 & $0.75 n$ & 0.7613 & 0.7599 & 0.7538 & 0.7304 & 0.6550 & 0.4676 & 0.3761 & 0.2904 & 0.2113 & 0.1742 \\
\hline
\end{tabular}


Table B.19. Relative power density values calculated with DORT using 20-group cross sections for the complex FOEHN configuration with void in the reflector components

\begin{tabular}{|c|c|c|c|c|c|c|c|c|c|c|c|}
\hline$H / r(\operatorname{man})$ & 143.5 & 146.5 & 149.5 & 152.5 & 159.0 & 167.5 & 176.0 & 182.5 & 185.5 & 188.5 & 193.9 \\
\hline 797.5 & 1.0869 & 0.9496 & 0.8476 & 0.7866 & 0.7166 & 0.7160 & 0.8122 & 0.9743 & 1.0922 & 1.2626 & 1.6732 \\
\hline 795.0 & 1.0695 & 0.9556 & 0.8318 & 0.7683 & 0.7028 & 0.7131 & 0.7915 & 0.9476 & 1.0640 & 1.2297 & 1.6546 \\
\hline 990.6 & 1.0630 & 0.9329 & 0.8283 & 0.7560 & 0.6760 & 0.6821 & 0.7564 & 0.9229 & 1.0424 & 1.2081 & 1.6502 \\
\hline 785.5 & 1.057 & 0.9278 & 0.8352 & 0.7582 & 0.6630 & 0.6430 & 0.7460 & 0.9183 & 1.0452 & 1.2019 & 1.6501 \\
\hline 720.6 & 1.0523 & 0.9156 & 0.82026 & 0.7541 & 0.6559 & 0.6507 & 0.7388 & 0.9198 & 1.0399 & 1.1896 & 1.6512 \\
\hline 77.5 & 1.0442 & 0.9146 & 0.8223 & 0.7588 & 0.6730 & 0.6582 & 0.7563 & 0.9260 & 1.0365 & 1.1937 & 1.6569 \\
\hline 750.0 & 1.0742 & 0.9405 & 0.8464 & 0.7813 & 0.6998 & 0.6931 & 0.7847 & 0.9531 & 1.0695 & 1.2299 & 1.7011 \\
\hline 725.0 & 1.1291 & 0.9898 & 0.8917 & 0.8252 & 0.7409 & 0.7336 & 0.8281 & 1.0006 & 1.1196 & 1.2856 & 1.772 \\
\hline 700.0 & 1.1918 & 1.0459 & 0.9445 & 0.8746 & 0.7847 & 0.7761 & 0.8737 & 1.0530 & 1.1763 & 1.3476 & 1.8522 \\
\hline 625.0 & 1.3708 & 1.2052 & 1.0893 & 1.0094 & 0.9053 & 0.8930 & 0.9994 & 1.1973 & 1.3339 & 1.5241 & 2.0840 \\
\hline 550.0 & 1.4862 & 1.3067 & 1.1800 & 1.0927 & 0.9818 & 0.9670 & 1.0798 & 1.2916 & 1.4390 & 1.6415 & 2.2416 \\
\hline 475.0 & 1.4766 & 1.2991 & 1.1768 & 1.0935 & 0.9874 & 0.9797 & 1.0994 & 1.3183 & 1.4685 & 1.6774 & 2.2923 \\
\hline 400.0 & 1.0928 & 0.9944 & 0.9272 & 0.8841 & 0.8406 & 0.8795 & 1.0252 & 1.2538 & 1.4063 & 1.6154 & 22041 \\
\hline 325.0 & 0.9550 & 0.8783 & 0.8257 & 0.7913 & 0.7619 & 0.8064 & 0.940 & 1.1666 & 1.3117 & 1.5103 & 2.0870 \\
\hline 250.0 & 0.8525 & 0.7828 & 0.7361 & 0.7069 & 0.6810 & 0.7232 & 0.8542 & 1.0541 & 1.1869 & 1.3085 & 1.8950 \\
\hline 175.0 & 0.7271 & 0.6683 & 0.6290 & 0.6047 & 0.5842 & 0.6230 & 0.7392 & 0.9160 & 1.0326 & 1.1929 & 1.6564 \\
\hline 100.0 & 0.5868 & 0.5394 & 0.5085 & 0.4895 & 0.4748 & 0.5101 & 0.6107 & 0.7619 & 0.8619 & 0.9983 & 1.3937 \\
\hline 25.0 & 0.5397 & 0.4963 & 0.4674 & 0.4502 & 0.4381 & 0.4722 & 0.5679 & 0.7108 & 0.8052 & 0.9343 & 1.3079 \\
\hline 50.0 & 0.4955 & 0.4559 & 0.4292 & 0.4129 & 0.4024 & 0.4360 & 0.5270 & 0.6629 & 0.7530 & 0.879 & 1.22835 \\
\hline 28.5 & 0.4623 & 0.4253 & 0.4014 & 0.3876 & $0.37 m 1$ & 0.0052 & 0.4961 & 0.6294 & 0.7138 & 0.8310 & 1.1706 \\
\hline 19.4 & 0.4565 & 0.4192 & 0.3955 & 0.3793 & 0.3631 & 0.3960 & 0.4817 & 0.6179 & 0.7059 & 0.8174 & 1.1515 \\
\hline 14.5 & 0.4550 & 0.4213 & 0.3983 & 0.3813 & 0.3602 & 0.3892 & 0.4005 & 0.6110 & 0.7030 & 0.8176 & 1.3421 \\
\hline 9.4 & 0.4513 & 0.4189 & 0.3942 & 0.3791 & 0.3720 & 0.4063 & 0.4004 & 0.6088 & 0.6957 & 0.8145 & 1.1339 \\
\hline 5.0 & 0.4182 & 0.4143 & 0.3898 & $0.37 m$ & 0.3764 & 0.4192 & 0.5006 & 0.6232 & 0.7000 & 0.8250 & 1.1287 \\
\hline 25 & 0.494 & 0.4149 & 0.3899 & 0.3781 & 0.3762 & 0.4186 & 0.5140 & 0.6407 & 0.7266 & 0.8455 & 1.1302 \\
\hline
\end{tabular}

Table B.20. Relative power density values calculated with DORT using 20-group cross sections for the complex FOEHN configuration with aluminum in the void

regions of the reflector components

\begin{tabular}{|c|c|c|c|c|c|c|c|c|c|c|c|}
\hline$H / r(m m)$ & 18.5 & 146.5 & 149.5 & 152.5 & 159.0 & 167.5 & 176.0 & 182.5 & 185.5 & 188.5 & 193.9 \\
\hline 797.5 & 1.0917 & 0.9537 & 0.8511 & 0.7894 & 0.7178 & 0.7142 & 0.8064 & 0.9643 & 1.0794 & 1.2459 & 1.6478 \\
\hline 795.0 & 1.0747 & 0.9400 & 0.8355 & 0.7712 & 0.7038 & 0.7115 & 0.7265 & 0.9384 & 1.0521 & 1.2140 & 1.6298 \\
\hline 790.6 & 1.0690 & 0.9377 & 0.8324 & 0.7593 & 0.6775 & 0.6812 & 0.7524 & 0.9146 & 1.0314 & 1.1933 & 1.6259 \\
\hline 785.5 & 1.0644 & 0.9334 & 0.8998 & 0.7621 & 0.6652 & 0.6429 & 0.7424 & 0.9104 & 1.0344 & 1.1877 & 1.0263 \\
\hline 700.6 & 1.0597 & 0.9219 & 0.8279 & 0.7585 & 0.6587 & 0.6508 & 0.7355 & 0.9120 & 1.0285 & 1.1759 & 1.627 \\
\hline 71.5 & 1.0530 & 0.9219 & 0.8285 & 0.7600 & 0.6762 & 0.6589 & 0.7533 & 0.9188 & 1.0267 & 1.1804 & 1.6339 \\
\hline 750.0 & 1.0853 & 0.9498 & 0.8544 & 0.7881 & 0.7043 & 0.6947 & 0.7826 & 0.9468 & 1.0005 & 1.2175 & 1.6789 \\
\hline 725.0 & 1.1423 & 1.0011 & 0.9014 & 0.8335 & 0.7467 & 0.7361 & 0.8269 & 0.9950 & 1.1113 & 1.2738 & 1.7505 \\
\hline 700.0 & 1.2069 & 1.0588 & 0.9555 & 0.8842 & 0.7914 & 0.795 & 0.8731 & 1.0479 & 1.1685 & 1.3363 & 1.8308 \\
\hline 625.0 & 1.3905 & 1.2000 & 1.1038 & 1.0000 & 0.9146 & 0.8984 & 1.0004 & 1.1936 & 1.3273 & 1.5138 & 2.0633 \\
\hline 550.0 & 1.5033 & 1.3257 & 1.1963 & 1.1070 & 0.9925 & 0.9736 & 1.0819 & 1.2888 & 1.4323 & 1.6320 & 22216 \\
\hline 475.0 & 1.4986 & 1.3179 & 1.1932 & 1.1079 & 0.9981 & 0.9063 & 1.1016 & 1.3157 & 1.4620 & 1.6682 & 2.2727 \\
\hline 400.0 & 1.1080 & 1.007 & 0.9389 & 0.8946 & 0.8485 & 0.8842 & 1.0260 & 1.2501 & 1.3998 & 1.0053 & 2.2037 \\
\hline 325.0 & 0.9672 & 0.8890 & 0.8352 & 0.7997 & 0.7681 & 0.8097 & 0.9475 & 1.1618 & 1.3042 & 1.4992 & 2.0659 \\
\hline 250.0 & 0.8623 & 0.7913 & 0.7435 & 0.7134 & 0.6856 & 0.7250 & 0.8525 & 1.0481 & 1.1782 & 1.3563 & 1.8728 \\
\hline 175.0 & 0.7342 & 0.6743 & 0.6342 & 0.6091 & 0.5868 & 0.6231 & 0.7359 & 0.9034 & 1.0225 & 1.1792 & 1.6327 \\
\hline 100.0 & 0.5912 & 0.5431 & 0.5115 & 0.4919 & 0.4757 & 0.5087 & 0.6061 & 0.7532 & 0.8505 & 0.9836 & 1.3692 \\
\hline 75.0 & 0.5433 & 0.4991 & 0.4697 & 0.4519 & 0.4384 & $0.4 \pi 4$ & 0.5628 & 0.7017 & 0.7937 & 0.9194 & 1.2833 \\
\hline 50.0 & 0.4982 & 0.4580 & 0.4307 & 0.4140 & 0.4022 & 0.4336 & 0.5216 & 0.6536 & 0.7411 & 0.8596 & 1.2038 \\
\hline 28.5 & 0.4642 & 0.4267 & 0.4022 & 0.3879 & 0.3763 & 0.0025 & 0.4903 & 0.6195 & 0.7016 & 0.8155 & 1.1456 \\
\hline 19.4 & 0.4578 & 0.4200 & 0.3959 & 0.3793 & 0.3621 & 0.3930 & 0.4757 & 0.6078 & 0.6932 & 0.8016 & 1.1263 \\
\hline 14.5 & 0.4560 & 0.4217 & 0.3983 & 0.3909 & 0.3649 & 0.3861 & 0.4743 & 0.6009 & 0.6902 & 0.8014 & 1.1168 \\
\hline 9.4 & 0.4520 & 0.4191 & 0.3939 & 0.3784 & $0.37 \mathrm{~m} 2$ & 0.4026 & 0.4740 & 0.5984 & 0.6828 & 0.7981 & 1.1085 \\
\hline 5.0 & 0.4486 & 0.4143 & 0.3894 & 0.3765 & 0.3743 & 0.4149 & 0.4932 & 0.6121 & 0.6944 & 0.8079 & 1.1030 \\
\hline 2.5 & 0.4497 & 0.4148 & 0.3895 & 0.3773 & 0.3741 & 0.4141 & 0.5060 & 0.6288 & 0.7121 & 0.8276 & 1.1043 \\
\hline
\end{tabular}


B-13

Table B.21. Relative power density values calculated with DORT using 20-group cross sections for the complex FOEHN configuration with a constant aluminum density in the reflector

\begin{tabular}{|c|c|c|c|c|c|c|c|c|c|c|c|}
\hline $\mathrm{H} / \mathrm{r}$ (min) & 143.5 & 146.5 & 149.5 & 152.5 & 159.0 & 167.5 & 176.0 & 182.5 & 185.5 & 188.5 & 193.9 \\
\hline 797.5 & 1.0957 & 0.9573 & 0.8545 & 0.7927 & 0.7210 & 0.7177 & 0.8108 & 0.9699 & 1.0858 & 1.2533 & 1.6581 \\
\hline 795.0 & 1.0788 & 0.9436 & 0.8389 & 0.7746 & 0.7071 & 0.7152 & 0.7910 & 0.9441 & 1.0586 & 1.2216 & 1.6406 \\
\hline 790.6 & 1.0733 & 0.9415 & 0.8359 & 0.7627 & 0.6809 & 0.6850 & 0.7570 & 0.9205 & 1.0382 & 1.2013 & 1.6376 \\
\hline 785.5 & 1.0689 & 0.9374 & 0.8436 & 0.7656 & 0.6687 & 0.6467 & 0.7473 & 0.9167 & 1.0416 & 1.1963 & 1.6388 \\
\hline 780.6 & 1.0644 & 0.9261 & 0.8318 & 0.7622 & 0.6623 & 0.6548 & 0.7406 & 0.9187 & 1.0362 & 1.1851 & 1.6411 \\
\hline $7 n 1.5$ & 1.0579 & 0.9264 & 0.8326 & 0.7680 & 0.6802 & 0.6632 & 0.7589 & 0.9262 & 1.0353 & 1.1906 & 1.6488 \\
\hline 750.0 & 1.0909 & 0.9549 & 0.8591 & 0.7927 & 0.7089 & 0.6999 & 0.7894 & 0.9558 & 1.0710 & 1.2300 & 1.6972 \\
\hline 725.0 & 1.1486 & 1.0068 & 0.9067 & 0.8387 & 0.7518 & 0.7422 & 0.8348 & 1.0057 & 1.1207 & 1.2036 & $1 . \mathrm{ms}$ \\
\hline 700.0 & 1.2138 & 1.0650 & 0.9614 & 0.8898 & 0.7971 & 0.7862 & 0.8820 & 1.0599 & 1.1825 & 1.3530 & 1.8555 \\
\hline 625.0 & 1.3976 & 1.22855 & 1.1100 & 1.0281 & 0.9208 & 0.9060 & 1.0105 & 1.2074 & 1.3435 & 1.5331 & 2.0918 \\
\hline 550.0 & 1.5141 & 1.3309 & 1.2014 & 1.1119 & 0.9977 & 0.9900 & 1.0906 & 1.3009 & 1.4464 & 1.6490 & 2.2468 \\
\hline 475.0 & 1.5013 & 1.3205 & 1.1957 & 1.1104 & 1.0010 & 0.9901 & 1.1071 & 1.3234 & 1.4722 & 1.0794 & 2.2895 \\
\hline $\mathbf{4 0 0 . 0}$ & 1.1073 & 1.0071 & 0.9385 & 0.8912 & 0.8485 & 0.8847 & 1.0274 & 1.2524 & 1.4028 & 1.0091 & 2.2098 \\
\hline 325.0 & 0.9633 & 0.8855 & 0.8319 & 0.7965 & 0.7652 & 0.8068 & 0.9445 & 1.1583 & 1.3006 & 1.4951 & 2.0606 \\
\hline 250.0 & 0.8559 & 0.7854 & 0.7379 & 0.7000 & 0.6003 & 0.7194 & 0.8459 & 1.0000 & 1.1692 & 1.3458 & 1.8584 \\
\hline 175.0 & 0.7262 & 0.6669 & 0.6272 & 0.6022 & 0.5901 & 0.6157 & 0.7210 & 0.897 & 1.0088 & 1.1645 & 1.6121 \\
\hline 100.0 & 0.5826 & 0.5351 & 0.5038 & 0.4844 & 0.4682 & 0.5003 & 0.5955 & 0.7396 & 0.8350 & 0.9654 & 1.3432 \\
\hline 75.0 & 0.5347 & 0.4911 & 0.4620 & 0.4443 & 0.4307 & 0.4617 & 0.5518 & 0.6874 & $0.7 m 2$ & 0.9000 & 1.2555 \\
\hline 50.0 & 0.4895 & 0.4499 & 0.4229 & 0.4063 & 0.3944 & 0.4246 & 0.5100 & 0.6385 & $0.723 ?$ & 0.8391 & 1.1741 \\
\hline 28.5 & 0.4553 & 0.4184 & 0.3943 & 0.3600 & 0.3682 & 0.3933 & 0.4783 & 0.0036 & 0.6832 & 0.7937 & 1.1141 \\
\hline 19.4 & 0.4486 & 0.4114 & 0.3877 & 0.3712 & 0.3541 & 0.3837 & 0.4035 & 0.5914 & 0.6741 & 0.7792 & 1.0938 \\
\hline 14.5 & 0.4465 & 0.4128 & 0.3897 & 0.3725 & 0.3565 & 0.3767 & 0.4619 & 0.5843 & 0.6706 & 0.7784 & 1.0838 \\
\hline 9.4 & 0.4423 & 0.4099 & 0.3852 & 0.3698 & 0.3613 & 0.3923 & 0.4612 & 0.5814 & 0.6630 & 0.7744 & 1.0748 \\
\hline 5.0 & 0.4388 & 0.4051 & 0.3806 & 0.3678 & 0.3651 & 0.4039 & 0.4794 & 0.5941 & 0.6736 & 0.7232 & 1.0086 \\
\hline 2.5 & 0.4398 & 0.4055 & 0.3806 & 0.3685 & 0.3649 & 0.4030 & 0.4915 & 0.6100 & 0.6903 & 0.0018 & 1.0698 \\
\hline
\end{tabular}

Table B.22. Relative power density values calculated with VENTURE using 20-group cross sections for the complex FOEHN configuration with void in the reflector components

\begin{tabular}{|c|c|c|c|c|c|c|c|c|c|c|c|}
\hline H/r(mm) & 143.5 & 146.5 & 149.5 & 152.5 & 159.0 & 167.5 & 176.0 & 182.5 & 185.5 & 188.5 & 193.9 \\
\hline 797.5 & 1.0960 & 1.0054 & 0.9357 & 0.8814 & 0.8158 & 0.8215 & 0.9287 & 1.0086 & 1.1900 & 1.3123 & 1.612 \\
\hline 795.0 & 1.0783 & 0.9795 & 0.9055 & 0.8491 & 0.7824 & 0.7861 & 0.8394 & 1.0481 & 1.1518 & 1.2204 & 1.6938 \\
\hline 790.6 & 1.0561 & 0.9479 & 0.8678 & 0.8077 & $0.73 n$ & 0.7385 & 0.8382 & 0.9983 & 1.1067 & 1.2417 & 1.6057 \\
\hline 735.5 & 1.0411 & 0.9271 & 0.8426 & 0.7791 & 0.7051 & $0 . \pi 333$ & 0.2025 & 0.9670 & 1.0004 & 1.2258 & 1.6003 \\
\hline 780.6 & 1.0337 & 0.9172 & 0.8002 & 0.7648 & 0.6879 & 0.6846 & 0.7850 & 0.9535 & 1.0702 & 1.2000 & 1.6103 \\
\hline 771.5 & 1.0298 & 0.9111 & 0.8200 & 0.7547 & 0.6748 & 0.6702 & 0.7731 & 0.9472 & 1.0678 & 1.2023 & 1.6230 \\
\hline 750.0 & 1.0494 & 0.9285 & 0.8376 & 0.7685 & 0.6861 & 0.6814 & 0.7286 & 0.9699 & 1.0952 & 1.2553 & 1.6690 \\
\hline 725.0 & 1.0962 & 0.9719 & 0.8782 & 0.8069 & 0.7218 & 0.7168 & 0.8277 & 1.0152 & 1.1448 & 1.3104 & 1.7360 \\
\hline $\boldsymbol{\pi 0 0 . 0}$ & 1.1538 & 1.0244 & 0.9267 & 0.8523 & 0.7633 & 0.7574 & 0.8717 & 1.0658 & 1.2000 & 1.3716 & 1.8145 \\
\hline 625.0 & 1.3235 & 1.1769 & 1.0661 & 0.9815 & 0.8793 & 0.8697 & 0.9944 & 1.2081 & 1.3562 & 1.5457 & $2.035 t$ \\
\hline 550.0 & 1.4339 & 1.2755 & 1.1558 & 1.0643 & 0.9535 & 0.9420 & 1.0747 & 1.3032 & 1.4616 & 1.6643 & 2.1879 \\
\hline 475.0 & 1.4323 & 1.2758 & 1.1578 & 1.0679 & 0.9606 & 0.9542 & 1.0941 & 1.3304 & 1.4936 & 1.7022 & 22005 \\
\hline 400.0 & 1.0754 & 0.9879 & 0.9209 & 0.8754 & 0.8297 & 0.8690 & 1.0321 & 1.2767 & 1.4414 & 1.6501 & 2.1844 \\
\hline 325.0 & 0.9417 & 0.8693 & 0.8165 & 0.7788 & 0.7476 & 0.7954 & 0.9571 & 1.1928 & 1.3505 & 1.5496 & 2.0584 \\
\hline 250.0 & 0.8412 & 0.7769 & 0.7302 & 0.6970 & 0.6705 & 0.7161 & 0.8653 & 1.0817 & 1.2064 & 1.4000 & 1.8754 \\
\hline 175.0 & 0.7203 & 0.6056 & 0.6260 & 0.5981 & 0.5768 & 0.6189 & 0.7517 & 0.9435 & 1.0715 & 1.2331 & 1.6456 \\
\hline 100.0 & 0.5855 & 0.5411 & 0.5092 & 0.4870 & 0.4713 & 0.5094 & 0.6244 & 0.7892 & 0.8990 & 1.0375 & 1.3912 \\
\hline 75.0 & 0.5413 & 0.5001 & 0.4706 & 0.4501 & 0.4361 & 0.4728 & 0.5819 & 0.7379 & 0.8419 & 0.9729 & 1.3075 \\
\hline 50.0 & 0.5015 & 0.4631 & 0.4356 & 0.4166 & 0.4041 & 0.4393 & 0.5126 & 0.6900 & 0.7881 & 0.9120 & 1.2082 \\
\hline 28.5 & 0.4757 & 0.4398 & 0.4144 & 0.3971 & 0.3866 & 0.4211 & 0.5189 & 0.6578 & 0.7504 & 0.8673 & 1.1666 \\
\hline 19.4 & 0.4697 & 0.4358 & 0.4121 & 0.3963 & 0.3882 & 0.4238 & 0.5195 & 0.6535 & 0.7424 & 0.8548 & 1.1436 \\
\hline 14.5 & 0.4685 & 0.4363 & 0.4142 & 0.3999 & 0.3941 & 0.4313 & 0.5266 & 0.6572 & 0.7435 & 0.8522 & 1.1325 \\
\hline 9.4 & 0.4698 & 0.4408 & 0.4214 & 0.4094 & 0.4073 & 0.4480 & 0.5445 & 0.6721 & 0.7545 & 0.8575 & 1.1226 \\
\hline 5.0 & 0.4740 & 0.4496 & 0.4337 & 0.4242 & 0.4263 & 0.4719 & 0.5727 & 0.6996 & 0.7785 & 0.8746 & 1.1156 \\
\hline 2.5 & 0.4781 & 0.4573 & 0.4437 & 0,4361 & 0.4008 & 0.4902 & 0.5951 & 0.7233 & 0.8006 & 0.8919 & 1.1149 \\
\hline
\end{tabular}


Table B.23. Relative power density values calculated with VENTURE using 20-group cross sections for the complex FOEHN configuration with aluminum in the void regions

of the reflector components

\begin{tabular}{|c|c|c|c|c|c|c|c|c|c|c|c|}
\hline $\mathrm{H} / \mathrm{r}(\mathrm{mm})$ & 143.5 & 146.5 & 149.5 & 152.5 & 159.0 & 167.5 & 176.0 & 182.5 & 185.5 & 188.5 & 193.9 \\
\hline 797.5 & 1.1029 & 1.0112 & 0.9404 & 0.8851 & 0.8173 & 0.8197 & 0.9227 & 1.0782 & 1.1772 & 1.2966 & 1.5898 \\
\hline 795.0 & 1.0857 & 0.9858 & 0.9107 & 0.8533 & 0.7843 & 0.7849 & 0.8840 & 1.0385 & 1.1397 & 1.2654 & 1.5865 \\
\hline 790.6 & 1.0644 & 0.9549 & 0.8736 & 0.8125 & 0.7403 & 0.7380 & 0.8339 & 0.989 & 1.0956 & 1.2305 & 1.5836 \\
\hline 7as.s & 1.0503 & 0.9349 & 0.8491 & 0.7845 & 0.7083 & 0.7035 & 0.7990 & 0.9592 & 1.0699 & 1.2121 & 1.5843 \\
\hline 780.6 & 1.0437 & 0.9256 & 0.8374 & 0.7707 & 0.6916 & 0.6853 & 0.7819 & 0.9461 & 1.0602 & 1.2066 & 1.5884 \\
\hline mis & 1.0410 & 0.9206 & 0.8301 & 0.7615 & 0.6793 & 0.6716 & 0.7706 & 0.9403 & 1.0582 & 1.2093 & 1.6013 \\
\hline 750.0 & 1.0630 & 0.9401 & 0.8475 & 0.7769 & 0.6918 & 0.6838 & 0.7869 & 0.9637 & 1.0061 & 1.2427 & 1.6477 \\
\hline 725.0 & 1.1121 & 0.9854 & 0.8897 & 0.8168 & 0.7286 & 0.7201 & 0.8267 & 1.0095 & 1.1362 & 1.2983 & 1.7169 \\
\hline 700.0 & 1.1715 & 1.0395 & 0.9396 & 0.8634 & 0.7711 & 0.7614 & 0.8714 & 1.0606 & 1.1919 & 1.3598 & 1.7936 \\
\hline 625.0 & 1.3454 & 1.1957 & 1.0823 & 0.9955 & 0.8895 & 0.8755 & 0.9954 & 1.2040 & 1.3490 & 1.5347 & 2.0145 \\
\hline 550.0 & 1.4581 & 1.2963 & 1.1737 & 1.0799 & 0.9649 & 0.9488 & 1.0766 & 1.2998 & 1.4552 & 1.6539 & 2.1679 \\
\hline 475.0 & 1.4562 & 1.2963 & 1.1755 & 1.0833 & 0.9719 & 0.9611 & 1.0059 & 1.3271 & 1.4873 & 1.6920 & 2.2007 \\
\hline$\infty 00.0$ & 1.0919 & 1.0024 & 0.9357 & 0.8866 & 0.8381 & 0.8739 & 1.0326 & 1.2723 & 1.4341 & 1.6389 & 2.1639 \\
\hline 325.0 & 0.9550 & 0.8009 & 0.8207 & 0.7878 & 0.7541 & 0.7987 & 0.9562 & 1.1872 & 1.3419 & 1.5373 & $2.03 \pi$ \\
\hline 250.0 & 0.8518 & 0.7861 & 0.7382 & 0.7039 & 0.6752 & 0.7179 & 0.8630 & 1.0747 & 1.2164 & 1.3953 & 1.8525 \\
\hline 175.0 & 0.7282 & 0.6723 & 0.6317 & 0.6029 & 0.5797 & 0.6189 & 0.7478 & 0.9349 & 1.0599 & 1.2178 & 1.6210 \\
\hline 100.0 & 0.5906 & 0.5454 & 0.5127 & 0.4897 & 0.4724 & 0.5079 & 0.6191 & 0.7793 & 0.8862 & 1.0211 & 1.3655 \\
\hline 75.0 & 0.5455 & 0.5036 & 0.4733 & 0.4521 & 0.4367 & 0.4709 & 0.5762 & 0.7278 & 0.8288 & 0.9562 & 1.2817 \\
\hline 50.0 & 0.5047 & 0.4657 & 0.4376 & 0.4180 & 0.4041 & 0.4369 & 0.5366 & 0.6795 & 0.7749 & 0.8952 & 1.2024 \\
\hline 28.5 & 0.4779 & 0.4415 & 0.4155 & 0.3976 & 0.3858 & 0.4180 & 0.5124 & 0.6470 & 0.7368 & 0.8502 & 1.1407 \\
\hline 19.4 & 0.4713 & 0.4368 & 0.4126 & 0.3963 & 0.3869 & 0.4203 & 0.5125 & 0.6422 & 0.7285 & 0.8375 & 1.1177 \\
\hline 14.5 & 0.4697 & 0.4370 & 0.4144 & 0.3995 & 0.3924 & 0.4274 & 0.5191 & 0.6457 & 0.7292 & 0.8347 & 1.1066 \\
\hline 9.4 & 0.4706 & 0.4410 & 0.4211 & 0.4085 & 0.4050 & 0.4433 & 0.5363 & $0.65 \%$ & 0.7397 & 0.8395 & 1.0966 \\
\hline 5.0 & 0.4743 & 0.4493 & 0.4328 & 0.4228 & 0.4234 & 0.4665 & 0.5635 & 0.6863 & 0.7628 & 0.8558 & 1.0895 \\
\hline 2.5 & 0.4780 & 0.4566 & 0.4426 & 0.4343 & 0.4375 & 0.4841 & 0.5852 & 0.7092 & 0.7800 & 0.8725 & 1.0898 \\
\hline
\end{tabular}

Table B.24. Relative power density values calculated with VENTURE using 20-group cross sections for the complex FOEHN configuration with a constant aluminum

density in the reflector

\begin{tabular}{|c|c|c|c|c|c|c|c|c|c|c|c|}
\hline$H / x(m)$ & 143.5 & 146.5 & 149.5 & 152.5 & 159.0 & 167.5 & 176.0 & 182.5 & 185.5 & 188.5 & 193.9 \\
\hline 797.5 & 1.1051 & 1.0132 & 0.9425 & 0.8872 & 0.8195 & 0.8221 & 0.9255 & 1.0816 & 1.1809 & 1.3007 & 1.5950 \\
\hline 795.0 & 1.0881 & 0.9881 & 0.9129 & 0.8555 & 0.7866 & 0.7874 & 0.8871 & 1.0421 & 1.1437 & 1.2699 & 1.5922 \\
\hline 790.6 & 1.0672 & 0.9574 & 0.8762 & 0.8150 & 0.7428 & 0.7408 & 0.8372 & 0.9938 & 1.1002 & 1.2056 & 1.5902 \\
\hline 785.5 & 1.0535 & 0.9379 & 0.8520 & 0.7873 & 0.7111 & 0.7066 & 0.2026 & 0.9637 & 1.0750 & 1.2180 & 1.5920 \\
\hline 780.6 & 1.0472 & 0.9289 & 0.8405 & $0.7 m 38$ & 0.6947 & 0.6886 & 0.7859 & 0.9511 & 1.0658 & 1.2131 & 1.597 \\
\hline 77.5 & 1.0452 & 0.9245 & 0.8338 & 0.7650 & 0.6827 & 0.6754 & 0.7752 & 0.9461 & 1.0649 & 1.2170 & 1.6117 \\
\hline 750.0 & 1.0684 & 0.9451 & 0.8521 & 0.7814 & 0.6962 & 0.6886 & 0.7930 & 0.9714 & 1.0950 & 1.2532 & 1.6618 \\
\hline 725.0 & 1.1186 & 0.9914 & 0.8953 & 0.8221 & 0.7339 & 0.7259 & 0.8341 & 1.0192 & 1.1474 & 1.3113 & 1.7348 \\
\hline 700.0 & 1.1789 & 1.0462 & 0.9460 & 0.8696 & $0.7 m 1$ & 0.7600 & 0.8799 & 1.0718 & 1.2049 & 1.3750 & 1.8145 \\
\hline 625.0 & 1.3541 & 1.2037 & 1.0897 & 1.0027 & 0.8965 & 0.8834 & 1.0056 & 1.2175 & 1.3646 & 1.5530 & 2.0398 \\
\hline 550.0 & 1.4660 & 1.3035 & 1.1806 & 1.0864 & 0.9713 & 0.9560 & 1.0858 & 1.3118 & 1.4690 & 1.6702 & 2.1902 \\
\hline 475.0 & 1.4614 & 1.3011 & 1.1800 & 1.087 & 0.9762 & 0.9658 & 1.1019 & 1.3348 & 1.4962 & 1.2024 & 2.2348 \\
\hline 400.0 & 1.0933 & 1.0037 & 0.9370 & 0.8879 & 0.8394 & 0.8752 & $1.03 \times 3$ & 1.2744 & 1.4364 & 1.6416 & 2.1674 \\
\hline 325.0 & 0.9531 & 0.879 & 0.8251 & 0.7862 & 0.7524 & 0.7967 & 0.9534 & 1.1833 & 1.3374 & 1.5319 & 2.0293 \\
\hline 250.0 & 0.8473 & 0.7819 & 0.7341 & 0.6999 & 0.6712 & 0.7130 & 0.8565 & 1.0660 & 1.2063 & 1.3833 & 1.8358 \\
\hline 175.0 & 0.7218 & 0.6663 & 0.6259 & 0.5972 & 0.5739 & 0.6122 & 0.7388 & 0.9208 & 1.0458 & 1.2012 & 1.5900 \\
\hline 100.0 & 0.5832 & 0.5384 & 0.5060 & 0.4831 & 0.4656 & 0.4998 & 0.6082 & 0.7646 & 0.8690 & 1.0007 & 1.3372 \\
\hline 75.0 & 0.5379 & 0.4964 & 0.4664 & 0.4453 & 0.4296 & 0.4624 & 0.5648 & 0.7122 & 0.8106 & 0.9347 & 1.2516 \\
\hline 50.0 & 0.4967 & 0.4581 & 0.4303 & 0.4109 & 0.3967 & 0.4280 & 0.5244 & 0.6631 & 0.7556 & 0.8723 & 1.1705 \\
\hline 28.5 & 0.4694 & 0.4334 & 0.4077 & 0.3900 & 0.3778 & 0.4085 & 0.4995 & 0.6296 & 0.7164 & 0.8261 & 1.1071 \\
\hline 19.4 & 0.4623 & 0.4283 & 0.4044 & 0.3882 & 0.3784 & 0.4101 & 0.4989 & 0.6240 & 0.2073 & 0.8126 & 1.0832 \\
\hline 14.5 & 0.4604 & 0.4281 & 0.4058 & 0.3910 & 0.3834 & 0.4166 & 0.5048 & 0.6269 & 0.7075 & 0.0093 & 1.0716 \\
\hline 9.4 & 0.4608 & 0.4317 & 0.4120 & 0.3993 & 0.3953 & 0.4317 & 0.5210 & 0.6399 & 0.7169 & 0.8132 & 1.0611 \\
\hline 5.0 & 0.4641 & 0.4394 & 0.4230 & 0.4129 & 0.4129 & 0.4537 & 0.5468 & 0.6650 & 0.7386 & 0.8282 & 1.0533 \\
\hline 2.5 & 0.4675 & 0.4463 & 0.4322 & 0.4239 & 0.4263 & 0.4706 & 0.5675 & 0.6867 & 0.7586 & 0.8439 & 1.0526 \\
\hline
\end{tabular}


Table B.25. Thermal fluxes calculated with DORT using 20-group cross sections for the different models of the complex FOEHN configuration (Vahes are normalized to a power of $1 \mathrm{~W}$ )

\begin{tabular}{cccc}
\hline \multirow{2}{*}{$\begin{array}{c}\text { Radius }^{a} \\
(\mathrm{~mm})\end{array}$} & \multicolumn{3}{c}{$\begin{array}{c}\text { Thermal flux } \\
10^{11} \text { neutrons } /\left(\mathrm{m}^{2} \mathrm{~s}\right)\end{array}$} \\
\cline { 2 - 4 } & $\begin{array}{c}\text { Void in the } \\
\text { reflector } \\
\text { components }\end{array}$ & $\begin{array}{c}\text { Aluminum in the void } \\
\text { regions of the reflector } \\
\text { components }\end{array}$ & $\begin{array}{c}\text { Constant aluminum } \\
\text { density in the } \\
\text { reflector }\end{array}$ \\
\hline 275 & 2.3391 & 2.2948 & 2.3097 \\
315 & 2.5478 & 2.4792 & 2.5108 \\
435 & 2.1436 & 2.0222 & 2.1197 \\
515 & 1.6402 & 1.5027 & 1.6519 \\
675 & 0.8582 & 0.7376 & 0.9108 \\
755 & 0.5973 & 0.4987 & 0.6595 \\
\hline
\end{tabular}

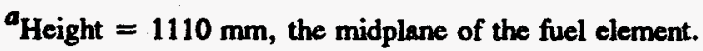

Table B.26. Thermal fluxes calculated with VENTURE using 20-group cross sections for the different models of the complex FOEHN configuration (Vahuea are normalizod to a power of $1 \mathrm{~W}$ )

\begin{tabular}{cccc}
\hline $\begin{array}{c}\text { Radius }^{a} \\
(\mathrm{~mm})\end{array}$ & \multicolumn{3}{c}{$\begin{array}{c}\text { Thermal flux } \\
10^{11} \text { neutrons } /\left(\mathrm{m}^{2} \mathrm{~s}\right)\end{array}$} \\
\cline { 2 - 4 } & $\begin{array}{c}\text { Void in the } \\
\text { reflector } \\
\text { components }\end{array}$ & $\begin{array}{c}\text { Aluminum in the void } \\
\text { of the reflector } \\
\text { components }\end{array}$ & $\begin{array}{c}\text { Constant aluminum } \\
\text { density in the } \\
\text { reflector }\end{array}$ \\
\hline 275 & 2.2236 & 2.1777 & 2.1825 \\
315 & 2.4802 & 2.4090 & 2.4171 \\
435 & 2.1957 & 2.0636 & 2.0779 \\
515 & 1.7498 & 1.5924 & 1.6224 \\
675 & 1.0279 & 0.8733 & 0.8983 \\
755 & 0.7713 & 0.6364 & 0.6538 \\
\hline
\end{tabular}

${ }^{a_{\text {Height }}}=1110 \mathrm{~mm}$, the midplane of the fuel element. 


\section{APPENDIX C}

\section{DIFFERENCES IN FOEHN CALCULATIONAL MODELS}

Because the results calculated by various institutions are often compared, it is important to document the differences between calculational models. The differences between the model of the FOEHN experiment used for the calculations performed at the Idaho National Engineering Laboratory reported in ref. 9 (INEL model) and the model in this report (ORNL model) are discussed in the following. The differences in the models used in the calculations performed at the Technische Universität München ${ }^{14}$ (TUM model) are also presented. Some of the differences are rather trivial but are included for completeness.

1. Additional borated heavy water: The 1971 FOEHN report ${ }^{6}$ documents the fuel element contained $28.85 \mathrm{~L}$ of borated $\mathrm{D}_{2} \mathrm{O}$. The calculated volume is $27 \mathrm{~L}$. In the ORNL model, the extra $\mathrm{D}_{2} \mathrm{O}$ was assumed to be at the inner and outer edges of the fuel region. The thickness of the inner layer is 0.3 $\mathrm{mm}$, and the thickness of the outer layer is $1.67 \mathrm{~mm}$. The INEL model assumes the extra $\mathrm{D}_{2} \mathrm{O}$ to be distributed in three layers. The layer at the edge of the fuel region is $0.3 \mathrm{~mm}$, and the layer at the outer edge of the fuel region is $1.1 \mathrm{~mm}$. The third layer is $0.5481-\mathrm{mm}$ thick and is located at the inside edge of the stack. This region is $0.5-\mathrm{mm}$ thick in the ORNL model and contains unborated $\mathrm{D}_{2} \mathrm{O}$. The $0.5-\mathrm{mm}$ gap is outside the can that holds the fuel element and the borated heavy water. In the TUM model, both the inner and outer gaps are $0.6 \mathrm{~mm}$ and are between the fuel element tube and the can. The third gap between the can and the stack is not present in the TUM model.

2. AG3-NE alloy: The impurity content of the AG3-NE alloy must be assumed. The composition used in this report is from a mill test of an AG3-NE sample. The nuclides and atom densities that make up this composition are quite different from those used in the INEL model. In the TUM model, the AG3-NE material cross section was artificially adjusted by adding 5\% to the thermal absorption cross section to account for the impurities in the alloy.

3. Light water content: The light water content in the heavy water reflector was reported with the measured results for each configuration of the FOEHN experiment. The reported values of 0.253 , 0.265 , and 0.263 atom percent for the simple, intermediate, and complex configurations respectively, were used in the ORNL models. The INEL models used a constant value of 0.25 at. \% light water for all cases. The TUM models used the reported values.

4. AG3-NE structure above and below the core: The exact position of aluminum structures above and below the core region is unknown. The position of the structures in this report was determined from Fig. 2.1 in the original FOEHN report. A 50-mm-thick region is assumed to be located $190 \mathrm{~mm}$ above the upper edge of the fuel element, and a $30-\mathrm{mm}$ region is located $176 \mathrm{~mm}$ below the lower edge of the fuel element. A 80-mm-thick region is part of the control element. The lower bound of the region is located at the lower edge of the nickel portion of the control element and moves with the element. The structure above the core in the INEL model is also 50-mm thick and is located $240 \mathrm{~mm}$ above the upper edge of the fuel element. The structure below the core is $180 \mathrm{~mm}$ below the lower edge of the fuel element and is $18-\mathrm{cm}$ thick. The region inside the control element is $130-\mathrm{mm}$ thick 
and is also $180-\mathrm{mm}$ below the lower edge of the fuel element. The region does not move as the control element changes positions. These structures are not present in the TUM model.

4. Hot source graphite atom density: In this report, the density of graphite is assumed to be $1.6 \mathrm{~g} / \mathrm{cm}^{3}$, which yields $8.02 \times 10^{-2}$ atoms/(barn $\mathrm{cm}$ ). The graphite atom density in the INEL model is $1.67 \times 10^{-2}$ atoms/(barn $\mathrm{cm}$ ). The INEL model uses $S(\alpha, \beta)$ cross section data at $2000 \mathrm{~K}$, while the graphite cross sections in the ORNL model were processed at $293 \mathrm{~K}$. The hot source was a mock-up of the actual facility and was at room temperature. Calculations by the TUM were not performed for the complex FOEHN configuration, which contains the hot source.

5. Reflector components: An explicit model of the reflector components was used in this report to calculate smeared atom densities for the reflector region. Several minor differences between the ORNL and INEL model should be documented. The reflector component positions and descriptions in the ORNL model were based on information obtained from ref. 6. The INEL model described in the appendix in ref. 9 differs from this information in the following ways: (a) the cold source is not filled with heavy water and is surrounded by aluminum, (b) the horizontal channel in the graphite of the hot source is not modeled correctly, (c) the beam tubes do not have caps, (d) beam tube No. 3 is in the incorrect position, and (e) the conical angle for beam tube No. 11 should be $5^{\circ} 30^{\prime \prime}$ not $5^{\circ} 30^{\prime}$. Calculations were not performed for the complex FOEHN configuration at the TUM. 
ORNL/TM-12829

\section{Internal Distribution}

1. B. R. Appleton

2. J. A. Bucholtz

3-4. J. H. Campbell

5. H. L. Dodds

6. G. F. Flanagan

7. F. X. Gallmeier

8-12. J. C. Gehin

13. M. L. Gildner

14. R. M. Harrington

15. D. T. Ingersoll

16-19. R. L. Johnson

20. K. K. Jones

21. R. A. Lillie

22. J. A. March-Leuba

23. J. T. Mihalczo
24. J. P. Renier

25. R. B. Rothrock

26. D. L. Selby

27-31. L. A. Smith

32. C. D. West

33. R. M. Westfall

34-38. B. A. Worley

39. G. L. Yoder

40. CPED Reports

41. ORNL Patent Office

42. Central Research Library Document Reference Section

43. Y-12 Technical Library

44-45. Laboratory Records Dept.

46. Laboratory Records, ORNL-RC

\section{External Distribution}

47. P. Ageron, Institut Laue-Langevin, 156X 38042, Grenoble Cedex, France.

48. K. Böning, Fakültät für Physik E21, Technische Universität München, D-8046, Garching, Germany.

49. J. Carew, Brookhaven National Laboratory, Building 475-B, Upton, New York 11973.

50. Edward Dugan, University of Florida-Gainesville, Department of Nuclear Engineering Sciences, Gainesville, Florida 32611.

51. A. F. Henry, Professor, Department of Nuclear Engineering, Massachusetts Institute of Technology, 77 Massachusetts Avenue, Cambridge, MA 02139.

52. R. F. Lidstone, Atomic Energy of Canada, Ltd., Whiteshell Nuclear Research Establishment, Pinawa, Manitoba, ROE 1LO, Canada.

53. J. M. Ryskamp, Idaho National Engineering Laboratory, P. O. Box 1625, Idaho Falls, ID 83415-3885.

54. Cindy Sheldon, ORISE/SEED, P.O. Box 117, Oak Ridge, Tennessee 37831-0117.

55. E. Shirai, Department of Research Reactor Operations, Japan Atomic Energy Research Institute, Toki-mura, Naka-gun, Ibaraki-ken 319-11, Tokyo, Japan.

56. N. Tsoulfanidis, University of Missouri-Rolla, Nuclear Engineering Department, Fulton Hall, Rolla, Missouri 65401.

57. J. S. Tulenko, University of Florida-Gainesville, Department of Nuclear Engineering Sciences, Gainesville, Florida 32611.

58. C. A. Wemple, Idaho National Engineering Laboratory, P.O. Box 1625, Idaho Falls, Idaho 83415.

59. U. S. Department of Energy, ANS Project Office, Oak Ridge Operations Office, FEDC, MS8218 , P. O. Box 2009, Oak Ridge, Tennessee 37831-8218.

60-61. Office of Scientific and Technical Information, P.O. Box 62, Oak Ridge, Tennessee 37831. 